Portland State University

PDXScholar

$1-1-2012$

\title{
Insight into the Reactivity of Metastasis Inhibitor, Imidazolium trans-[tetrachloro (dimethyl sulfoxide)(imidazole)ruthenate(III)], with Biologically- active Thiols
}

Risikat Ajibola Adigun

Portland State University

Follow this and additional works at: https://pdxscholar.library.pdx.edu/open_access_etds Let us know how access to this document benefits you.

\section{Recommended Citation}

Adigun, Risikat Ajibola, "Insight into the Reactivity of Metastasis Inhibitor, Imidazolium trans-[tetrachloro (dimethyl sulfoxide)(imidazole)ruthenate(III)], with Biologically-active Thiols" (2012). Dissertations and Theses. Paper 378.

https://doi.org/10.15760/etd.378

This Dissertation is brought to you for free and open access. It has been accepted for inclusion in Dissertations and Theses by an authorized administrator of PDXScholar. Please contact us if we can make this document more accessible: pdxscholar@pdx.edu. 
Insight into the Reactivity of Metastasis Inhibitor, Imidazolium trans-[tetrachloro (dimethyl sulfoxide)(imidazole)ruthenate(III)], with Biologically-active Thiols

by

Risikat Ajibola Adigun

A dissertation submitted in partial fulfillment of the requirements for the degree of

\author{
Doctor of Philosophy \\ in \\ Chemistry
}

\author{
Dissertation Committee: \\ Reuben H. Simoyi, Chair \\ Albert S. Benight \\ Dean B. Atkinson \\ John G. Rueter \\ Radu Popa
}

Portland State University

(C) 2012 


\begin{abstract}
Imidazolium trans-[tetrachloro (dimethyl sulfoxide)(imidazole)ruthenate(III)], NAMI-A, is an experimental metastasis inhibitor whose specific mechanism of activation and action remains to be elucidated. In the nucleophilic and reducing physiological environment; it is anticipated that the most relevant and available reductants upon introduction of NAMI-A as a therapeutic agent will be the biologicallyrelevant free thiols. The kinetics and mechanisms of interaction of NAMI-A with biologically-active thiols cysteamine, glutathione, cysteine and a popular chemoprotectant, 2-mercaptoethane sulfonate (MESNA) have been studied spectrophotometrically under physiologically-relevant conditions.
\end{abstract}

The reactions are characterized by initial reduction of NAMI-A with simultaneous formation of dimeric thiol and subsequent ligand exchange with water to various degrees as evidenced by Electospray Ionization Mass Spectrometry. Stoichiometry of reactions shows that one molecule of NAMI-A reacted with one mole of thiol to form corresponding disulfide cystamine, dimeric MESNA, oxidized glutathione and cystine. Observed rate constants, $k_{o}$, for the reaction of NAMI-A with cysteamine, MESNA, GSH and cysteine were deduced to be $6.85 \pm 0.3 \times 10^{-1}, 9.4 \pm 0.5$ x $10^{-2}, 7.42 \pm 0.4 \times 10^{-3}$ and $3.63 \pm 0.3 \times 10^{-2} \mathrm{~s}^{-1}$ respectively.

Activation parameters determined from Arrhenius plots are indicative of formation of associative intermediates prior to formation of products. A negative correlation was obtained from the Brønsted plot derived from observed rate constants 
and the $\mathrm{pKa}$ of the different thiols demonstrating significant contribution of thiolate species towards the rate. In conclusion, interactions of NAMI-A with biologicallyactive thiols are kinetically and thermodynamically favored and should play significant roles in in vivo metabolism of NAMI-A. 


\section{DEDICATION}

\section{To Almighty Allah,}

to my husband, Adeniran, who was there for late nights and weekends in the lab and my daughter, Amal who has not seen much of me yet. 


\section{ACKNOWLEDGEMENTS}

I would like to acknowledge my supervisor Professor R.H. Simoyi for his guidance, support and encouragement that made this Ph.D. dissertation a reality. There is a short story that might explain his personality. My first meeting with him was in 2003 while I was completing my Master's degree, he drove a two-hour journey to ensure that I got recommendation letters from my former school. He goes all out to help although he speaks funny Yoruba. I am grateful for all he has taught me.

I would also like to thank members of my dissertation committee; Drs. Dean Atkinson, Albert Benight, Radu Popa and John Rueter for their contributions towards completion of my degree requirements. Special gratitude goes to Dr. Mark Woods for his suggestions on NAMI-A synthesis and for access to resources in his lab during the synthesis. I am also grateful to the Department of Chemistry for financial support throughout my studies and National Science Foundation for funding. I am also grateful to Prof. J.W. Ige for his words of encouragement.

I greatly appreciate the love and support of my husband and daughter. Thank you Adeniran Adigun for being there for me every step of the way, from taking classes through writing conclusions for this dissertation, you are one in a million. I also say thank you to Amal, mom will be there more often. I am indebted to my mom who gave up her education to have me and my dad who always ensured that I had all I needed for school. I can't but thank my sister, Bashirat Jouett for all her support and 
encouragement and all members of my family (the Ajibolas and the Adiguns) for their love and support through the years.

Special thanks go to my friend, Dr. Adenike Otoikhian, who asked me to apply to PSU and has been a friend in deed. The Adenuga family, all your support is greatly appreciated. I would like to thank present members of Simoyi research group especially Wilbes Mbiya, Morgen Mhike, Kudzanai Chipiso and all our undergraduates for their cooperation and positive contributions to this work. It is a pleasure to have worked with Drs. Edward Chikwana, Itai Chipinda, Kayode Morakinyo, Funke Olagunju and Tinashe Ruwona. Thank you all for insightful discussions.

Finally I say thank you to all whose names have not been mentioned, but have contributed to the successful completion of this dissertation. 


\section{TABLE OF CONTENTS}

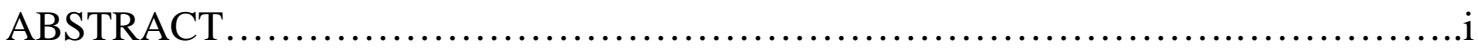

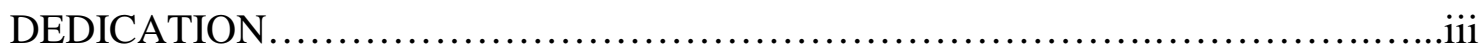

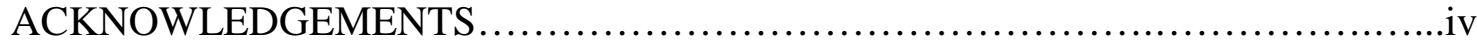

LIST OF TABLES ..................................................................

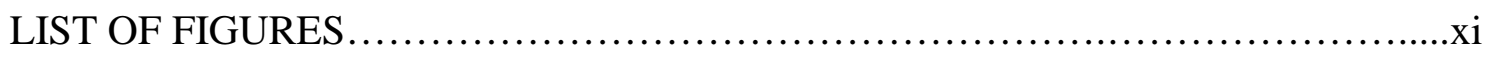

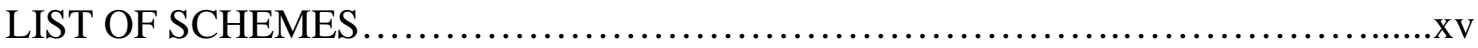

LIST OF ABBREVIATIONS......................................................

\section{CHAPTER ONE: Introduction}

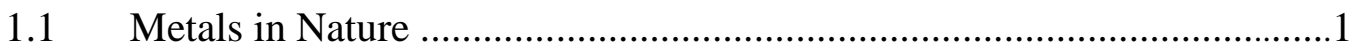

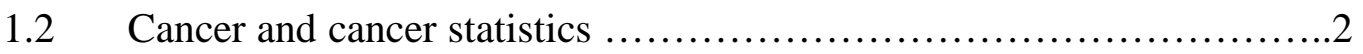

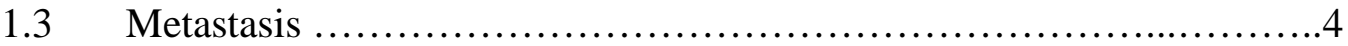

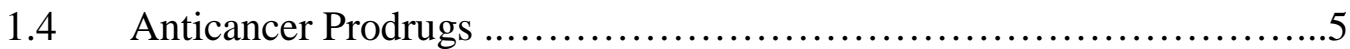

$1.5 \quad$ Antitumor Metastasis Inhibitor.........................................

1.6 Activation by reduction hypothesis.................................. 10

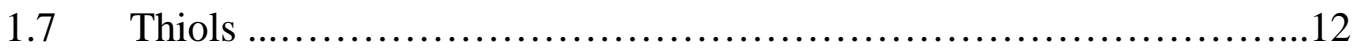

1.7.1 Thiol oxidation.................................................

1.7.2 Metal binding ........................................... 16

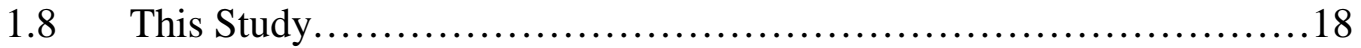

\section{CHAPTER TWO: Instrumentation, Materials and Methods}

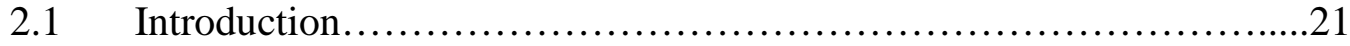

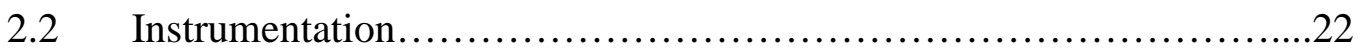

2.2.1 Conventional UV/Vis spectrophotometry....................22

2.2.2 Stopped-flow Spectrophotometry ...........................22

2.2.3 Electrospray-Ionization Mass Spectrometry (ESI-MS)............24

2.2.4 Nuclear Magnetic Resonance Spectrometry (NMR)..............26

2.2.5 Electron Paramagnetic Resonance Spectroscopy (EPR) ..........27 


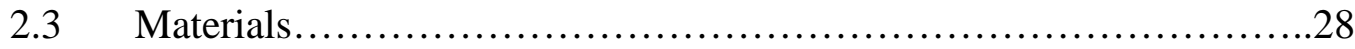

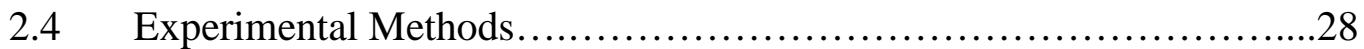

2.4.1 Synthesis of hydrogen trans-bis(dimethyl sulfoxide)tetrachloro ruthenate- (III) ................................................

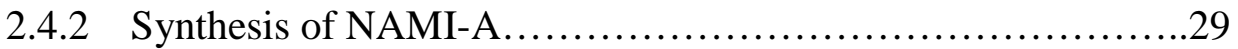

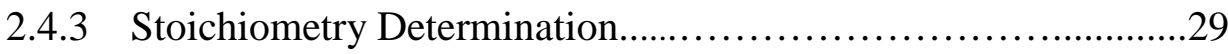

2.4.4 Product Identification...........................................30

2.4.5 Reaction Dynamics........................................... 30

CHAPTER THREE: Kinetics and Mechanism of Interaction of NAMI-A with Cysteamine

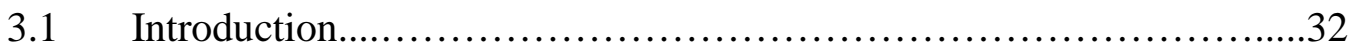

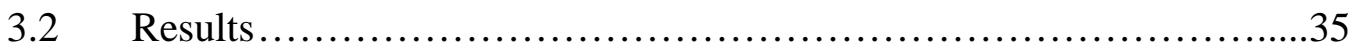

3.2.1 Stoichiometry and Product Identification ......................35

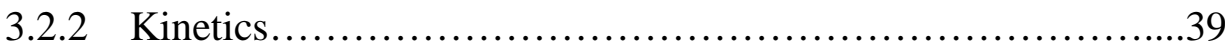

3.2.2.1 NAMI-A Dependence..................................39

3.2.2.2 Cysteamine Dependence.................................40

3.2.2.3 Effect of Ionic Strength................................44

3.2.2.4 Effect of Chloride ion.....................................45

3.2.2.3 Thermodynamic and Activation Parameters.....................46

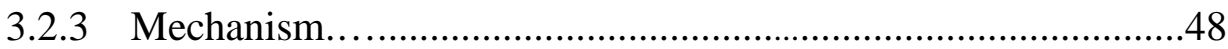

3.2.3.1 Electron Transfer.....................................48

3.2.3.2 Ligand Exchange......................................50

CHAPTER FOUR: Kinetics and Mechanistic Investigation into the Possible Activation of NAMI-A by 2-Mercaptoethane sulfonate

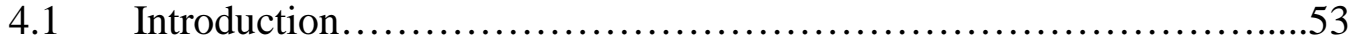

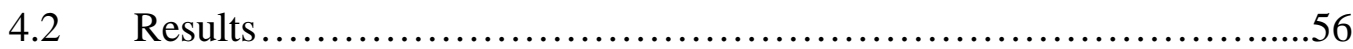

4.2.1 Stoichiometry and Product Identification .....................56 
4.2.2 Kinetics................................................... 61

4.2.2.1 NAMI-A Dependence...................................61

4.2.2.2 MESNA Dependence...................................63

4.2.2.3 Buffer and $\mathrm{pH}$ Effects...................................65

4.2.2.4 Temperature Dependence..............................67

4.2.2.3 Effect of Ionic Strength...................................69

4.2.3 Mechanism.................................................... 70

CHAPTER FIVE: Kinetics and Mechanism of Interaction of NAMI-A with Glutathione

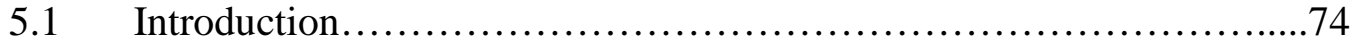

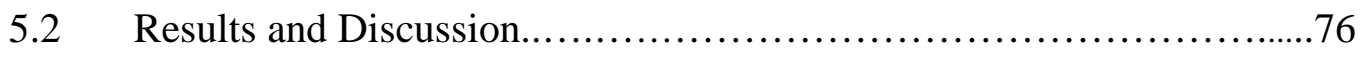

5.2.1 Stoichiometry and Product Identification .......................76

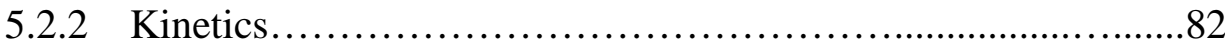

5.2.2.1 NAMI-A Dependence.....................................82

5.2.2.2 GSH Dependence........................................ 83

5.2.2.3 Effect of Ionic Strength...................................................85

5.2.2.4 Thermodynamic and Activation Parameters ..............85

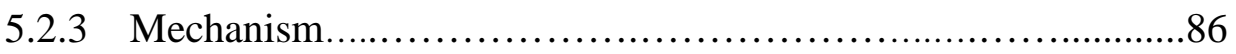

CHAPTER SIX: Kinetics and Mechanism of Interaction of NAMI-A with Cysteine

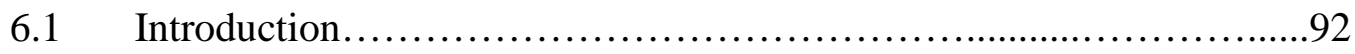

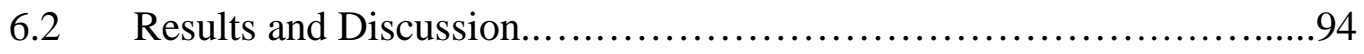

6.2.1 Stoichiometry and Product Identification..........................94

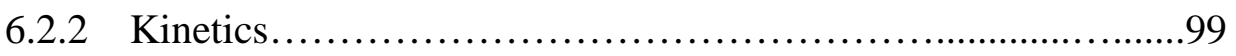

6.2.2.1 NAMI-A Dependence................................99

6.2.2.2 Cysteine Dependence......................................101

6.2.2.3 Effect of Ionic Strength ...............................102

6.2.2.4 Thermodynamic and Activation Parameters .............103 


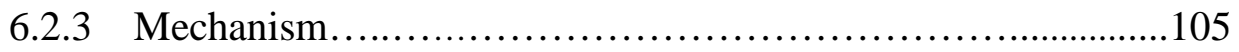

6.2.3.1 Electron Transfer.........................................105

6.2.3.2 Ligand Exchange.........................................108

CHAPTER SEVEN: Summary and Conclusions..................................................111

\section{CHAPTER EIGHT: Supplementary Results}

8.0 Kinetics and Mechanism of One-electron Oxidation of Tris(1,10-

phenanthroline)iron(III) ..........................................................118

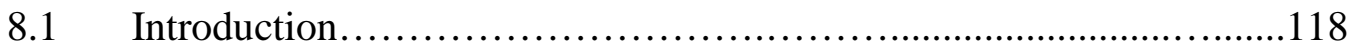

$8.2 \quad$ Materials ........................................................... 119

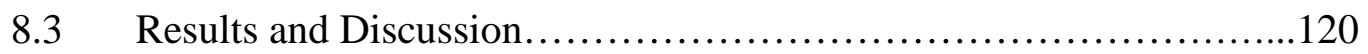

8.3.1 Stoichiometry and product identification ............................120

8.3.2 Effect of $\left[\mathrm{Fe}(\mathrm{phen})_{3}{ }^{3+}\right]$ on rate of reaction.........................122

8.3.3 Effect of cysteine on reaction rate ...........................125

8.3.4 Effect of acid on reaction rate ............................... 125

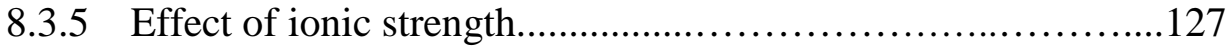

8.3.6 Thermodynamic and activation parameters.............................127

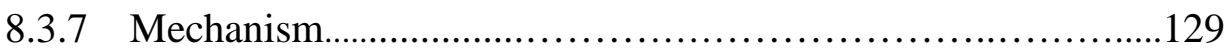

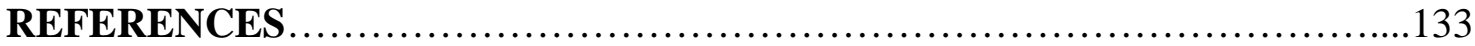




\section{LIST OF TABLES}

Table 3.1: Anticancer agents and effects against which Amifostine offers protection...33

Table 4- 1: Widely used chemotherapy drugs with inherent nephrotoxicity............54

Table 7-1: Summary of observed rate constants in relation to thiol pKa..............112

Table 7-2: Summary of activation parameters............................... 115

Table 7-3: Observed rate constants and activation parameters for from literature......116 


\section{LIST OF FIGURES}

Figure 1-1: Structure of cis-diamminedichloroplatinum(II), (Cisplatin)................2

Figure 1-2: Structures of platinum complexes used in cancer treatment................3

Figure 1-3: Organ specific colonization demonstrated by metastatic cells...............5

Figure 1-4: Classification of prodrug research objectives.........................6

Figure 1-5: Ruthenium anticancer prodrugs.......................................

Figure 1-6: Selective metastatic removal by NAMI-A.............................9

Figure 1-7: Hypothetical tumor growth curve................................. 10

Figure 1-8: Selective uptake of ruthenium loaded transferrin by cancer cells...........12

Figure 2-1: Sample Handling Unit (SHU) flow circuit diagram for the SF-61DX2

Hi-Tech KinetAsyst stopped-flow spectrometer......................24

Figure 2-2: Schematic for ion formation in ESI...............................25

Figure 3-1: Structure of 2-aminoethanethiol also called cysteamine.................34

Figure 3-2: Plot of Residual absorbance of NAMI-A against molar ration of

NAMI-A to Cysteamine.......................................... 36

Figure 3-3: Full ESI-MS spectrum of 1:1 ratio of NAMI-A to Cysteamine

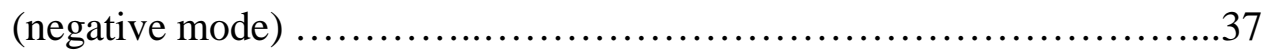

Figure 3-4: Full ESI-MS spectrum of equimolar concentrations of NAMI-A and

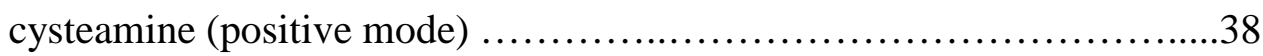

Figure 3-5a: Kinetics traces showing dependence on NAMI-A concentrations.........39

Figure 3-5b: Initial rate plot derived from Figure $3-5 a \ldots \ldots \ldots \ldots \ldots \ldots \ldots \ldots \ldots \ldots . .40$ 
Figure 3-6a: Effect of cysteamine variation on the consumption of NAMI-A..........41

Figure 3-6b: Initial rate plot derived from data shown in Figure 4a.................42

Figure 3-6c: Effect of cysteamine variation at temperatures 15, 20, 30 and $37{ }^{\circ} \mathrm{C} \ldots \ldots .43$

Figure 3-6d: Summary of rate dependence on cysteamine at various temperatures......44

Figure 3-7: Ionic strength dependence of cysteamine-NAMI-A reaction..............45

Figure 3-8: Effect of varying initial chloride concentration.......................46

Figure 3-9a: Temperature dependence of cysteamine-NAMI-A reaction..............47

Figure 3-9b: Temperature dependence of cysteamine-NAMI-A reaction...............48

Figure 4-1: Nephroprotection by BNP7787 showing involvement of MESNA........55

Figure 4-1: Rapid spectral scan of aqueous solution of MESNA and NAMI-A taken at

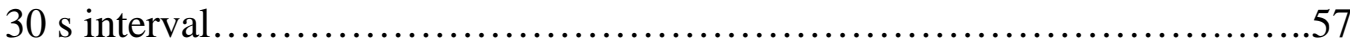

Figure 4-2a: Negative ESI-MS spectrum of a stoichiometric solution of MESNA and NAMI-A within the first minute of reaction...............................58 Figure 4-2b: Negative ESI-MS spectrum of the same solution in Figure 4-2a taken five minutes later .59

Figure 4-2c: Negative ESI-MS spectrum of solution in Figure 3-2a taken ten minutes

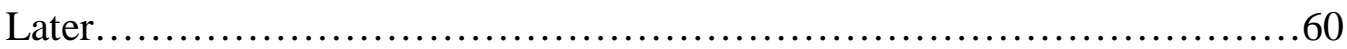

Figure 4-3a: Kinetics traces showing dependence on NAMI-A concentrations........62

Figure 4-3b: Initial rate plot derived from Figure 4-3a.........................63

Figure 4-4a: Effect of MESNA variation on NAMI-A consumption (pH 7.4).........64

Figure 4-4b: Initial rate plot derived from Figure $4-4 a \ldots \ldots \ldots \ldots \ldots \ldots \ldots \ldots \ldots \ldots . \ldots 5$

Figure 4-4c: Effect of MESNA variation on NAMI-A consumption (no buffer)..........66 
Figure 4-4d: Influence $\mathrm{pH}$ on reaction rate...................................67

Figure 4-5a: Temperature dependence of NAMI-A-MESNA reaction..................68

Figure 4-5b: Arrhenius plot extracted from Figure 4-5a..........................69

Figure 4-6: Influence of ionic strength on reaction rate............................70

Figure 5-1: Involvement of GSH in important cellular processes.....................75

Figure 5-2a: Multiple spectral scans showing GSH- NAMI-A reaction progress.......77

Figure 5-2b: A later absorption profile of solution in Figure 5-2a....................78

Figure 5-3: Full ESI-MS spectrum of stoichiometric solution of NAMI-A and GSH

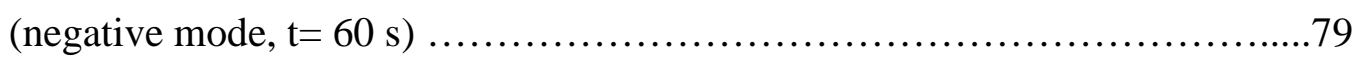

Figure 5-4: Full ESI-MS spectrum of solution in Figure 5-3 taken a minute later.......80

Figure 5-5: Full ESI-MS spectrum of solution in Figure 5-3 (positive mode)...........81

Figure 5-6a: Kinetics traces of GSH-NAMI-A reaction (NAMI-A dependence)............82

Figure 5-6b: Initial rate plot derived from Figure $3.5 \mathrm{a} \ldots \ldots \ldots \ldots \ldots \ldots \ldots \ldots \ldots \ldots . \ldots 3$

Figure 5-7: Effect of increasing GSH concentration on NAMI-A consumption .........84

Figure 5-8a: Temperature dependence of GSH-NAMI-A reaction...................86

Figure 5-8b: Rate plot from data shown in Figure 5-8a............................ 87

Figure 5-8c: Arrhenius plot extracted from Figure 5-8a......................... 87

Figure 6-1: Functional domains of tumor suppressor gene, p53...................93

Figure 6-2: Plot of Residual absorbance of NAMI-A against [NAMI-A]/[cysteine].....95

Figure 6-3: Rapid spectral scan of solution of cysteine and NAMI-A................95

Figure 6-4a: Full ESI-MS spectrum of 1:1 ratio of NAMI-A to Cysteine $t=60 \mathrm{~s}$

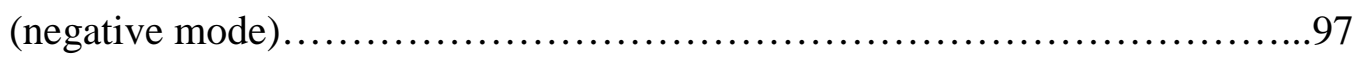


Figure 6-4b: Full ESI-MS of solution in Figure 6-4a, $t=120$ s.......................98

Figure 6-4c: Full ESI-MS of solution in Figure 6-4a (positive mode).................99

Figure 6-7: Kinetics traces of NAMI-A dependence. Inset: Plot of initial rate .........100

Figure 6-8a: Effect of varying cysteine concentrations, $\mathrm{pH}$ 7.4........................101

Figure 6-8b: Effect of varying cysteine concentrations (no added buffer).............102

Figure 6-9: Effect of ionic strength on NAMI-A-cysteine reaction...................103

Figure 6-10a: Temperature dependence of cysteine-NAMI-A reaction...............104

Figure 6-10b: Arrhenius plot extracted from Figure 6-10a..........................105

Figure 7-1: Brønsted relationship for the reactivities of thiols towards NAMI-A.....114

Figure 8-1: Structure of Tris(1,10-phenanthroline)iron(III)........................119

Figure 8-2: Rapid spectral scan of solution of cysteine and $\mathrm{Fe}(\mathrm{phen})_{3}{ }^{3+} \ldots \ldots \ldots \ldots \ldots \ldots \ldots 121$

Figure 8-3: Positive ESI-MS spectrum of the reaction products of a stoichiometric

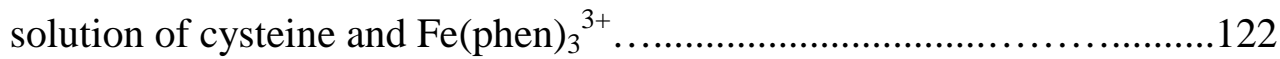

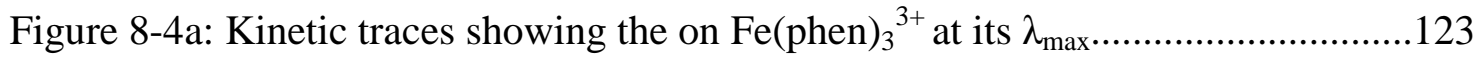

Figure 8-4b: Initial rate plot derived from Figure 8-4a................................124

Figure 8-4c: Effect of $\left[\mathrm{Fe}(\mathrm{phen}) 3^{3+}\right]$ variation on the formation of $\mathrm{Fe}(\mathrm{phen})_{3}{ }^{2+} \ldots \ldots \ldots .124$

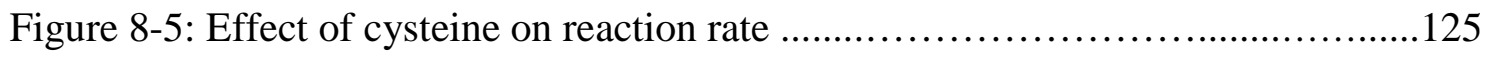

Figure 8-6: Evaluation of effect of initial acid concentrations.....................................126

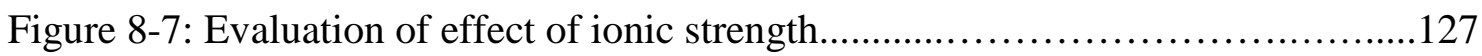

Figure 8-8a: Temperature dependence of cysteine-ferriin reaction...............................128

Figure 8-8b: Arrhenius plot extracted from study of effect of temperature variation on the reaction for determination of activation parameters......................128 


\section{LIST OF SCHEMES}

Scheme 1-1: Possible oxidation pathways for a thiol..............................15

Scheme 1-2: Reactions involved in thiol oxidation by a metal ion or complex.........16

Scheme 1-3: Reactions between cisplatin and L-cysteine at neutral $\mathrm{pH} . \ldots \ldots \ldots \ldots \ldots . . . .18$

Scheme 3-1: Hydrolysis of amifostine to form its active metabolite, WR-1065........34

Scheme 3-2: Proposed mechanism for the reduction of NAMI-A by cysteamine and subsequent ligand exchange process..................................52

Scheme 6-1: Proposed mechanism for the reduction of NAMI-A by cysteine

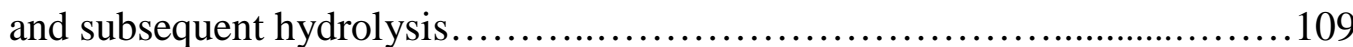




\section{LIST OF ABBREVIATIONS}

NAMI: $\quad$ New Antitumor Metastasis Inhibitor (Sodium trans-[tetrachloro (dimethyl sulfoxide)(imidazole) ruthenate(III)])

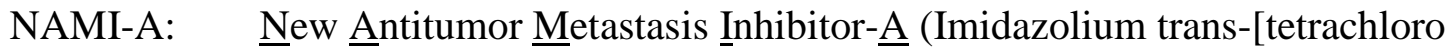
(dimethyl sulfoxide)(imidazole) ruthenate(III)])

GSH Glutathione

GSSG Oxidized glutathione

Cisplatin Cis-diamminedichloroplatinum(II),

MESNA Sodium mercaptoethane sulfonate

ESI-MS Electrospray ionization mass spectrometry

EPR Electron paramagnetic resonance spectroscopy

UV-Vis Ultraviolet visible spectroscopy

FTIR Fourier transform infrared spectroscopy

DMSO Dimethyl sulfoxide

S-DMSO Dimethyl sulfoxide coordinated through sulfur

r.m.s Root mean square

Carboplatin cis-Diammine(1,1-cyclobutanedicarboxylato)platinum(II)

Nedaplatin cis-Diammine(glycolato)platinum(II)

ICR Imidazolium trans-bis(imidazole)tetrachlororuthenate(III)

IndICR Indazolium trans-bis(indazole)tetrachlororuthenate(III)

$\Delta \mathrm{H}^{\neq} \quad$ Activation enthalpy

$\Delta \mathrm{S}^{\ddagger} \quad$ Activation entropy 


$\begin{array}{ll}\Delta \mathrm{G}^{\ddagger} & \text { Free energy of activation } \\ \text { DMPO } & \text { 5,5-Dimethyl-1-pyrroline N-oxide } \\ \text { EDTA } & \text { Ethylenediaminetetraacetic Acid } \\ \text { BNP7787 } & \text { Disodium 2,2'-dithio-bis-ethanesulfonate } \\ \text { pKa } & \text { Acid dissociation constant } \\ \text { DNA } & \text { Deoxyribonucleic acid } \\ \text { HSA } & \text { Human serum albumin } \\ \text { p53 } & \text { Tumor suppressor protein } \\ \text { NSCLC } & \text { Non-small cell lung cancer } \\ \text { FDA } & \text { US Food and drug administration }\end{array}$




\section{CHAPTER ONE}

\subsection{Introduction}

\subsection{Metals in nature}

The existence and importance of metal ions in the physiological system is well established. ${ }^{1-3}$ Nature utilizes metal ions for functions such as oxygen transport, synthesis of vitamin A, fatty acids and cholesterol; formation of urea, detoxification, bone development, and normal functioning of the nervous system. ${ }^{4-8}$ Transition metal ions are of particular interest because, even though they occur in trace amounts, their excess or deficiency may result in deleterious conditions such as anemia, ${ }^{2}$ liver and oxidative damage, among others. ${ }^{3 ; 9}$ Iron, for instance, supports fundamental biological functions involved in the handling and transport of oxygen, detoxification and synthesis of DNA, ${ }^{10}$ but is potentially toxic to cells. ${ }^{11-13}$ It has been implicated in events that lead to liver and heart diseases, ${ }^{14}$ neurodegenerative disorders, ${ }^{15}$ diabetes, ${ }^{2}$ cancer ${ }^{16}$ and catalytic production of free radicals. ${ }^{9}$ Transition metals are mostly found complexed in the active sites of metalloenzymes such as nickel in urease ${ }^{17}$ or iron in tyrosine hydroxylase, carbonic anhydrase dioxygenases, and isopenicillin N-synthase. ${ }^{18}$

Today there is increased understanding of the activities of transition metal ions and complexes in biological systems. ${ }^{19}$ Enlightenment in areas such as metalloprotein functions, models of metal ion active sites, how metal ions are delivered to the active sites, $^{20 ; 21}$ and involvement of transition metals in some disease states $^{22,23}$ have stimulated the use of metal ions and complexes for therapeutic strategies. One area of global application of metal-based therapeutics is in the treatment of cancer. ${ }^{24}$ 


\subsection{Cancer and cancer statistics}

According to the American Cancer Society, cancer is a group of diseases characterized by uncontrolled growth and spread of abnormal cells that result from sequential acquisition of mutations in genes that control cell growth, differentiation, and death. ${ }^{25}$ A recent report from Centers for Disease Control and Prevention's National Center for Health Statistics names cancer as the second leading cause of death in the United States, solely accounting for 559,888 (23\%) of the 2.42 million total registered deaths in $2006 .{ }^{26}$ It is second only to heart disease which accounts for twenty six percent of registered deaths. ${ }^{26 ; 27}$ Although overall cancer incidence rates have been on the decline, 1,638,910 new cases and 577,190 cancer deaths are predicted to occur in 2012. ${ }^{28 ; 29}$ Considerable treatment success has been achieved with the use of transition metal complexes, especially in the case of testicular cancer with the use of cisdiamminedichloroplatinum(II) (Cisplatin). ${ }^{30}$ The structure is shown in Figure 1. Cisplatin is able to damage DNA by binding to N-7 of adjacent guanosine residues which effects distortions that make DNA function and repair impossible. ${ }^{31}$ Cisplatin has up to a $90 \%$ cure rate for testicular cancer and, in combination with other drugs, has a very high activity against ovarian, cervical and bladder carcinomas. ${ }^{32-35}$

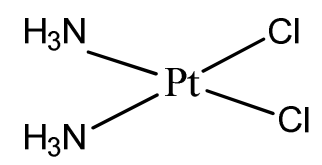

Figure 1-1: cis-diamminedichloroplatinum(II), (Cisplatin) 
This success is, however, marred by neurotoxicity, nephrotoxicity, alopecia and a lack of selectivity towards cancer cells. ${ }^{36 ; 37}$ Drug resistance, metastasis and activity over a small range of cancer types are other limiting factors. Analogues of cisplatin, two of which are shown in Figures 1.2a-b, have been synthesized, in an effort to circumvent the aforementioned problems. These complexes are also in clinical use ${ }^{38}$ and have demonstrated similar mechanism of action to that of Cisplatin. ${ }^{39}$

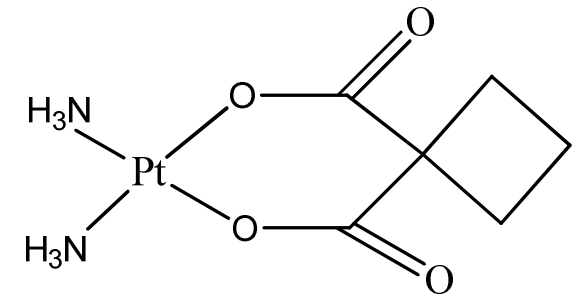

(a)

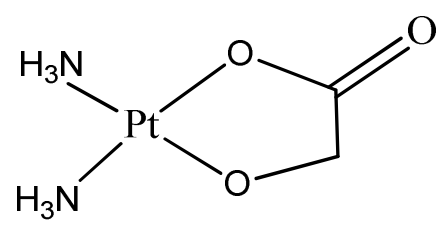

(b)

Figure 1-2: (a) cis-Diammine(1,1-cyclobutanedicarboxylato)platinum(II),

\section{(Carboplatin)}

(b) cis-Diammine(glycolato)platinum(II), (Nedaplatin)

Carboplatin and Nedaplatin are less toxic. Cisplatin and its analogues, however, are almost inactive against several malignancies with high incidence rates such as colon and rectum, lung, breast and prostate carcinomas. ${ }^{40-43}$ Also, a commonly occurring side effect of platinum anticancer drugs is ototoxicity ${ }^{44}$ Reports have indicated elevation of hearing threshold in greater than $50 \%$ of patients treated with cisplatin, ${ }^{45}$ and $84 \%$ of children treated with both cisplatin and carboplatin experience hearing loss. ${ }^{44}$ Otoxicity 
has been labeled as a commonly occurring toxicity that may influence academic and social development. ${ }^{44}$

\subsection{Metastasis}

Metastasis describes the ability of cancer cells to penetrate into lymphatic and blood vessels, circulate through the bloodstream, and then invade normal tissues elsewhere in the body. Metastasis, rather than primary tumor, is the major cause of death for cancer patients with solid tumors. ${ }^{46}$ This is reflected by 5 -year-survival rates which are higher than $90 \%$ for patients in early stages, which drop to $65 \%$ for patients initially diagnosed with regional lymph node metastases and is further reduced to less than $10 \%$ in patients with distant metastases. ${ }^{47-49}$ Metastasis involves a series of events through which cancer cells separate from the parent tumor and enter the circulatory system, float elsewhere, continue proliferation and form a secondary locus of tumor. ${ }^{50}$ This process is grossly inefficient in that only few of millions of cells released into circulation are able to colonize a secondary site. ${ }^{51 ; 52}$ Alarming failure rate of the process might be due to hostility of normal healthy tissues. ${ }^{53}$ Metastatic cells acquire characteristics making them adaptable to their new microenvironment: these characteristics differentiate them from the primary tumor and consequently present differing chemical sensitivity to cytotoxic agents. ${ }^{54-57}$ Figure 1-3 highlights the selectivity of metastatic cells for their preferred site for colonization in comparison to primary tumor. Tumor cells can survive in their new microenvironment only if they meet certain cellular preconditions which explain organ-specific metastatic behavior. ${ }^{50}$ 
These cells flourish in new tissue habitats and ultimately cause organ dysfunction and death. No effective therapeutic option is currently available for metastasis, ${ }^{58}$ neither is there an anticancer drug with activity over a wide range of cancer and metastasis. Hence, the intense research efforts towards finding therapeutics of a more desirable profile.

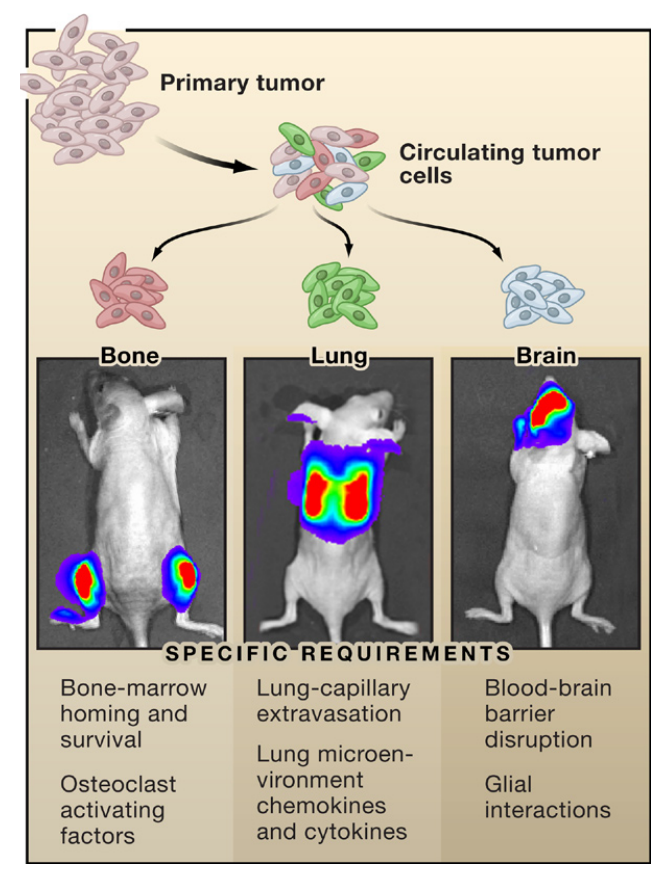

Figure 1-3: $\quad$ Organ specific colonization demonstrated by metastatic cells. Secondary organs place certain demands on invading tumor cells. ${ }^{50}$

\subsection{Anticancer prodrugs}

Prodrugs are chemicals with little or no pharmacological activity before undergoing biotransformation to a therapeutically active metabolite. ${ }^{59}$ In drug research and development, several possible improvements on the pharmacological profile of a 
drug may be achieved by exploring the prodrug concept. Several improvements have been achieved with this concept. Figure 1-4 summarizes the possible effects.

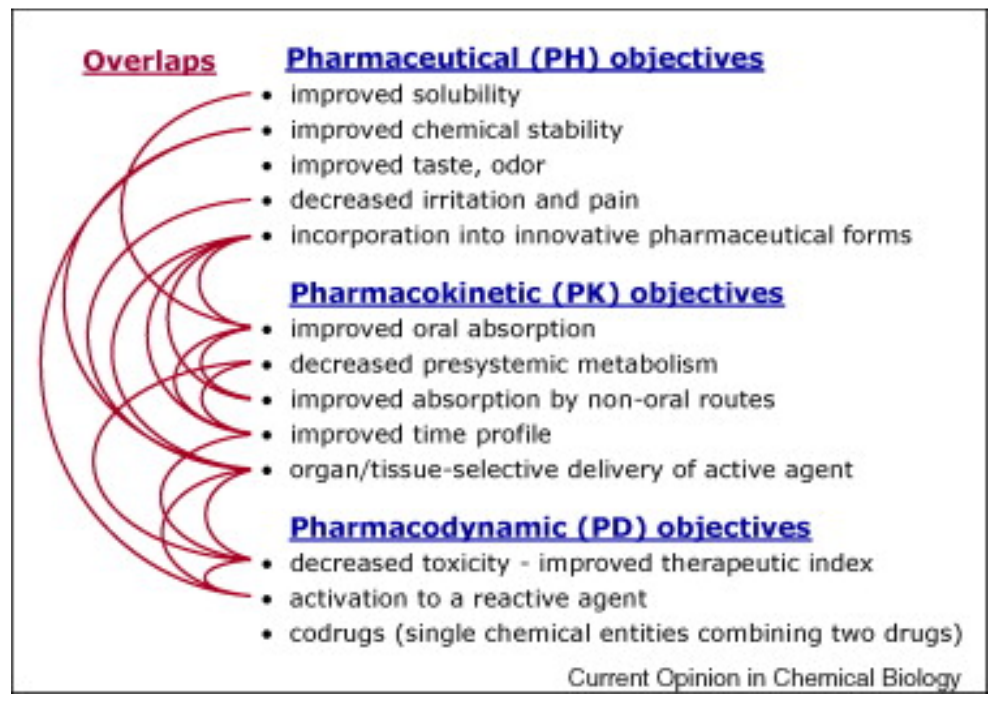

Figure 1-4: Classification of prodrug research objectives. [Adapted from Testa, $B$. 2009. $\left.{ }^{59}\right]$

Several non-platinum transition metal complexes have been synthesized for possible reduction or elimination of the undesired effects associated with platinum anticancer drugs presently in clinical use. ${ }^{60-65}$ Of special interest are ruthenium complexes that have shown activity against platinum resistant cancer cell lines, colorectal cancer and metastasis Figure $1.5(\mathrm{a}-\mathrm{d}) .{ }^{58}$ Indazolium trans-bis(indazole)tetrachlororuthenate(III), IndICR, is active against colon carcinomas and a variety of primary explanted human tumors. ${ }^{66 ; 67}$ It is noteworthy that $83 \%$ of patients with solid tumors who were treated with IndICR present stable disease. ${ }^{68}$ Sodium trans[tetrachloro (dimethyl sulfoxide)(imidazole) ruthenate(III)], called by the acronym 
NAMI (Figure 1-5c) also shows low host toxicity in active doses. ${ }^{69 ; 70}$ The observed reactivities of these complexes can be considered peculiar since ruthenium to date has no known biological function.

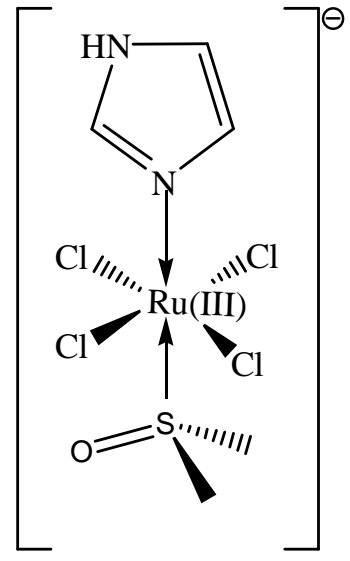

(a) NAMI-A
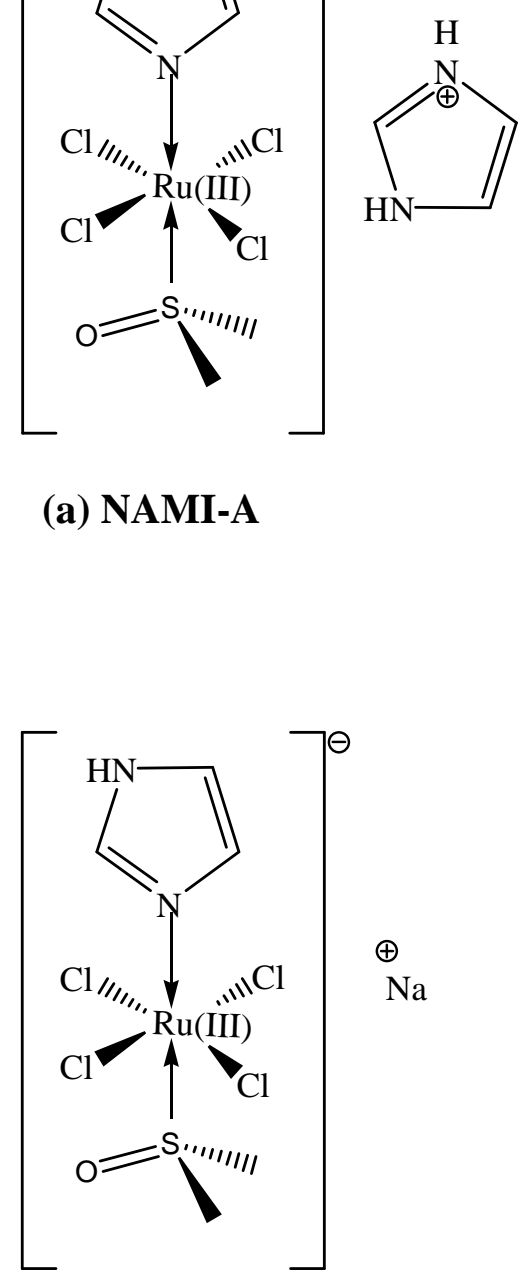

(c) NAMI

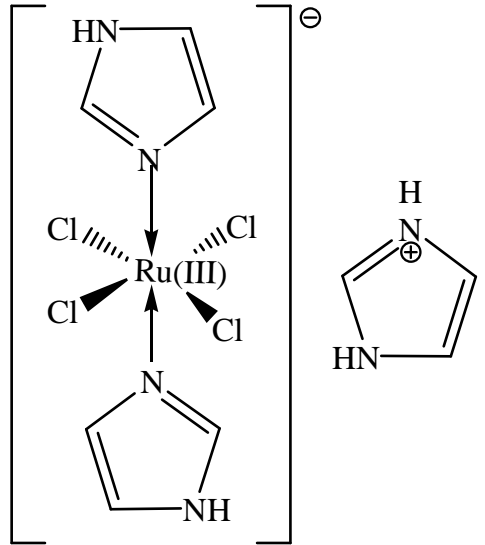

(b) ICR

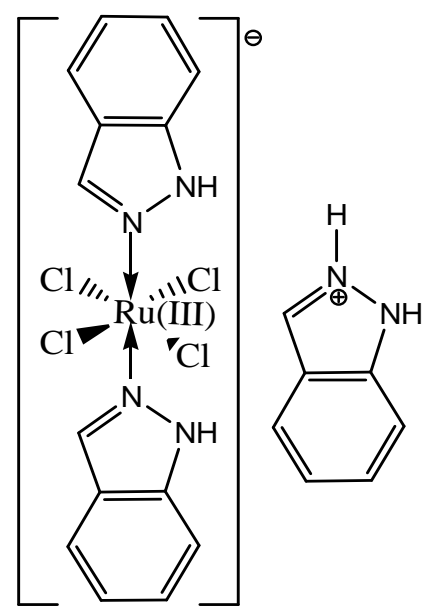

(d) IndICR

Figure 1-5: Ruthenium anticancer prodrugs 


\subsection{Antitumor Metastasis Inhibitor}

Imidazolium trans-[tetrachloro (dimethyl sulfoxide)(imidazole)ruthenate(III)], NAMI-A (Figure 1-5 a), is a ruthenium complex that shows low host toxicity with marked efficacy against metastases. ${ }^{70-72}$ It has successfully completed phase I of clinical trials and is currently undergoing phase II studies. ${ }^{73}$ Results of Phase I and pharmacological study of this prodrug demonstrate no severe side effect (formal common toxicity criteria (CTC) grade 3) was developed from its use. Formation of painful blister was considered dose limiting. ${ }^{73}$ NAMI-A has demonstrated up to $100 \%$ metastasis reduction on preclinical models of solid metastasizing tumors such as Lewis lung carcinoma, TS/A mammary adenocarcinoma, ${ }^{72} \mathrm{MCa}$ mammary carcinoma, ${ }^{74} \mathrm{~B} 16$ melanoma, ${ }^{75}$ and up to $90 \%$ on H460M2 human NSCLC xenograft. ${ }^{74 ; 76}$

One of the initial stages in metastasis progression is reduction of cell adherence leading to detachment from a primary site ${ }^{50}$ NAMI-A has been found to increase cell adherence thereby interfering with other processes leading to full colonization. ${ }^{76-78}$ NAMI-A has very high selectivity towards metastases while still having some effect on the primary tumor. Figure 1-6 illustrates the effect of NAMI-A. ${ }^{79}$ NAMI-A has been shown to be effective, irrespective of the origin or the stage of growth of metastasis. ${ }^{72} \mathrm{~A}$ critical observation of Figure 1-6 also reveals the inconsequential effect of NAMI-A on primary tumor. 


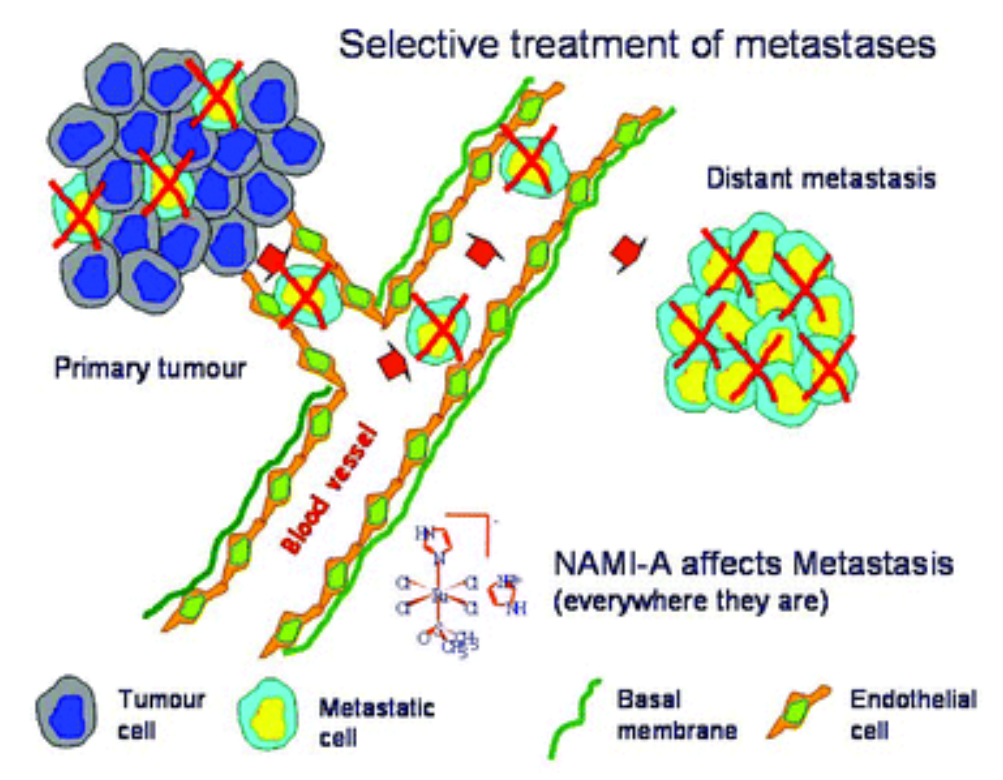

Figure 1-6: $\quad$ Selective metastatic removal by NAMI-A. It shows weak reduction of primary tumor while removing close to $100 \%$ of metastatic cells. ${ }^{79}$

Cancer cells are constantly proliferating and an important characteristic of tumor growth is the doubling time. Usually a tumor is undetected until it has doubled 30 times $\left(10^{9}\right.$ cells). A tumor mass is sufficient to kill its host after 35 doublings which corresponds to $10^{12}$ cells. ${ }^{80}$ Figure 1-7 illustrates the relationship between tumor cell count, number of doublings and tumor detection. This indicates that a significant portion of tumor growth is completed by the time of detection, although, methods such as ultrasonography and Magnetic Resonance Imaging offers detection of tumors less than $1 \mathrm{~cm} .{ }^{81}$ A chemotherapy regimen that focuses solely on elimination of metastasis will spare the primary tumor which continues its growth cycle normally. It is then rational to suggest that a regimen that will maximize NAMI-A to full potential should contain another anticancer drug that is effective towards primary tumor. 


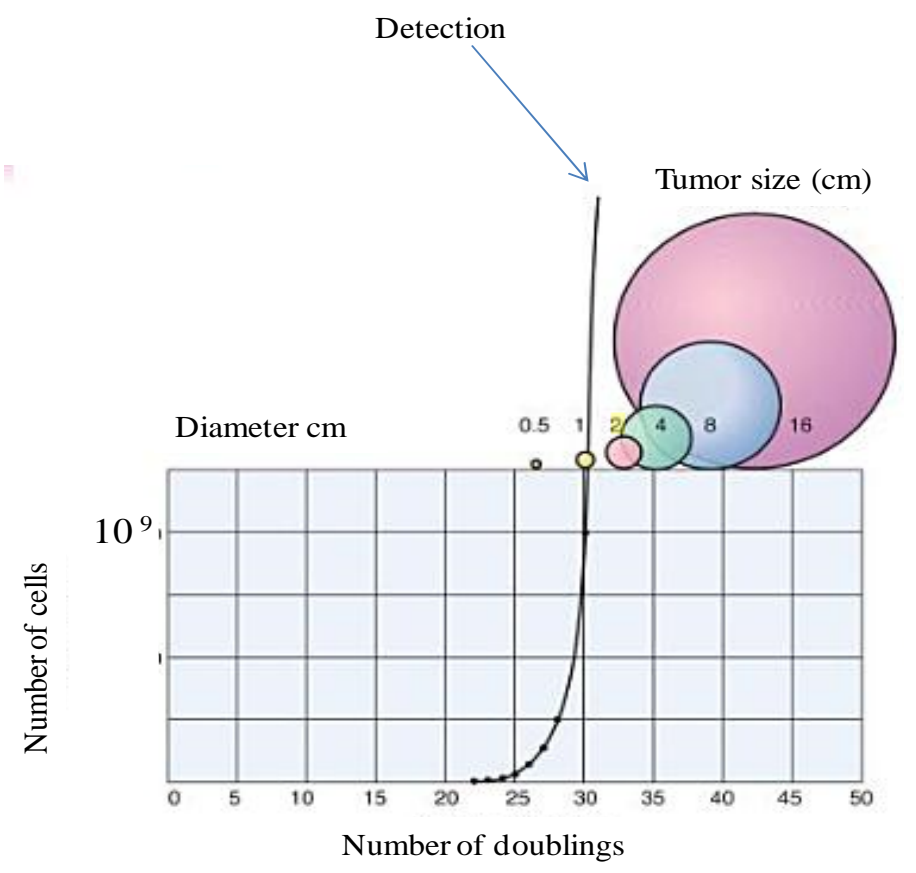

Figure 1-7: Hypothetical tumor growth curve. ${ }^{80}$

Research efforts directed at understanding the mechanism of action of NAMI-A are still in their infancy, with recent efforts focused on finding the effects of chemical stability, photostability, interaction with human serum albumi and comparison of treatment outcomes employing different routes of application, among others. ${ }^{79 ; 82-86}$

\subsection{Activation by reduction hypothesis}

Transition metal complexes readily undergo ligand substitution and redox reactions. The roles of these reactions and the biological activity of a metal complex depend both on thermodynamics and kinetics. Activation by reduction has been proposed for this prodrug, NAMI-A, ${ }^{33 ; 82 ; 87 ; 88}$ which may be a factor in its preferential toxicity towards hypoxic tumor and metastatic cancer cells. ${ }^{33}$ In support of this 
"activation-by-reduction" hypothesis, ligand exchange and antimetastatic activity of NAMI-A is enhanced upon addition of biological reductants such as ascorbic acid, cysteine, or glutathione..$^{84: 89}$

The major difference between solid tumors and healthy tissues is the nutritional and metabolic environment. The vasculature of tumors is often inadequate to supply the nutritional needs of constantly growing tumor cells leading to oxygen deficiency (hypoxia). Tumor cells produce lactic acid due to their high dependence on aerobic glycolysis, resulting in low $\mathrm{pH} .{ }^{90}$ Low $\mathrm{pH}$ environment and low oxygen favor reduction and this contributes towards the specificity of reduction-activated prodrugs. Ruthenium is able to mimic iron by binding to certain biological molecules such as serum transferrin and albumin since ruthenium and iron are in the same group. ${ }^{91}$ Transferrin and albumin are proteins used by mammals to solubilise and transport iron, thereby reducing its toxicity. Preferential selective delivery of the prodrug to tumor cells by transferrin transport has been suggested. ${ }^{91}$ Rapidly dividing cancer cells have higher demand for iron and thus have an increased number of transferrin receptors compared to normal cells, resulting in selective deposition of the prodrug. ${ }^{85: 92}$ Figure 1-8 illustrates the low host toxicity of the ruthenium complex. Binding of NAMI-A to albumin and tranferrin were reported not to be particularly beneficial for antimetastatic activity although may extends biological half life. ${ }^{93}$

Ruthenium complexes in the +3 state are kinetically inert compared to the +2 complexes. This kinetic inertness offers an advantage in that the prodrug gets to its target before transformation or activity. Electrons needed for this reduction are 
physiologically accessible and may be provided by biological reductants such as glutathione, ascorbic acid and cysteine residue of proteins. ${ }^{94}$

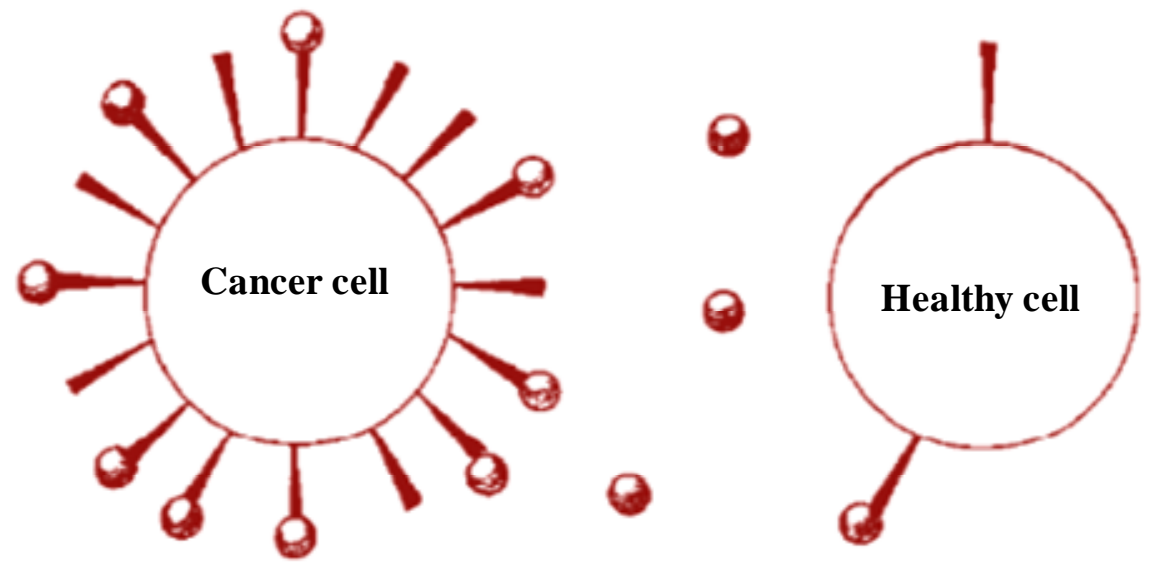

\section{Ruthenium loaded transferrin \\ - Transferrin receptor}

Figure 1-8: Selective uptake of ruthenium loaded transferrin by cancer cells. ${ }^{92}$

\subsection{Thiols}

Thiols are sulfhydryl compounds. The presence of thiol functionality in compounds makes them susceptible to various transformations due to wide range of accessible oxidation states of sulfur, -2 to +6 . Endogenous thiols include glutathione (GSH), cysteine, cysteamine and homocysteine. GSH, a tripeptide, is the most abundant and occurs in virtually all mammalian cells. ${ }^{95}$ Thiols are involved in many redox processes especially in maintaining the intracellular redox state through thiol-disulfide exchange. ${ }^{96}$ Extracellular cysteine/cystine redox status has been implicated in cell 
growth and apoptosis. ${ }^{97}$ Also, inadequate sulfur amino acid intake results in oxidized thiol/disulfide redox status which is associated with oxidative stress and onset or progression of diseases. ${ }^{98 ; 99}$ An interesting illustration of the importance of redox status is that the reduction potential of a cell with $1.0 \mathrm{mM}$ intracellular GSH concentration changes from $-250 \mathrm{mV}$ to $-190 \mathrm{mV}$ if $18 \mu \mathrm{M}$ of the GSH is oxidized. ${ }^{97}$ This change in reduction potential is adequate to change the functional state of the cell from proliferation (multiplication of epithelial cells) to differentiation (specialization or maturation). ${ }^{97: 100-103}$ Involvement of thiols in several important cell functions makes it impossible to exclude their interaction with most drugs in establishing a detailed mechanism of drug biotransformation and action.

There are biologically-active thiols that may be introduced as pharmaceuticals. For example, $\mathrm{N}$-acetyl cysteine is used as an adjuvant in respiratory conditions with excessive mucus production and has been shown to prevent metastasis in animal models. ${ }^{104}$ Sodium-2-mercaptoethanesulfonate, $\quad$ MESNA, prevents ischemia/reperfusion-induced renal damage, and is also used as a detoxifying agent to inhibit the hemorrhagic cystitis induced by chemotherapy drugs. ${ }^{105-109} 2$ mercaptopropionyl glycine, also known as thiopronin, prevents hepatotoxicity of Isoniazid used in tuberculosis treatment by inhibiting and scavenging free radicals. ${ }^{110}$ It reduces cisplatin-induced nephrotoxicity ${ }^{111}$ and is also used in treatment of rheumatoid arthritis and cystinuria. ${ }^{12 ; 113}$ Thiol protection may not necessarily be desirable in some cases since this may result in drug resistance as observed in reduced anticancer activity of cisplatin in the presence of homocysteine and N-acetyl cysteine. ${ }^{114}$ It has been 
reported that a possible pathway for regulation of human immunodeficiency virus 1(HIV-1) protease activity involves modification of the cysteine residue of HIV-1. ${ }^{115}$

The highly nucleophilic sulfur center is critical to the functioning of thiol-based drugs as radioprotective agents and in DNA repair. The chemistry involved in DNA repair by thiols is represented by $\mathrm{R} 1.1-\mathrm{R} 1.4{ }^{116}$

$$
\begin{array}{lc}
\mathrm{DNA}^{+}+\mathrm{RSH} \longrightarrow \mathrm{DNA}+\mathrm{RS}^{\bullet}+\mathrm{H}^{+} & \mathrm{R} 1.1 \\
\mathrm{DNA}^{+}+\mathrm{RS}^{-} \longrightarrow \mathrm{DNA}+\mathrm{RS}^{\bullet} & \mathrm{R} 1.2 \\
\mathrm{RS}{ }^{-}+\mathrm{RSH}^{-} \longrightarrow \mathrm{RSSR}^{-}+\mathrm{H}^{+} & \mathrm{R} 1.3 \\
\mathrm{RSSR}^{-}+\mathrm{DNA}^{+} \longrightarrow \mathrm{DNA}+\mathrm{RSSR}^{+} & \mathrm{R} 1.4
\end{array}
$$

\subsubsection{Thiol oxidation}

Most biological processes involving the thiol moiety occur through oxidation, some of which were mentioned earlier. ${ }^{97 ; 117}$ Non-radical oxidants of potential relevance to oxidative stress include $\mathrm{H}_{2} \mathrm{O}_{2}, \mathrm{HOCl}$ and $\mathrm{ONOOH},{ }^{118-120}$ and these can react with cysteine or methionine residues of proteins. Oxidation of thiols may proceed through a variety of pathways resulting in series of different metabolites and products. ${ }^{121-125}$ Studies from our lab have demonstrated exotic dynamics in oxidation of low molecular weight organosulfur compounds involving some of these oxidants. ${ }^{126-130}$ Scheme 1-1 shows possible oxidation pathways for a thiol ranging from a one electron oxidation to disulfide all the way to eight-electron oxidation to form sulfate. 


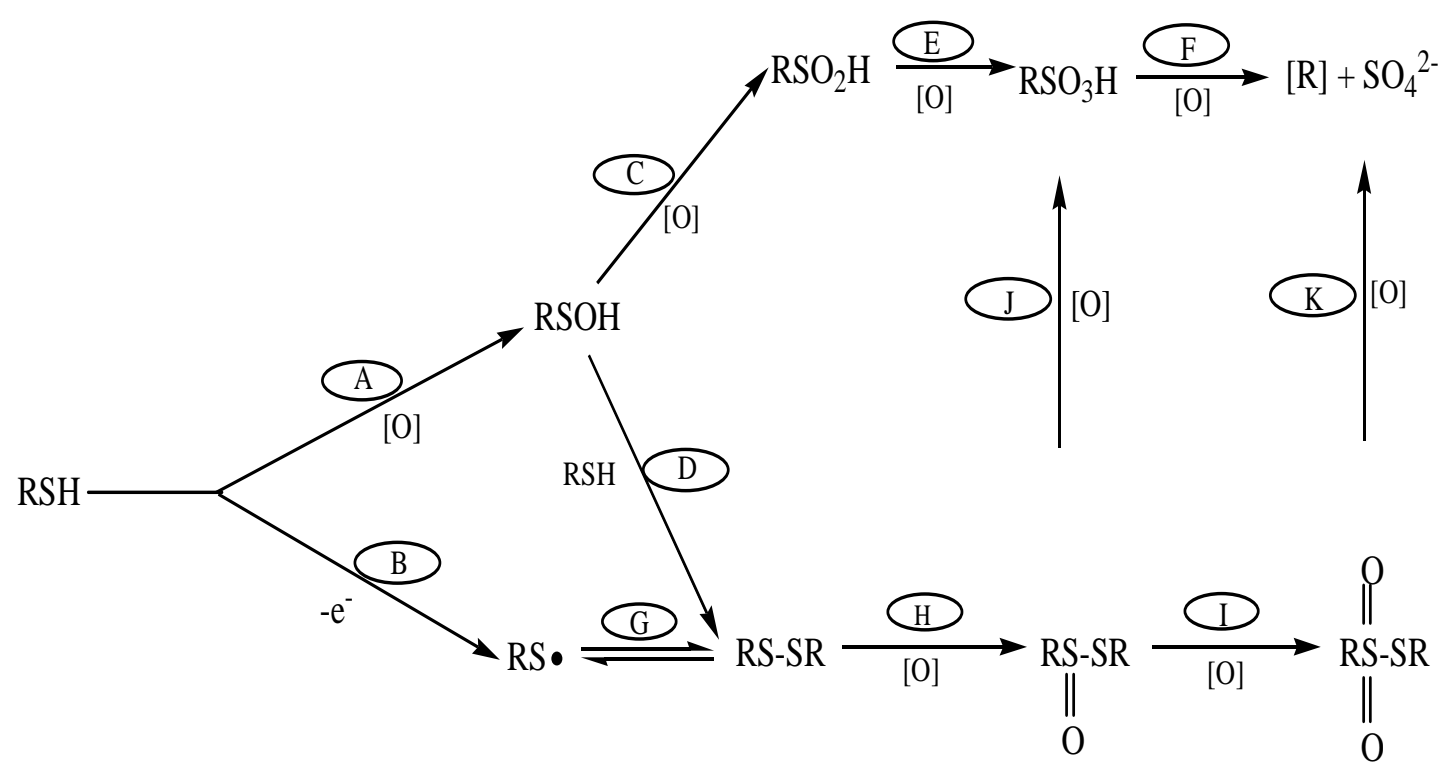

Scheme 1-1: Possible oxidation pathways for a thiol $^{127}$

Enzymatic oxidation of thiols by peroxidase; mainly by horseradish peroxidase, lactoperoxidase, and myeloperoxidase, have been shown to yield thiyl radicals ${ }^{131 ; 132}$. Thiols can also be oxidized to disulfide by metal ions or complexes. This oxidation generally proceeds through thiyl radical formation (R1.5 and 1.6). Once formed, the thiyl radical can undergo several other reactions depending on what species are immediately available. Two thiyl radical molecules can react to form the disulfide (R1.6), a thiyl radical can react with the parent thiol (R1.7) or thiolate anion (R1.8) to form disulfide radical anion. ${ }^{133-135}$ Thiyl radicals have also been shown to form sulfenic acid and other oxygen containing products. ${ }^{133 ; 135 ; 136}$ 


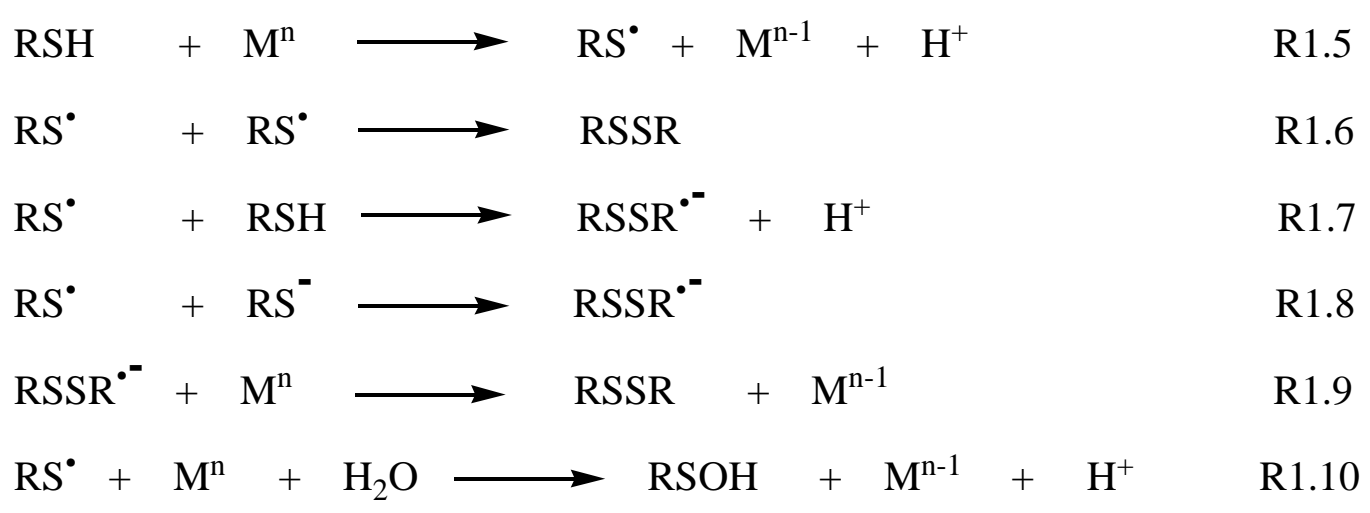

Scheme 1-2: Reactions involved in thiol oxidation by a metal ion or complex. ${ }^{133-135}$

\subsubsection{Metal binding}

Thiols can form complexes with metals ions or transition metal complexes where the sulfur atom of the $\mathrm{SH}$ group acts as the binding site. ${ }^{137 ; 138}$ For instance, Dpenicillamine has been shown to form variable complexes; a purple paramagnetic complex and a yellow diamagnetic complex with copper; depending on the ratio of copper to penicillamine. ${ }^{139}$ The ability of thiols to form complexes with metals is being utilized in medicine for treatment of diseases involving excess metals in the physiological environment such as Alzheimer's, Parkinson's and Huntington's diseases. ${ }^{140}$ Thiols can effectively remove excess metal by competing for the metal ion with biological binding sites. This type of treatment requires selectivity of the thiol towards certain metals in order to avoid possible depletion of essential metals. Dpenicillamine, a disubstituted cysteine, chelates excess copper and enhances copper excretion in Wilson's disease. ${ }^{141 ; 142}$ A process involving thiol-disulfide exchange in zinc fingers has been used to release complexed zinc. This process has been found to inhibit 
both laboratory strains and clinical isolates of HIV-1. ${ }^{143-145}$ Dimercaptosuccinic acid and dimercaptopropionic sulfonate have gained general acceptance in the management of many human metal intoxications which include lead, arsenic, and mercury compounds. ${ }^{146-150}$ Metal binding properties of thiols have also been explored in modulating the functions of proteins containing the thiol moiety. ${ }^{151}$

In platinum cancer therapy, the metal binding characteristic of thiols may be beneficial $^{152}$ but more often is undesirable since this interaction leads to reduced availability and deactivation of the platinum complex. ${ }^{153}$ Reports have shown this to play a significant role in drug resistance and inactivation ${ }^{153-157}$ Scheme 1-3 describes interactions of cisplatin with L-cysteine that results in its unavailability for its desired function. ${ }^{153 ; 158}$

It is interesting that interactions of NAMI-A with biological reductants such as thiols have been proposed to play a significant role in its activation as opposed to deactivation in the case of platinum drugs. ${ }^{153 ; 158}$ It has also been shown that NAMI-A is rapidly reduced under physiological conditions ${ }^{94}$ with ambiguity as to whether its reduced form or hydrolytic derivative react with human serum albumin and ascorbic acid in acidic medium. ${ }^{159}$ There have been several reports of hydrolysis pathways for the promising prodrug, ${ }^{160 ; 161}$ the mechanism of action and the nature of chemical species responsible for the pharmacological properties of this prodrug are yet to be unraveled and kinetics studies directed at elucidating the mechanism of its interaction with biologically-relevant thiols is simply nonexistent. 


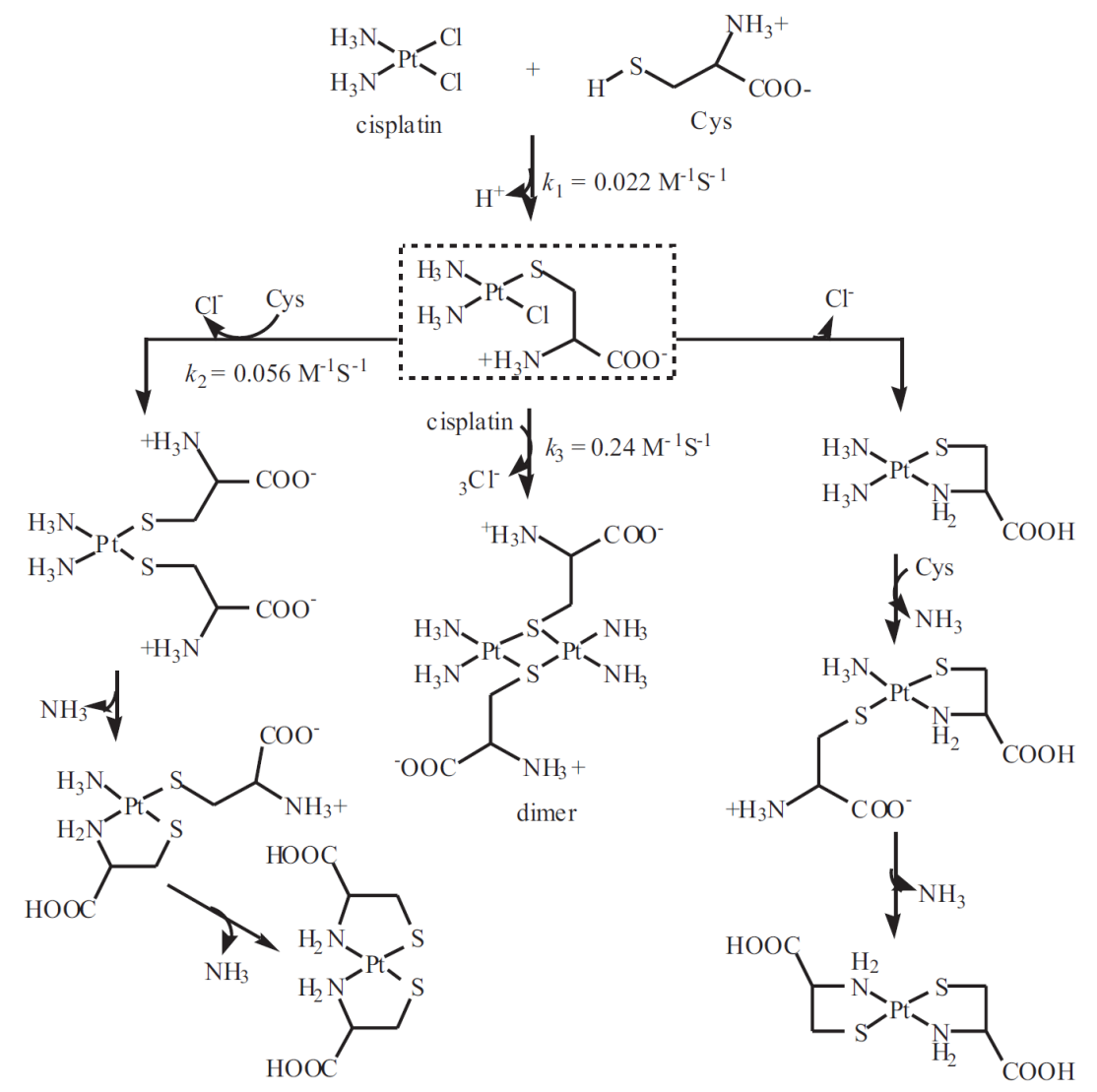

Scheme 1-3: Reactions between cisplatin and L-cysteine at neutral $\mathrm{pH}^{153 ; 158}$

Legend: Cys - Cysteine, $\mathrm{Cl}^{-}$- Chloride ion

\section{$1.8 \quad$ This Study}

Metastases, due to their inadequate responsiveness towards any clinically available cancer drug heighten the need for drugs that are effective against metastases. Development of NAMI-A, a compound that is 1,053 times less toxic than cisplatin, ${ }^{162}$ is a step towards achieving the long desired activity against metastasis. Reports have excluded DNA binding as the major target for antimetastatic activity of NAMI-A ${ }^{163-165}$ suggesting that its interaction with biomolecules other than nucleobases may represent 
the molecular basis for its peculiar biological activity. An understanding of the chemical transformations of NAMI-A upon interaction with endogenous molecules and xenobiotics is of prime importance for its pharmaceutical and biomedical applications.

Absorption, distribution, metabolism, excretion and toxicity (ADMET) are important concepts in drug therapy and depend on kinetics and thermodynamics of interactions of the drug with biomolecules. Even after 40 years of clinical use of Cisplatin (world's most widely used anticancer drug), the mechanism of action of the drug is yet to be completely unraveled. ${ }^{166}$ Recognizing this fact and understanding that interaction of NAMI-A with xenobiotics are of potential biological importance, the work reported in this dissertation therefore focused on:

(1) Investigating molecular transformations involved in the interactions of NAMI-A with select thiols (GSH, cysteine, cysteamine and MESNA) and identification of observable species. The choice of these thiols examines reactions of NAMI-A with cellular thiols and clinical chemoprotectant, MESNA, while providing a model for NAMI-A interaction with proteins and enzymes with thiol residues.

(2) Studying and determining the kinetics and thermodynamics of these interactions.

(3) Deduction of plausible mechanism of interaction from experimental results. Plausible reaction mechanisms will be proposed for the studied reactions based on experimental results obtained.

This is information necessary for any xenobiotic, especially an experimental drug with a desirable pharmacological profile whose cellular target remains to be determined. An understanding of these interactions on a molecular level may give access to control of 
drug activity, refinement of structures for more desirable effects and, most importantly, ensure that treatment/drug metabolism proceeds in a predictable manner. 


\section{CHAPTER TWO}

\subsection{Instrumentation, Materials and Methods}

\section{$2.1 \quad$ Introduction}

Kinetics deal with the study of reaction rates in an effort to understand the quantities that influence the rates, describe the series of elementary steps involved in reaction systems (the mechanism) and deduce rate parameters governing such reactions. Knowledge of reaction rates has many practical applications including, but not limited to, designing an industrial process, understanding complex dynamics of the atmosphere, optimizing synthetic processes, establishing the best administration mode for a drug, deducing metabolic pathways and improving specificity of therapeutics. Kinetics can also be employed in establishing indices responsible for drug resistance and elucidating pathways to such drug resistance. In order to achieve these applications, reaction dynamics require a series of information on the progress of reaction. The necessary information includes dynamical variables such as temperature, pressure, $\mathrm{pH}$, reactant concentrations, solvent and ionic strength.

The reaction to be studied dictates the set of conditions required. Careful choice of analytical techniques and instrumentation, therefore, is required for reliable kinetic outcomes. The stoichiometry of reaction is the first step in establishing an overall equation for a reaction. Specialized analytical methods such as nuclear magnetic resonance spectroscopy, electron paramagnetic resonance spectroscopy, infrared and Raman spectroscopy, ultraviolet and visible spectrophotometry, mass spectrometry, stopped flow spectrophotometry, etc. are tools used for monitoring reaction progress via 
determination of reactants or intermediate concentrations as well as product identification.

\subsection{Instrumentation}

\subsubsection{Conventional UV/Vis Spectrophotometry}

$\mathrm{UV}$-visible spectroscopy measures absorption of the electromagnetic radiation caused by electronic transitions from the ground state to the excited state of bonding and non-bonding electrons of ions or molecules. For this study, a Perkin-Elmer Lambda 25 UV-VIS spectrophotometer featuring a double beam, all-reflecting system with a spectral range of $200 \mathrm{~nm}$ to $700 \mathrm{~nm}$ was used. For this instrument, the visible region uses a halogen lamp and the UV region uses a deuterium lamp. ${ }^{167}$ The spectrophotometer is interfaced to a computer with Perkin-Elmer UV WinLab software $^{167}$ for data acquisition, storage and analyses. The instrument is attached to a thermostated water bath for maintenance of constant temperature. Spectral changes of reaction mixtures were recorded over the wavelength range to establish suitable wavelength for kinetics observations.

\subsubsection{Stopped-flow Spectrophotometry}

Stopped-flow spectrophotometry has the advantage of using small amounts of reactants, and providing rapid and efficient mixing that comes with an analytical response that has good time resolution. It allows for changes in optical properties of solutions (in this case absorbance) to be monitored using UV-VIS detection. It offers an 
advantage in the study of fast reactions which might have been impossible with conventional UV/Vis spectrophotometric techniques. A Hi-Tech Scientific SF61-DX2 double mixing stopped-flow spectrophotometer was used for all kinetic studies. Amplification and digitization of detector signal from the spectrophotometer was done via an Omega Engineering DAS-50/1 16-bit A/D board interfaced to a computer for storage and data analysis. A dead time of $1.0 \mathrm{~ms}$ will ensure observation of the crucial initial parts of rapid and even complex reactions which otherwise might have been impossible. The light source is a $75 \mathrm{~W}$ super quiet Xenon arc lamp. Figure 2.1 is a schematic diagram for the sample handling unit that separates compartments for up to three reactants allowing for different mixing sequences in optimizing experiment procedure.

The double mixing mode enables transient species formed by mixing reactants in $\mathrm{A}$ and $\mathrm{B}$ to be subsequently mixed with a third reactant, $\mathrm{C}$, after a delay period if needed (refer to Figure 2-1). Reactant reservoir D can be reserved for the buffer and this pushes the premixed solutions $\mathrm{A}$ and $\mathrm{B}$ (from mixer 1) to a second mixer (mixer 2) where it reacts further with reactant $C$. The resultant mixture passes through a measurement flow cell and into a stopping syringe where the flow is stopped. Just prior to stopping, a steady state flow is achieved. 


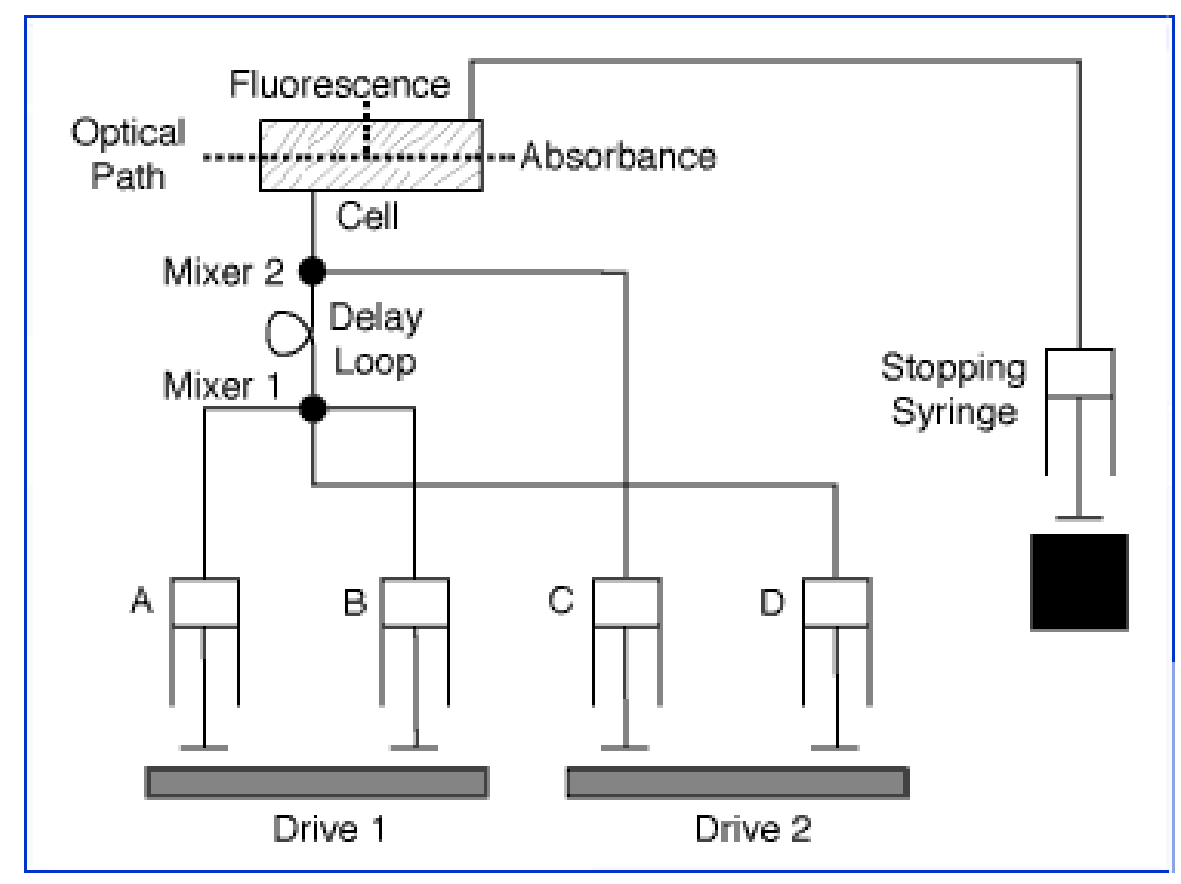

Figure 2-1: Sample Handling Unit (SHU) flow circuit diagram for the SF-61DX2 HiTech KinetAsyst stopped-flow spectrometer. [Courtesy of Hi-Tech Scientific operator's Manual]

\subsubsection{Electrospray-Ionization Mass Spectrometry (ESI-MS):}

Mass spectrometry, MS, is an analytical technique that sorts and measures ionized molecules based on their mass-to-charge ratios. The possibility of observing the fragmentation pattern of a molecule makes MS an invaluable technique for structural elucidation. This spectrometric method works on the basic principle of separation of ions of a compound on the basis of their mass-to-charge ratio $(\mathrm{m} / \mathrm{z})$ and the number of ions representing each $\mathrm{m} / \mathrm{z}$ unit when a compound is ionized. Ionization method is dictated by the nature of analyte. Electrospray ionization method which has the advantage possible molecular determination of intact analytes is a method of choice. 
Figure 2-2 describes the mechanism of ion formation using ESI. An analyte, usually dissolved in a polar volatile solvent, is introduced and passes through the electrospray needle to which a high potential difference has been applied (typically 2.5 to $4 \mathrm{kV}$ ). This potential difference forces the spraying of droplets with a surface charge of the same polarity as the needle. Solvent evaporation occurs as the charged droplets are repelled towards the counter electrode (shown in blue). The rapid shrinking of the droplets by evaporation of solvent increased charge density on their surface, a critical point (Rayleigh Stability limit) is reached when the charge density of the droplet and the attraction of the positive ions to the counter electrode overcomes the surface tension holding the droplet together, leading to fission (coulombic explosion) with the release of smaller droplets containing charged analyte molecules. ${ }^{168 ; 169}$

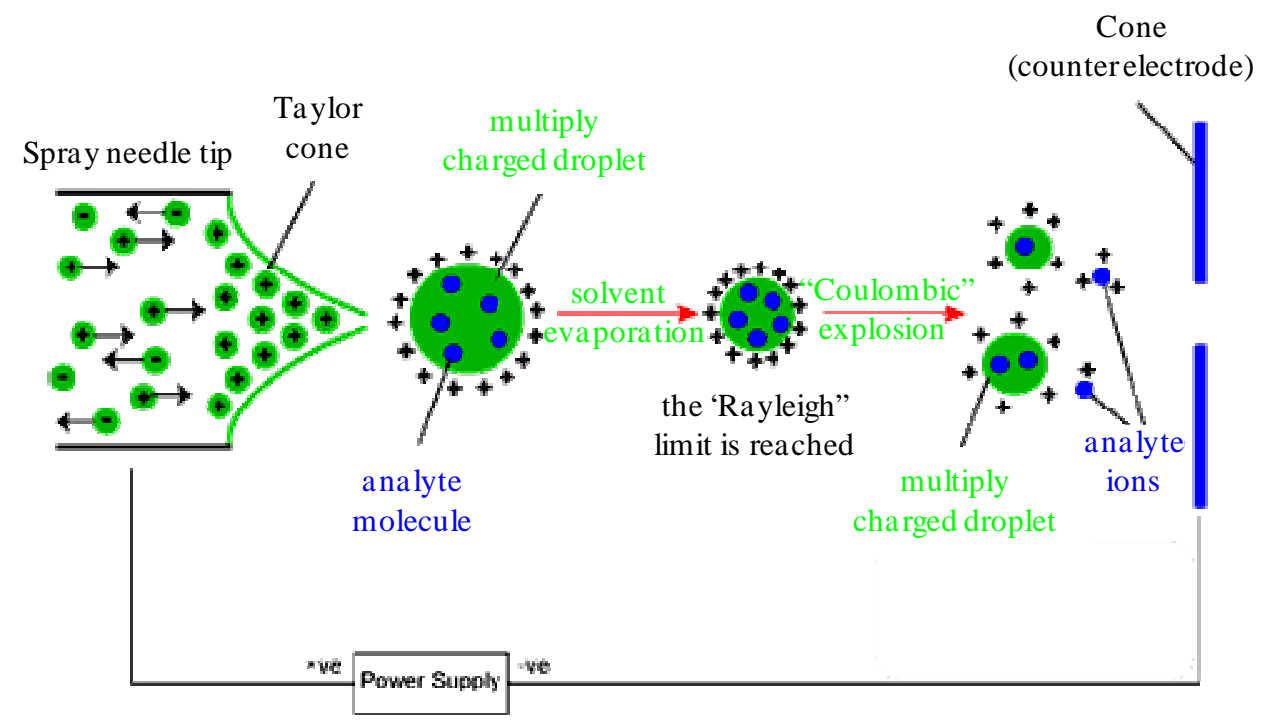

Figure 2-2: Schematic for ion formation in ESI. ${ }^{170}$ 
The mass spectral analysis for product identification in this study was performed using a Thermo LTQ Orbitrap Discovery hybrid mass spectrometer (San Jose, CA), equipped with an Ion Max ESI source. This combines a soft ionization technique, large mass range of $(50-2000 \mathrm{~m} / \mathrm{z})$, mass accuracy of $<2 \mathrm{ppm}$ root mean square (r.m.s) and up to 30,000 resolving power with a detect time of $400 \mathrm{~ms}^{171 ; 172}$ (LTQ Orbitrap Discovery Hardware Manual 1-5 ThermoFisher Scientific)

\subsubsection{Nuclear Magnetic Resonance Spectroscopy (NMR)}

Nuclear Magnetic Resonance spectroscopy is an essential analytical tool used in chemical analysis and fundamental research. Its versatility derives from the atomic nature of the information it provides. In principle, nuclei that contain odd mass numbers

(such as ${ }^{1} \mathrm{H},{ }^{13} \mathrm{C},{ }^{19} \mathrm{~F}$, and ${ }^{31} \mathrm{P}$ ) or odd atomic number (such as ${ }^{14} \mathrm{~N}$ and ${ }^{2} \mathrm{H}$ ) absorb electromagnetic radiation at a frequency characteristic of the nuclei in the presence of an external magnetic field. ${ }^{173}$ The signal in NMR spectroscopy is due to the disparities in the energy absorbed by the nuclei as they are excited from the lower energy state to the higher energy state, and the energy emitted by the nuclei as they relax from the higher energy state to the lower energy state. The NMR technique was used in this study for confirming the structure of NAMI-A, where a comparison was made to literature. 


\subsubsection{Electron Paramagnetic Resonance Spectroscopy (EPR)}

EPR is a technique for measuring absorption of electromagnetic radiation by an electron spin system. ${ }^{173}$ EPR has evolved to be a nondestructive, noninvasive analytical technique for structural and dynamical information. It has very high sensitivity with a detection limit in the nanomolar range. EPR has been applied in the measurement of both in vitro and in vivo free radical intermediates from drugs and oxidative processes. Pharmacokinetic information of paramagnetic compounds in mice have been obtained in mice just by placing the tail of the animal directly in the EPR resonator. ${ }^{174}$ EPR has proven useful in evaluation of oxidative stability of vegetable oils. ${ }^{175}$

Free radicals have been implicated in metabolism of sulfhydryl moieties especially in oxidative disease states. ${ }^{176}$ Since reactions in this study involve electron transfer, the possibility therefore arises for involvement of free radical mechanisms. EPR measurements were carried out for detection and possible quantification of free radicals on a Bruker ${ }^{\mathrm{TM}}$ Biospin e-scan spectrometer designed to perform EPR measurements in the X-band-range. However, our reactions did not demonstrate involvement of free radicals as indicated by EPR silent reaction solutions in the presence of DMPO spin trap. This gave an indication that at least, non-metal centered radical (sulfur, oxygen or carbon) were not involved, since the $300 \mathrm{G}$ sweep width of our instrument is not sufficient for a most metal based radicals. 


\subsection{Materials}

Glutathione, cysteamine, L-cysteine, 2-mercaptoethane sulfonate (MESNA), sodium hydroxide, sodium chloride, sodium perchlorate, perchloric acid, absolute ethanol, acetone, diethyl ether, hydrochloric acid, imidazole, dimethyl sulfoxide, deuterium chloride, deuterium oxide (all from Sigma-Aldrich), monosodium phosphate, monohydrate, disodium phosphate heptahydrate (from Fisher Scientific) and ruthenium chloride (from GFS chemicals) were of analytical grade and used as obtained. Aqueous solutions of reactants and buffers were prepared in distilled deionized water obtained from a Barnstead Sybron Corporation water purification unit that dispenses water with resistance of at least $18 \mathrm{M} \Omega$.

$\mathrm{pH}$ of the solutions was measured with a $720 \mathrm{~A}+$, Thermo Orion $\mathrm{pH}$ meter. Phosphate or acetate buffer was used to adjust the $\mathrm{pH}$ of the experimental solutions. Reactions were carried out at $25.0 \pm 0.1^{\circ} \mathrm{C}$ (except for when isolating the effect of temperature) and at a constant ionic strength of $1.0 \mathrm{M}$ using $\mathrm{NaClO}_{4}$ or $\mathrm{NaCl}$ (except when isolating the effect of ionic strength).

\subsection{Experimental Methods}

\subsubsection{Synthesis of hydrogen trans-bis(dimethyl sulfoxide)tetrachlororuthenate-} (III)

NAMI-A precursor, Hydrogen trans-Bis(dimethyl sulfoxide) tetrachlororuthenate(III), was synthesized using published method. ${ }^{177}$ Briefly, $1.0 \mathrm{~g}$ of $\mathrm{RuCl}_{3} \cdot 3 \mathrm{H}_{2} \mathrm{O}$ was dissolved in $30 \mathrm{~mL}$ of ethanol and refluxed for 3 hours. The filtered solution was 
concentrated to about $3 \mathrm{~mL}$ and a mixture of $1 \mathrm{~mL}$ of $37 \% \mathrm{HCl}$ and $2 \mathrm{~mL}$ of DMSO was added. The resulting solution was kept at $80{ }^{\circ} \mathrm{C}$ for 15 minutes and a bright orange solution was obtained. The solution was cooled to room temperature and a $10 \mathrm{~mL}$ aliquot of acetone was added and then four drops of ethyl ether. Crystals were filtered, washed with cold acetone and ethyl ether and dried in a desiccator. The obtained crystals were characterized using X-ray crystallography using a Siemens P4 diffractometer equipped with a graphite monochromator, a monocap collimator, a Mo K $\alpha$ radiation source $(\lambda=0.71073 \AA)$, and a SMART CCD detector.

2.4.2 Synthesis of NAMI-A: NAMI-A was synthesized from this precursor. ${ }^{8} 0.49 \mathrm{~g}$ of imidazole was added to $1.0 \mathrm{~g}$ of precursor suspended in $20 \mathrm{~mL}$ of acetone at room temperature. This mixture was stirred for 4 hours. The precipitate obtained in this manner was washed with cold acetone and ethyl ether. Characterization of this complex was done using FTIR, UV/VIS, NMR and electrospray ionization mass spectrometry (ESI-MS). Spectral data are in good agreement with those reported in the literature. ${ }^{178}$ Stock solution of NAMI-A was freshly prepared for each experiment. Proctection from light was not necessary due to reported evidence of photostability of NAMI-A solutions ${ }^{179}$ and more importantly, it maintained pharmacological efficacy even after aging up to 8 hours. ${ }^{84}$

2.4.3 Stoichiometric Determinations: Different ratios of NAMI-A to thiol concentrations were prepared from freshly prepared stock solutions vis: 0.25 to 4 . 
Residual absorbance at $390 \mathrm{~nm}$ of the solutions were measured and plotted against corresponding oxidant to reductant ratio. The stoichiometry was obtained as the ratio beyond which no more NAMI-A was consumed.

2.4.4 Product Identification: Possible detection and identification of intermediates and product would be performed utilizing UV/VIS, NMR, ESI-MS or EPR techniques as the reactions require. For ESI-MS, aqueous reactant solutions were prepared in distilled deionized water with resistance of at least $18 \mathrm{M} \Omega$.

2.4.5 Reaction Dynamics: Kinetics measurements were performed on the Hi-Tech Scientific single mixing (SF-61SX2) and double mixing (SF-61DX2) models stoppedflow spectrophotometers. Stock solutions of thiols and metal complexes were freshly prepared for each set of experiments. The biologically-active thiols used in this work lack distinct absorption in the $200-700 \mathrm{~nm}$ region. This necessitated monitoring of reaction progress at the absorption wavelength of NAMI-A which has a distinct absorption in the visible region, $\lambda_{\max } 390 \mathrm{~nm}$. All kinetics experiments were carried out at $25.0 \pm 0.1^{\circ} \mathrm{C}$ except when the effect of temperature was monitored, in which case temperature range was $10{ }^{\circ} \mathrm{C}-37^{\circ} \mathrm{C}$. A constant ionic strength of $1.0 \mathrm{M}$ was maintained using sodium chloride or sodium perchlorate except when the effect of ionic strength was explored. For evaluation of reaction dependence on ionic strength, kinetics of reactions were examined using varying amounts of $\mathrm{NaClO}_{4}$. Contributions from all charged species (buffer, NAMI-A and sometimes the thiol) present in solution were 
taken into consideration for these measurements using the standard calculation for ionic strength.

To evaluate effect of oxygen, argon was bubbled into freshly prepared solutions, and since reaction rate and profile did not change significantly from reactions run in ambient air. Similar results have been reported for the reaction of Indazolium transbis(indazole)tetrachlororuthenate(III) with glutathione. ${ }^{180}$ All reactions were as such run in ambient air. In an attempt to simulate the physiological environment, experiments were carried out using bicarbornate buffer. The results, however, demonstrated that the $\mathrm{pH}$ was not adequately maintained. Phosphate buffer was therefore used to maintain a $\mathrm{pH}$ of 7.4. For reactions of NAMI-A with MESNA, reaction profile was monitored at four other pHs: 3, 4, 5, 6. Phase I clinical trials reported that NAMI-A can be safely administered at $300 \mathrm{mg} / \mathrm{m}^{2} /$ day for 5 days every 3 weeks, ${ }^{181}$ corresponding to $6.55 \times 10^{-}$ ${ }^{4} \mathrm{~mol} / \mathrm{m}^{2} /$ day, therefore, $<1.50 \times 10^{-4} \mathrm{M}$ of NAMI-A was used. Pseudo-first-order condition of excess thiol was adhered to.

Chloride is found in most body fluids, including blood, plasma, serum, urine and saliva. Plasma chloride concentrations approximate to $100 \mathrm{mM}$ in normal human blood. Kinetics experiments with this chloride concentration were considered initially, however, kinetics traces containing 0.1 and $1.0 \mathrm{M} \mathrm{NaCl}$ were indistinguishable. Therefore, chloride concentrations greater than $0.5 \mathrm{M}$ were used. This is particularly advantageous for ensured stability of NAMI-A, since inhibition of chloride and DMSO hydrolysis of NAMI-A at high chloride concentrations have been reported. ${ }^{160}$ 


\section{CHAPTER THREE}

\subsection{Kinetics and Mechanism of Interaction of NAMI-A with Cysteamine}

\subsection{Introduction}

One of the most devastating facts about cancer treatment is lack of specificity for cancerous cells such that an effective drug candidate has equal potential of harming (normal) healthy cells. According to the National Cancer Institute, cancer treatment options include surgery, chemotherapy, radiation therapy, biological and targeted therapies, all with an endless list of side effects that are sometimes lethal. ${ }^{182}$ Up to $30 \%$ of patients undergoing radiation-therapy for lung cancer, breast cancer, lymphoma, or thymoma present radiation-related symptoms. ${ }^{183 ; 184}$ Incidences of acute adverse effects of chemotherapy such as bone marrow suppression, renal failure, cardiotoxicity, mutagenicity and emesis are well documented. ${ }^{185-188}$

Cancer treatment options attempt to strike a balance between beneficial and adverse effects, necessitating the use of agents that protect healthy cells from toxic effects of these treatment types. ${ }^{189-191}$ Aminothiols have been successful as chemo and radio protectants. ${ }^{192 ; 193}$ Prevention of immediate and delayed effects of therapy is expected of an ideal protectant. A Phase III clinical trials report has proven Amifostine, an FDA approved aminothiol, as the only effective cytoprotectant against cisplatininduced cumulative renal toxicity. ${ }^{194 ; 195}$ Amifostine was originally selected as a radioprotective agent by the Antiradiation Drug Development Program of the U.S. Army Medical Research and Development Command after synthesis and testing of 4,400 compounds. ${ }^{196}$ The range of applications of Amifostine is on the increase (see 
Table 3.1). Studies have demonstrated selective chemo and radio protection of normal cells by Amifostine. ${ }^{197}$

\begin{tabular}{|l|l|}
\hline Agent & Adverse Effect \\
\hline Cisplatin & $\begin{array}{l}\text { Nephrotoxicity } \\
\text { Neurotoxicity } \\
\text { Renal toxicity } \\
\text { Peripheral nerve damage }\end{array}$ \\
\hline Cyclophosphamide & Pulmonary toxicity \\
\hline Fotemustine & Mutagenicity \\
\hline Doxorubicin & Cardiotoxicity \\
\hline Mitomycin C & Hematological toxicity \\
\hline Radiation therapy & Hematological toxicity \\
& Mutagenicity \\
& Carcinogenicity \\
& Mucosa, skin and salivary gland \\
\hline
\end{tabular}

Table 3.1: Summary of selected anticancer agents and corresponding effects against which Amifostine offers protection. ${ }^{195 ; 198-201}$

In vivo, Aminofostine is dephosphorylated by alkaline phosphatase enzyme to the free thiol, WR-1065, which is the active metabolite (see Scheme 3-1). Alkaline 
phosphatase is expressed more in normal cells compared to cancerous cells leading to higher contents of WR-1065 in normal cells. ${ }^{202-204}$ WR-1065 is structurally related to cysteamine, a cellular thiol (Figure 3-1).

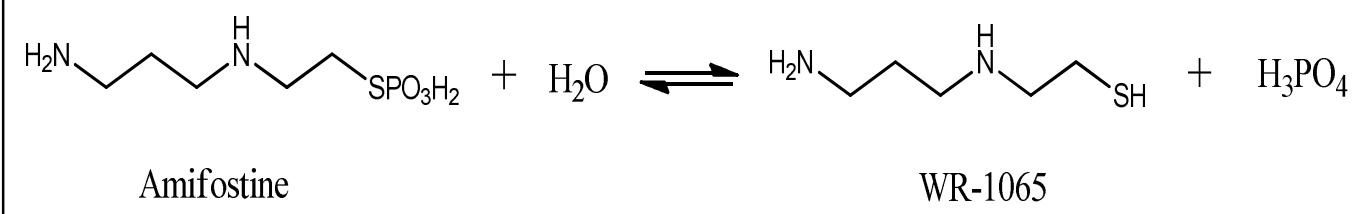

Scheme 3-1: Hydrolysis of amifostine to form its active metabolite, WR-1065

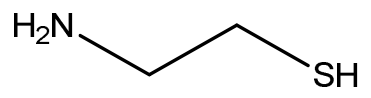

Figure 3-1: 2-aminoethanethiol also called cysteamine. Structurally related to the active metabolite of amifostine, WR-1065.

Cysteamine modulates cellular levels of glutathione ${ }^{205}$ and is an important intermediate in the alternative pathway of taurine biosynthesis (i.e coenzyme A degradation). ${ }^{206}$ The discovery of cysteamine dioxygenase emphasizes biological importance of this simple thiol. Cysteamine dioxygenase adds two atoms of oxygen to free cysteamine to form hypotaurine which is further oxidized to taurine. ${ }^{207-209}$ Cysteamine has been approved by the FDA for treating nephropathic cystinosis, a rare lysosomal storage disease that might result in kidney failure or death if unattended. ${ }^{210-212}$ Applications of cysteamine are on the increase with recent studies demonstrating its specific activity against 
Plasmodium malaria parasite ${ }^{213}$ and potentiation of antimalaria activity of $\operatorname{artemisinin.~}^{214 ; 215}$

Reports on effectiveness of cysteamine in radioprotection and chemoprotection are extensive. ${ }^{216-220}$ Documented effectiveness of cysteamine in cystinosis treatment, radio and chemo protection and its structural similarity to amifostine makes its interaction with NAMI-A a possibility in a combination-regimen involving NAMI-A and any cancer treatment against which protection is necessary. In this chapter, results are presented for such an interaction.

\subsection{Results}

3.2.1 Stoichiometry and Product Identification: Stoichiometric determinations employing measurement of residual absorbance at $390 \mathrm{~nm}$ of solutions containing varying ratios of NAMI-A and cysteamine are shown in Figure 3-2. Absorbances were recorded within 2 minutes of solution preparation. 


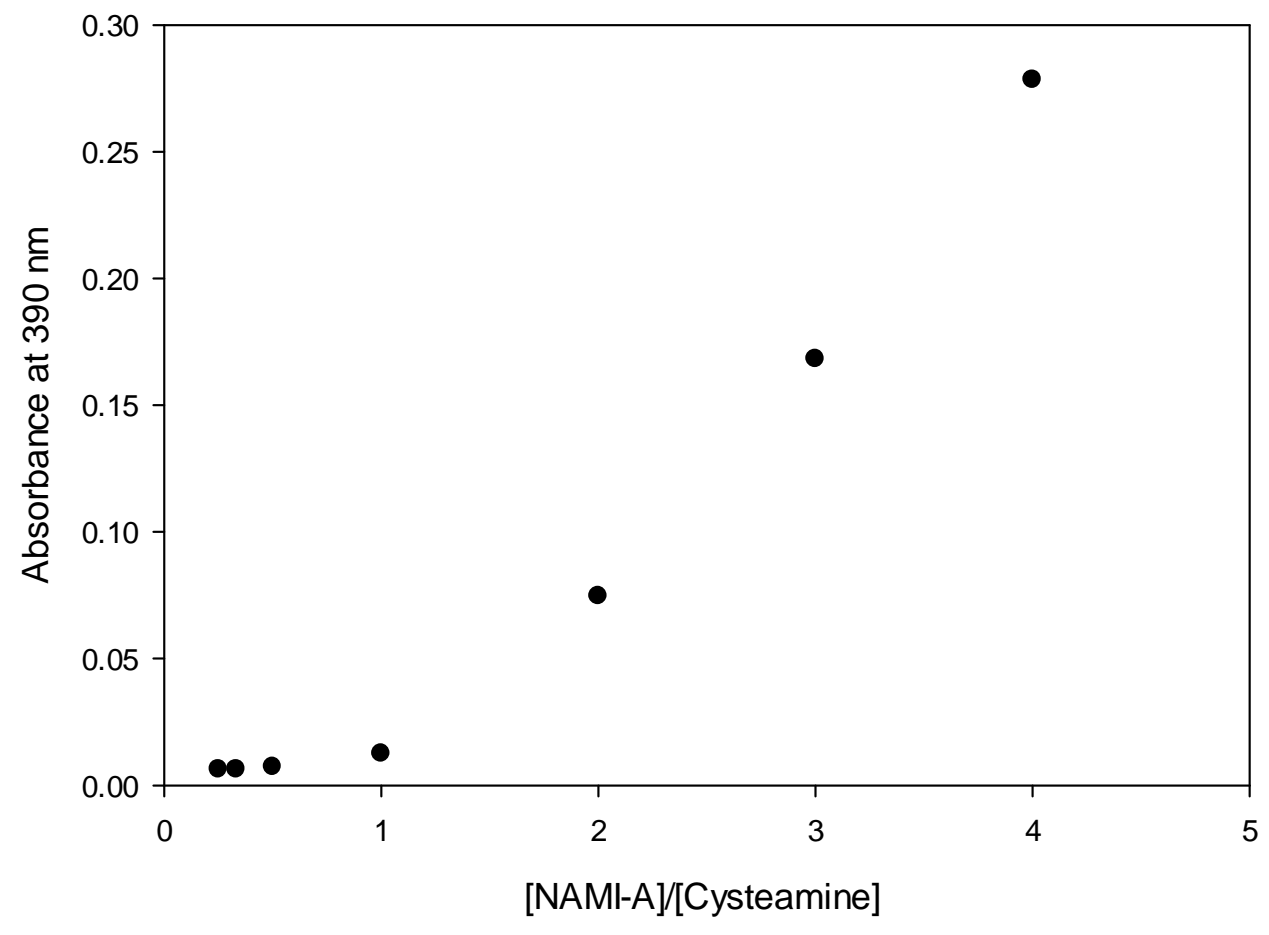

Figure 3-2: Plot of Residual absorbance of NAMI-A against [NAMI-A]/[cysteamine] ratio revealing stoichiometric ratio beyond which residual absorbance persists. [NAMIA]/[cysteine $]=0.25,0.33,0.5,1.0,2.0,3.0$ and 4.0 .

A full ESI-MS spectrum of equimolar concentrations of NAMI-A and cysteamine was taken within the first minute of the reaction in order to identify molecular species and possible intermediates involved in the reaction progress (see Figure 3-3). An ESI-MS peak corresponding to NAMI-A was observed at $389 \mathrm{~m} / \mathrm{z}$. The small relative abundance of this peak is expected since the reaction occurs in the order of $\sim 4 \mathrm{~s}$ as recorded on the stopped-flow. The reaction is essentially complete on comparing the time scale of the reaction with that of ESI-MS experiment, although the sample was run with as short a time-lapse as possible from mixing time. Other peaks observed in the negative mode 
spectrum demonstrate hydrolysis of NAMI-A involving two of the axial chloride ligands, $352 \mathrm{~m} / \mathrm{z}$, and loss of one or both of the apical ligands 274 and $209 \mathrm{~m} / \mathrm{z}$ respectively. The peak at $180 \mathrm{~m} / \mathrm{z}$ cannot be identified at this time, although its profile may suggest a non ruthenium-containing species.

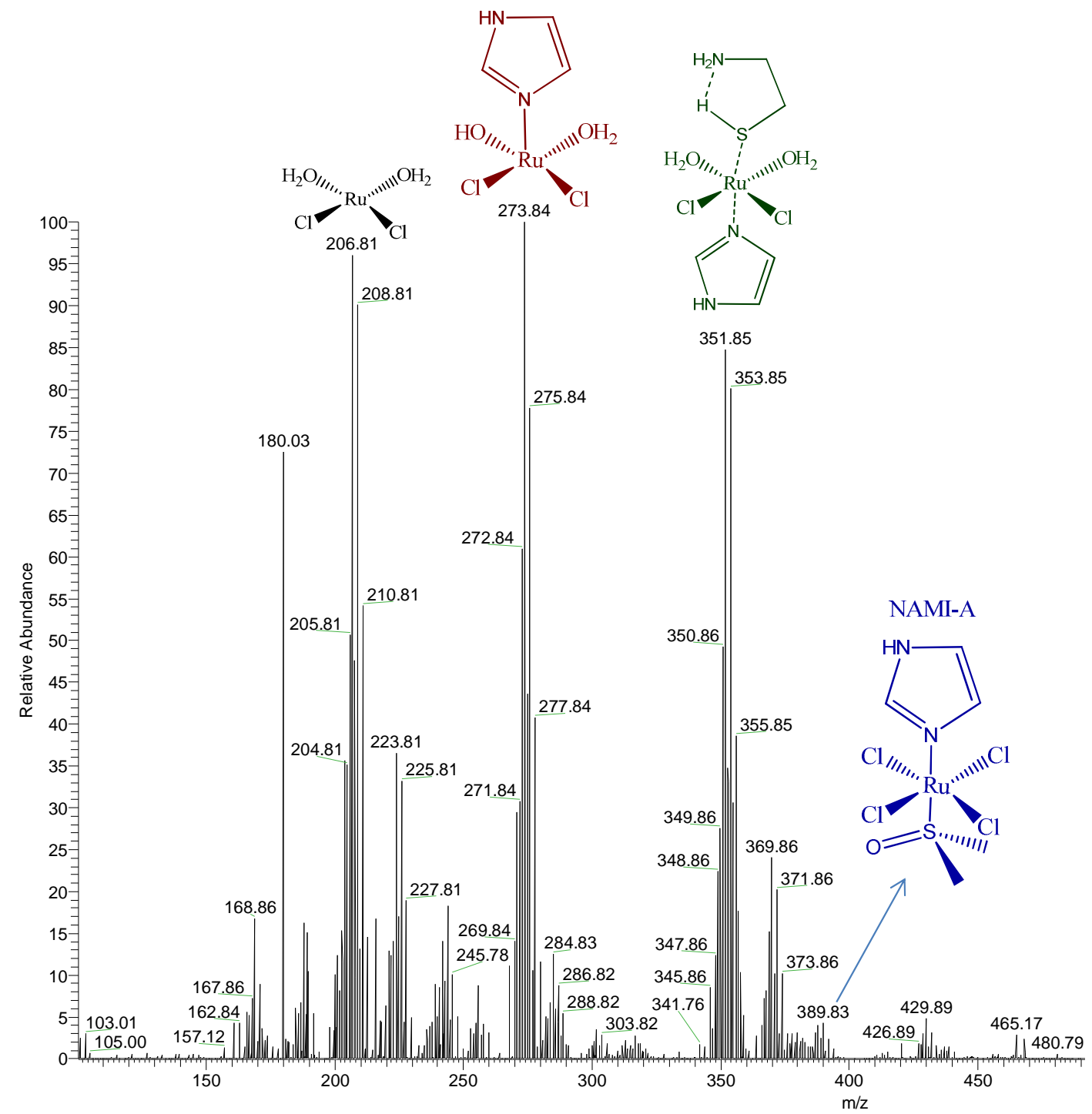

Figure 3-3: Full ESI-MS (negative mode) spectrum of 1:1 ratio of NAMI-A to cysteamine taken within the first minute of the reaction in $50 \%$ methanol. 
Spectrum of the same reaction in the positive mode (Figure 3-4) features cystamine, disulfide of cysteamine at $153 \mathrm{~m} / \mathrm{z}$. This conforms to the expected result of a one-electron oxidation of cysteamine which should result in cystamine.

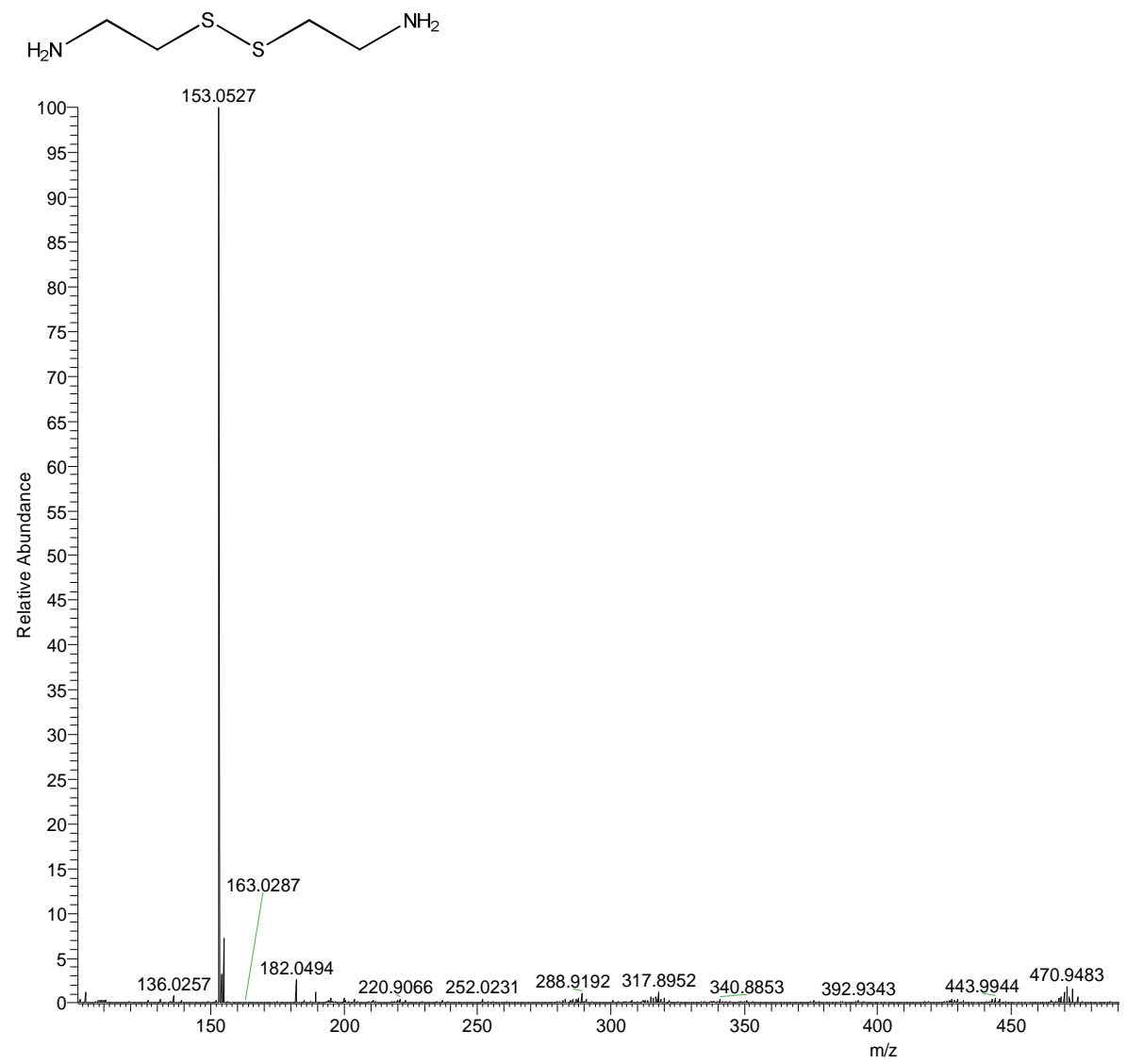

Figure 3-4: Full ESI-MS (positive mode) spectrum of equimolar concentrations of NAMI-A and cysteamine taken within the first minute of the reaction in $50 \%$ methanol. Spectrum shows cystamine as the product. 


\subsubsection{Kinetics}

3.2.2.1 NAMI-A dependence: Effect of varying initial concentrations of NAMI-A on the reaction in $0.05 \mathrm{M}$ phosphate buffer at $\mathrm{pH} 7.4$ was examined, (see Figure 3-5a). The rate of consumption of NAMI-A increased with increasing initial NAMI-A concentrations. Rate measurements were confined to the initial $2 \%$ of the reaction where determination of contributing species is fairly accurate before contributions from intermediates.

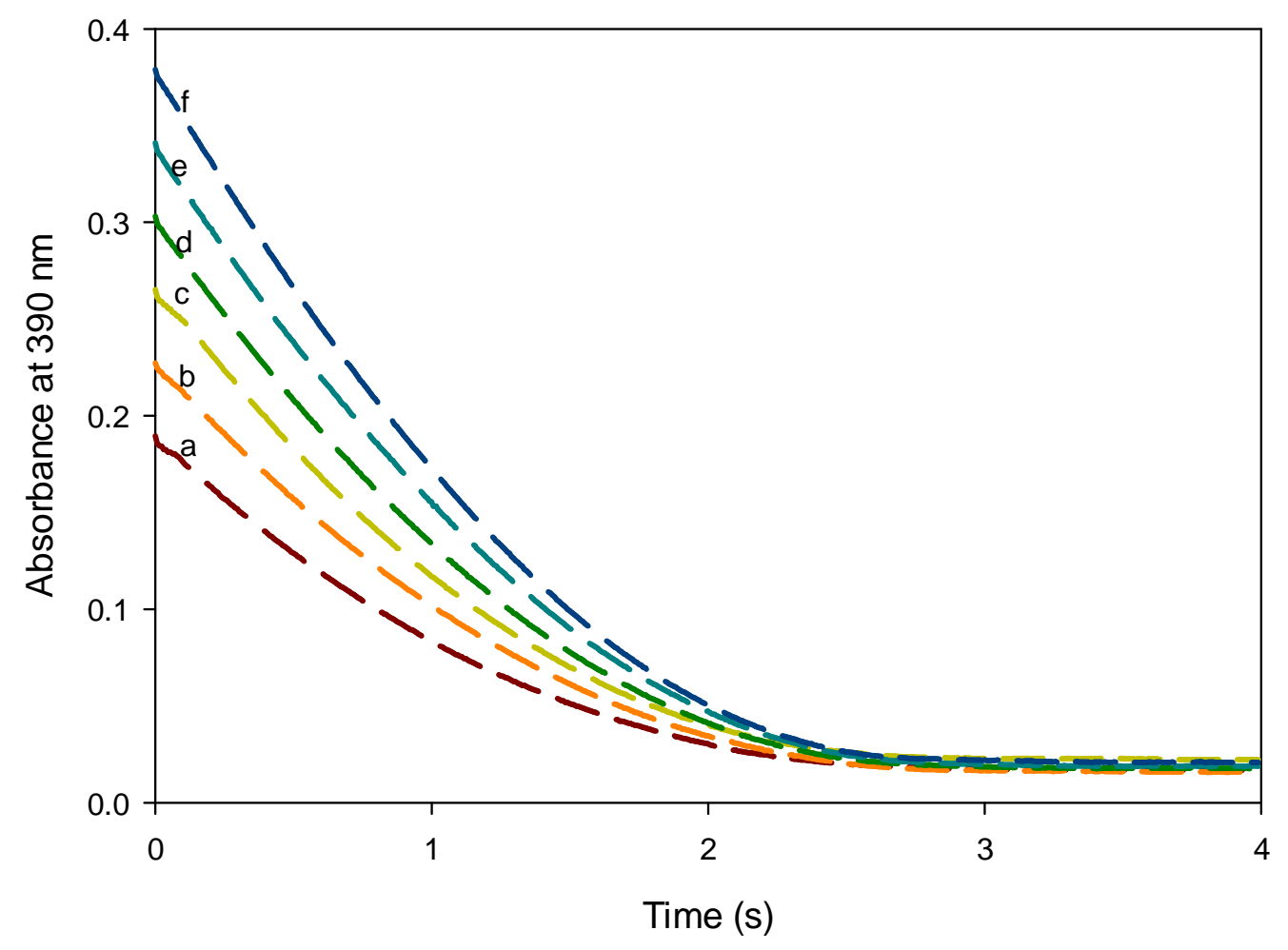

Figure 3-5a: Kinetic traces of reaction in 0.05M phosphate buffer ( $p H 7.4$ ) showing dependence on $[N A M I-A]$ at its $\lambda_{\max }$ [Cysteamine $]_{o}=1.0 \times 10^{-2} \mathrm{M} ;[\mathrm{NAMI}-\mathrm{A}]_{o}=($ a) 5.0 $x 10^{-5} \mathrm{M}(\mathrm{b}) 6.0 \times 10^{-5} \mathrm{M}(\mathrm{c}) 7.0 \times 10^{-5} \mathrm{M}(\mathrm{d}) 6.0 \times 10^{-5} \mathrm{M}(\mathrm{e}) 9.0 \times 10^{-5} \mathrm{M}(\mathrm{f}) 1.0 \times 10^{-4} \mathrm{M}$ 
Plots of initial rates against initial NAMI-A concentrations gave straight lines, indicating a linear dependence on NAMI-A (Figure 3-5b). Since [cysteamine] is much greater than [NAMI-A] o, cysteamine concentration effectively remained unchanged during the reaction. The observed pseudo rate constant was then determined to be $6.85 \mathrm{x}$ $10^{-1} \pm 0.03 \mathrm{~s}^{-1}$

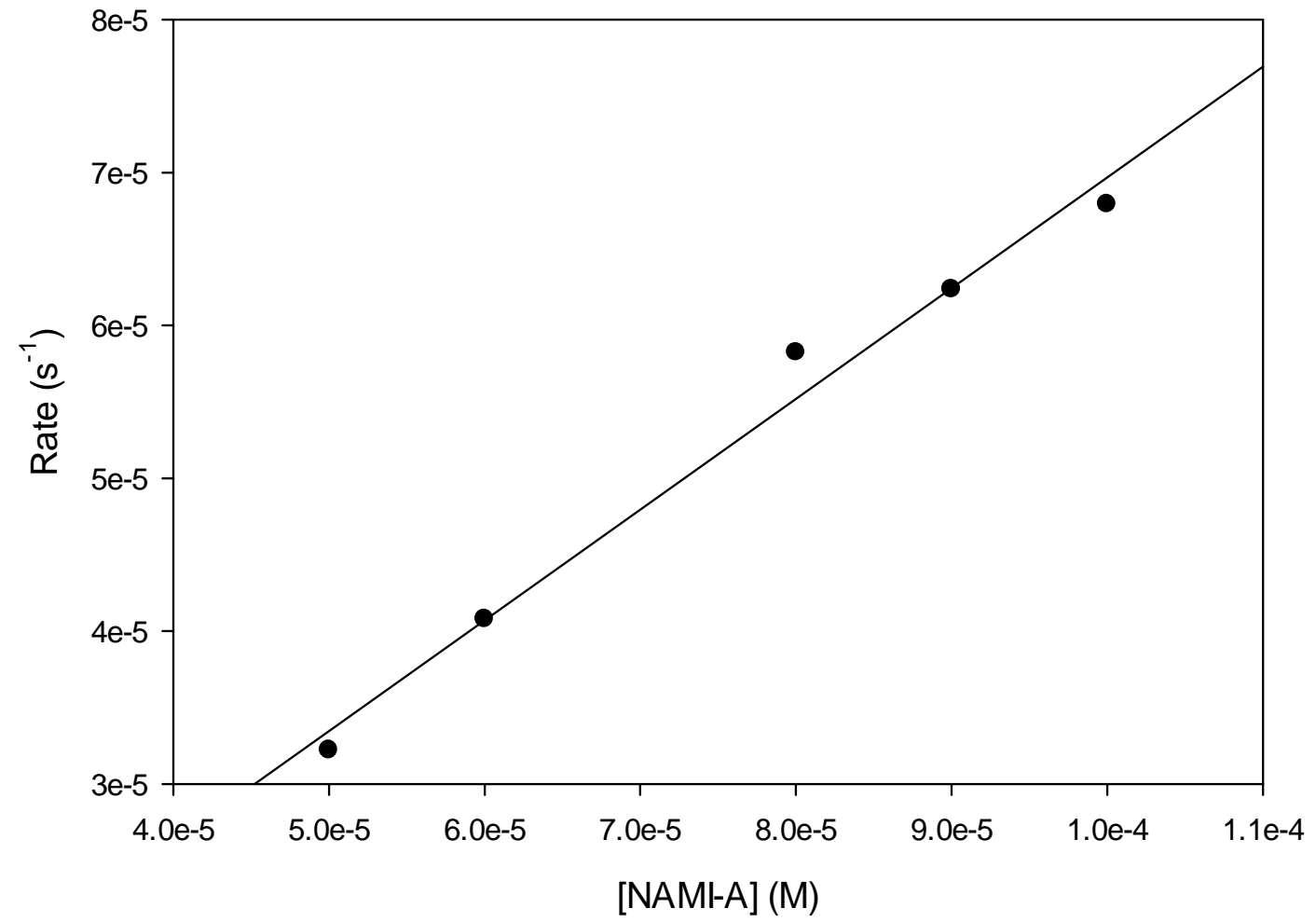

Figure 3-5b: Initial rate plot derived from Figure 3-5a, showing linear dependence on NAMI-A. $[\mathrm{Cys}]_{o}=1.0 \times 10^{-3} \mathrm{M} ;[\mathrm{NAMI}-\mathrm{A}]_{o}=5.0 \times 10^{-5} \mathrm{M}$ to $1.0 \times 10^{-4} \mathrm{M}$

3.2.2.2 Cysteamine dependence: Dependence of the reaction on initial concentrations of cysteamine (all other reaction conditions fixed) was monitored at $390 \mathrm{~nm}$. Reaction rate increased with increasing concentrations of cysteamine (Figure 3-6a). The 
sigmoidal-type traces, more pronounced at low cysteamine concentrations and later also observed at high temperatures, might suggest autocatalysis. Initial rate plots deduced from this plot are nonlinear (see Figure 3-6b) which might suggest adduct formation. Similar effects were observed at various temperatures vis-à-vis: $15,20,30$ and $37{ }^{\circ} \mathrm{C}$ (Figure 3-6c) and are summarized in Figure 3-6d.

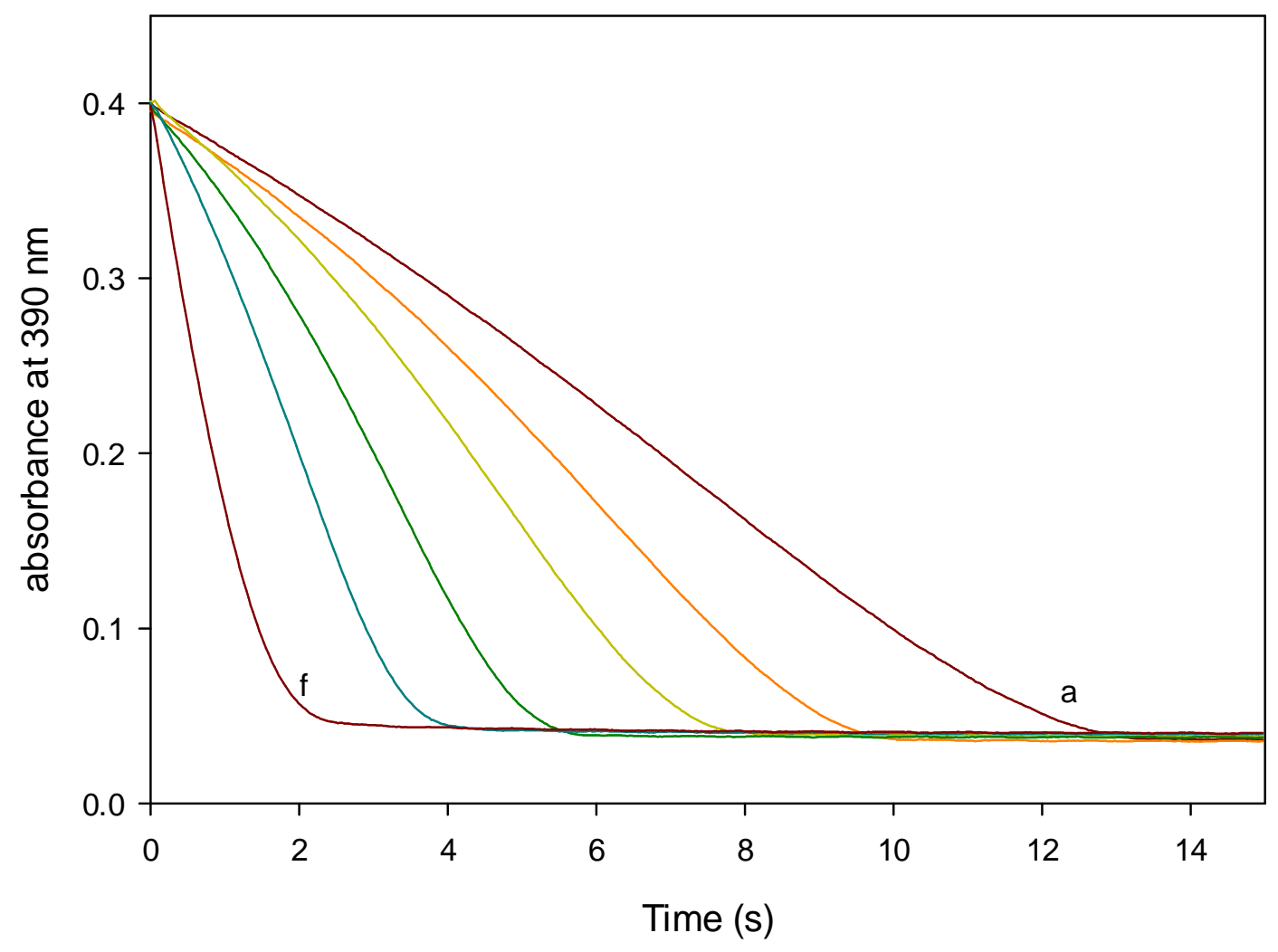

Figure 3-6a: Effect of cysteamine variation on the consumption of NAMI-A at $390 \mathrm{~nm}$.

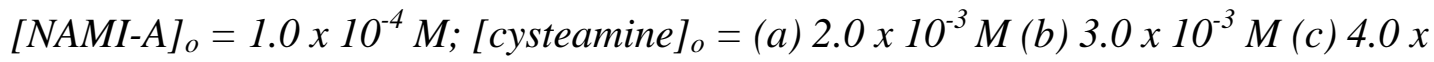
$10^{-3} \mathrm{M}(\mathrm{d}) 6.0 \times 10^{-3} \mathrm{M}(\mathrm{e}) 8.0 \times 10^{-3} \mathrm{M}(\mathrm{f}) 1.0 \times 10^{-2} \mathrm{M}$. Reaction rate increased with cysteamine concentration. 


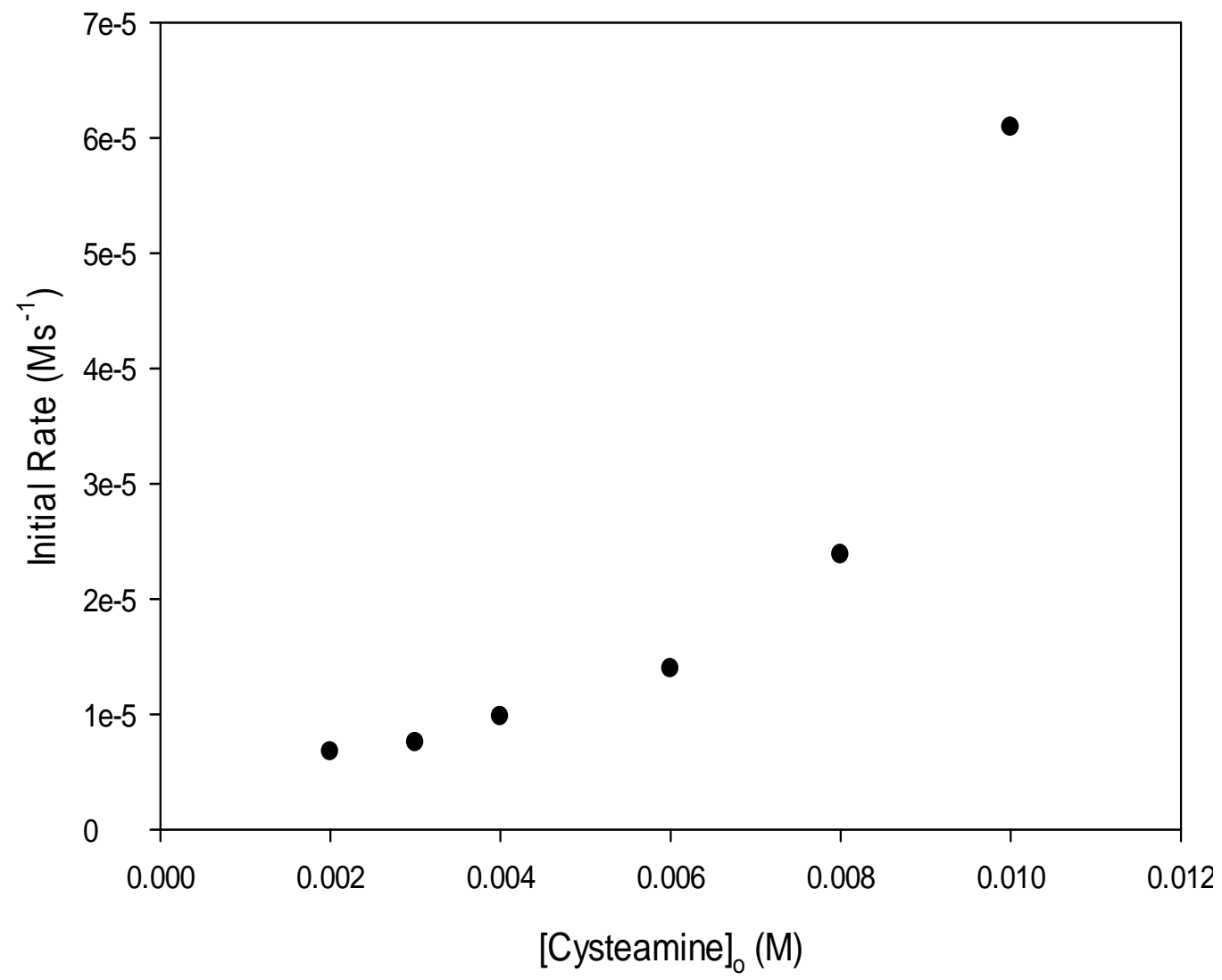

Figure 3-6b: Initial rate plot derived from data shown in Figure 4a, showing nonlinear dependence on NAMI-A concentrations. $[\text { NAMI-A }]_{o}=1.0 \times 10^{-4} \mathrm{M} ;[\text { cysteamine }]_{o}=2.0$ $x 10^{-3} \mathrm{M}$ to $1.0 \times 10^{-2} \mathrm{M}$. 

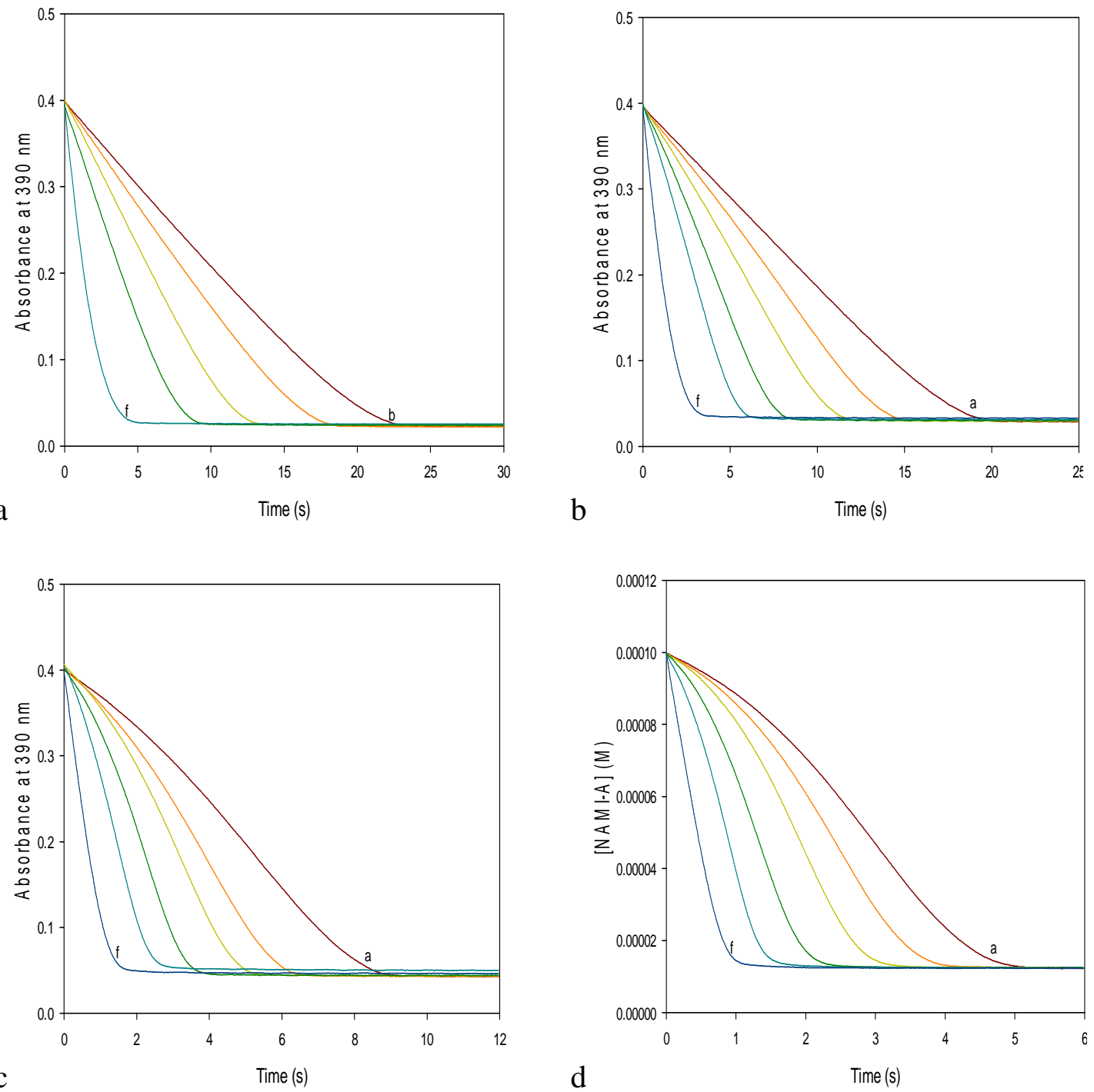

Figure 3-6c: Effect of cysteamine variation at temperatures $15,20,30$ and $37^{\circ} \mathrm{C}$ from a through d respectively. 


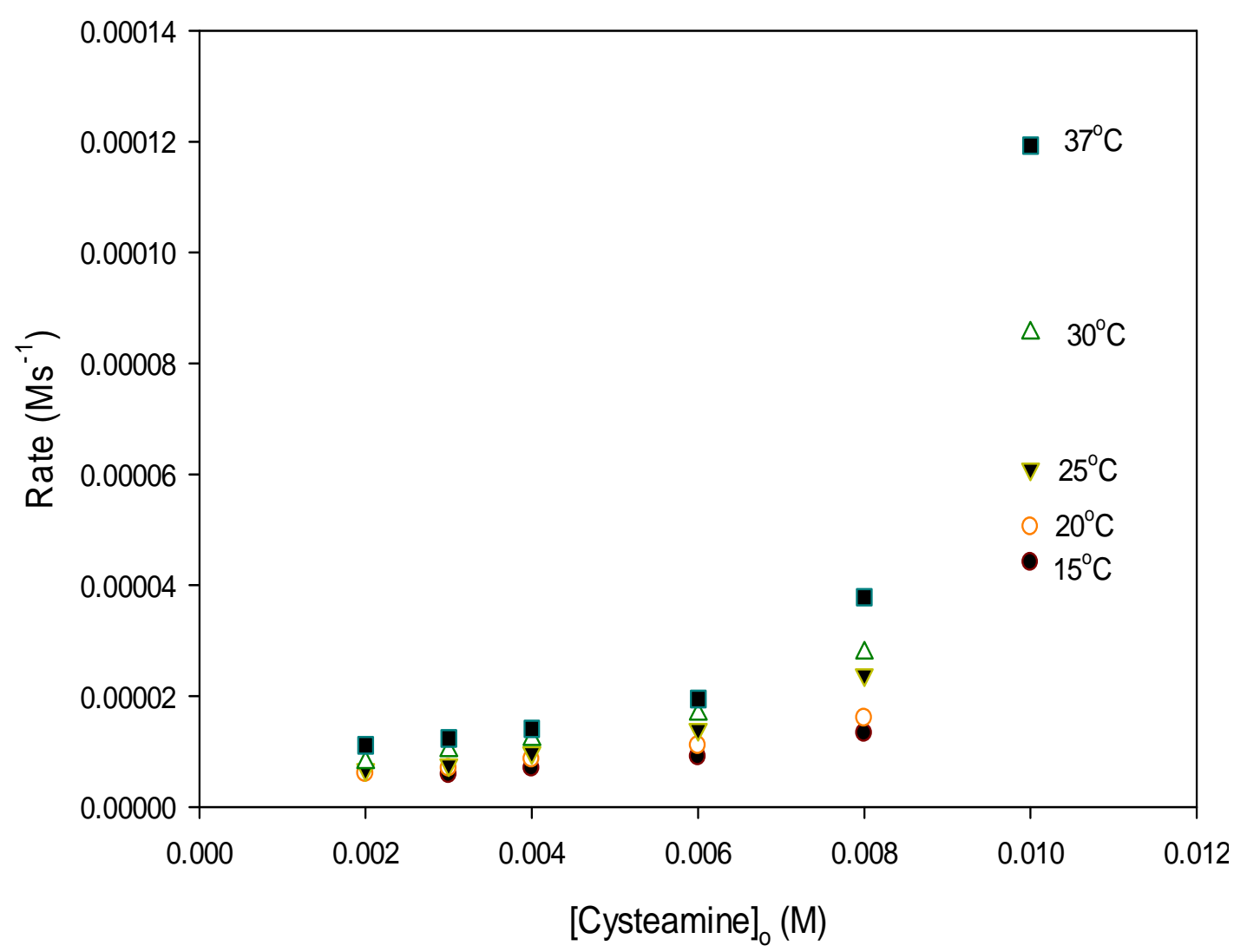

Figure 3-6d: Summary of rate dependence on cysteamine at various temperatures. $[\mathrm{NAMI}-\mathrm{A}]_{o}=1.0 \times 10^{-4} \mathrm{M} ;{ }^{\prime}[\text { cysteamine }]_{o}=2.0 \times 10^{-3} \mathrm{M}$ to $1.0 \times 10^{-2} \mathrm{M}$.

3.2.2.3 Effect of ionic strength: The response of this reaction to changes in concentration of an inert salt $\left(\mathrm{NaClO}_{4}\right)$, at constant temperature and reactants concentrations, was monitored at $\mathrm{pH} 7.4$ without a buffering environment. Increasing ionic strength slowed down the reaction rate in both cases as shown in the representative plot, Figure 3-7 (no buffer). This suggests that the rate determining step(s) involve species of different charges. Although, from $\mathrm{pKa}$ of cysteamine, appreciable amount of zwitterionic cysteamine exists in solution, the net positively charged species should be predominant in the rate determining step. 


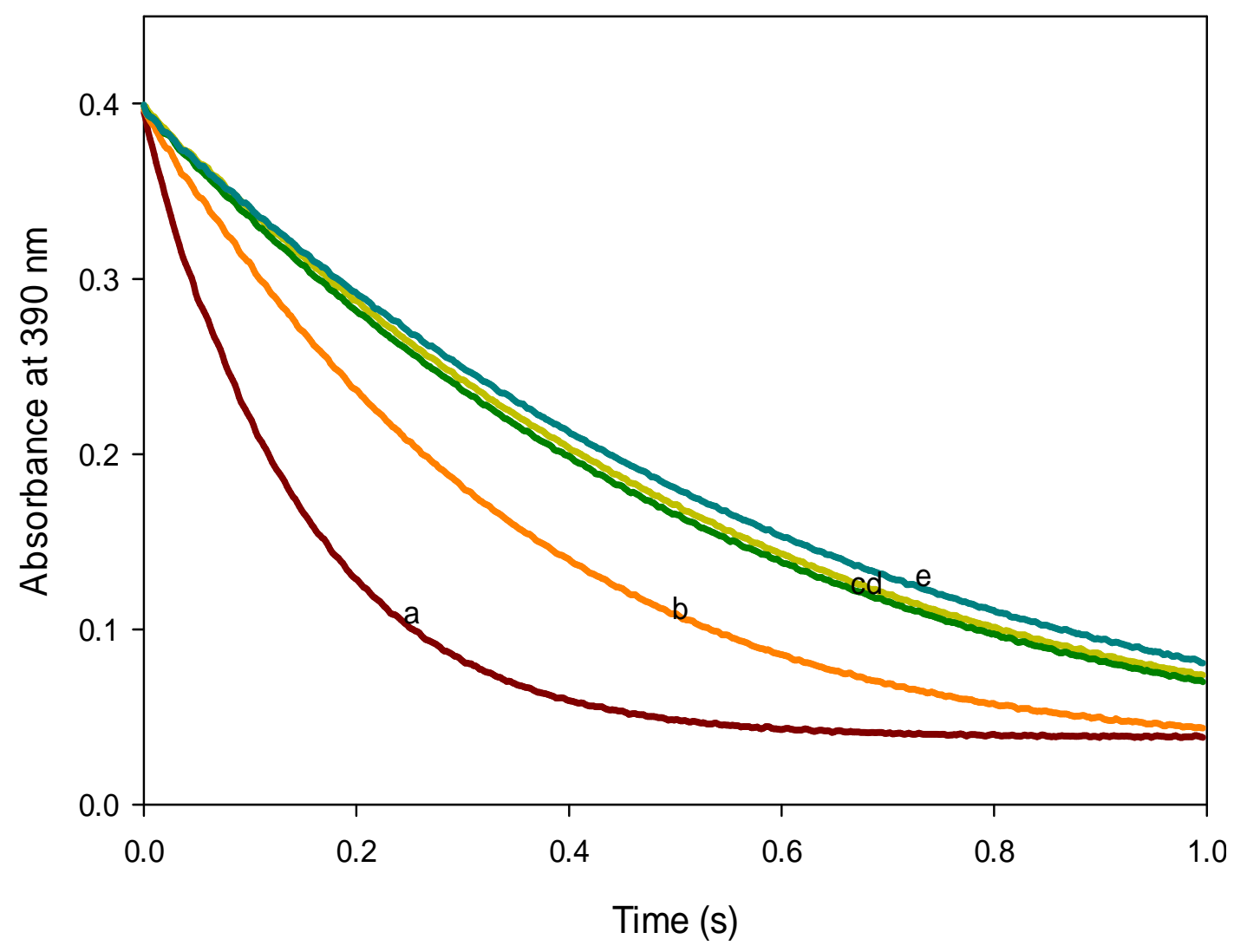

Figure 3-7: Ionic strength dependence of cysteamine-NAMI-A reaction. [Cysteamine]。 $=1.0 \times 10^{-2} \mathrm{M} ;[\mathrm{NAMI}-\mathrm{A}]_{o}=1.0 \times 10^{-4} \mathrm{M} ;[\mathrm{I}]_{\mathrm{NaClO} 4}=(a) 1.00 \times 10^{-4} \mathrm{M}(\mathrm{b}) 0.15 \mathrm{M}(\mathrm{c})$ $0.30 M(d) 0.45 M(e) 0.90 M$

3.2.2.4 Effect of chloride ion: The dependence of this reaction to changes in chloride ion concentrations at constant temperature and other reaction conditions $(\mathrm{pH}$, reactants concentrations and ionic strength) was examined. Chosen chloride concentrations were corresponded to concentrations in the cytoplasmic matrix $(\sim 2 \mathrm{mM})$, blood/extracellular fluids (up to $100 \mathrm{mM}$ ) and in some experiments higher concentrations were used. The presence of small amounts of chloride ions retarded the reaction as seen in Figure 3-8, but increasing chloride ion concentrationsfurther, however, did not significantly affect 
the overall rate of reaction. No observable difference was observed in the kinetics traces of solutions containing chloride concentrations of $0.02,0.1,1.0 \mathrm{M}$ and higher.

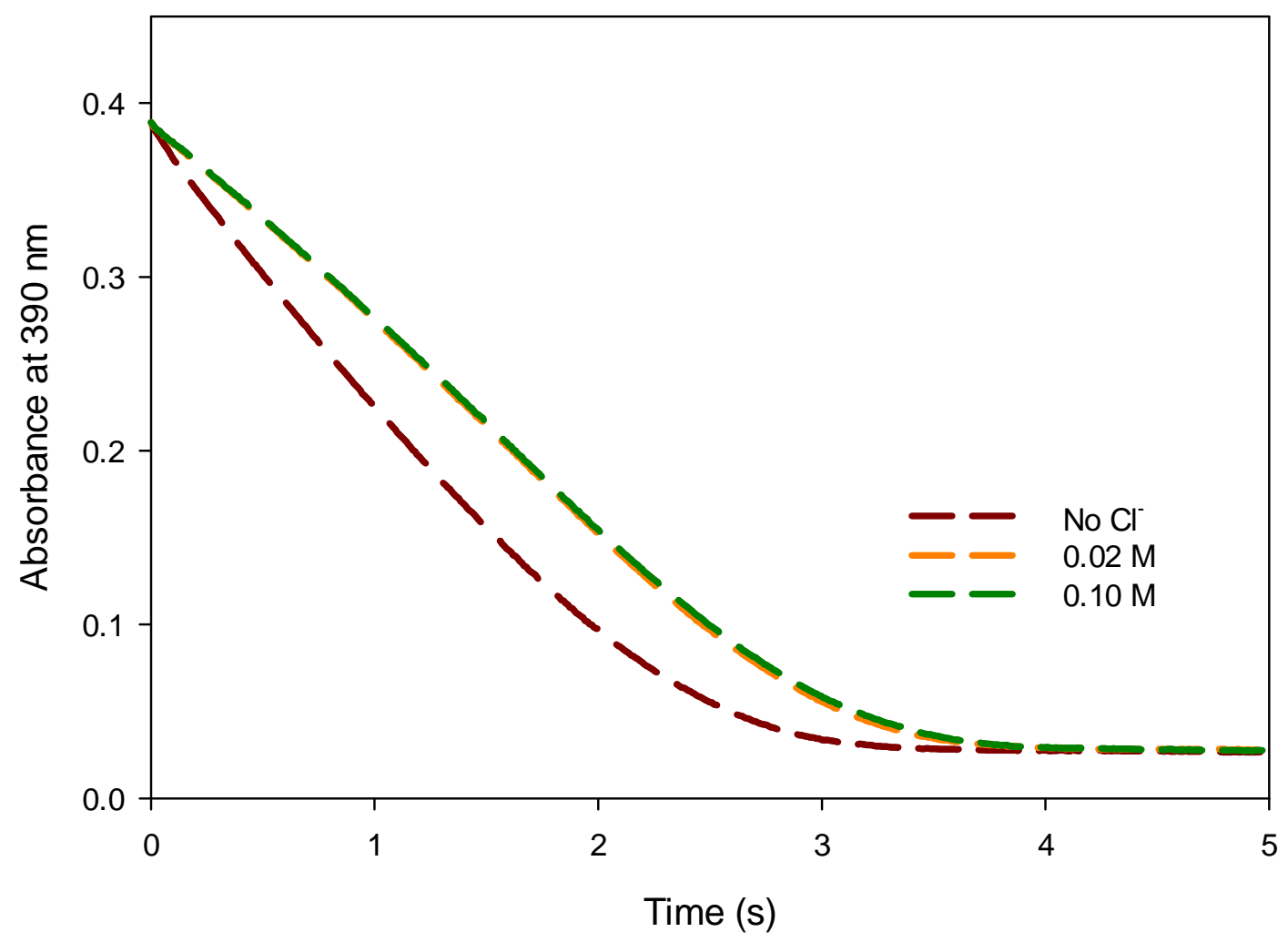

Figure 3-8: Effect of varying initial chloride concentration. $[\text { cysteamine }]_{o}=1.0 \times 10^{-2}$ $\mathrm{M} ;[\mathrm{NAMI}-\mathrm{A}]_{o}=1.0 \times 10^{-4} \mathrm{M} ;[\mu]_{\mathrm{NaClO} 4}=1.0 \mathrm{M} ;[\mathrm{Cl}-]=0.00 \mathrm{M}$ to $0.10 \mathrm{M}$

3.2.2.5 Thermodynamics and activation parameters: At fixed concentrations of substrate, oxidant and ionic strength, the effect of temperature on the reaction was evaluated. Reaction rate increased proportionally with increasing temperatures as expected (see Figure 3-9a). The data obtained were used to construct an Arrhenius plot (see Figure 3-9b). 


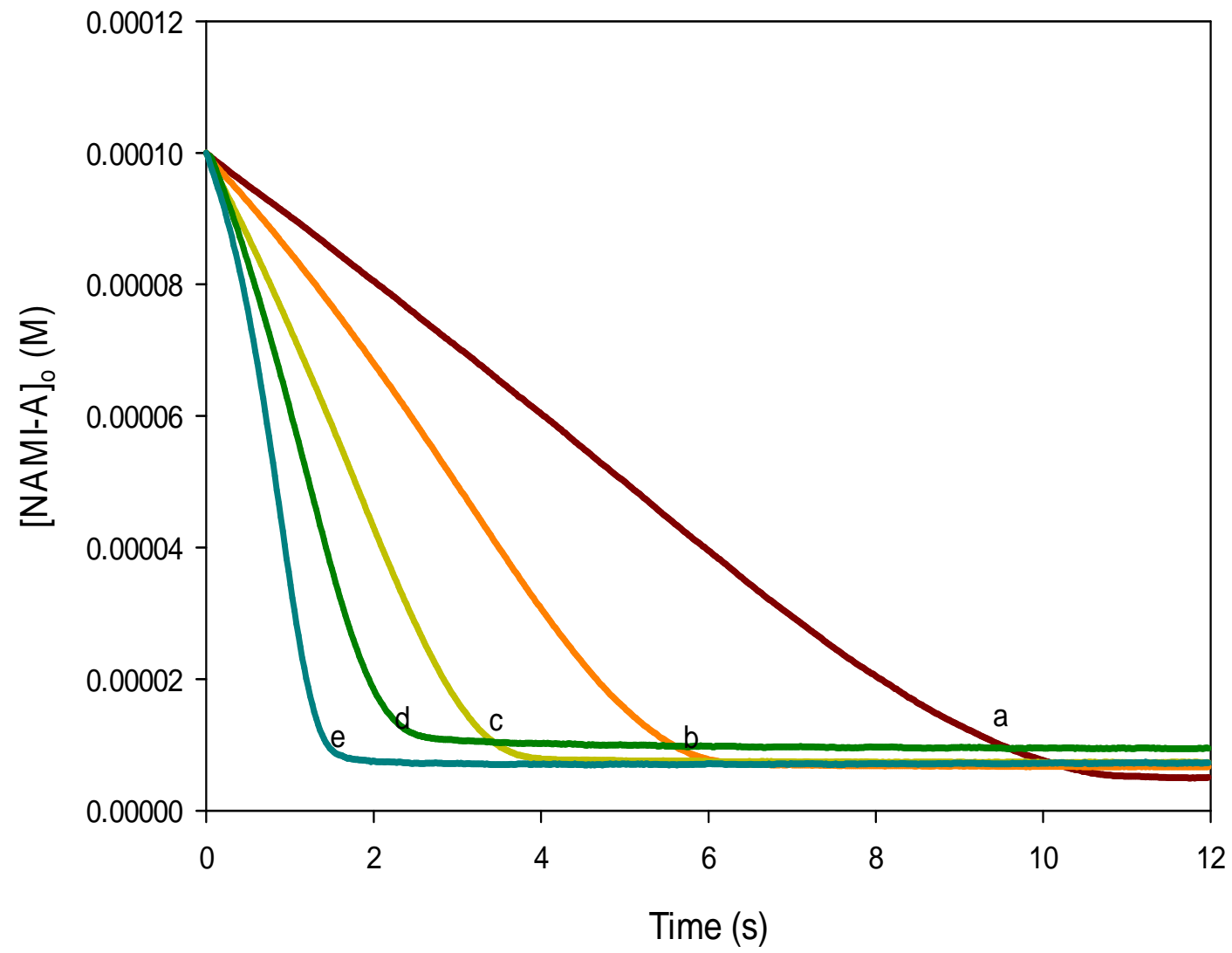

Figure 3-9a: Temperature dependence of cysteamine-NAMI-A reaction. $[N A M I-A]_{o}=$ $1.0 \times 10^{-4} \mathrm{M}$; $[\text { cysteamine }]_{o}=1.0 \times 10^{-2} \mathrm{M}$, Temperature $=\left(\right.$ a) $15{ }^{\circ} \mathrm{C}(\mathrm{b}) 20^{\circ} \mathrm{C}(\mathrm{c}) 25^{\circ} \mathrm{C}$ (d) $30^{\circ} \mathrm{C}$ (e) $37^{\circ} \mathrm{C}, \mathrm{pH}$ 7.4; Ionic strength maintained at $1.0 \mathrm{M}$ using $\mathrm{NaCl}$

The Arrhenius plot afforded these activation parameters: entropy of activation, $\Delta \mathrm{S}^{\ddagger}=-117 \mathrm{~J} \mathrm{~K}^{-1} \mathrm{~mol}^{-1}$, enthalpy of activation, $\Delta \mathrm{H}^{\ddagger}=41.5 \mathrm{~kJ} \mathrm{~mol}^{-1}$ and free energy of activation as $\Delta \mathrm{G}^{\neq}=76 \mathrm{~kJ} \mathrm{~mol}^{-1}$ (at $25{ }^{\circ} \mathrm{C}$ ). Low positive enthalpy and distinctly negative entropy of activation suggests some degree of molecular ordering in the rate determining step. These parameters are indicative of an associative mechanism. 


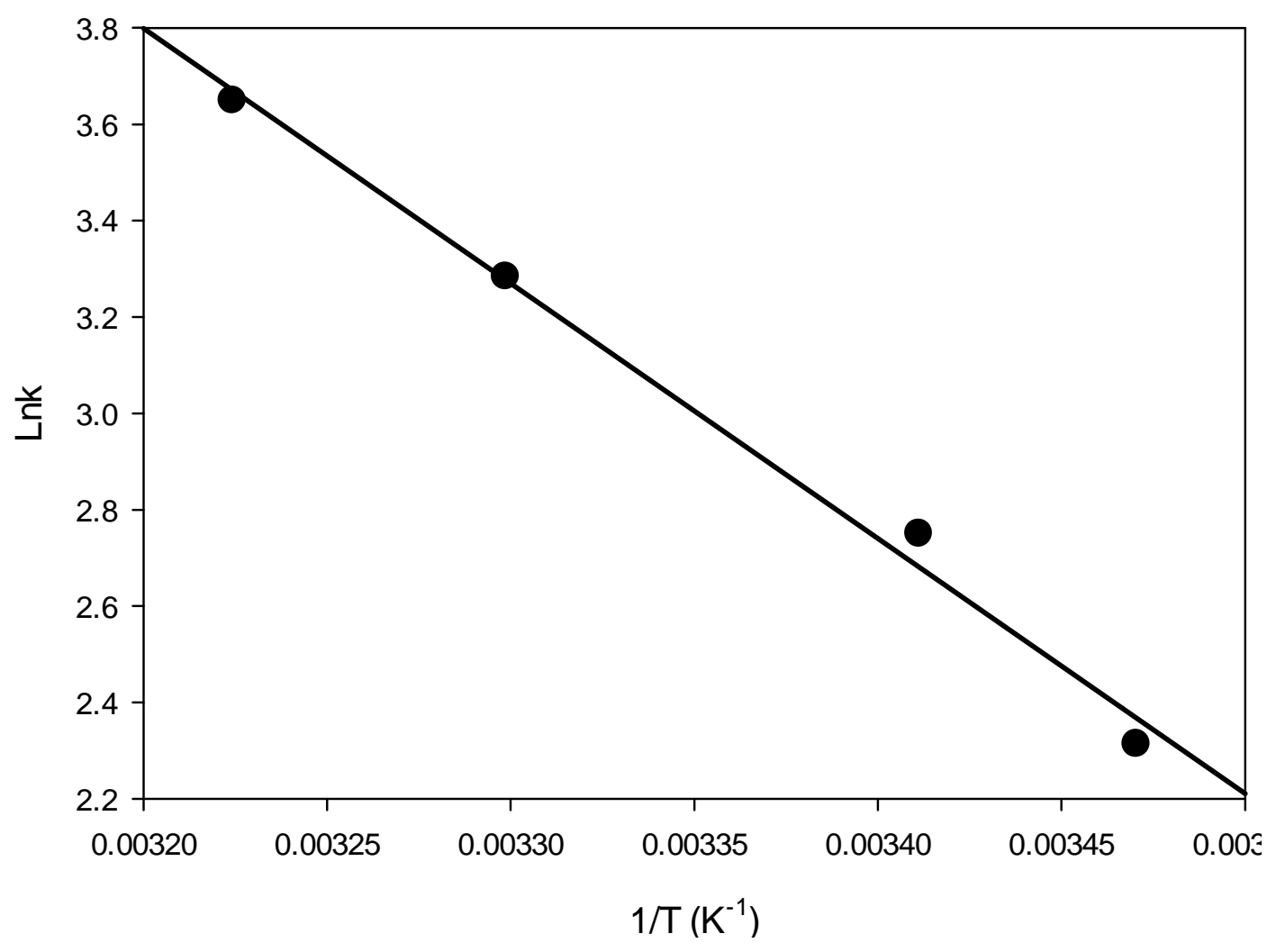

Figure 3-9b: Temperature dependence of cysteamine-NAMI-A reaction. $[N A M I-A]_{o}=$

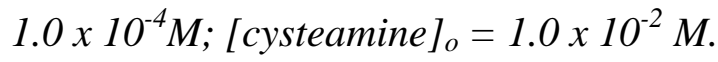

\subsection{Mechanism}

3.3.1 Electron Transfer: Reactions were carried out at $\mathrm{pH}$ 7.4. At this $\mathrm{pH}$, the amine functional group of cysteamine should be predominantly protonated since the thiol and amine pKa's are 8.27 and 10.53 respectively. ${ }^{221}$

$\mathrm{H}_{2} \mathrm{NCH}_{2} \mathrm{CH}_{2} \mathrm{SH} \rightleftharpoons \mathrm{H}_{3} \mathrm{~N}^{+} \mathrm{CH}_{2} \mathrm{CH}_{2} \mathrm{SH}+\mathrm{H}^{+}$

$\mathrm{K}_{\mathrm{b}} \quad \mathrm{R} 1$ 
Although cysteamine exists predominantly in the protonated form under these reaction conditions, appreciable amounts of zwitter-ionic form (see R2) are also present at $13 \%$ of total cysteamine after using the Henderson-Hasselbach equation.

$$
\mathrm{H}_{3} \mathrm{~N}^{+} \mathrm{CH}_{2} \mathrm{CH}_{2} \mathrm{SH} \rightleftharpoons \mathrm{H}_{3} \mathrm{~N}^{+} \mathrm{CH}_{2} \mathrm{CH}_{2} \mathrm{~S}^{-}+\mathrm{H}^{+} \quad \mathrm{K}_{\mathrm{a} 1} \quad \mathrm{R} 2
$$

These species react with anionic NAMI-A to form an activated complex derived from reactions $\mathrm{R} 3$ and $\mathrm{R} 4$. The activated complex, sitting at the maximum energy point along the reaction coordinate, may, however, rearrange to form products or fall back to reactants. Activation parameters obtained are suggestive of an associative mechanism in which the activated complex is more ordered in comparison to the reactants.

$$
\begin{aligned}
& \mathrm{H}_{3} \mathrm{~N}^{+} \mathrm{CH}_{2} \mathrm{CH}_{2} \mathrm{SH}+\left[\mathrm{ImRuCl}_{4} \mathrm{DMSO}\right]^{-} \\
& \rightarrow\left[\mathrm{H}_{3} \mathrm{~N}^{+} \mathrm{CH}_{2} \mathrm{CH}_{2} \mathrm{SH} \ldots\left[\mathrm{ImRuCl}_{4} \mathrm{DMSO}^{-}\right]^{\neq} \quad \mathrm{k}_{1} \quad \mathrm{R} 3\right. \\
& \mathrm{H}_{3} \mathrm{~N}^{+} \mathrm{CH}_{2} \mathrm{CH}_{2} \mathrm{~S}^{-}+\left[\mathrm{ImRuCl}_{4} \mathrm{DMSO}\right]^{-} \\
& \rightarrow\left[\mathrm{H}_{3} \mathrm{~N}^{+} \mathrm{CH}_{2} \mathrm{CH}_{2} \mathrm{~S}^{-} \ldots\left[\mathrm{ImRuCl}_{4} \mathrm{DMSO}^{-}\right]^{\neq} \quad \mathrm{k}_{2} \quad \mathrm{R} 4\right.
\end{aligned}
$$

R3 and R4 estimate the nature of the activated complex in terms of composition only, specific molecular arrangement of the species cannot be determined at this time. R5 and R6 demonstrate formation of products: the reduced NAMI-A and cystamine from the activated complex. 


$$
\begin{aligned}
& 2\left[\mathrm{H}_{3} \mathrm{~N}^{+} \mathrm{CH}_{2} \mathrm{CH}_{2} \mathrm{SH} \ldots\left[\mathrm{ImRuCl}_{4} \mathrm{DMSO}\right]^{-}\right]^{\neq} \rightarrow \mathrm{H}_{2} \mathrm{NCH}_{2} \mathrm{CH}_{2} \mathrm{SSCH}_{2} \mathrm{CH}_{2} \mathrm{NH}_{2} \\
& +2\left[\mathrm{ImRuCl}_{4} \mathrm{DMSO}^{2-}+4 \mathrm{H}^{+} \quad \mathrm{k}_{3} \quad \mathrm{R} 5\right. \\
& 2\left[\mathrm{H}_{3} \mathrm{~N}^{+} \mathrm{CH}_{2} \mathrm{CH}_{2} \mathrm{~S}^{-} \ldots\left[\mathrm{ImRuCl}_{4} \text { DMSO }\right]^{-}\right]^{\neq} \rightarrow \mathrm{H}_{3} \mathrm{~N}^{+} \mathrm{CH}_{2} \mathrm{CH}_{2} \mathrm{SSCH}_{2} \mathrm{CH}_{2} \mathrm{~N}^{+} \mathrm{H}_{3} \\
& +2\left[\mathrm{ImRuCl}_{4} \mathrm{DMSO}^{2-}+2 \mathrm{H}^{+} \quad \mathrm{k}_{4} \quad \mathrm{R} 6\right.
\end{aligned}
$$

Redox interactions between reduced NAMI-A and cystamine were anticipated. The labile nature of the reduced complex however, with a half life of $\sim 14 \mathrm{~s}^{82}$ implies that reaction is effectively irreversible. This short half life taken together with reaction duration of $\sim 4 \mathrm{~s}$ for electron transfer (measured by disappearance of charge transfer band of NAMI-A at $390 \mathrm{~nm}$ ) might explain obvious absence of reduced NAMI-A from ESI-MS spectrum.

3.3.2 Ligand Exchange: Following electron transfer process, is a series of ligand exchange processes involving two chloride ligands and the apical ligands, imidazole and dimethyl sulfoxide as described by R7- R13.

$$
\begin{aligned}
& {\left[\mathrm{ImRuCl}_{4} \mathrm{DMSO}\right]^{2-}+\mathrm{H}_{2} \mathrm{O} \rightarrow\left[\operatorname{ImRuCl}_{3}\left(\mathrm{H}_{2} \mathrm{O}\right) \mathrm{DMSO}^{-}+\mathrm{Cl}^{-} \quad \mathrm{R} 7\right.} \\
& {\left[\operatorname{ImRuCl}_{3}\left(\mathrm{H}_{2} \mathrm{O}\right) \mathrm{DMSO}^{-}+\mathrm{H}_{2} \mathrm{O} \rightarrow\left[\operatorname{ImRuCl}_{2}\left(\mathrm{H}_{2} \mathrm{O}\right)_{2} \mathrm{DMSO}\right]+\mathrm{Cl}^{-} \quad \mathrm{R} 8\right.} \\
& {\left[\operatorname{ImRuCl}_{2}\left(\mathrm{H}_{2} \mathrm{O}\right)_{2} \mathrm{DMSO}\right] \rightarrow\left[\operatorname{ImRuCl}_{2}\left(\mathrm{H}_{2} \mathrm{O}\right)(\mathrm{OH})\right]^{-}+\mathrm{H}^{+}+\text {DMSO R9 }}
\end{aligned}
$$




$$
\begin{aligned}
& {\left[\operatorname{ImRuCl}_{2}\left(\mathrm{H}_{2} \mathrm{O}\right)_{2} \mathrm{DMSO}\right] \rightarrow\left[\operatorname{ImRuCl}_{2}(\mathrm{OH})_{2} \mathrm{DMSO}^{-}+\mathrm{H}^{+} \quad \mathrm{R} 10\right.} \\
& {\left[\operatorname{ImRuCl}_{2}\left(\mathrm{H}_{2} \mathrm{O}\right)_{2} \mathrm{DMSO}\right]+\mathrm{H}_{2} \mathrm{O} \rightarrow\left[\operatorname{ImRuCl}_{2}\left(\mathrm{H}_{2} \mathrm{O}\right)_{3}\right]+\text { DMSO } \mathrm{R} 11} \\
& {\left[\operatorname{ImRuCl}{ }_{2}\left(\mathrm{H}_{2} \mathrm{O}\right)_{3}\right]+\mathrm{H}_{3} \mathrm{~N}^{+} \mathrm{CH}_{2} \mathrm{CH}_{2} \mathrm{~S}^{-}} \\
& \rightarrow\left[\operatorname{ImRuCl}_{2}\left(\mathrm{H}_{2} \mathrm{O}\right)_{3}{ }^{-} \mathrm{SCH}_{2} \mathrm{CH}_{2} \mathrm{~N}^{+} \mathrm{H}_{3}\right]+\mathrm{H}_{2} \mathrm{O} \\
& {\left[\operatorname{ImRuCl}{ }_{2}\left(\mathrm{H}_{2} \mathrm{O}\right)_{3}\right] \rightarrow\left[\mathrm{RuCl}_{2}\left(\mathrm{H}_{2} \mathrm{O}\right)_{2}\right]+\mathrm{H}_{2} \mathrm{O}+\mathrm{Im}}
\end{aligned}
$$

Results of influence of chloride ions on the reaction as seen in Figure 3.8 suggest that the chloride exchange reactions, R7 and R8) could be reversible. These interactions have been summarized graphically into Scheme 3-2. Structures labeled F and G were not observed on the ESI-MS spectra (refer to Figure 3.3), however, the presence of K and the $352 \mathrm{~m} / \mathrm{z}$ with such high relative abundance strongly suggests formation of these species. The $352 \mathrm{~m} / \mathrm{z}$ might be due to either J or L. Formation of J will require loss of acidic protons from coordinated water. Availability of protons (refer to R5 and R6) in the reaction mixture however, might make formation of $\mathrm{J}$ less viable. More so, the nonlinear dependence of reaction on cysteamine concentration might affirm adduct formation as was the case with respect to $\mathrm{L}$.

Reaction scheme 3-2 exemplifies labilization and subsequent ligand exchange reactions that have been observed for metal-based anticancer prodrugs vis-à-vis; IndICR and platinum (IV) complexes ${ }^{33 ; 180}$ Consequently, reduction of NAMI-A by cysteamine should enhance reactivity of NAMI-A with biomolecules, this is in agreement with 
reports of increased antimetastactic activity of NAMI-A and adduct formation with transferrin, human serum and albumin in the presence of cysteine and GSH. ${ }^{222}$

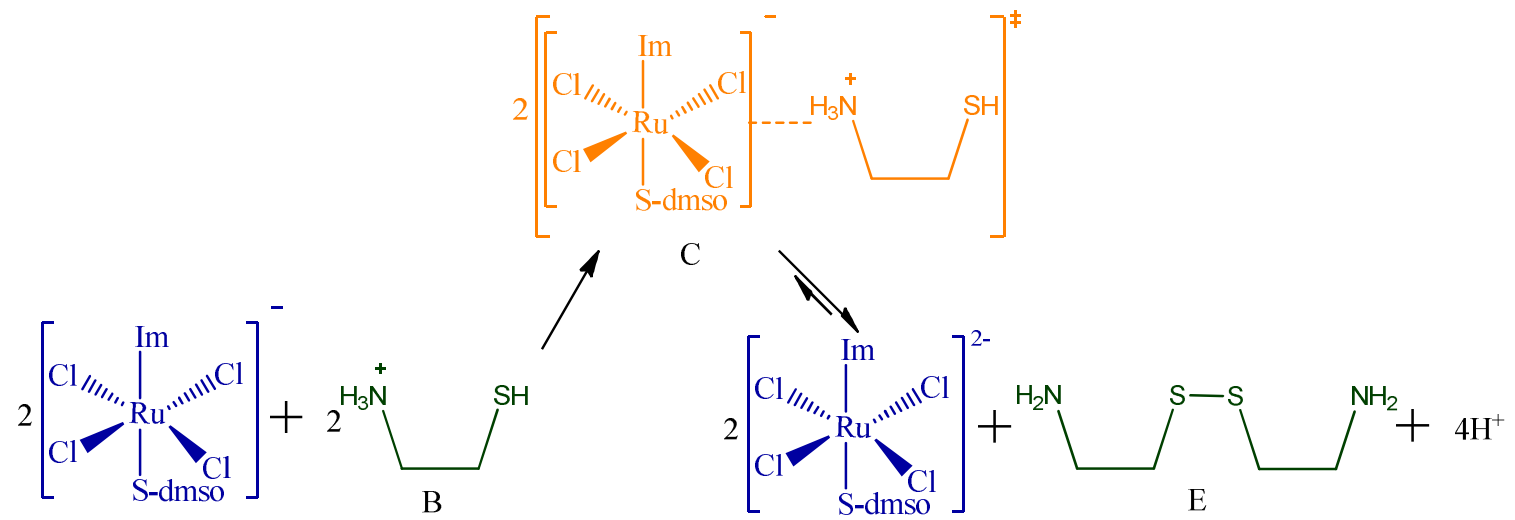

A
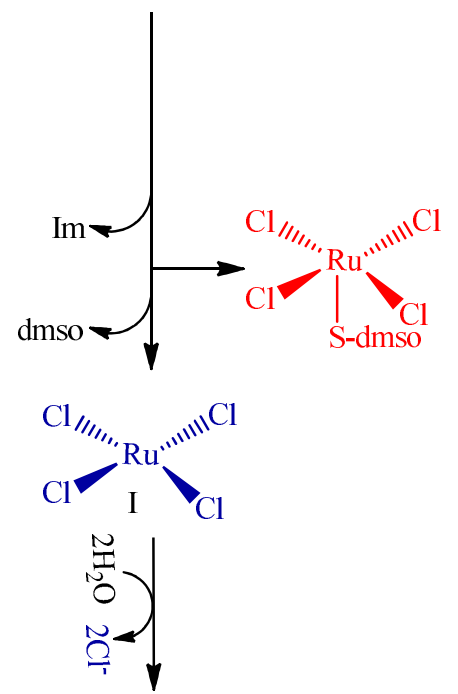

$\mathrm{D}$
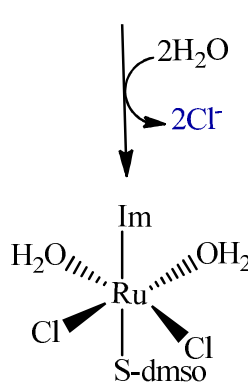

$\mathrm{F}$
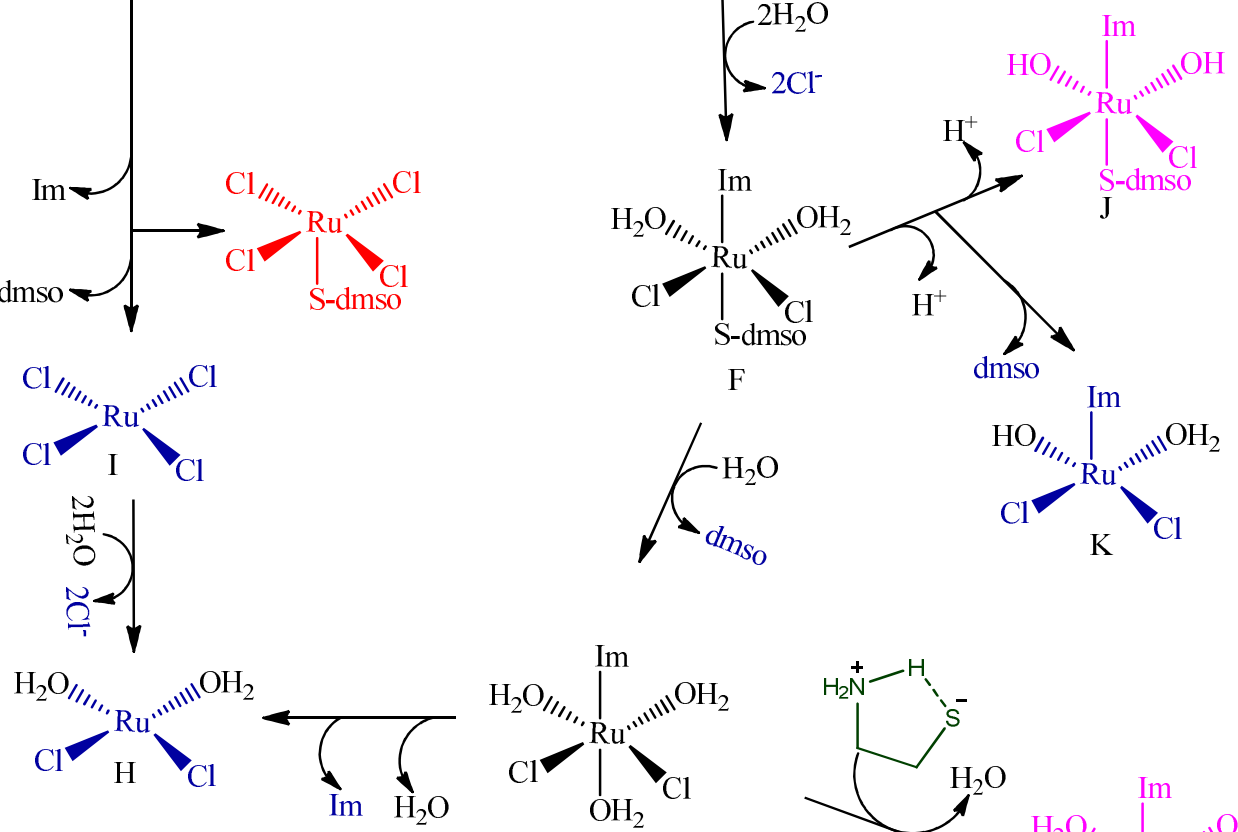

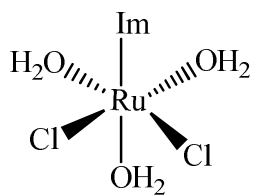

$\mathrm{G}$

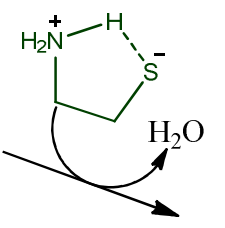

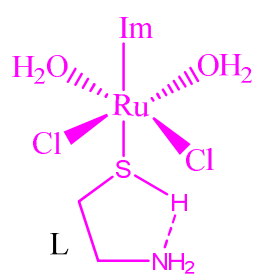

Scheme 3-2: Proposed mechanism for the reduction of NAMI-A by cysteamine and subsequent ligand exchange process. 


\section{CHAPTER FOUR}

\subsection{Kinetics and Mechanistic Investigation into the Possible Activation of NAMI-A by 2-Mercaptoethane sulfonate}

\subsection{Introduction}

Cancer still poses a significant health threat mostly due to the inability of individual drugs to cure cancer at clinically tolerable doses. ${ }^{223-225}$ The two exceptions to these are choriocarcinoma and Burtitt's lymphoma. ${ }^{226}$ These factors have necessitated combination chemotherapy.

Imidazolium trans-[tetrachloro (dimethyl sulfoxide)(imidazole)ruthenate(III)], NAMI-A, is an experimental prodrug that shows low host toxicity and selectively targets metastatic cells. ${ }^{74 ; 177 ; 181 ; 227}$ NAMI-A, while being very active against metastases has relatively limited activity towards primary tumor. ${ }^{228 ; 229}$ This suggests that administration of NAMI-A in combination with $\operatorname{drug}(\mathrm{s})$ active against primary tumor might present more desirable chemotherapy outcome. Likely options for this purpose are widely used anticancer drugs shown in Table 1 . These drugs form an integral part of chemotherapy regimens used in cancer treatment, for instance, cisplatin is used in 50$70 \%$ of all cancer patients most often in combination with other drug(s). ${ }^{230}$ A notable

disadvantage with these and other drugs is their induction of nephrotoxicity. ${ }^{186 ; 188 ; 226}$ Most anticancer drugs and their metabolites are eliminated through the kidneys, thus, making the kidneys susceptible to injury. ${ }^{185}$ 


\begin{tabular}{|l|l|l|}
\hline Alkylating Agents & Antimetabolites & Miscellaneous \\
\hline Cisplatin & Azacitidine & Diaziquone \\
\hline Carboplatin & Methotrexate & Clofarabine \\
\hline Carmustine & 6-Thioguanine & Mitomycin \\
\hline Streptozocin & Pentostatin & Temsirolimus \\
\hline Ifosfamise & & \\
\hline Cyclophosphamide & & \\
\hline Chloroethylnitrosoureas & & \\
\hline
\end{tabular}

Table 4- 1: Widely used chemotherapy drugs with inherent nephrotoxicity. ${ }^{185 ; 186 ; 188 ; 226}$ Antimetabolite: drug that interferes with normal metabolic processes within cells ${ }^{231}$ Alkylating agent: drug that causes DNA damage by addition of alkyl groups to specific bases. $^{232}$

A combination, therefore, of NAMI-A and any of the above mentioned drugs will require a concurrent use of a chemoprotectant to prevent nephrotoxicity. Chemoprotection aims at prevention, mitigation or delay of toxicity, thereby increasing therapeutic index of chemotherapy without interfering with efficacy of applied drug. ${ }^{233}$ These are all expected to improve patients' quality of life. Failure to provide adequate chemoprotection during therapy may mandate withdrawal or postponement of treatment and consequently lowers the probability of treatment success. Sodium-2mercaptoethanesulfonate, MESNA, is a low molecular weight thiol in clinical use as a 
chemoprotectant which inhibits the hemorrhagic cystitis and prevents bladder and kidney toxicities induced by cisplatin, ifosfamide and cyclophosphamide. ${ }^{234-237}$ Chemoprotection by simultaneous administration of $100 \mathrm{mg} / \mathrm{kg}$ MESNA did not affect survival times observed with vincristine, 5-fluorouracil, doxorubicin, methotrexate, cisplatin, or cyclophosphamide. ${ }^{237 ; 238}$ This current clinical utility of MESNA suggests that an encounter with NAMI-A should be inevitable should NAMI-A be used as part of a combination regimen involving any nephrotoxic cancer drug. Interestingly, the disulfide of MENSA, BNP7787, is currently undergoing Phase III clinical trials for chemoprotection. Reports have revealed the involvement of MESNA in the mechanism of protection of cisplatin-induced nephrotoxicity as illustrated in Figure 4-1. ${ }^{239-241}$ This further emphasizes the potential for interaction of MESNA with NAMI-A when administered in combination with cisplatin.

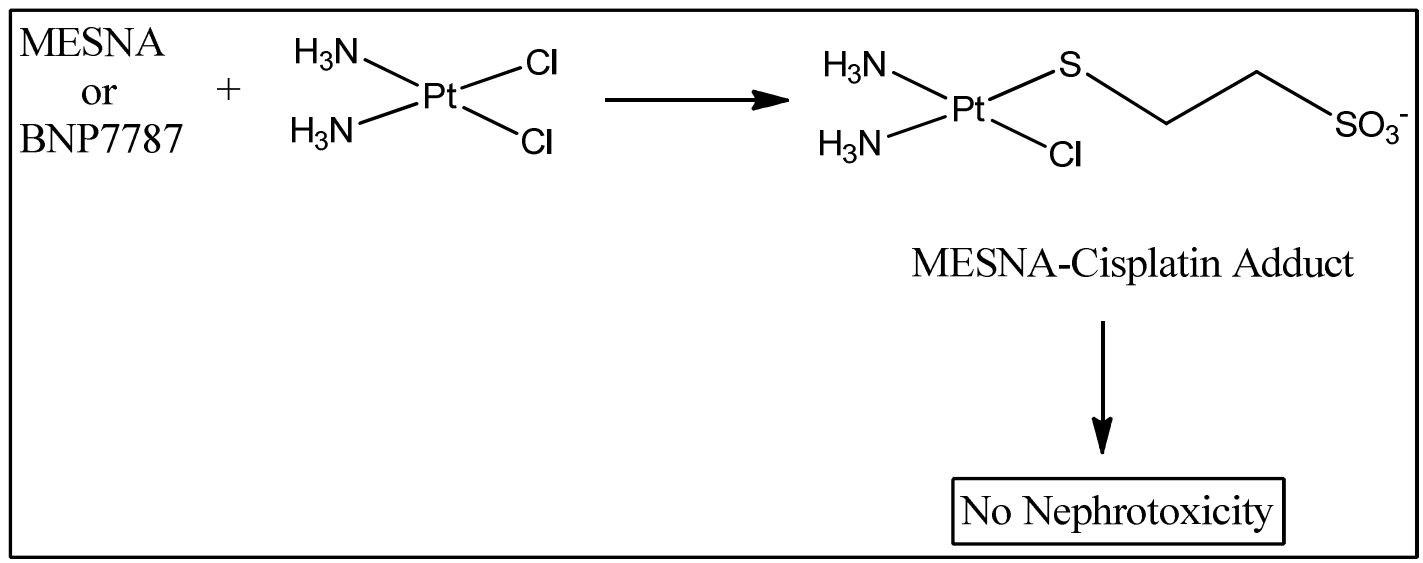

Figure 4-1: Nephroprotection by BNP7787 showing involvement of MESNA. ${ }^{239}$ 
A recent study reports cure of cancer in about $60 \%$ of the animals treated for lung metastasis using a combination of cisplatin and NAMI-A in mouse models. ${ }^{242}$ This represents the most successful treatment reported for metastasis. ${ }^{230}$ Presented here is a first report on kinetics and mechanism of interaction of NAMI-A with MESNA under physiologically-relevant conditions. An understanding of this interaction is important for optimizing clinical use of NAMI-A with high-dose nephrotoxic agents.

\subsection{Results}

4.2.1 Stoichiometry and Product Identification: Stoichiometry of reaction was found to be 1:1 with NAMI-A reacting with MESNA to give dimeric form of MESNA and reduced NAMI-A as represented in S1

$$
\begin{aligned}
2 \mathrm{HSCH}_{2} \mathrm{CH}_{2} \mathrm{SO}_{3}^{-} & +2\left[\mathrm{ImRuCl}_{4} \mathrm{DMSO}^{-}\right. \\
& \rightarrow{ }^{-} \mathrm{O}_{3} \mathrm{SCH}_{2} \mathrm{CH}_{2} \mathrm{SSCH}_{2} \mathrm{CH}_{2} \mathrm{SO}_{3}^{-}+2\left[\mathrm{ImRuCl}_{4} \mathrm{DMSO}^{2-}+2 \mathrm{H}^{+} \mathrm{S} 1\right.
\end{aligned}
$$

Figure 4-1 shows the spectral changes observed from a solution of MESNA and NAMI-A scanned at 30 second intervals. The charge transfer band of NAMI-A at 390 $\mathrm{nm}$ decreased as the reaction progressed showing one electron reduction of NAMI-A. The shoulder at $345 \mathrm{~nm}$ initially increased and then decreased towards the end of reaction. Absence of an isosbestic point indicates involvement of other absorbing species. 


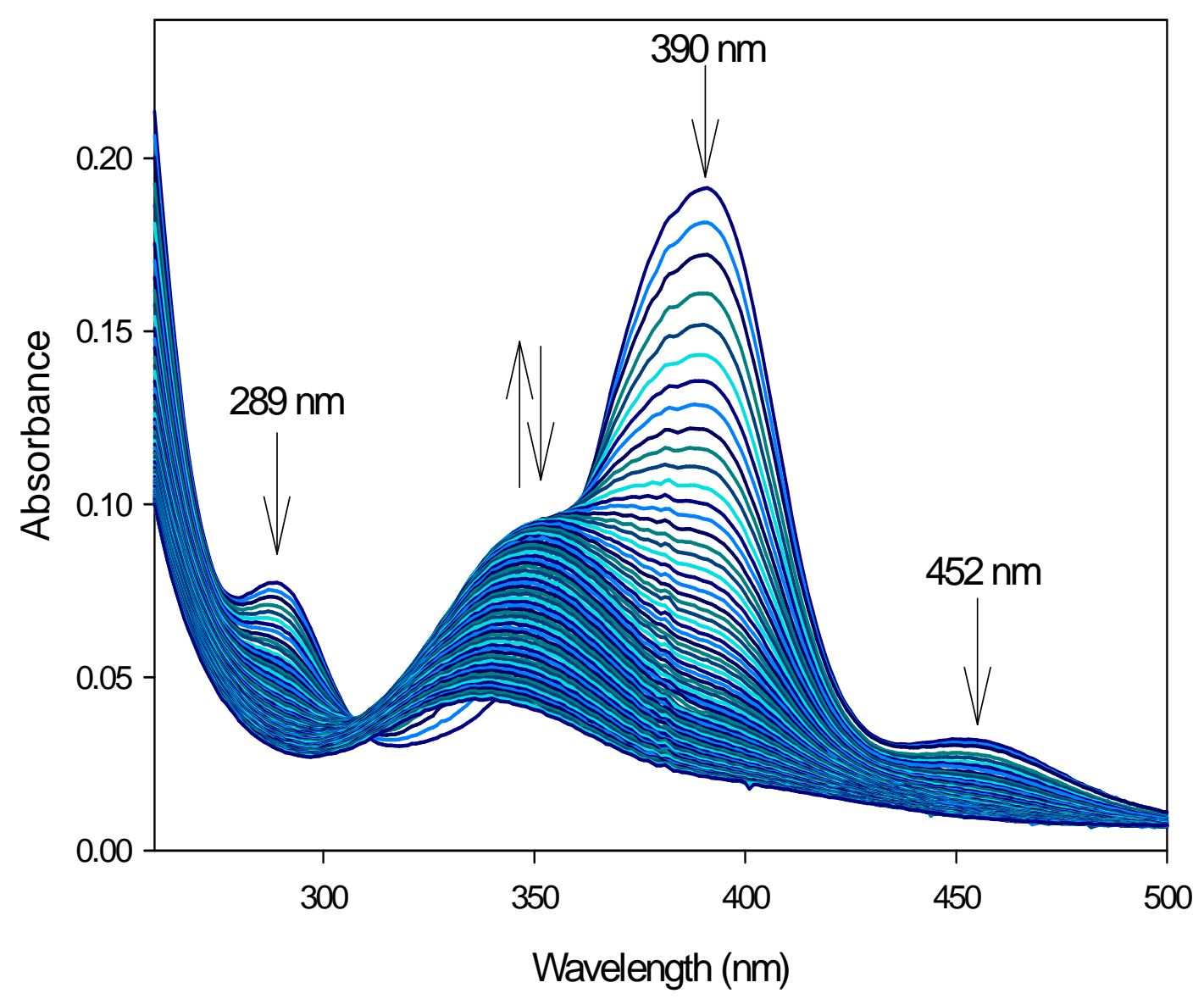

Figure 4-1: Rapid spectral scan of aqueous solution of MESNA and NAMI-A taken at 30 s interval. $[\mathrm{MESNA}]_{o}=1.5 \times 10^{-4} \mathrm{M} ;[\mathrm{NAMI}-\mathrm{A}]_{o}=5.0 \times 10^{-5} \mathrm{M}$.

Reduced form of NAMI-A, $\left[\mathrm{ImRuCl}_{4} \mathrm{dmso}\right]^{2-}$, has been reported to have a half life of approximately $14 \mathrm{~s}{ }^{82}$ Upon formation, it is expected that this labile species will be rapidly hydrolyzed in these aqueous reaction conditions. A full electrospray ionization mass spectrum of the stoichiometric solution was taken in the negative mode within the first minute of reaction (Figure 4-2a). The spectrum features NAMI-A at m/z $=389$ and MESNA at $\mathrm{m} / \mathrm{z}=140$ being the most abundant. A small peak at $\mathrm{m} / \mathrm{z}=$ 
139.96 represents the already formed disulfide of MESNA. No peak was observed for the reduced NAMI-A at $\mathrm{m} / \mathrm{z}=194$ since it is extremely labile.

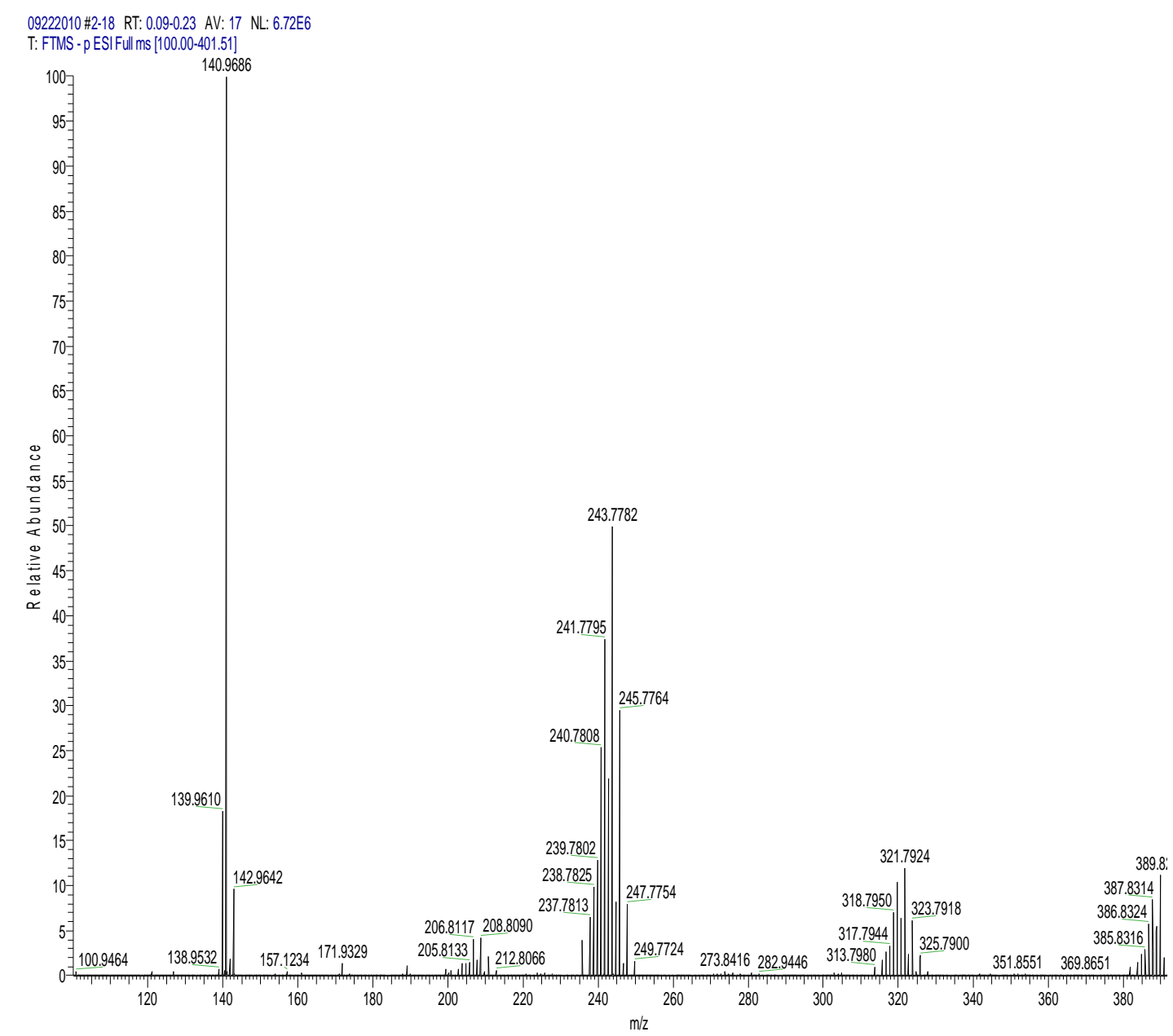

Figure 4-2a: Negative ESI-MS spectrum of a stoichiometric solution of MESNA and NAMI-A within the first minute of start of reaction.

Other crucial features of this spectrum are the group of peaks at $\mathrm{m} / \mathrm{z} \sim 208,243$ and 321 . The $208 \mathrm{~m} / \mathrm{z}$ peaks might seem insignificant (5\% relative abundance) but evidence from other studies in this dissertation (Chapters 3 and 6) suggest these are ions 
formed from reduced NAMI-A with a basic structure, $\left[\mathrm{RuCl}_{2}\left(\mathrm{H}_{2} \mathrm{O}\right)_{2}\right]$. Figure 4-2a displays $\left[\mathrm{RuCl}_{2}\left(\mathrm{H}_{2} \mathrm{O}\right)_{2}+\mathrm{H}\right]$ and $\left[\mathrm{RuCl}_{2}\left(\mathrm{H}_{2} \mathrm{O}\right)_{2}-\mathrm{H}\right]$ with the same relative abundance. 243 and $321 \mathrm{~m} / \mathrm{z}$ are due to ionization since NAMI-A without reductant shows these peaks. ${ }^{82}$ Spectrum in Figure 4-2b, taken five minutes after Figure 4-2a shows decrease in both NAMI-A and MESNA peaks with simultaneous growth of the disulfide of MESNA.

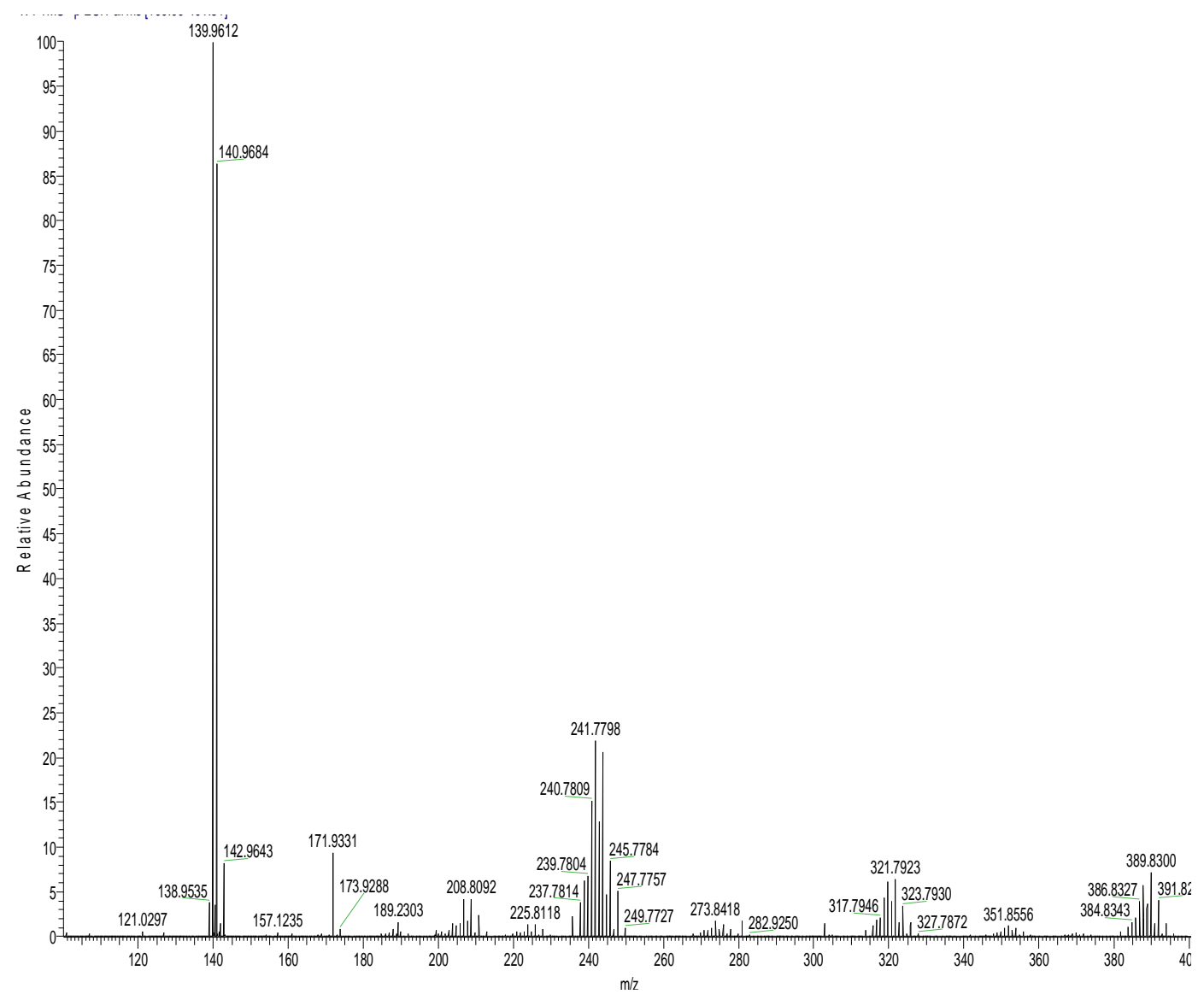

Figure 4-2b: Negative ESI-MS spectrum of the same solution in Figure 4-2a taken five minutes later showing the depletion of both NAMI-A peak at $389.8300 \mathrm{~m} / \mathrm{z}$ and MESNA peak at $140.9684 \mathrm{~m} / \mathrm{z}$ with simultaneous growth of disulfide of MESNA at $139.9612 \mathrm{~m} / \mathrm{z}$ and decay of MESNA. 
Figure 4-2c, taken at 5 minutes shows the disulfide as most abundant, demonstrating progress of the reaction towards completion, according to stoichiometric reaction S1.

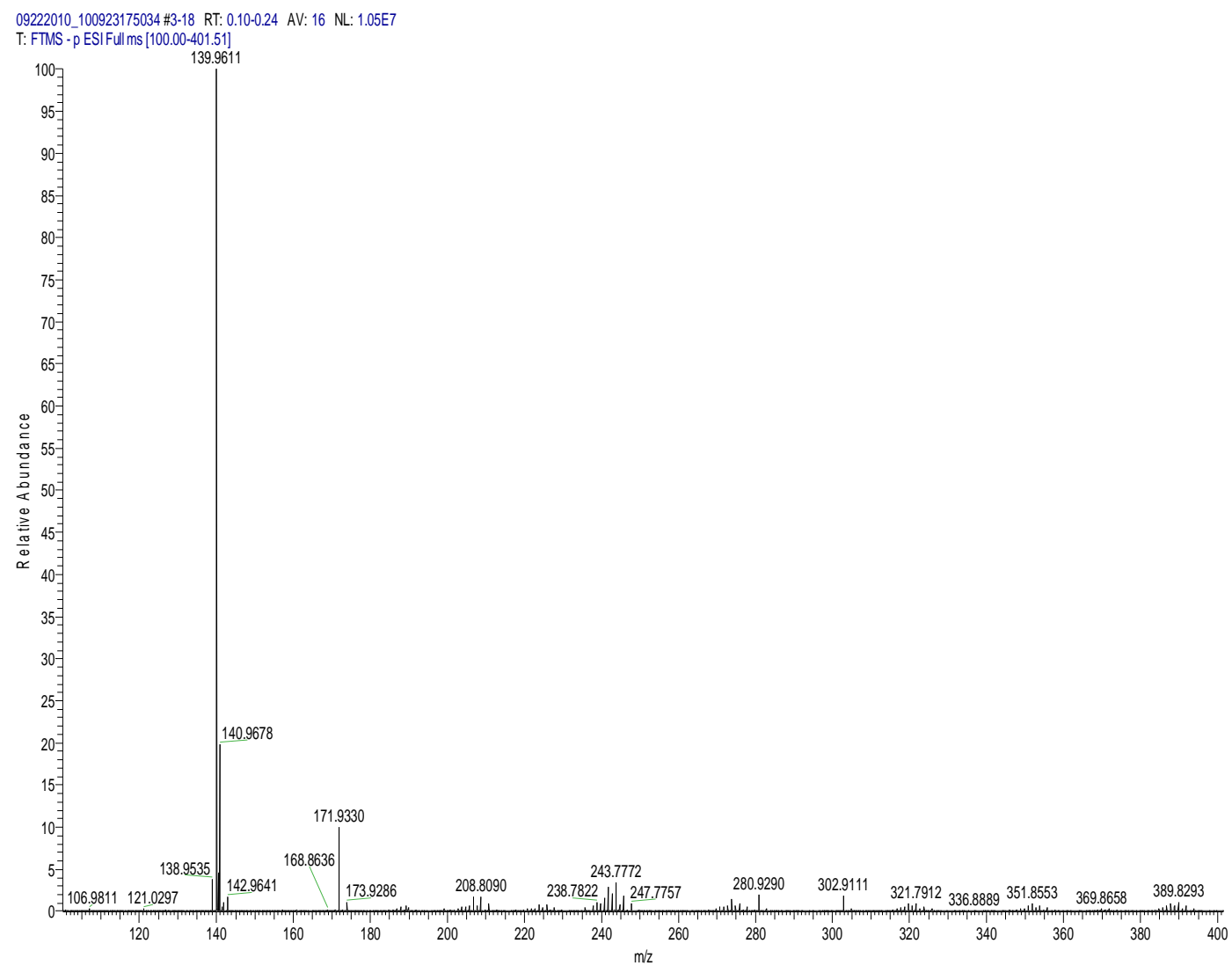

Figure 4-2c: Negative ESI-MS spectrum of solution in Figure 3-2a taken ten minutes later showing disulfide of MESNA as the major peak.

Of note is the nature of the product, dimeric form of MESNA (referred to as BNP7787), ${ }^{239}$ and its relevance to cancer chemotherapy. BNP7787 has demonstrated chemoprotection that surpasses that of MESNA and may protect against cisplatin- 
induced nephrotoxicity without interfering with efficacy, thus suggesting a more improved quality of life for patients. ${ }^{241 ; 243 ; 244}$

\subsection{Kinetics}

\subsubsection{NAMI-A Dependence}

Effect of varying initial concentrations of NAMI-A on the reaction in $0.1 \mathrm{M}$ phosphate buffer at $\mathrm{pH} 7.4$ was examined (see Figure 4-3a). The rate of consumption of NAMI-A increased with increasing initial NAMI-A concentrations. Absorbance traces at $390 \mathrm{~nm}$ in Figure 4-3a (and all other subsequent traces which monitor consumption of NAMI-A) show what might appear, erroneously, as mild autocatalysis. This peak at $390 \mathrm{~nm}$ is not entirely isolated and is influenced by contribution from a peak at $345 \mathrm{~nm}$, which appears as a shoulder to the $390 \mathrm{~nm}$ peak. Since the peak at $345 \mathrm{~nm}$ initially increases, one expects a positive contribution, measured at $390 \mathrm{~nm}$ from this peak. As the reaction proceeds, however, the peak at $345 \mathrm{~nm}$ starts to fall, with a concomitant decrease in its contribution at $390 \mathrm{~nm}$. Thus the observed rate of decrease of the peak at $390 \mathrm{~nm}$ will be enhanced, without necessarily an increased decrease in rate of loss of NAMI-A. There is no stoichiometric link between NAMI-A and the intermediate that absorbs at $345 \mathrm{~nm}$, thus initial rates for all our kinetics determinations were confined to a very short initial part of the reaction before establishment of intermediates. 


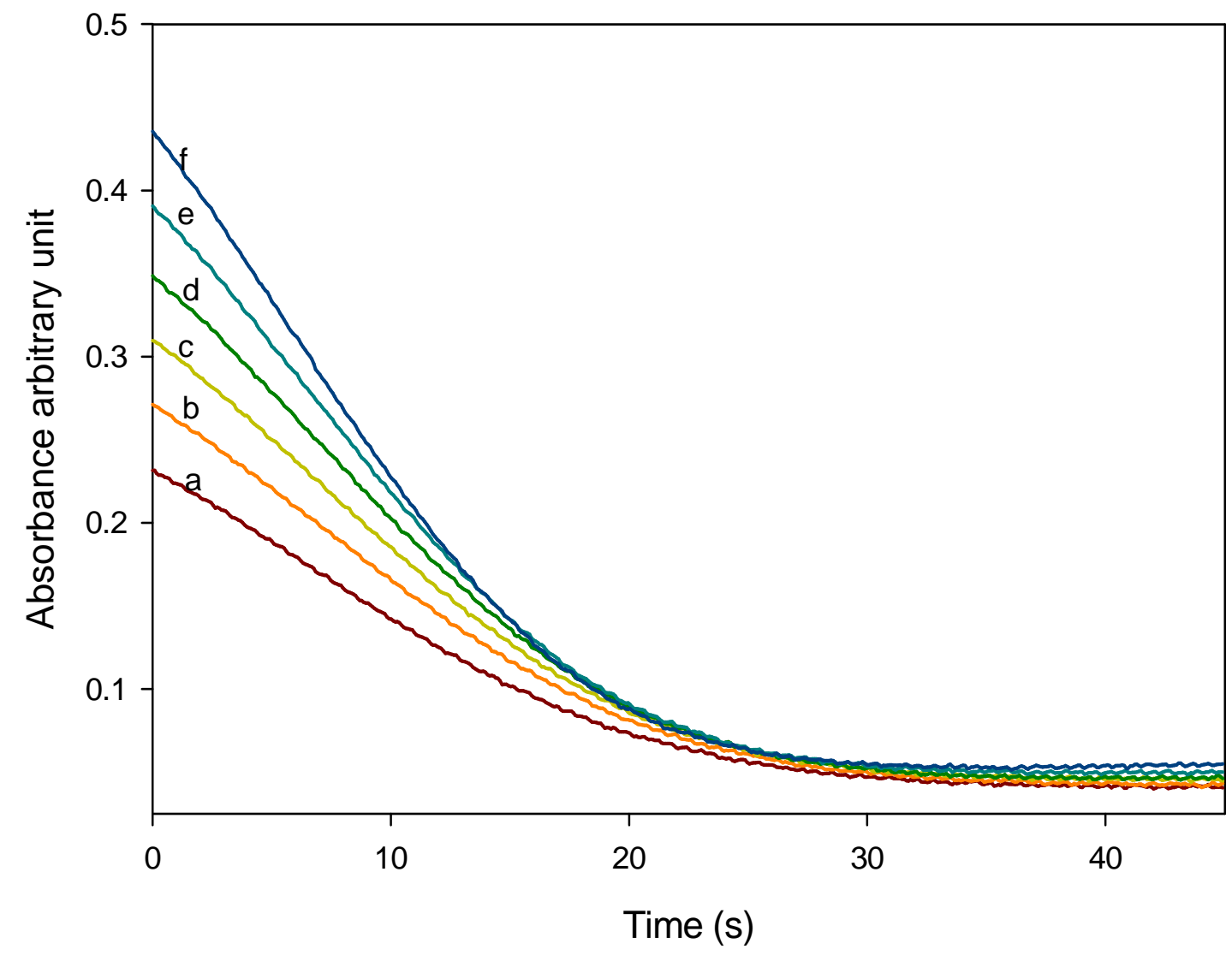

Figure 4-3a: Kinetic traces of reaction in 0.1M phosphate buffer (pH7.4) showing dependence on $[N A M I-A]$ at its $\lambda_{\max } \cdot[M E S N A]_{o}=5.0 \times 10^{-2} M ;[N A M I-A]_{o}=(a) 5.0 x$ $10^{-5} \mathrm{M}(b) 6.0 \times 10^{-5} \mathrm{M}(\mathrm{c}) 7.0 \times 10^{-5} \mathrm{M}(\mathrm{d}) 6.0 \times 10^{-5} \mathrm{M}$ (e) $9.0 \times 10^{-5} \mathrm{M}$ (f) $1.0 \times 10^{-4} \mathrm{M}$

Plot of initial rates against initial NAMI-A concentrations gives a straight line, with an intercept kinetically indistinguishable from zero, suggesting a linear dependence on NAMI-A (Figure 4-3b). A bimolecular rate constant of $7.07 \times 10^{-1} \pm 0.06 \mathrm{M}^{-1} \mathrm{~s}^{-1}$ was deduced from the data shown in Figures 4-3a and $b$. 


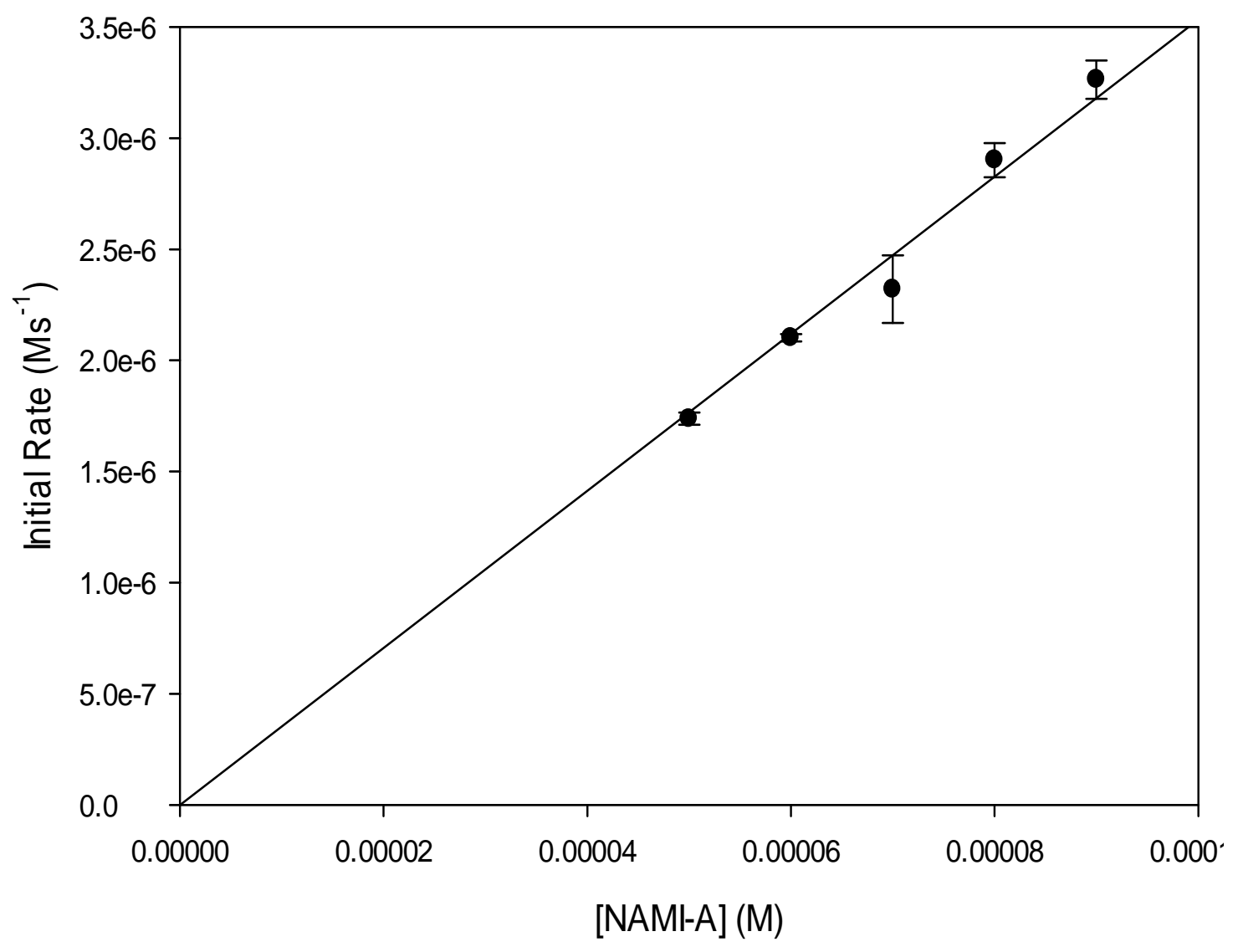

Figure 4-3b: Initial rate plot derived from Figure 4-3a, showing linear dependence on NAMI-A. $[\mathrm{MESNA}]_{o}=2.0 \times 10^{-3} \mathrm{M} ;[\mathrm{NAMI}-\mathrm{A}]_{o}=5.0 \times 10^{-5} \mathrm{M}$ to $9.0 \times 10^{-5} \mathrm{M}$

\subsubsection{MESNA Dependence.}

Effect of variation of initial concentrations of MESNA was also monitored at $390 \mathrm{~nm}$. The reaction rate monotonically increased with increasing concentrations of MESNA with no apparent saturation but with an apparent slight increase in rate at high MESNA concentrations (Figure 4-4a). Initial rate plots deduced from this plot, Figure 4-4b, again show a linear dependence on MESNA concentrations. Increase in rate observed at the tail end of the traces is due to the aforementioned absorbance 
contribution at $345 \mathrm{~nm}$ which magnifies rate of decrease in observed absorbance at 390 nm. Sigmoidal-type traces are much more pronounced at higher MESNA concentrations, and hence the expected deviations at high MESNA concentrations.

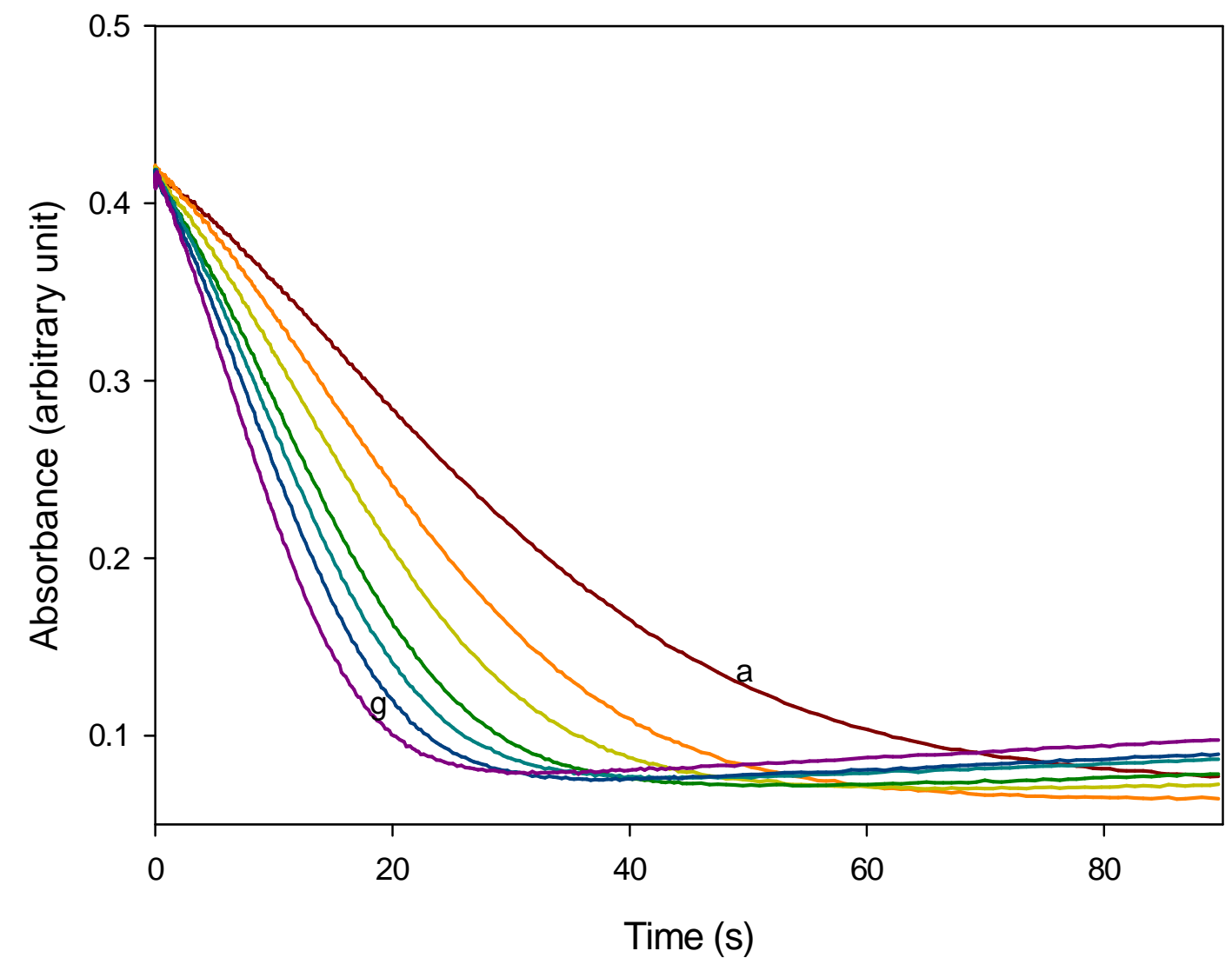

Figure 4-4a: Effect of MESNA variation on the consumption of NAMI-A at $390 \mathrm{~nm}$. $[N A M I-A]_{o}=1.0 \times 10^{-4} \mathrm{M} ;[\mathrm{MESNA}]_{o}=(a) 1.0 \times 10^{-2} \mathrm{M}(\mathrm{b}) 2.0 \times 10^{-2} \mathrm{M}(\mathrm{c}) 3.0 \times 10^{-2}$ $M(d) 4.0 \times 10^{-2} M(e) 5.0 \times 10^{-2} M(f) 6.0 \times 10^{-2} M(g) 7.0 \times 10^{-2} M$. 


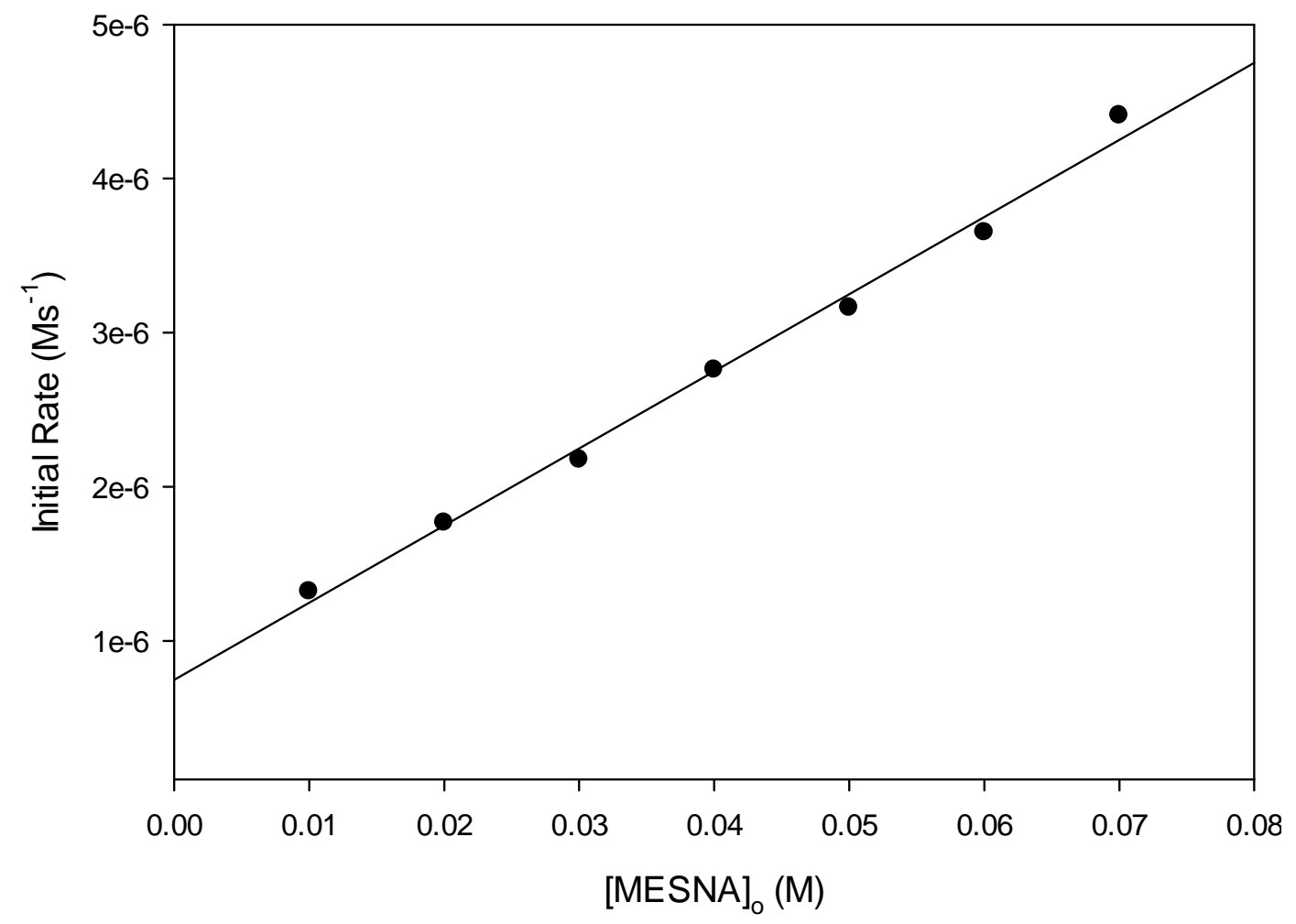

Figure 4-4b: Initial rate plot derived from Figure 4-4a, showing linear dependence on $[M E S N A]_{o}$

\subsubsection{Buffer and pH Effects.}

In the absence of buffer ions, varying initial concentration of MESNA influenced the reaction in similar manner as were obtained when reaction was carried out at $\mathrm{pH} 7.4$, compare Figures 4-4a and c. The slower rate in the absence of buffer might be due to reported stability of NAMI-A at lower pHs. ${ }^{245}$ At much lower $\mathrm{pH}$ values of 5 through 3 , lower rates were observed and sigmoidal characteristics on the traces became more pronounced as $\mathrm{pH}$ decreased, see Figure 4-4d. 


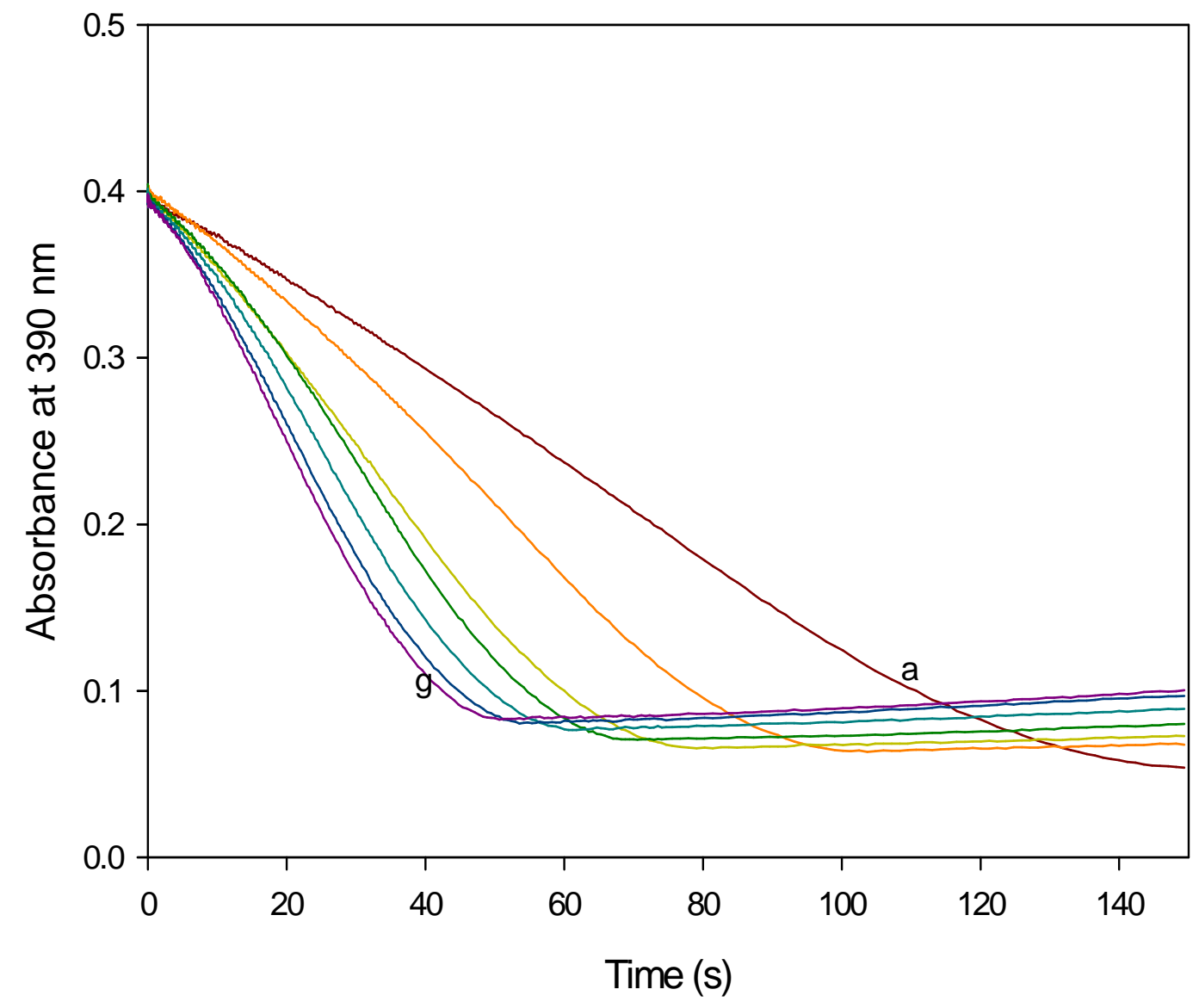

Figure 4-4c: Effect of MESNA variation on the consumption of NAMI-A at $390 \mathrm{~nm}$. Reaction not buffered. $[N A M I-A]_{o}=1.0 \times 10^{-4} \mathrm{M} ;[\mathrm{MESNA}]_{o}=\left(\right.$ a) $1.0 \times 10^{-2} \mathrm{M}(\mathrm{b}) 2.0$ $\times 10^{-2} M(c) 3.0 \times 10^{-2} M(d) 4.0 \times 10^{-2} M(e) 5.0 \times 10^{-2} M(f) 6.0 \times 10^{-2} M(g) 7.0 \times 10^{-2}$ M. Reaction is slower than observed at pH 7.4, compare Figure 4-4a. 


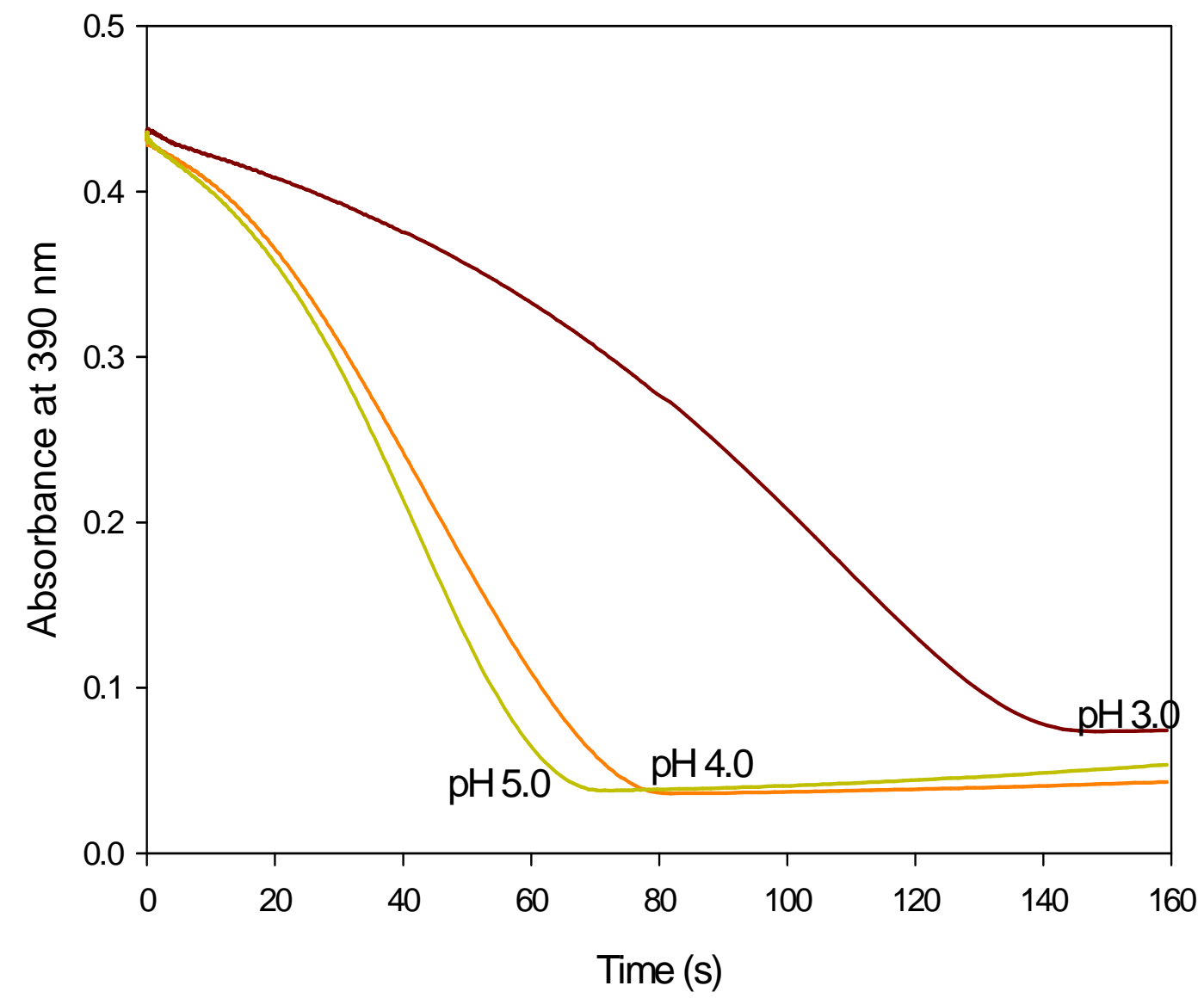

Figure 4-4d: Influence $p H$ on reaction rate. Reaction in $0.1 \mathrm{M}$ phosphate buffered at

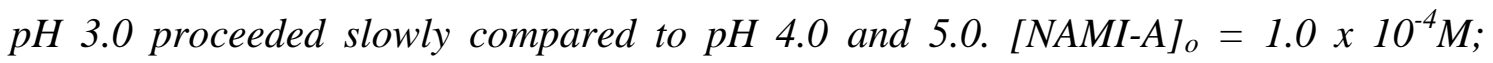
$[M E S N A]_{o}=5.0 \times 10^{-2} \mathrm{M}$

\subsubsection{Temperature dependence.}

At constant ionic strength, concentrations of NAMI-A and MESNA, the effect of temperature on the reaction was evaluated. Reaction rate increased proportionally with increasing temperatures as would be expected from standard Arrhenius kinetics (see Figure 4-5a), suggesting the existence of a single dominant rate-determining step. The data obtained were used to construct an Arrhenius plot (see Figure 4-5b). 
Activation parameters deduced using information obtained from the Arrhenius plots are: entropy of activation, $\Delta \mathrm{S}^{\neq}=-178.12 \pm 0.28 \mathrm{~J} \mathrm{~K}^{-1} \mathrm{~mol}^{-1}$, enthalpy of activation, $\Delta \mathrm{H}^{\neq}=$ $20.64 \pm 0.082 \mathrm{~kJ} \mathrm{~mol}^{-1}$ and free energy of activation as $\Delta \mathrm{G}^{\ddagger}=75.89 \pm 1.76 \mathrm{~kJ} \mathrm{~mol}^{-1}$ at $37 \pm 0.1{ }^{\circ} \mathrm{C}$ and $\mathrm{pH}$ 7.4. The distinctly negative entropy of activation suggests some degree of molecular ordering in the rate determining step. These parameters are indicative of an associative mechanism.

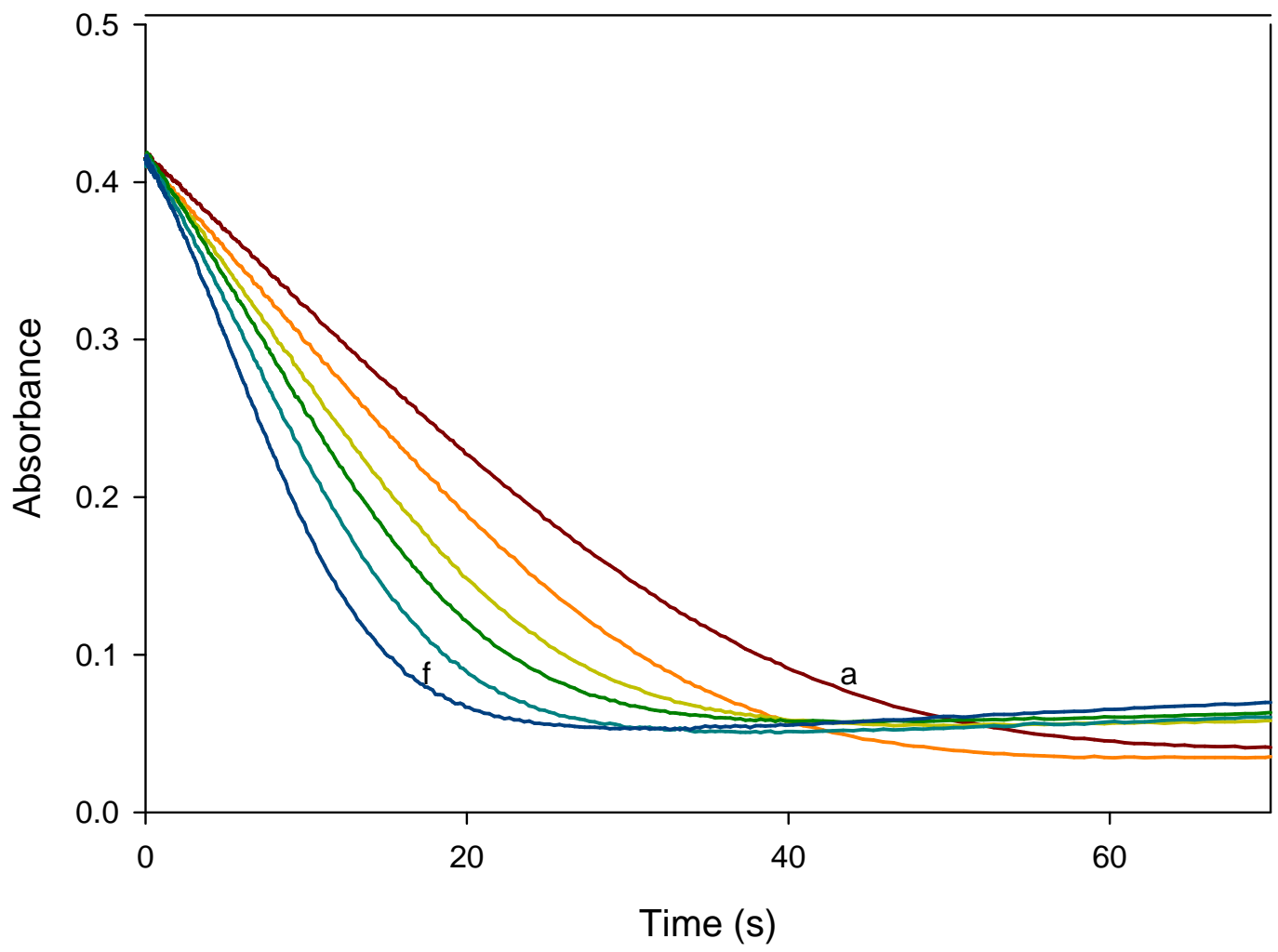

Figure 4-5a: Temperature dependence of the reaction between NAMI-A and MESNA (0.1 M phosphate buffer, $p H$ 7.4). Reaction rate increased with temperature increase. $[M E S N A]_{o}=5.0 \times 10^{-2} \mathrm{M} ;[\mathrm{NAMI}-\mathrm{A}]_{o}=1.0 \times 10^{-4} \mathrm{M} ; \mathrm{Temp}=\left(\right.$ a) $10^{\circ} \mathrm{C}(\mathrm{b}) 15^{\circ} \mathrm{C}(\mathrm{c}) 20^{\circ}$ $C(d) 25^{\circ} C(e) 30^{\circ} C(f) 37^{\circ} C$. 


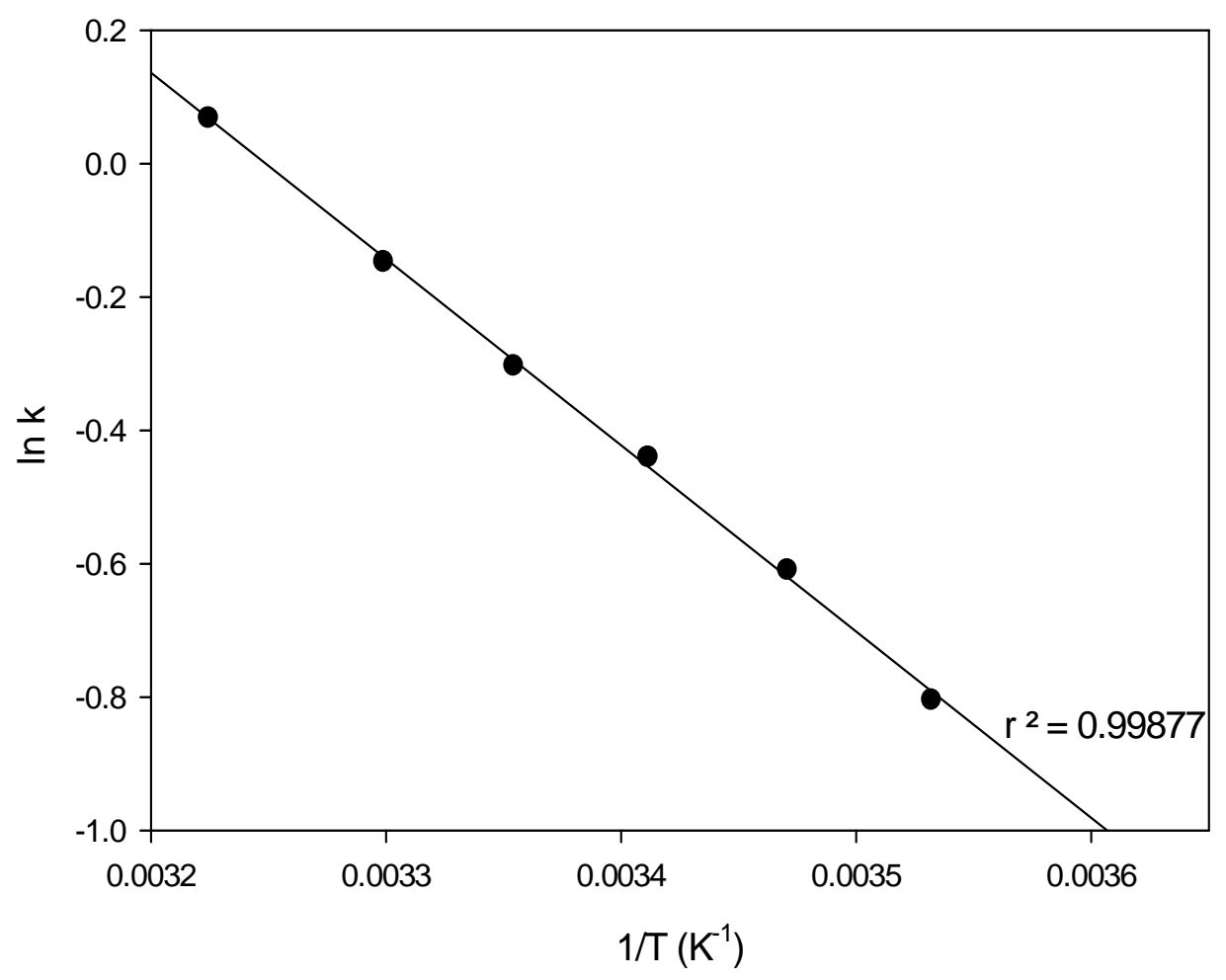

Figure 4-5b: Arrhenius plot extracted from study of effect of temperature variation on the reaction for determination of activation parameters.

\subsubsection{Effect of ionic strength:}

The response of the present reaction to changes in concentration of an inert salt, at constant temperature and reactants concentrations, was examined (Figure 4-6). Increasing ionic strength increased the rate of reaction. This might suggest that the rate determining step(s) contain species of similar charges. 


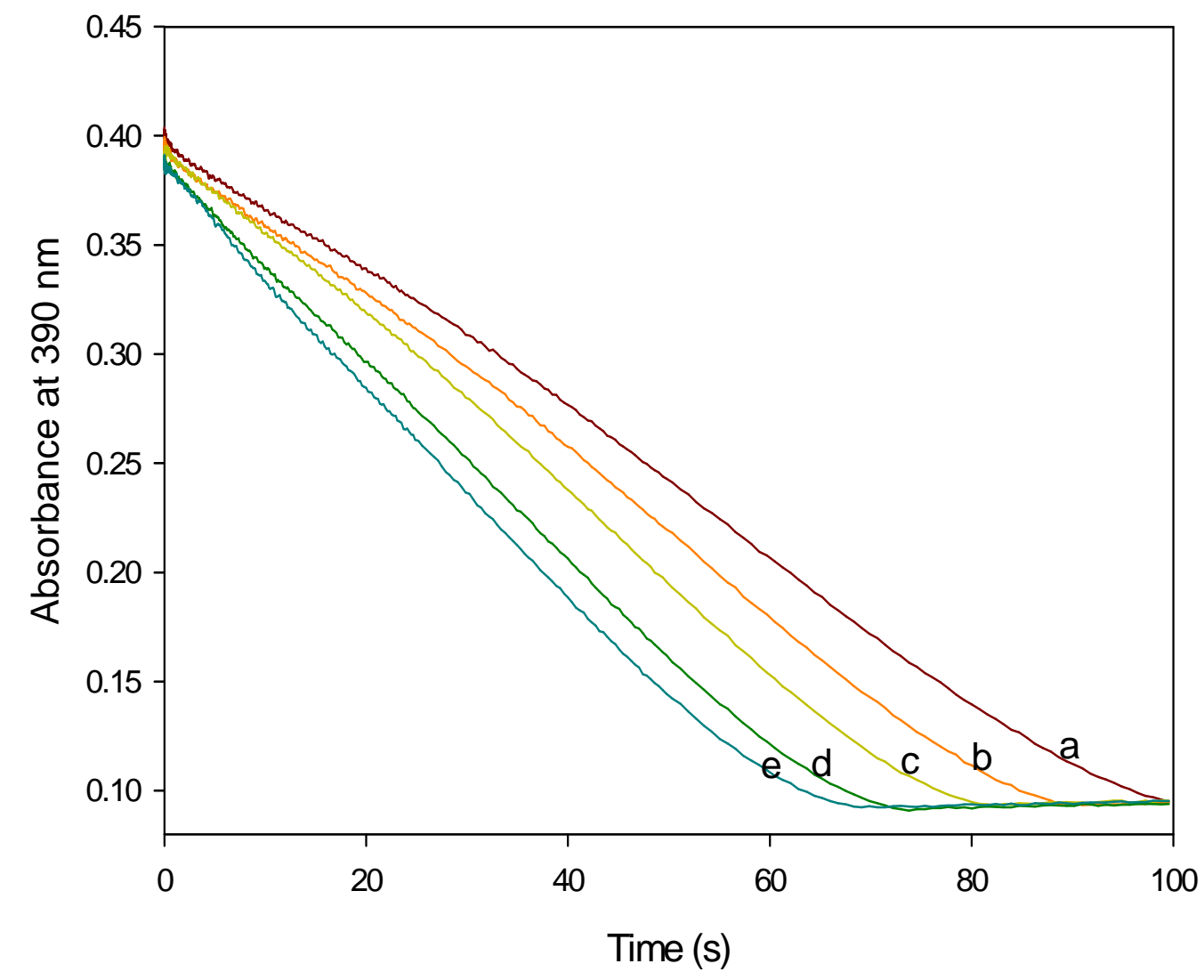

Figure 4-6: Influence of ionic strength on reaction rate. Ionic strength increase from (a) to (e) increased the reaction rate as shown. $[N A M I-A]_{o}=1.0 \times 10^{-4} \mathrm{M} ;[\mathrm{MESNA}]_{o}=$ $5.0 \times 10^{-2} \mathrm{M} ;[\mathrm{I}]_{\mathrm{NaClO}}=($ a) $0.05 \mathrm{M}($ b) $0.10 \mathrm{M}(\mathrm{c}) 0.20 \mathrm{M}(\mathrm{d}) 0.30 \mathrm{M}(\mathrm{e}) 0.40 \mathrm{M}$.

\subsection{Mechanism}

Ionization of MESNA in aqueous solution is represented in R1. Under reaction conditions of $\mathrm{pH} 7.4$, predominant species is the monoanionic as seen in this reaction. Dianionic form (see R2) is expected to be present in quantifiable amounts based on the Henderson-Hasselbach equation. 


$$
\begin{array}{llllll}
\mathrm{HSCH}_{2} \mathrm{CH}_{2} \mathrm{SO}_{3} \mathrm{Na} & \rightleftharpoons & \mathrm{HSCH}_{2} \mathrm{CH}_{2} \mathrm{SO}_{3}{ }^{-}+\mathrm{Na}^{+} & & \mathrm{R} 1 \\
\mathrm{HSCH}_{2} \mathrm{CH}_{2} \mathrm{SO}_{3}{ }^{-} & \rightleftharpoons & -\mathrm{SCH}_{2} \mathrm{CH}_{2} \mathrm{SO}_{3}{ }^{-}+ & \mathrm{H}^{+} & \mathrm{K}_{\mathrm{a}} & \mathrm{R} 2
\end{array}
$$

These species react with anionic NAMI-A to form associative complexes (see R3; R4) as indicated by deduced activation parameters. The activated complexes then proceed to form BNP7787 and reduced NAMI-A as products as shown in R5 and R6.

$$
\begin{aligned}
& \mathrm{HSCH}_{2} \mathrm{CH}_{2} \mathrm{SO}_{3}^{-}+\left[\mathrm{ImRuCl}_{4} \mathrm{DMSO}\right]^{-} \\
& \rightarrow\left[\mathrm{HSCH}_{2} \mathrm{CH}_{2} \mathrm{SO}_{3}^{-} \ldots\left[\mathrm{ImRuCl}_{4} \mathrm{DMSO}\right]^{-}\right]^{\neq} \quad \mathrm{k}_{1} \quad \mathrm{R} 3 \\
& { }^{-} \mathrm{SCH}_{2} \mathrm{CH}_{2} \mathrm{SO}_{3}^{-}+\left[\mathrm{ImRuCl}_{4} \mathrm{DMSO}\right]^{-} \\
& \rightarrow\left[{ }^{-} \mathrm{SCH}_{2} \mathrm{CH}_{2} \mathrm{SO}_{3}{ }^{-} \ldots\left[\mathrm{ImRuCl}_{4} \mathrm{DMSO}^{-}\right]^{\neq} \quad \mathrm{k}_{2} \quad \mathrm{R} 4\right. \\
& 2\left[\mathrm{HSCH}_{2} \mathrm{CH}_{2} \mathrm{SO}_{3}^{-} \ldots\left[\mathrm{ImRuCl}_{4} \mathrm{DMSO}\right]^{-}\right]^{\neq} \\
& \rightarrow{ }^{-} \mathrm{O}_{3} \mathrm{SCH}_{2} \mathrm{CH}_{2} \mathrm{SSCH}_{2} \mathrm{CH}_{2} \mathrm{SO}_{3}{ }^{-}+2\left[\mathrm{ImRuCl}_{4} \mathrm{DMSO}^{2-} 2 \mathrm{H}^{+} \quad \mathrm{R} 5\right. \\
& 2\left[{ }^{-} \mathrm{SCH}_{2} \mathrm{CH}_{2} \mathrm{SO}_{3}{ }^{-} \ldots\left[\mathrm{ImRuCl}_{4} \mathrm{DMSO}\right]^{-}\right]^{\neq} \\
& \rightarrow{ }^{-} \mathrm{O}_{3} \mathrm{SCH}_{2} \mathrm{CH}_{2} \mathrm{SSCH}_{2} \mathrm{CH}_{2} \mathrm{SO}_{3}{ }^{-}+2\left[\mathrm{ImRuCl}_{4} \mathrm{DMSO}^{2-}\right.
\end{aligned}
$$

Results of the ESI-MS experiments (Figure 4-2a-c) suggests a clean conversion of NAMI-A to the reduced dianion form. The absence of an isosbestic point on the multiple UV/Vis spectra suggests involvement of multiple absorbing species. Redox 
interaction between the products was anticipated, however, the nature of these species in terms of charge strongly indicate prevention of such interactions due to electrostatic repulsions.

Reaction rate measured as the rate of disappearance of $\left[\mathrm{ImRuCl}_{4} \mathrm{DMSO}\right]^{-}$, NAMI-A is defined as:

Rate $=\mathrm{k}_{1}[\mathrm{RSH}]\left[\mathrm{ImRuCl}_{4} \mathrm{DMSO}^{-}+\mathrm{k}_{2}\left[\mathrm{RS}^{-}\right]\left[\mathrm{ImRuCl}_{4} \mathrm{DMSO}^{-}\right.\right.$

where RSH and $\mathrm{RS}^{-}$represent protonated and deprotonated MESNA respectively as shown in R1 and R2. Results obtained from ionic strength effects demonstrate that the reaction of $\mathrm{RS}^{-}$is rate limiting thus indicating that $k_{1} \gg k_{2}$ and E1 reduces to

$$
\text { Rate }=\mathrm{k}_{2}\left[\mathrm{RS}^{-}\right]\left[\mathrm{ImRuCl}_{4} \mathrm{DMSO}^{-}\right.
$$

E2 can be expressed in terms of initial MESNA concentration which is distributed between RSH and RS. From mass balance,

$$
[\mathrm{RSH}]_{\mathrm{o}}=[\mathrm{RSH}]+\left[\mathrm{RS}^{-}\right]
$$

Combining E3 with Henderson-Hasselbach equation, a ratio of [RS'] to [RSH] can be derived. Substitution for [RSH] using R2 results in the rate law; 


$$
\text { Rate }=\frac{K a k_{2}[\mathrm{RSH}]_{\mathrm{o}}\left[\mathrm{ImRuCl}_{4} \mathrm{DMSO}\right]^{-}}{\left[\mathrm{H}^{+}\right]\left(1+10^{\mathrm{pH}-\mathrm{p} K a}\right)}
$$

which in conditions of overwhelming excess of MESNA can be written as

$$
\text { Rate }=k_{o}\left[\mathrm{ImRuCl}_{4} \mathrm{DMSO}\right]^{-}
$$

where

$$
k_{o}=\frac{K a k_{2}[\mathrm{RSH}]_{\mathrm{o}}}{\left[\mathrm{H}^{+}\right]\left(1+10^{\mathrm{pH}-\mathrm{p} K a}\right)}
$$




\section{CHAPTER FIVE}

\subsection{Kinetics and Mechanism of interaction of NAMI-A with Glutathione}

\subsection{Introduction}

Intracellular thiols are essential for maintenance of cellular redox homeostasis in living systems. ${ }^{246}$ Glutathione (GSH) is the most abundant and most important cellular antioxidant in animal cells with concentrations up to $10 \mathrm{mM}$ in the cytoplasm and 2 $20 \mu \mathrm{M}$ in extracellular fluids. ${ }^{247 ; 248}$ It performs cytoprotectivity against reactive oxygen and nitrogen species vis: hydrogen peroxide, peroxynitrite, lipid peroxyl, hydroxyl, nitric oxide and superoxide radicals. ${ }^{249}$ These reactive species have been implicated in the pathogenesis of various disease states including atherosclerosis, hypertension, ischemia/reperfusion injury, cardiovascular disease, diabetes mellitus, neurodegenerative diseases (Alzheimer's and Parkinson's diseases), rheumatoid arthritis, cancer and ageing ${ }^{246 ; 250 ; 251}$ Participation of GSH in various metabolism and regulatory processes such as synthesis of prostaglandins, cell proliferation and apoptosis is well documented. ${ }^{248 ; 252-254}$ Its direct and indirect involvement in various important biochemical processes is further illustrated in Figure $5-1,{ }^{255}$ where it is shown to act as a center wheel influencing all featured processes.

Interactions of a drug with biomolecules and other xenobiotics influence its absorption, distribution, metabolism, excretion and toxicity (ADMET) properties and ultimately its activity. These properties are determinants of a drug's clinical relevance. Drugs are metabolised either to active or inactive metabolites by interaction with proteins and non-protein biomolecules. Such interactions impact drug efficacy 
positively or otherwise. Interaction of any xenobiotic with GSH invariably translates to potential for modulation of processes involving GSH. ${ }^{256}$

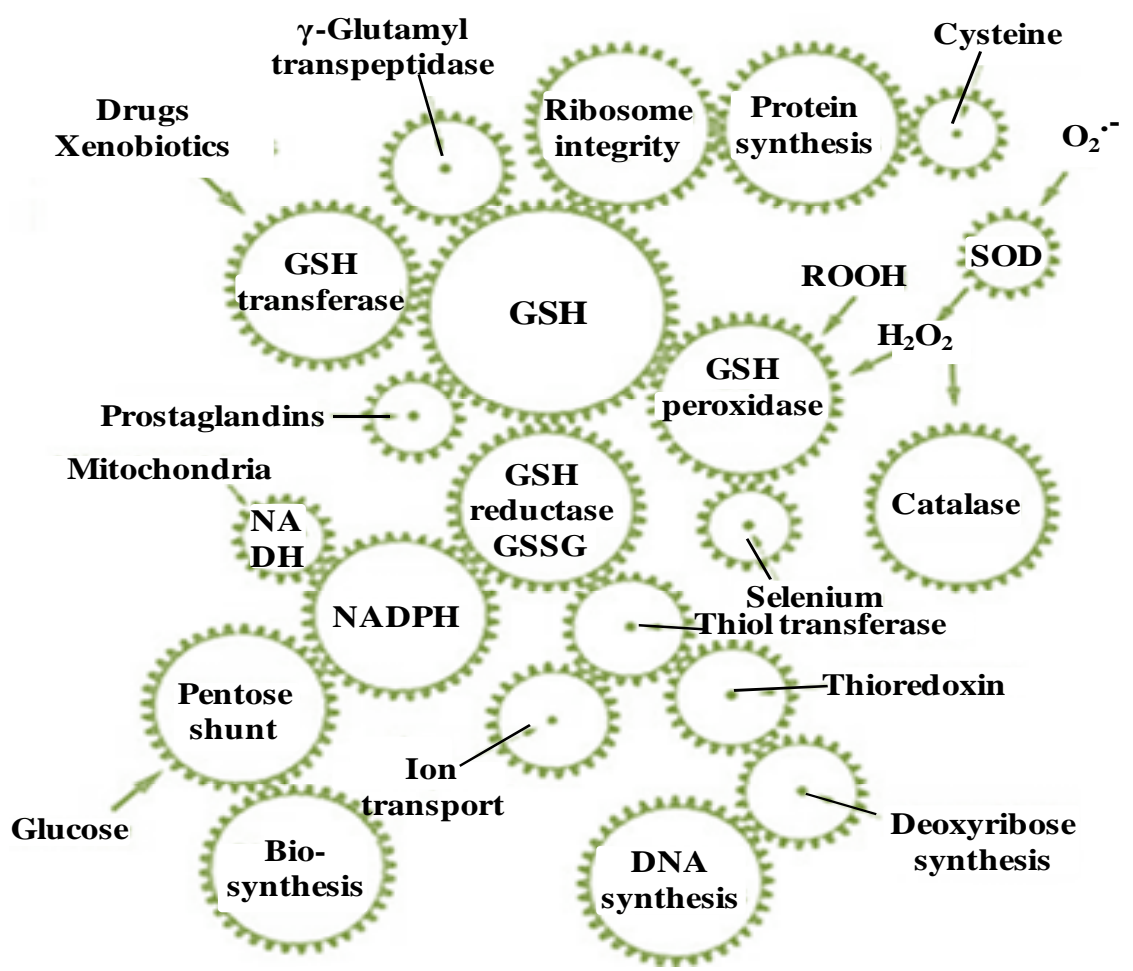

Figure 5-1: A representation of the GSH involvement in important cellular processes. (Modified figure adapted from Mitchell, J.B. \& Russo, A. 1987 Br. J. Cancer Suppl. $8: 96-104)^{255}$

Decrease in GSH levels impairs a cell's ability to protect itself thereby increasing sensitivity to effects of toxic substances. It is then not surprising that higher levels of GSH in cancer cells are associated with observed resistance to chemotherapeutic agents. ${ }^{257-259}$ This is in agreement with mounting evidence that tumor cells have higher levels of GSH compared to normal healthy cells. ${ }^{260-262}$ 
There is great potential for interaction between NAMI-A and GSH considering the extent of GSH involvement in many processes of biological significance. In view of the above, this chapter reports on the investigation conducted on the reactivity of NAMI-A with GSH in hopes of better understanding of mechanism of action of this promising prodrug.

\subsection{Results and Discussion}

5.2.1 Stoichiometry and Product Identification: Absorbance measurement at 390 $\mathrm{nm}$ of varying ratios of NAMI-A to GSH afforded determination of reaction stoichiometry. A 1:1 ratio represented by R1 was obtained (GSSG stands for oxidized glutathione).

$$
2 \mathrm{GSH}+2\left[\mathrm{ImRuCl}_{4} \mathrm{DMSO}\right]^{-} \rightarrow \mathrm{GSSG}+2\left[\mathrm{ImRuCl}_{4} \mathrm{DMSO}\right]^{2-}+2 \mathrm{H}^{+}
$$

An absorption profile of a solution containing about 1:3 ratio of GSH to NAMI-A was recorded at $30 \mathrm{~s}$ intervals. Consumption of NAMI-A was observed as the reaction progressed as demonstrated by reduction at $390 \mathrm{~nm}$ (Figure 5-2a). The disappearance of this band occurred with concomitant formation of a new band at $\sim 339 \mathrm{~nm}$ which progressively shifted to lower wavelength. Growth of the new peak represents conversion of reduced NAMI-A to a new absorbing form, supposedly through ligand exchange. Kinetic observation at $\sim 339 \mathrm{~nm}$ could unveil some information regarding the species present. Several attempts to study reaction kinetics at this wavelength however, 
demonstrated that consistent results could not be obtained under these reaction conditions. Contributions from multiple species might be responsible.

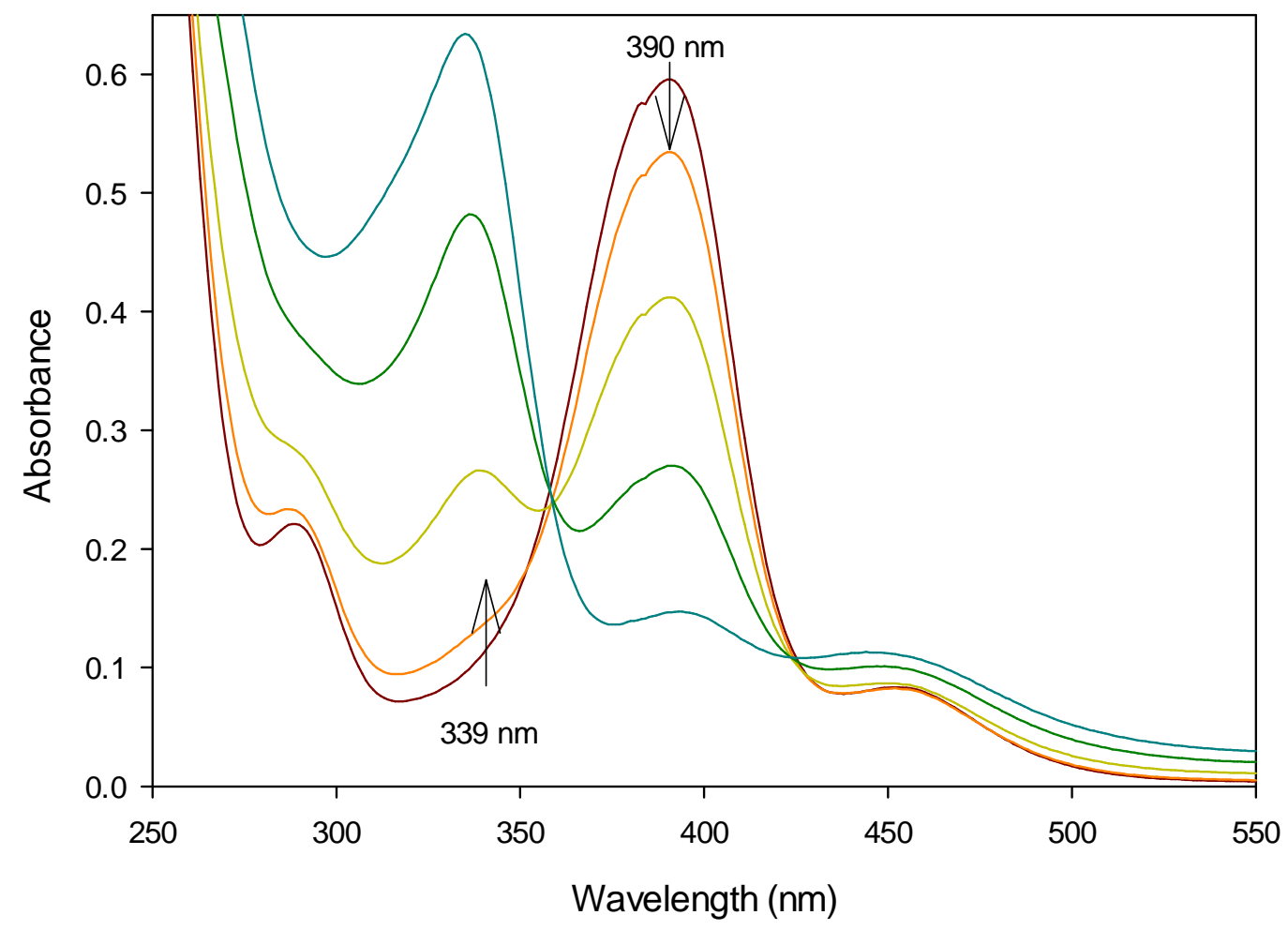

Figure 5-2a: Multiple spectral scans showing absorption profile as reaction progressed of a GSH-NAMI-A reaction mixture. Spectral interval was $30 \mathrm{~s} .[\mathrm{NAMI-A}]_{o}=1.5 \times 10^{-4}$ $M ;[G S H]_{o}=5.0 \times 10^{-4} \mathrm{M}$.

A continuous spectral scan of the same solution as shown in Figure 5-2a revealed a decrease in the shifting $339 \mathrm{~nm}$ peak followed by an increase in absorption over the entire visible wavelength (Figure 5-2b). Blue shift in absorbance maximum and absence of well-defined isosbestic points might be suggestive of progress of reaction 
towards product formation through various intermediates. Similar observations had been reported for GSH oxidation by chromium acetate cluster. ${ }^{263}$

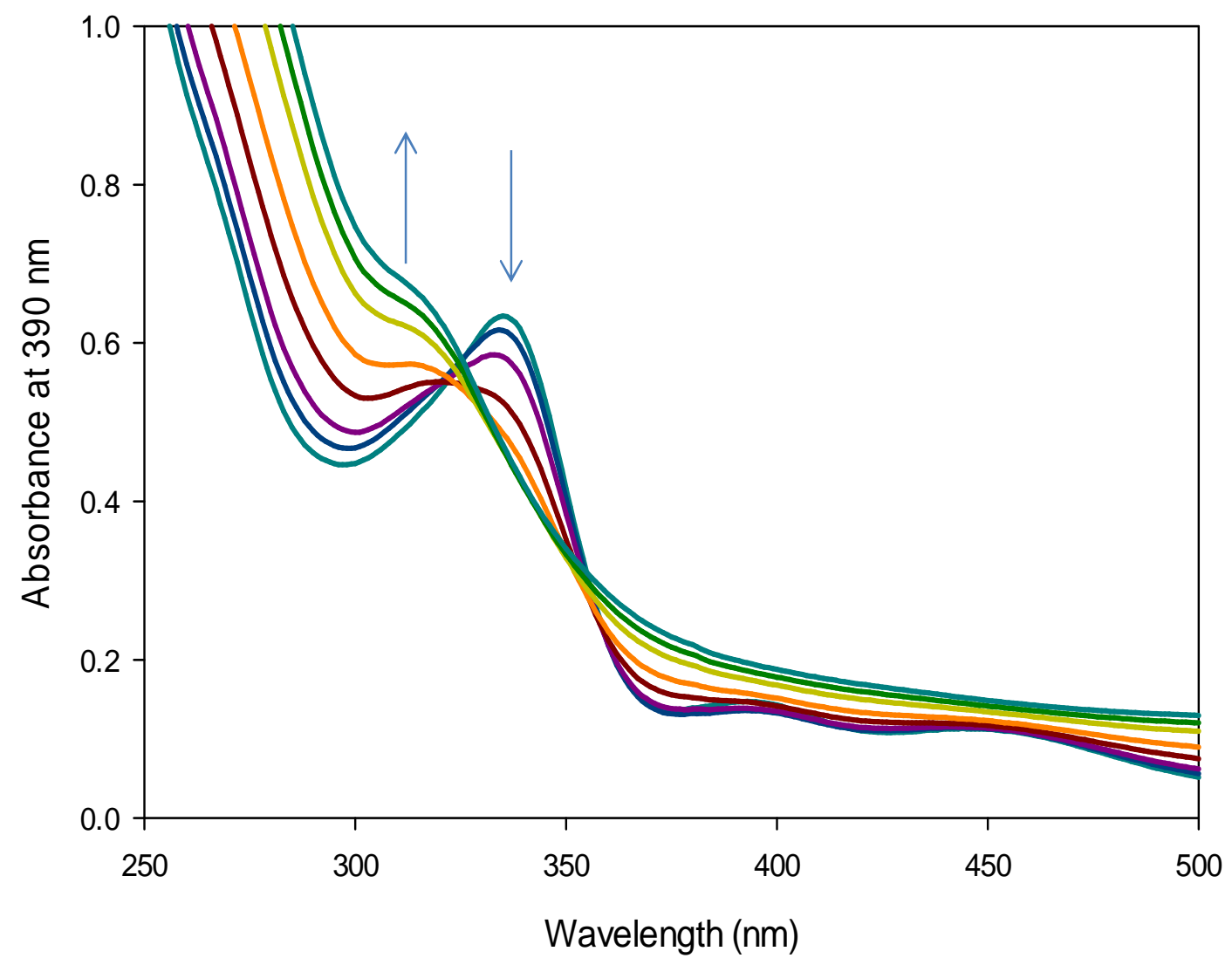

Figure 5-2b: Multiple spectral scans of same solutions observed in Figure 5-2a. The new peak grew to a maximum and later decreased. Absorption over entire spectrum is observed with the disappearance of this peak.

Identification of all observable molecular species present in a dynamic reaction mixture and after completion of reaction is key to establishing pathway for interaction of reactants to form products. A full ESI-MS spectrum of solution containing a stoichiometric ratio of NAMI-A and GSH was taken in the negative mode within the 
first minute of the reaction in order to identify molecular species involved (Figure 5-3).

Observed ions were monoanionic NAMI-A, [ $\left[\mathrm{RuCl}_{4} \mathrm{DMSO}\right]^{-},[\mathrm{GSH}-\mathrm{H}]^{-}$and $\mathrm{RuCl}_{4}$ at 389,321 and $243 \mathrm{~m} / \mathrm{z}$ respectively. One electron oxidation of GSH should result in formation of dimeric GSH and dianionic NAMI-A.

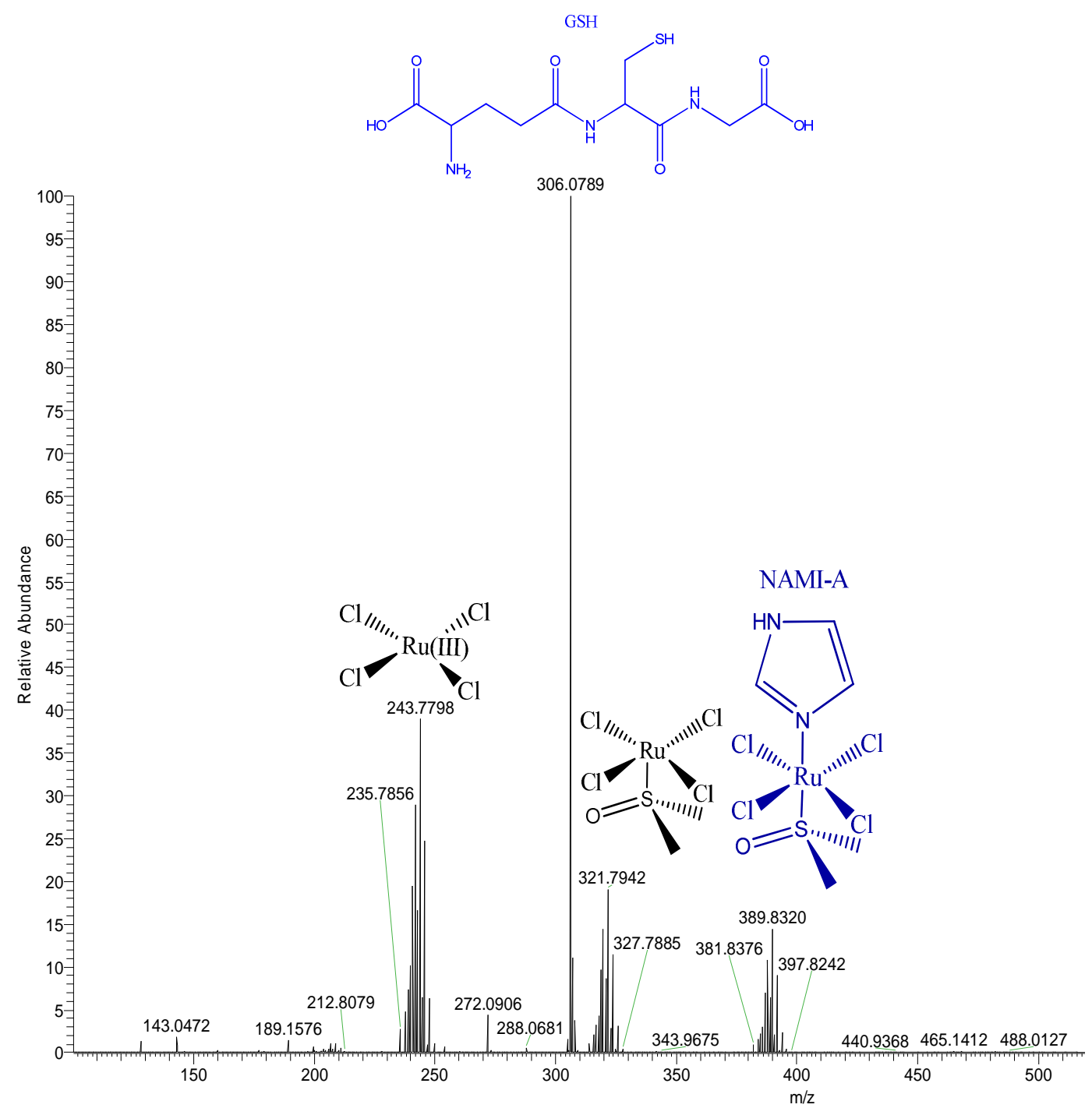

Figure 5-3: Full ESI-MS spectrum of stoichiometric solution of NAMI-A and glutathione within the first minute of the reaction. (50\% methanol, negative mode) 
An ESI-MS spectrum of the same solution taken in the negative mode a minute later is shown in Figure 5-4. Same peaks as the ones observed in Figure 5-3 were present with the appearance of a new peak at $611 \mathrm{~m} / \mathrm{z}$ displaying formation of dimeric GSH, GSSG.

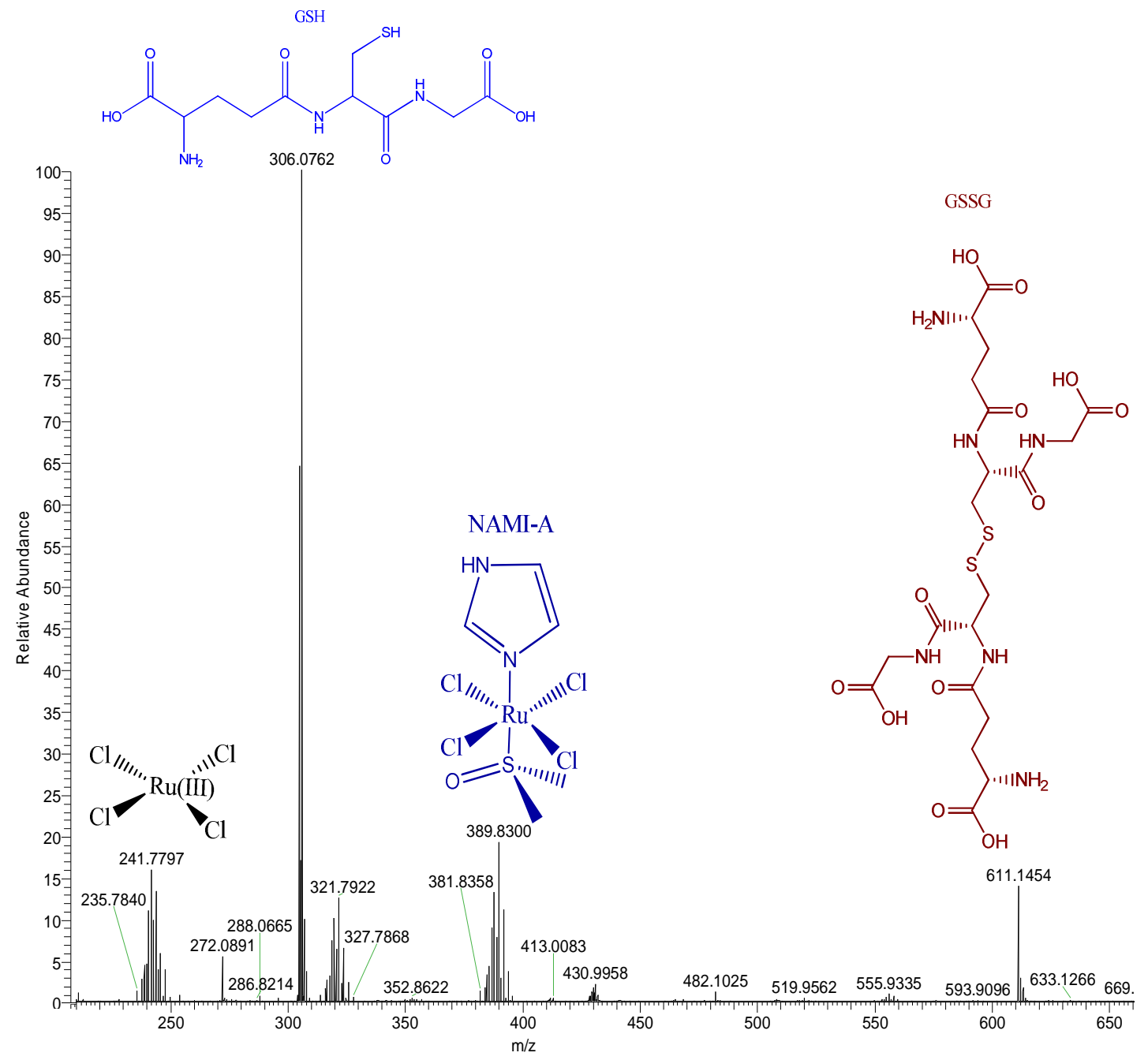

Figure 5-4: Full ESI-MS spectrum of solution in Figure 5-1 taken a minute later. Formation of GSSG was observed. (50\% methanol, negative mode) 
Dianionic NAMI-A was not observed, its obvious absence could be attributed to its short half life. No ions indicating aquation of any of the apical or axial ligands were observed. In the positive mode (Figure 5-5), only ions corresponding to GSH and GSSG were observed in significant relative abundances.

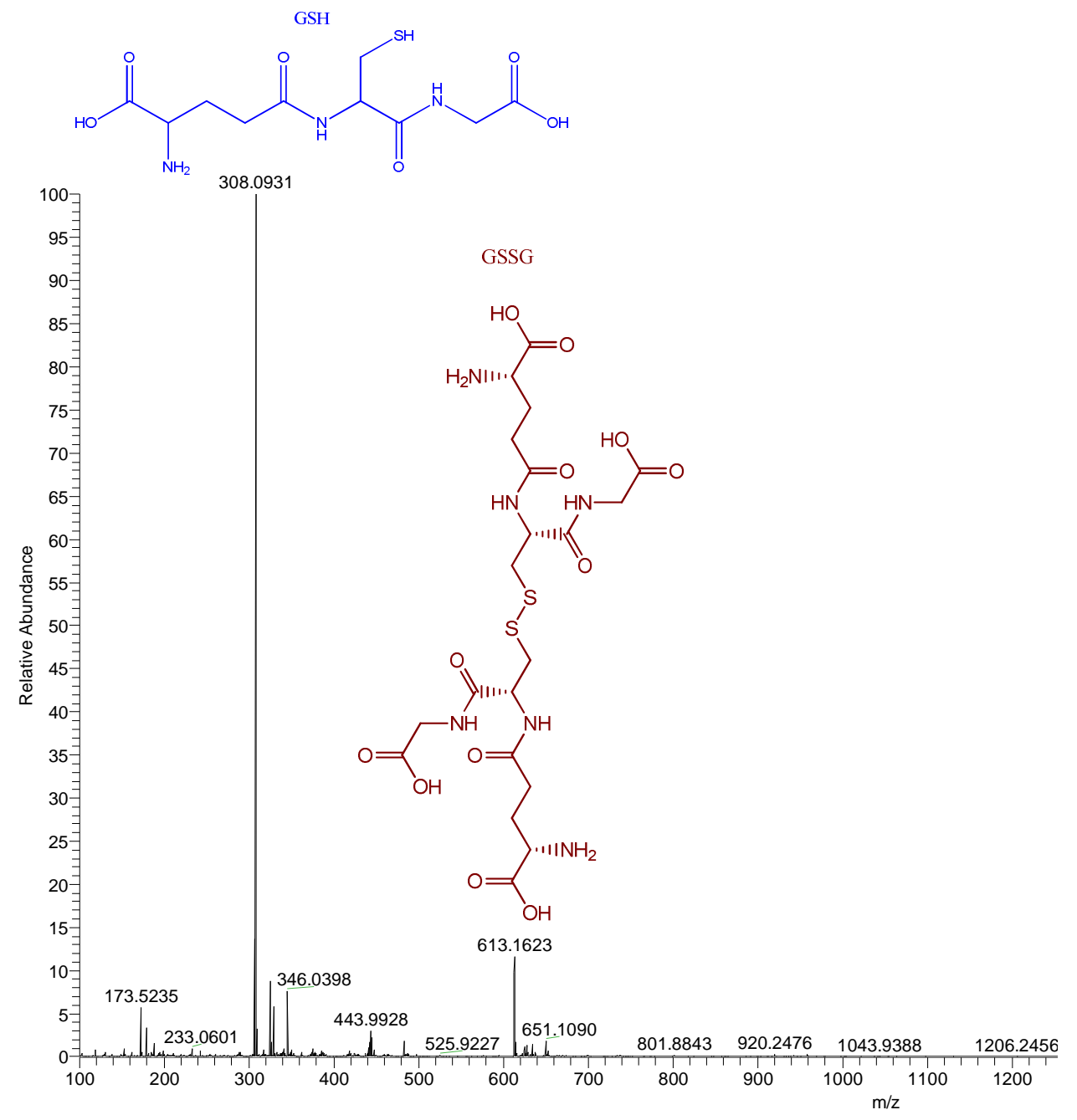

Figure 5-5: Full ESI-MS spectrum of equimolar concentrations of NAMI-A and glutathione ran in the positive mode, showing formation of product, GSSG. (solvent$50 \%$ methanol) 


\subsubsection{Kinetics}

5.2.2.1 NAMI-A dependence: The peak serum concentration, $C_{\max }$, of NAMI-A following administration of recommended safe dose of $300 \mathrm{mg} / \mathrm{m}^{2} /$ day ranged on the average between $1.58 \times 10^{-4} \mathrm{M}$ and $4.00 \times 10^{-4} \mathrm{M}$ for day 1 and day 5 respectively. Sets of initial NAMI-A concentrations were chosen such that highest concentration used is at least bioavailable. Under pseudo first-order conditions of excess GSH (100 - 200 fold), effect of varying initial concentrations of NAMI-A on the reaction at $\mathrm{pH} 7.4$ was examined, see Figure 5-6a.

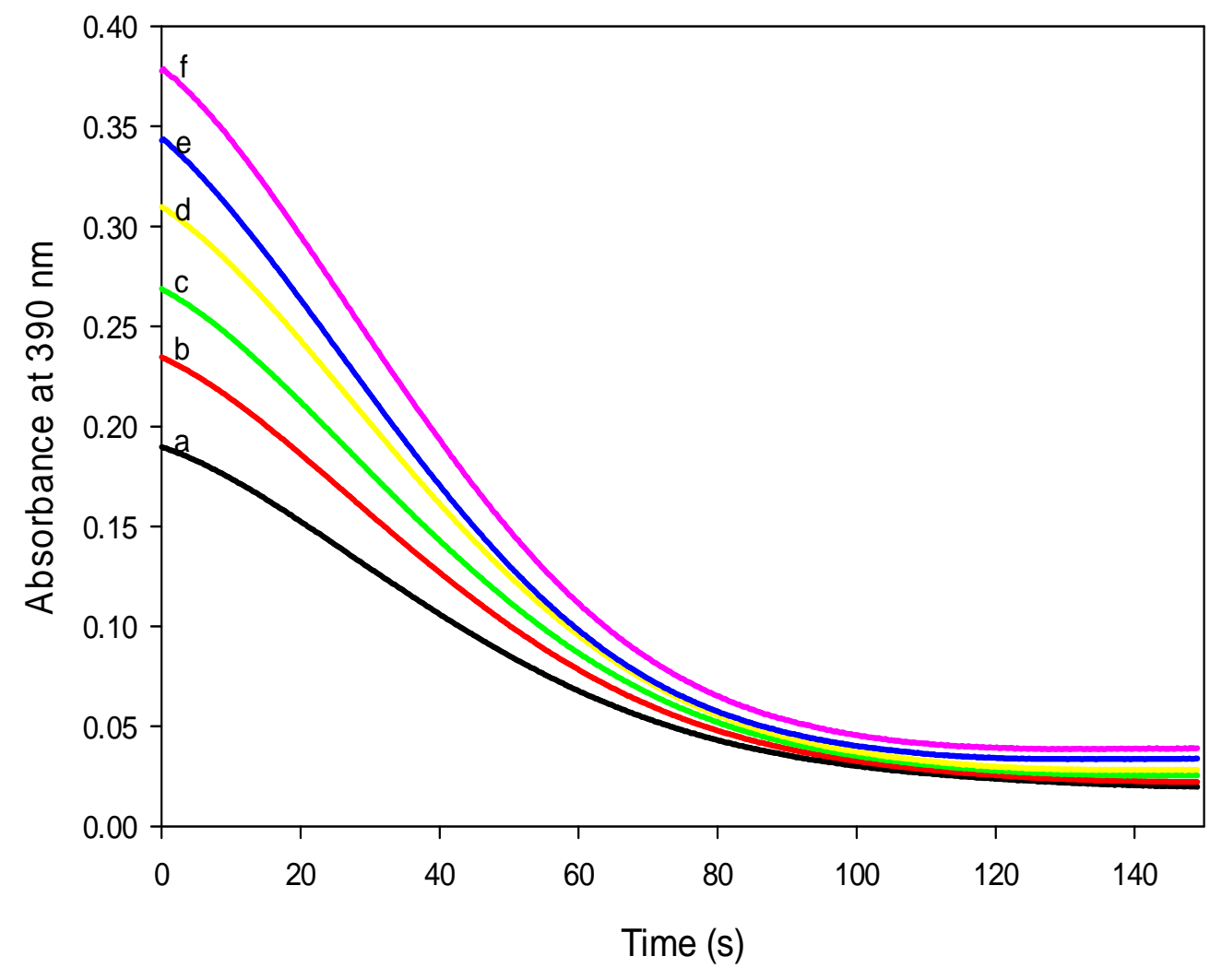

Figure 5-6a: Kinetic traces of reaction in 0.1M phosphate buffer ( $p H$ 7.4) showing dependence on $[N A M I-A]$ at its $\lambda_{\max } \cdot[G S H]_{o}=1.0 \times 10^{-2} \mathrm{M} ;[N A M I-A]_{o}=\left(\right.$ a) $5.0 \times 10^{-5}$ M through (f) $1.0 \times 10^{-4} \mathrm{M}$ 
The rate of consumption of NAMI-A increased with increasing initial NAMI-A concentrations. Initial rates deduced from these data were employed to give Figure 5$6 \mathrm{~b}$, plot of initial rates against NAMI-A concentrations indicates a linear dependence on NAMI-A. Pseudo first-order rate constant was then deduced to be $7.42 \times 10^{-3} \pm 0.0004$ $\mathrm{s}^{-1}$

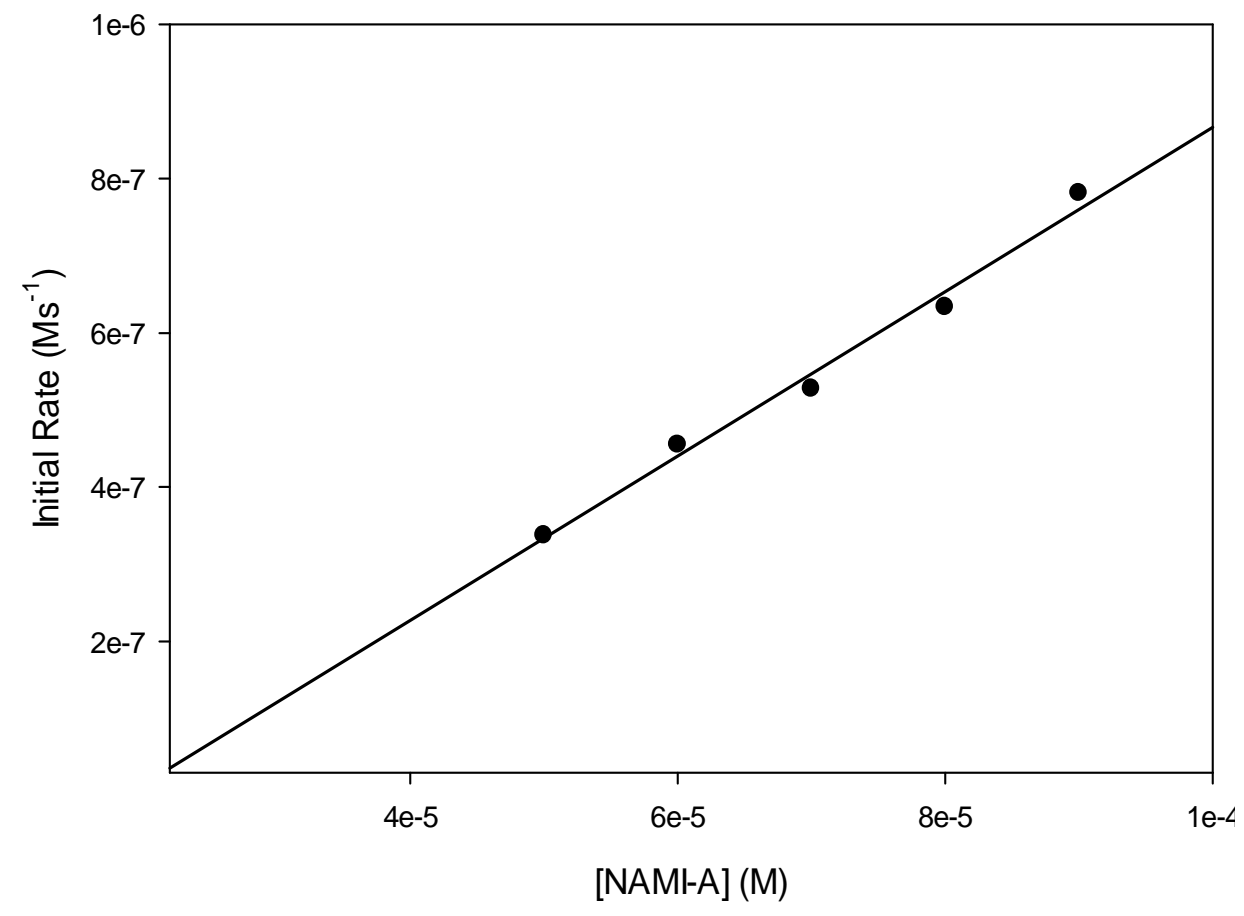

Figure 5-6b: Initial rate plot derived from Figure 3.5a, showing linear dependence on NAMI-A. $[G S H]_{o}=1.0 \times 10^{-3} \mathrm{M} ;[\mathrm{NAMI}-\mathrm{A}]_{o}=5.0 \times 10^{-5} \mathrm{M}$ to $1.0 \times 10^{-4} \mathrm{M}$

5.2.2.2 GSH Dependence: Dependence of the reaction on initial concentrations of GSH (all other reaction conditions fixed) was monitored at $390 \mathrm{~nm}$. Several independent runs of this experiment were performed to confirm the observed trend. A representative plot of the results, Figure 5-7, demonstrates independence of reaction rate on initial GSH 
concentrations. The zero-order dependence of this reaction on GSH concentration thus renders the pseudo-first-order rate constant equivalent to overall reaction rate constant.

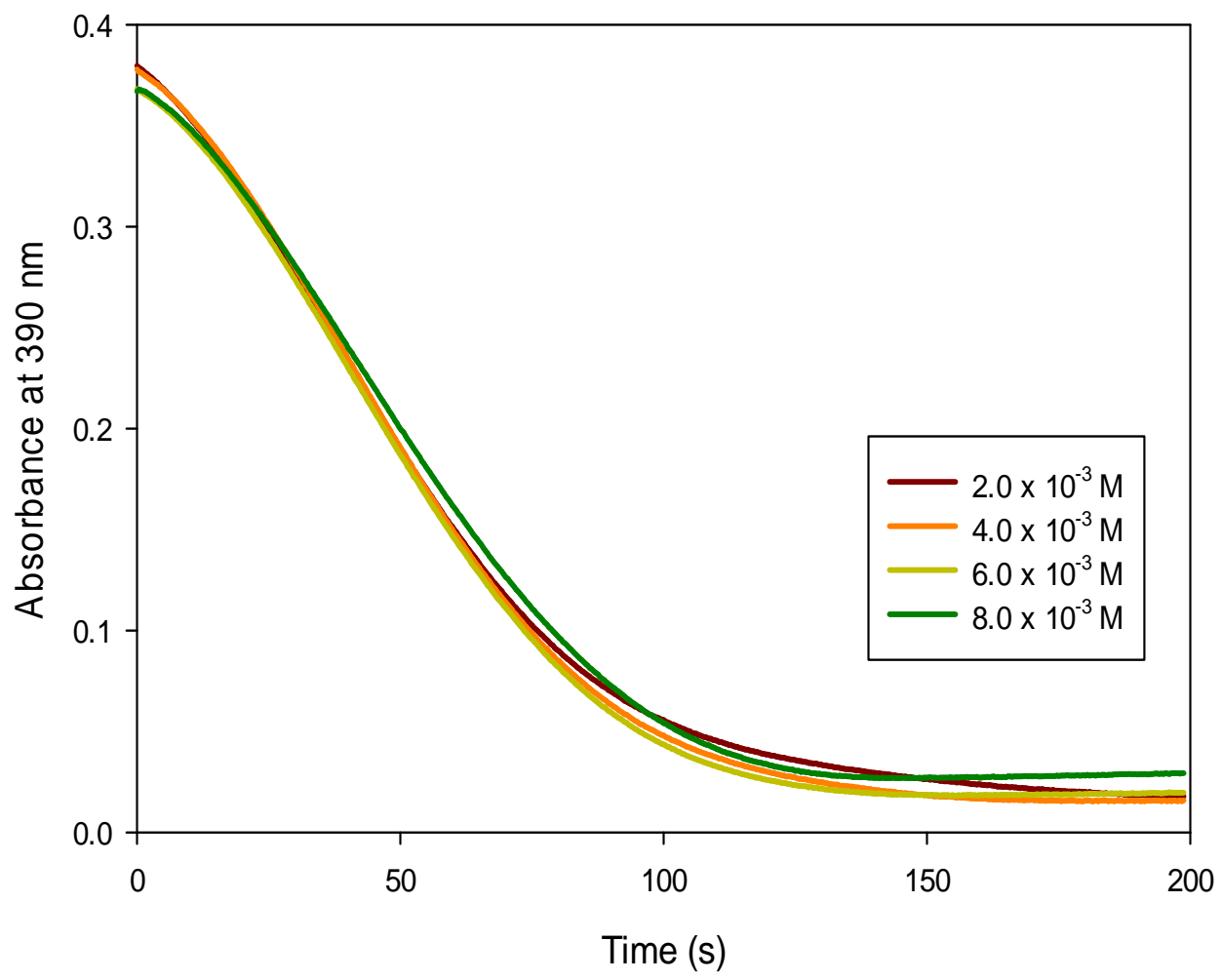

Figure 5-7: Effect of increasing initial GSH concentration on the consumption of NAMI-A at $390 \mathrm{~nm} .[\mathrm{NAMI}-\mathrm{A}]_{o}=1.0 \times 10^{-4} \mathrm{M} ;[\mathrm{I}]=1.0 \mathrm{M},[\mathrm{GSH}]_{o}$ varies from $2.0 \times$ $10^{-3} \mathrm{M}$ to $8.0 \times 10^{-3} \mathrm{M}$

This suggests that GSH is not involved in the rate-determining step and does not affect the transition state. This observation might be suggestive of a chelate formation process. GSH possesses multiple potential binding sites: carboxylic acid, amino, amide and sulfhydryl groups, all of which cannot be coordinated simultaneously to the ruthenium 
center. Species demonstrating the formation of coordinated GSH were not observed on the ESI-MS.

5.2.2.3 Effect of ionic strength: Under unbuffered conditions of constant temperature, oxidant and reductant concentrations, the influence of varying concentrations of an inert salt $\left(\mathrm{NaClO}_{4}\right)$ was evaluated to establish effect of ionic strength on the reaction. Increasing ionic strength slowed down the reaction rate suggesting that the rate determining step contain species of opposite charges.

5.2.2.4 Thermodynamic and activation parameters: Temperature dependence of the reaction was isolated with all other reaction conditions were fixed. Reaction rate increased proportionally with increasing temperature (see Figure 5-8a). Rate constants for individual temperature conditions were obtained using initial rate plots shown in Figure 5-8b. The derived rate constants were used to construct an Arrhenius plot, Figure $5-8 \mathrm{c}$, resulting in the following activation parameters: entropy of activation, $\Delta S^{\neq}=-$ 100.6 $\mathrm{J} \mathrm{K}^{-1} \mathrm{~mol}^{-1}$, enthalpy of activation, $\Delta \mathrm{H}^{\ddagger}=55.1 \mathrm{~kJ} \mathrm{~mol}^{-1}$ and free energy of activation as $\Delta \mathrm{G}^{\neq}=85 \mathrm{~kJ} \mathrm{~mol}^{-1}\left(25^{\circ} \mathrm{C}\right)$. The distinctly negative entropy of activation suggests a more ordered activated transition state compared to the reactants and is indicative of an associative mechanism. 


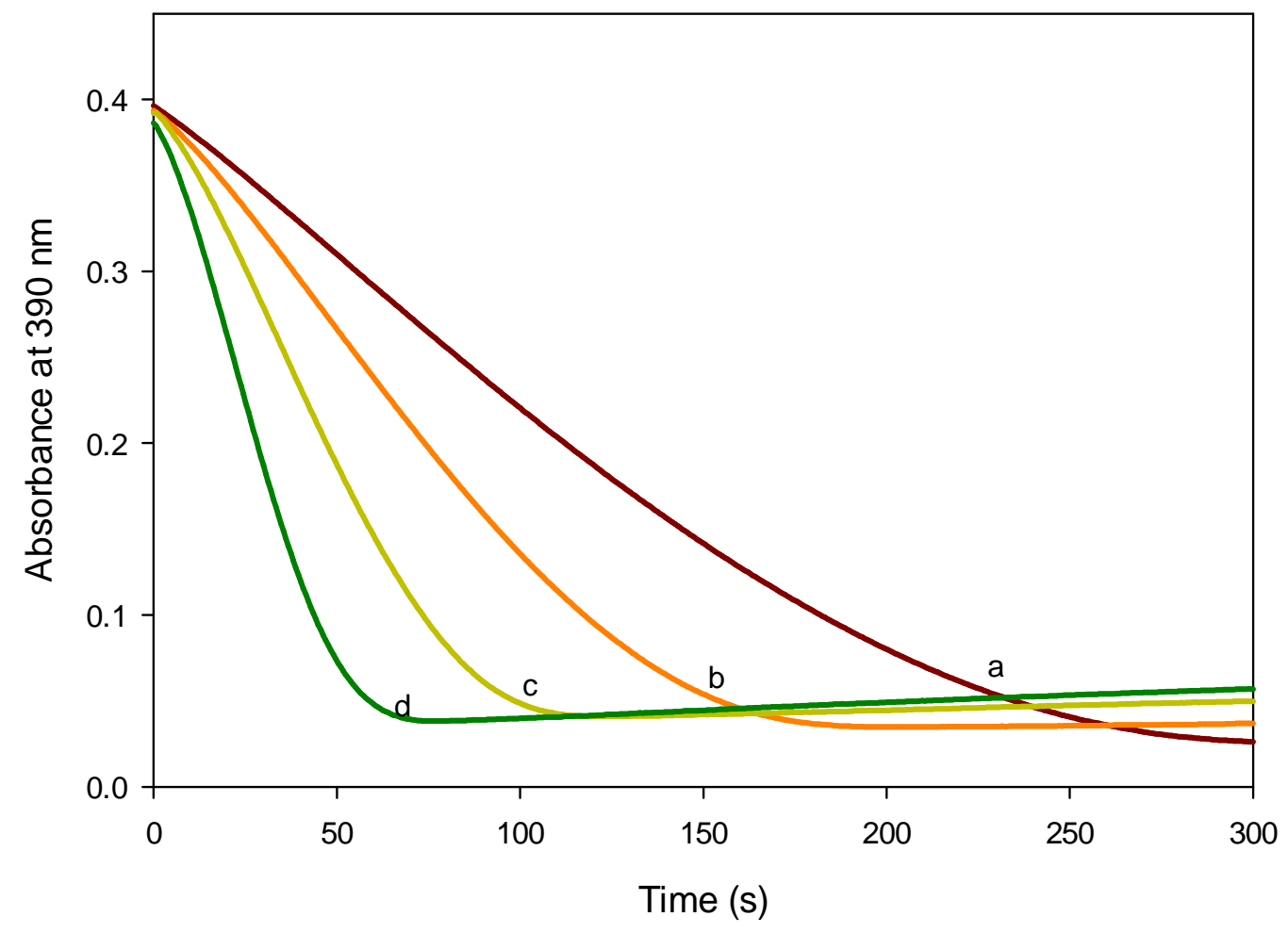

Figure 5-8a: $[N A M I-A]_{o}=1.0 \times 10^{-4} \mathrm{M} ;[\mathrm{GSH}]_{o}=5.0 \times 10^{-2} \mathrm{M}$, Temperature $=($ a) 15 ${ }^{o} \mathrm{C}(\mathrm{b}) 20^{\circ} \mathrm{C}$ (c) $25^{\circ} \mathrm{C}(\mathrm{d}) 30^{\circ} \mathrm{C}$; $\mathrm{pH} 7.4$; Ionic strength maintained at $1.0 \mathrm{M}$ using $\mathrm{NaCl}$ 


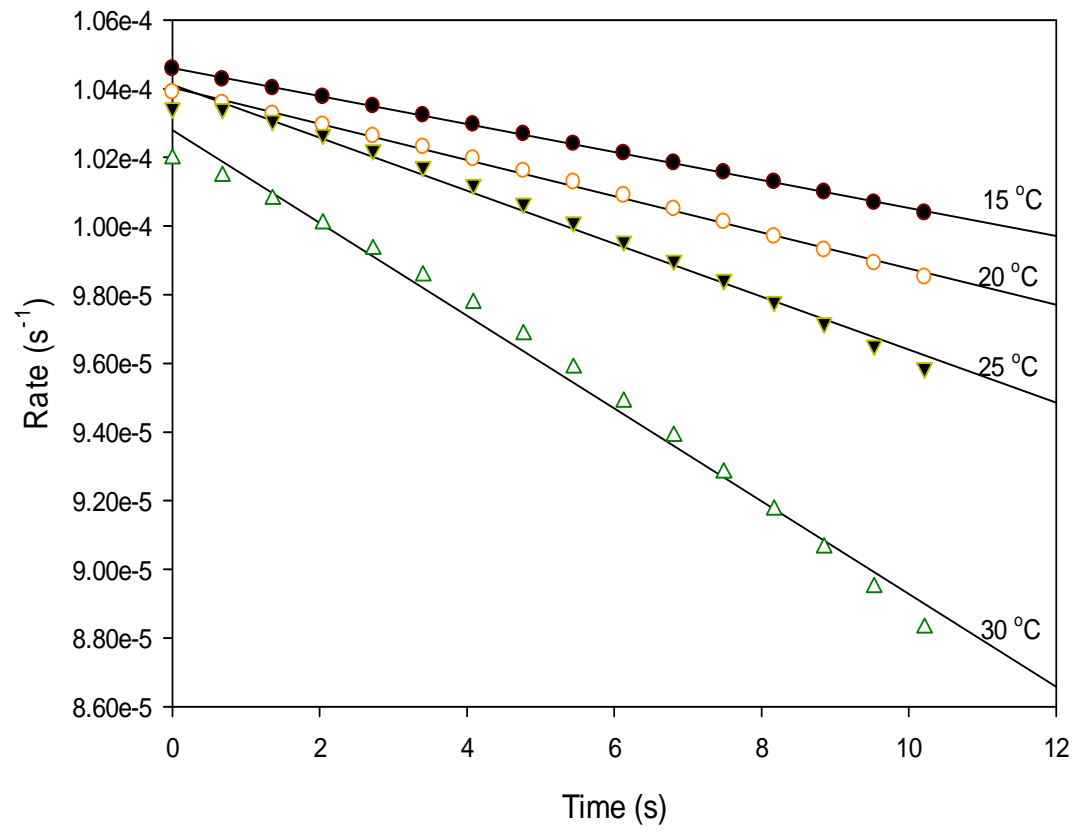

Figure 5-8b: Rate plot from data shown in Figure 5-8a. All reaction conditions same as shown for Figure 5-8a.

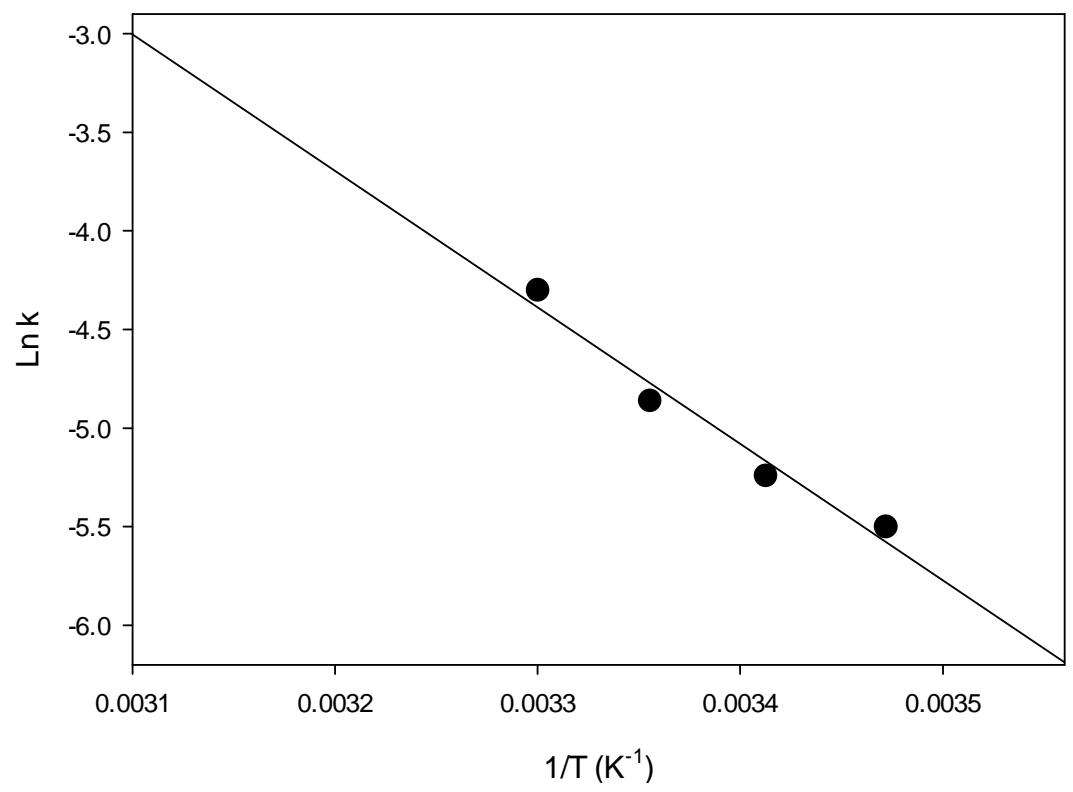

Figure 5-8c: Arrhenius plot extracted from study of effect of temperature (Figure 5-8a) for determination of activation parameters. 


\subsection{Mechanism}

GSH has four pKa values: $2.12,3.59,8.75$ and 9.65 for its carboxylic, thiol and amine functional groups. At $\mathrm{pH} 7.4$, at which reactions were performed, both carboxylic groups are expectedly deprotonated while thiol and amine groups are protonated. ${ }^{221}$ These dissociations are represented by $\mathrm{R} 1-\mathrm{R} 3$, where $\mathrm{HO}_{2} \mathrm{CCH}\left(\mathrm{NH}_{2}\right)(\mathrm{SH}) \mathrm{RCO}_{2} \mathrm{H}$ represents GSH.

$$
\begin{aligned}
& \mathrm{HO}_{2} \mathrm{CCH}\left(\mathrm{NH}_{2}\right)(\mathrm{SH}) \mathrm{RCO}_{2} \mathrm{H} \rightleftharpoons{ }^{-} \mathrm{O}_{2} \mathrm{CCH}\left(\mathrm{NH}_{2}\right)(\mathrm{SH}) \mathrm{RCO}_{2} \mathrm{H}+\mathrm{H}^{+} \mathrm{K}_{\mathrm{a} 1} \mathrm{R} 1 \\
& { }^{-} \mathrm{O}_{2} \mathrm{CCH}\left(\mathrm{NH}_{2}\right)(\mathrm{SH}) \mathrm{RCO}_{2} \mathrm{H} \rightleftharpoons{ }^{-} \mathrm{O}_{2} \mathrm{CCH}\left(\mathrm{NH}_{2}\right)(\mathrm{SH}) \mathrm{RCO}_{2}{ }^{-}+\mathrm{H}^{+} \quad \mathrm{K}_{\mathrm{a} 2} \quad \mathrm{R} 2 \\
& { }^{-} \mathrm{O}_{2} \mathrm{CCH}\left(\mathrm{NH}_{2}\right)(\mathrm{SH}) \mathrm{RCO}_{2}{ }^{-}+\mathrm{H}^{+} \rightleftharpoons{ }^{-} \mathrm{O}_{2} \mathrm{CCH}\left({ }^{+} \mathrm{NH}_{3}\right)(\mathrm{SH}) \mathrm{RCO}_{2}{ }^{-} \quad \mathrm{K}_{\mathrm{b}} \quad \mathrm{R} 3
\end{aligned}
$$

GSH will have a predominant net charge of -1 . All of the different GSH forms will react with NAMI-A to form more ordered transition state, see R4 - R6.

$$
\begin{aligned}
& { }^{-} \mathrm{O}_{2} \mathrm{CCH}\left(\mathrm{NH}_{2}\right)(\mathrm{SH}) \mathrm{RCO}_{2} \mathrm{H}+\left[\mathrm{ImRuCl}_{4} \mathrm{DMSO}^{-}\right. \\
& \rightarrow \quad\left[{ }^{-} \mathrm{O}_{2} \mathrm{CCH}\left(\mathrm{NH}_{2}\right)(\mathrm{SH}) \mathrm{RCO}_{2} \mathrm{H} \ldots\left[\mathrm{ImRuCl}_{4} \mathrm{DMSO}^{-}\right]^{\neq} \quad \mathrm{k}_{1} \quad \mathrm{R} 4\right. \\
& { }^{-} \mathrm{O}_{2} \mathrm{CCH}\left(\mathrm{NH}_{2}\right)(\mathrm{SH}) \mathrm{RCO}_{2}{ }^{-}+\left[\mathrm{ImRuCl}_{4} \mathrm{DMSO}^{-} \rightarrow\right. \\
& {\left[{ }^{-} \mathrm{O}_{2} \mathrm{CCH}\left(\mathrm{NH}_{2}\right)(\mathrm{SH}) \mathrm{RCO}_{2}{ }^{-} \ldots\left[\mathrm{ImRuCl}_{4} \mathrm{DMSO}^{-}\right]^{\neq} \quad \mathrm{k}_{2} \quad \mathrm{R} 5\right.} \\
& { }^{-} \mathrm{O}_{2} \mathrm{CCH}\left({ }^{+} \mathrm{NH}_{3}\right)(\mathrm{SH}) \mathrm{RCO}_{2}{ }^{-}+\left[\mathrm{ImRuCl}_{4} \mathrm{DMSO}\right]^{-} \\
& \rightarrow \quad\left[{ }^{-} \mathrm{O}_{2} \mathrm{CCH}\left({ }^{+} \mathrm{NH}_{3}\right)(\mathrm{SH}) \mathrm{RCO}_{2}{ }^{-} \ldots\left[\mathrm{ImRuCl}_{4} \mathrm{DMSO}^{-}\right]^{\neq} \quad \mathrm{k}_{3} \quad \mathrm{R} 6\right.
\end{aligned}
$$


Representing all associative complexes by $\mathrm{X}$ and all different forms of glutathione by $\mathrm{GSH}_{\mathrm{T}}$, the reaction can be written as $\mathrm{R} 7$

$$
\begin{array}{rrrr}
{\left[\mathrm{ImRuCl}_{4} \mathrm{DMSO}\right]} & +\mathrm{GSH}_{\mathrm{T}} \rightleftharpoons \mathrm{X} & \mathrm{K}_{4} & \mathrm{R} 7 \\
\mathrm{X} & \rightarrow \text { Products } & k_{5} & \mathrm{R} 8
\end{array}
$$

where products are oxidized GSSG and $\left[\mathrm{ImRuCl}_{4} \mathrm{DMSO}\right]^{2-}$. Rate of product formation can then be written as

$$
\begin{array}{lll}
\text { Rate }=k_{5}[\mathrm{X}] & \mathrm{E} 4
\end{array}
$$

From R7,

$$
K_{4}^{-1}=\frac{\left[\mathrm{ImRuCl}_{4} \mathrm{DMSO}\right][\mathrm{GSH}]_{\mathrm{T}}}{[\mathrm{X}]}
$$

From mass balance,

$$
\left[\mathrm{ImRuCl}_{4} \mathrm{DMSO}^{-}\right]=\left[\mathrm{ImRuCl}_{4} \mathrm{DMSO}^{-}\right]_{\mathrm{o}}-[\mathrm{X}] \quad \mathrm{E} 6
$$

substituting for $\left[\mathrm{ImRuCl}_{4} \mathrm{DMSO}^{-}\right]$in E5 implies

$$
K_{4}^{-1}=\frac{\left(\left[\mathrm{ImRuCl}_{4} \mathrm{DMSO}^{-}\right]_{\mathrm{o}}-[\mathrm{X}]\right)[\mathrm{GSH}]_{\mathrm{T}}}{[\mathrm{X}]}
$$

and

$$
[\mathrm{X}]=\frac{\left[\mathrm{ImRuCl}_{4} \mathrm{DMSO}^{-}\right]_{\mathrm{o}}[\mathrm{GSH}]_{\mathrm{T}}}{K_{4}+[\mathrm{GSH}]_{\mathrm{T}}}
$$


Substituting for $[\mathrm{X}]$ in the rate expression, $\mathrm{E} 5$,

$$
\text { Rate }=\frac{k_{5}\left[\mathrm{ImRuCl}_{4} \mathrm{DMSO}^{-}\right]_{\mathrm{o}}[\mathrm{GSH}]_{\mathrm{T}}}{K_{4}+[\mathrm{GSH}]_{\mathrm{T}}}
$$

The reaction shows a complex dependence on glutathione concentration as seen in E9. At low $[\mathrm{GSH}]$, where $[\mathrm{GSH}]_{\mathrm{T}}<<\mathrm{K}_{4}$, the rate becomes first order in $[\mathrm{GSH}]$ but at high [GSH], when $[\mathrm{GSH}]>\mathrm{K}_{4}$, rate becomes zero order in [GSH]. At high [GSH] under which reaction was performed,

$$
\text { Rate }=\frac{k_{5}\left[\mathrm{ImRuCl}_{4} \mathrm{DMSO}^{-}\right]_{\mathrm{o}}}{K_{4}}
$$

which can be written as

$$
\text { Rate }=k_{o}\left[\operatorname{ImRuCl}_{4} \mathrm{DMSO}^{-}\right]_{\mathrm{o}}
$$

where $k_{o}$ is $k_{5} / K_{4}$. This is in agreement with experimental observation as demonstrated by Figure 5.7.

Ligand substitution reactions are expected to occur especially following formation of the reduced form of NAMI-A. Evidence is lacking however, on suggestion of possible structures. 
In conclusion, independence of NAMI-A reaction with GSH on initial GSH concentrations might suggest that administration of NAMI-A will not adversely affect cellular detoxification (those dependent on GSH), in agreement with its reported low host toxicity. ${ }^{162}$ 


\section{CHAPTER SIX}

\subsection{Kinetics and Mechanism of interaction of NAMI-A by L-Cysteine}

\subsection{Introduction}

Cysteine is a non-essential amino acid that exists in various forms in vivo due to the different accessible oxidation states of sulfur, -2 to +6 . It is the only sulfur contributor and the rate-limiting substrate in the biosynthesis of GSH, the most abundant non-protein antioxidant. ${ }^{264}$ The ability of cysteine to undergo redox cycling is involved in many protein functions and redox-reactions in biological systems. Cysteine has been reported to be one of the few biological thiols that have inhibitory effects on direct acting and indirect-acting mutagens. ${ }^{265}$

Cysteine is a component responsible for many protein/enzyme structure and functions by modifications to the sulfhydryl functional group. ${ }^{266}$ The most abundant protein found in plasma is Human serum albumin (HSA) which transports blood solutes to target organs and maintain $\mathrm{pH}$ and osmotic pressure. HSA contains 35 cysteine residues in the form of 17 pairs of intramolecular disulfides and one free thiol, Cys-34. It is noteworthy that this lone free thiol in HSA accounts for almost $80 \%$ of plasma thiol and most of its antioxidant capacity. ${ }^{267-269}$

Mutation of tumor suppressor gene, p53, is a common characteristic of a wide variety of human cancers. ${ }^{270-273}$ This is not surprising since p53 plays significant role in a wide range of biochemical processes including: cell cycle regulation, DNA repair, programmed cell death among others. ${ }^{274}$ p53 protein contains 393 amino acids, modifications of cysteine residues in its central core (see Figure 6-1) critically affects its 
functions. This is largely due to occurrence of most p53 interactions with target proteins in the central core. ${ }^{274-276}$ Report has also shown involvement of cysteine residues in suppression of transactivation and transformation functions of $\mathrm{p} 53 .{ }^{277}$

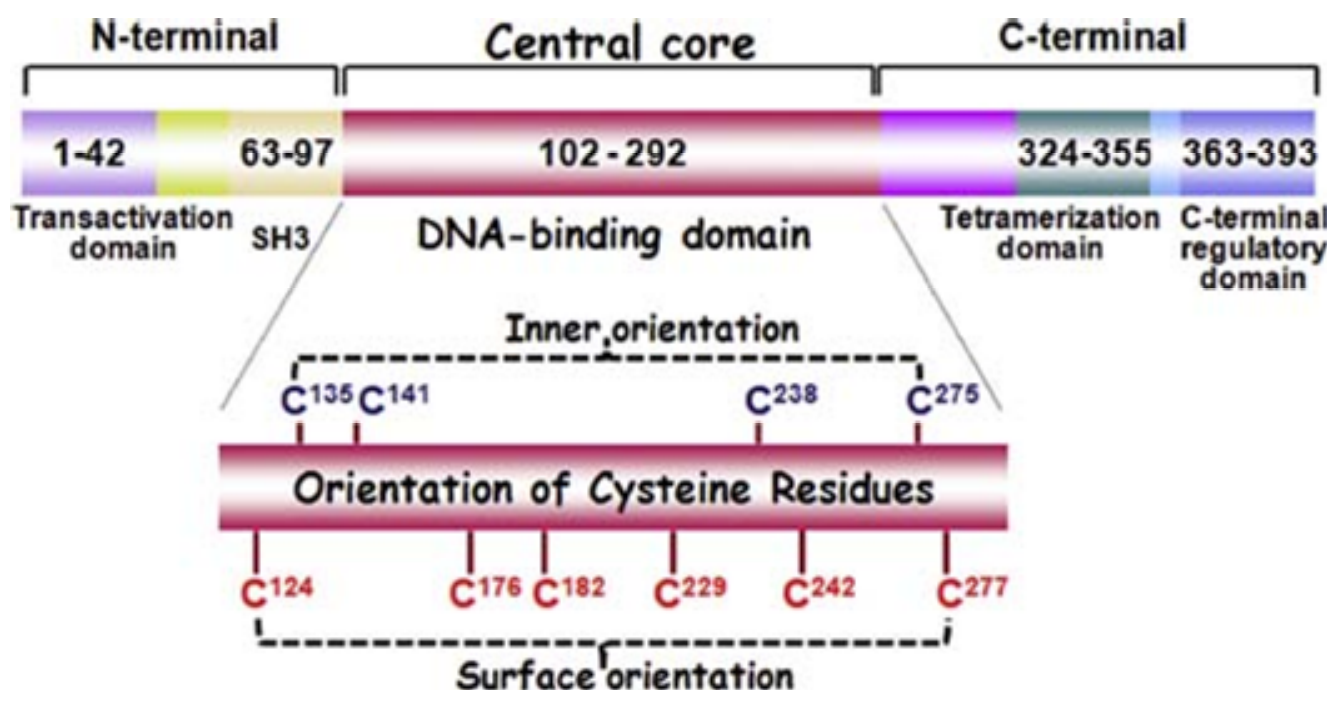

Figure 6-1: Functional domains of p53. The DNA-binding domain contains 10 cysteine residues that affect its functions. (Adapted from Kim, D. et al ${ }^{274}$ )

Also of importance is the role of cysteine in the activity of macrophage migration inhibitory factor, MIF, a protein involved in cell-mediated immunity, immuno-regulation, and inflammation. It effectively modulates p53 activities. It has been reported that a specific cysteine residue, 81 , (Cys-81) plays a critical role in MIFinduced inhibition of p53 activity. ${ }^{278}$

Studying interaction of a drug candidate with cysteine can be regarded in one part, as investigating the reaction of the potential drug with a free amino acid and in another model the interaction of such drug candidate with all intracellular peptides, 
proteins and enzymes containing cysteine residues. An investigation of the reactivity of NAMI-A with cysteine is therefore of high biological relevance. Results are thus presented in this chapter for the reactivity of NAMI-A with cysteine.

\subsection{Results and Discussions}

6.2.1 Stoichiometry and Product Identification: Reaction stoichiometry was determined using residual absorbance measurements of different ratios of NAMI-A to cysteine recorded within 10 minutes of solution preparation. The plot of residual absorbance at $390 \mathrm{~nm}$ against NAMI-A : cysteine ratio, Figure 6-2, clearly demonstrate significant residual NAMI-A in solution at ratios above the stoichiometry. Therefore, one mole of cysteine reacts with one mole of NAMI-A to form cystine (disulfide of cysteine) and reduced form of NAMI-A as shown in reaction R1. RSH, RSSR, $\left[\mathrm{ImRuCl}_{4} \mathrm{DMSO}\right]^{-}$and $\left[\mathrm{ImRuCl}_{4} \mathrm{DMSO}\right]^{2-}$ represent cysteine, cystine, NAMI-A and reduced NAMI-A respectively.

$2 \mathrm{RSH}+2\left[\mathrm{ImRuCl}_{4} \mathrm{DMSO}^{-} \rightarrow \mathrm{RSSR}+2\left[\mathrm{ImRuCl}_{4} \mathrm{DMSO}\right]^{2-}+2 \mathrm{H}^{+}\right.$ R1

Figure 6-3 shows the spectral changes observed from a solution of cysteine and NAMI-A scanned at 30 second intervals. The characteristic absorption of NAMI-A at $390 \mathrm{~nm}$ decreased as the reaction progressed indicating conversion of [ $\left.\mathrm{ImRuCl}_{4} \mathrm{DMSO}\right]^{-}$ to $\left[\mathrm{ImRuCl}{ }_{4} \mathrm{DMSO}\right]^{2-}$. 


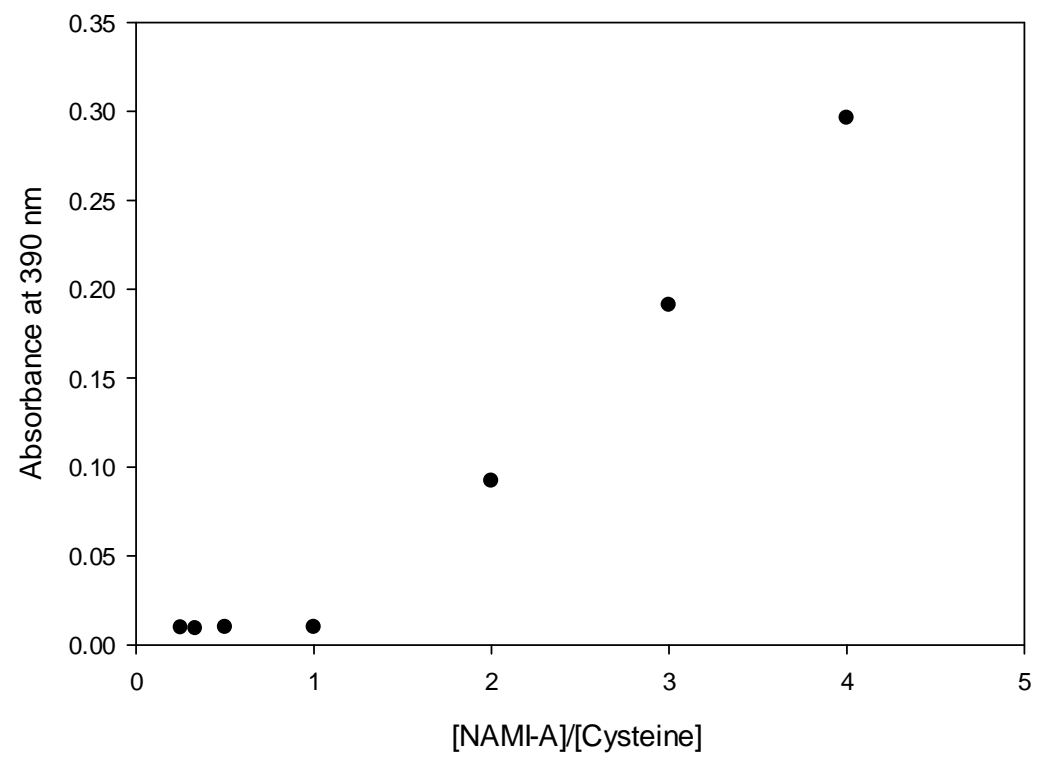

Figure 6-2: Plot of Residual absorbance of NAMI-A against NAMI-A/cysteine revealing stoichiometric ratio beyond which residual absorbance persists. [NAMI-A]/[cysteine] $=$ $0.25,0.33,0.5,1.0,2.0,3.0$ and 4.0 .

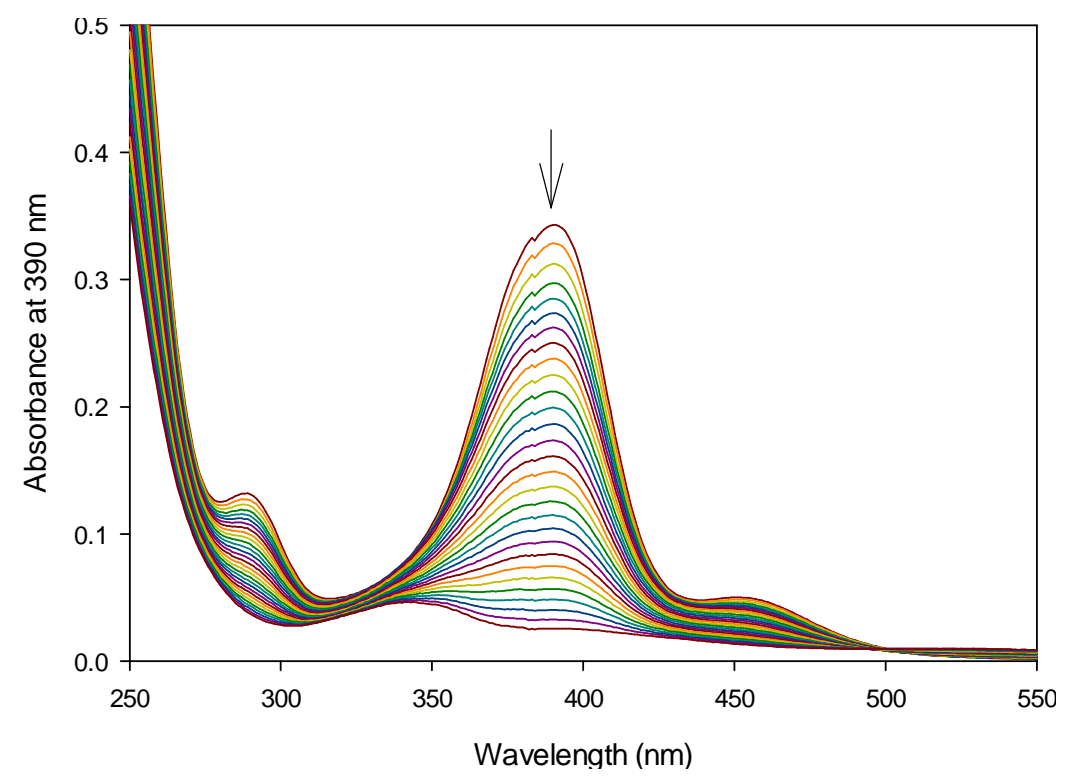

Figure 6-3: Rapid spectral scan of solution of cysteine and NAMI-A taken at $5 \mathrm{~s}$ interval. $[\text { cysteine }]_{o}=4.0 \times 10^{-4} \mathrm{M} ;[\mathrm{NAMI}-\mathrm{A}]_{o}=1.0 \times 10^{-4} \mathrm{M} ;$ no added buffer . 
Absence of clearly defined isobestic points might suggest involvement of intermediates of kinetic significance during this reduction reaction. A full electrospray ionization mass spectrum of stoichiometric solution was taken in the negative mode (Figure 6-4a) within the $60 \mathrm{~s}$ of mixing. Ions representing [ $\left.\mathrm{ImRuCl}_{4} \mathrm{DMSO}\right]^{-}$, $\left.\left[\mathrm{RuCl}_{4} \mathrm{DMSO}\right]^{-}, \mathrm{RuCl}_{4}\right]^{-}$and $[\mathrm{Cys}-\mathrm{H}]^{-}$were observed at 390, 322, 244 and $120 \mathrm{~m} / \mathrm{z}$ respectively. One electron oxidation of GSH should result in formation of cystine and dianionic NAMI-A. An ESI-MS spectrum of the same solution taken in the negative mode a minute later, Figure 6-4b, demonstrates cystine formation ([cystine-H] with 239 $\mathrm{m} / \mathrm{z}$ ). The peak at $209 \mathrm{~m} / \mathrm{z}$ was not stable; compare Figure 6-4a and b. The m/z changed between scans, this could mean multiple ions with about the same m/z. Ions showing most abundance at this $\mathrm{m} / \mathrm{z}$ have a basic structure, $\left[\mathrm{RuCl}_{2}\left(\mathrm{H}_{2} \mathrm{O}\right)_{2}\right]$, switching between $\left[\mathrm{RuCl}_{2}\left(\mathrm{H}_{2} \mathrm{O}\right)_{2}+\mathrm{H}\right]$ and $\left[\mathrm{RuCl}_{2}\left(\mathrm{H}_{2} \mathrm{O}\right)_{2}-\mathrm{H}\right]$. These could arise from: loss of both apical ligands from reduced NAMI-A with exchange of two of the $\mathrm{Cl}^{-}$for aquo ligands; or electron transfer to the $\mathrm{Ru}^{3+}$ center of 243 and $321 \mathrm{~m} / \mathrm{z}$ from cysteine followed by appropriate ligand exchange. However, the lack of corresponding increase in relative abundance of the 209 peak with consumption of 243 and $321 \mathrm{~m} / \mathrm{z}$ strongly support formation from reduced NAMI-A. In the positive mode, formation of cystine with 241 $\mathrm{m} / \mathrm{z}$ is confirmed, Figure 6-4c. 


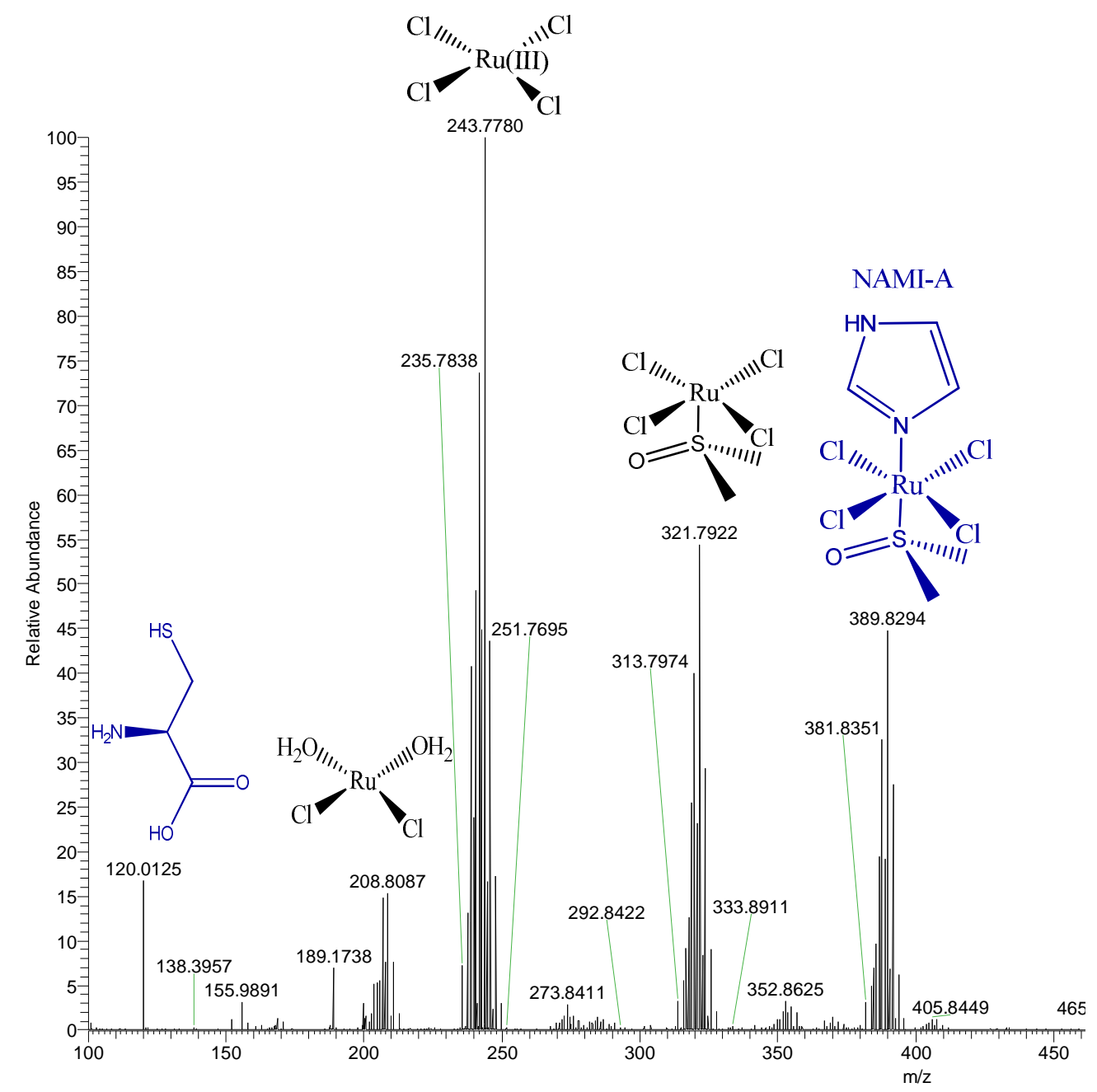

Figure 6-4a: Full ESI-MS (negative mode) spectrum of 1:1 ratio of NAMI-A to Cysteine taken within the first minute of the reaction in $50 \%$ methanol. 


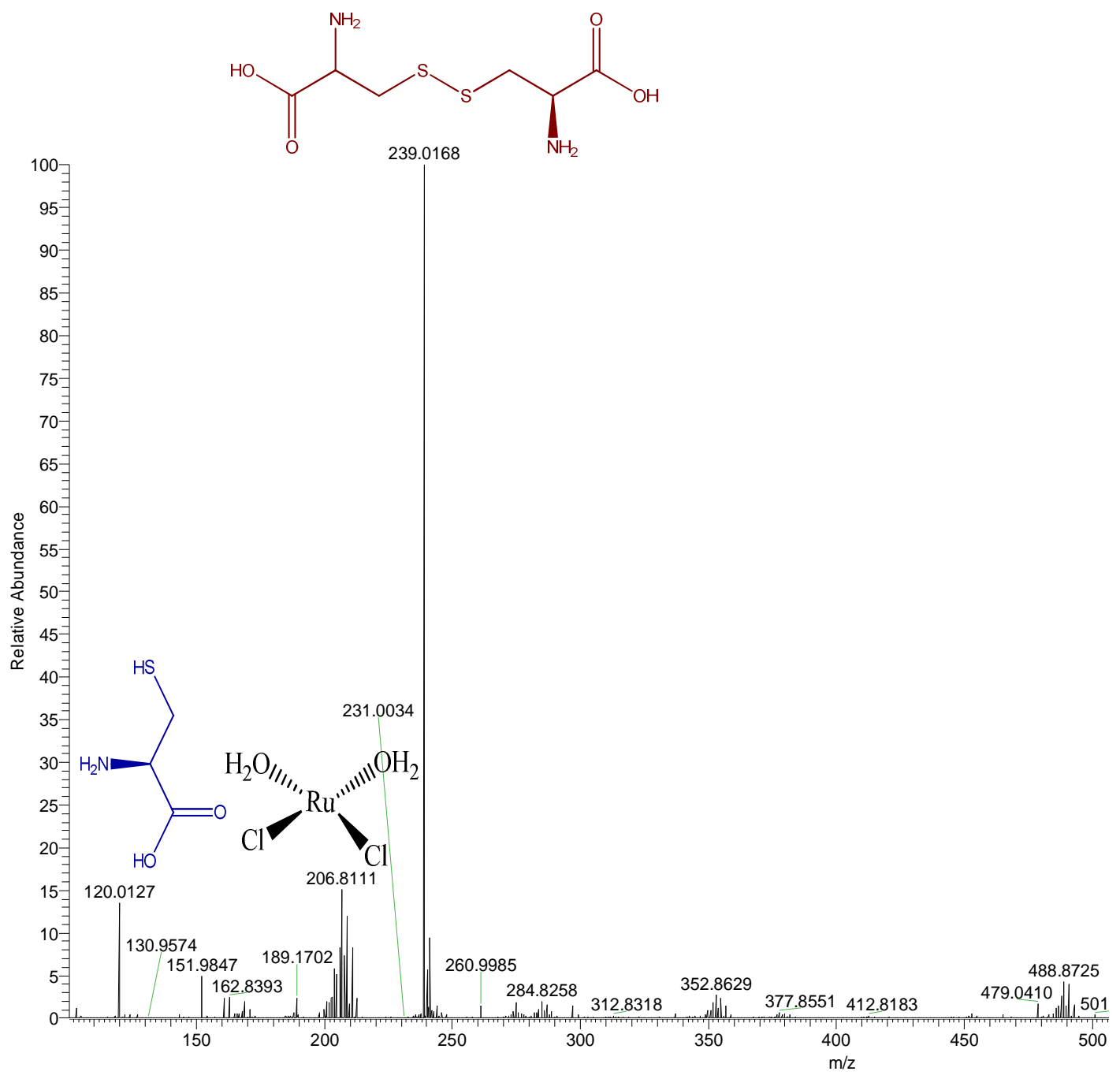

Figure 6-4b: Full ESI-MS (negative mode) spectrum of 1:1 ratio of NAMI-A to

Cysteine taken a minute later. Showing cystine and hydrolyzed NAMI-A (Solvent is 50\% methanol). 


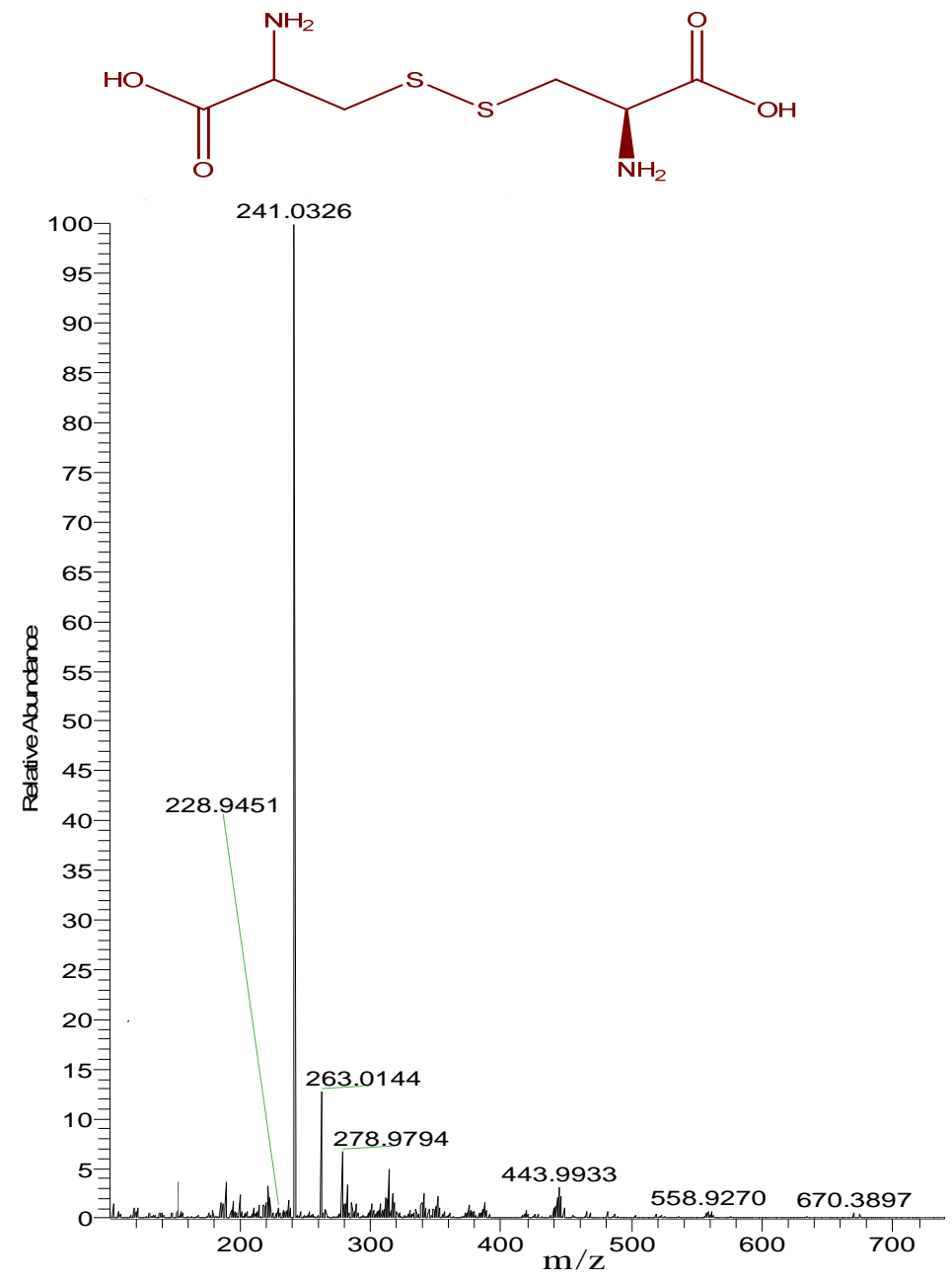

Figure 6-4c: Full ESI-MS (positive mode) spectrum of product solution of 1:1 ratio of NAMI-A to Cysteine showing formation of cystine ( $t=3$ mins $)$.

\subsubsection{Kinetics}

6.2.2.1 NAMI-A Dependence: Under pseudo-first order conditions of excess cysteine, dependence of the present reaction on NAMI-A concentration was examined. Reaction rate increased with increase in initial NAMI-A concentrations as seen in Figure 6-7. Initial rate plot deduced from this confers a linear dependence on cysteine, see Figure 6- 
7 inset. Under these reaction conditions, cysteine concentrations effectively remained unchanged during the reaction leading to deduction of an observed rate constant of 9.40 $\mathrm{x} 10^{-2} \pm 0.005 \mathrm{~s}^{-1}$.

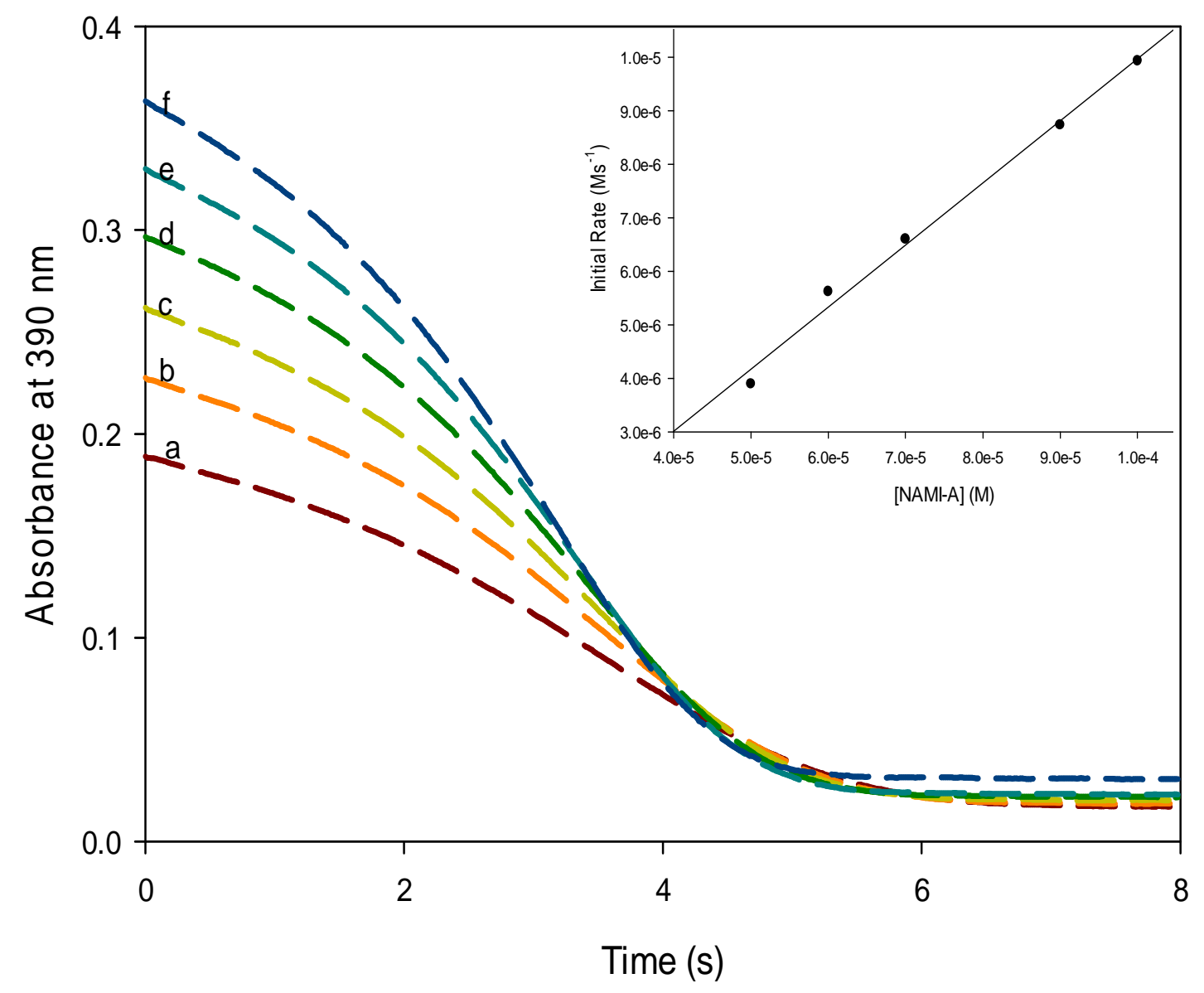

Figure 6-7: Kinetic traces of reaction in phosphate buffer ( $p H$ 7.4) showing dependence on $[N A M I-A]$ at its $\lambda_{\max }, 390 \mathrm{~nm}$. $[\text { cysteine }]_{o}=5.0 \times 10^{-2} \mathrm{M} ;[N A M I-A]_{o}=$ (a) $5.0 \times 10^{-5} \mathrm{M}$ (b) $6.0 \times 10^{-5} \mathrm{M}$ (c) $7.0 \times 10^{-5} \mathrm{M}$ (d) $6.0 \times 10^{-5} \mathrm{M}$ (e) $9.0 \times 10^{-5} \mathrm{M}$ (f) 1.0 $\times 10^{-4} \mathrm{M}$. Inset: Initial rate plot showing linear dependence on NAMI-A. 
6.2.2.2 Cysteine Dependence: Influence of varying initial concentration of cysteine was examined under $\mathrm{pH} 7.4$ and in condition of no added buffer. Rate of reaction increased with increasing initial cysteine concentration as seen in Figures 6-8a and b. Reactions rates were faster at $\mathrm{pH} 7.4$ than no added buffer conditions.

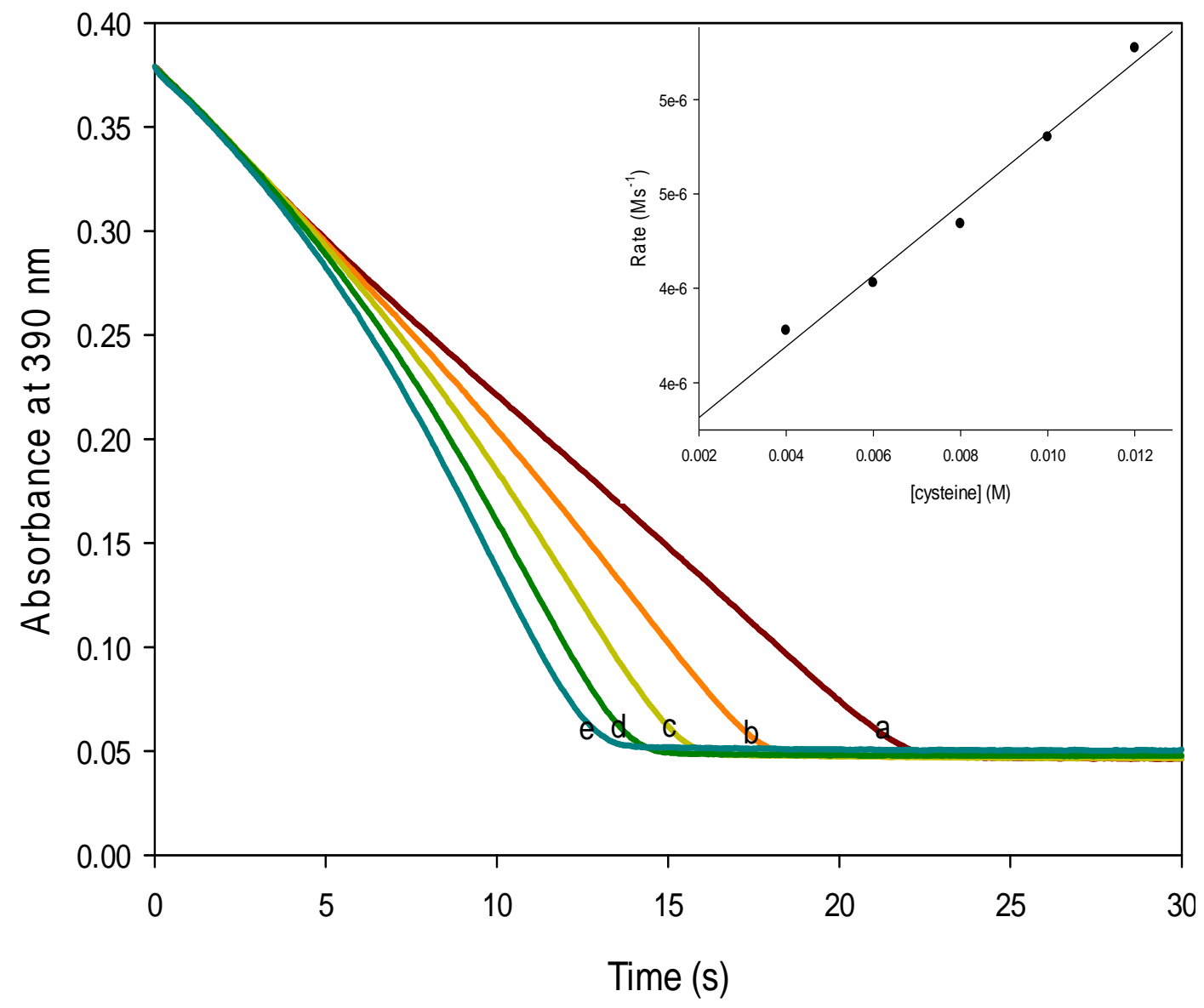

Figure 6-8a: Effect of changing initial concentrations of cysteine on NAMI-A-cysteine reaction at $\mathrm{pH}$ 7.4. $[\mathrm{NAMI-A}]_{o}=1.0 \times 10^{-4} \mathrm{M} ;[\text { Cysteine }]_{o}=\left(\right.$ a) $4.0 \times 10^{-3} \mathrm{M}(\mathrm{b}) 6.0 \times$ $10^{-3} \mathrm{M}(\mathrm{c}) 8.0 \times 10^{-3} \mathrm{M}(\mathrm{d}) 1.0 \times 10^{-2} \mathrm{M}(\mathrm{e}) 1.2 \times 10^{-2} \mathrm{M}$. Inset: Plot of initial rate deduced from cysteine dependence conferring a linear dependence on cysteine. 
Documented stability of NAMI-A at lower $\mathrm{pH}$ should be considered responsible for this observation. ${ }^{84 ; 245}$ Difference is only expected in rates under the two conditions.

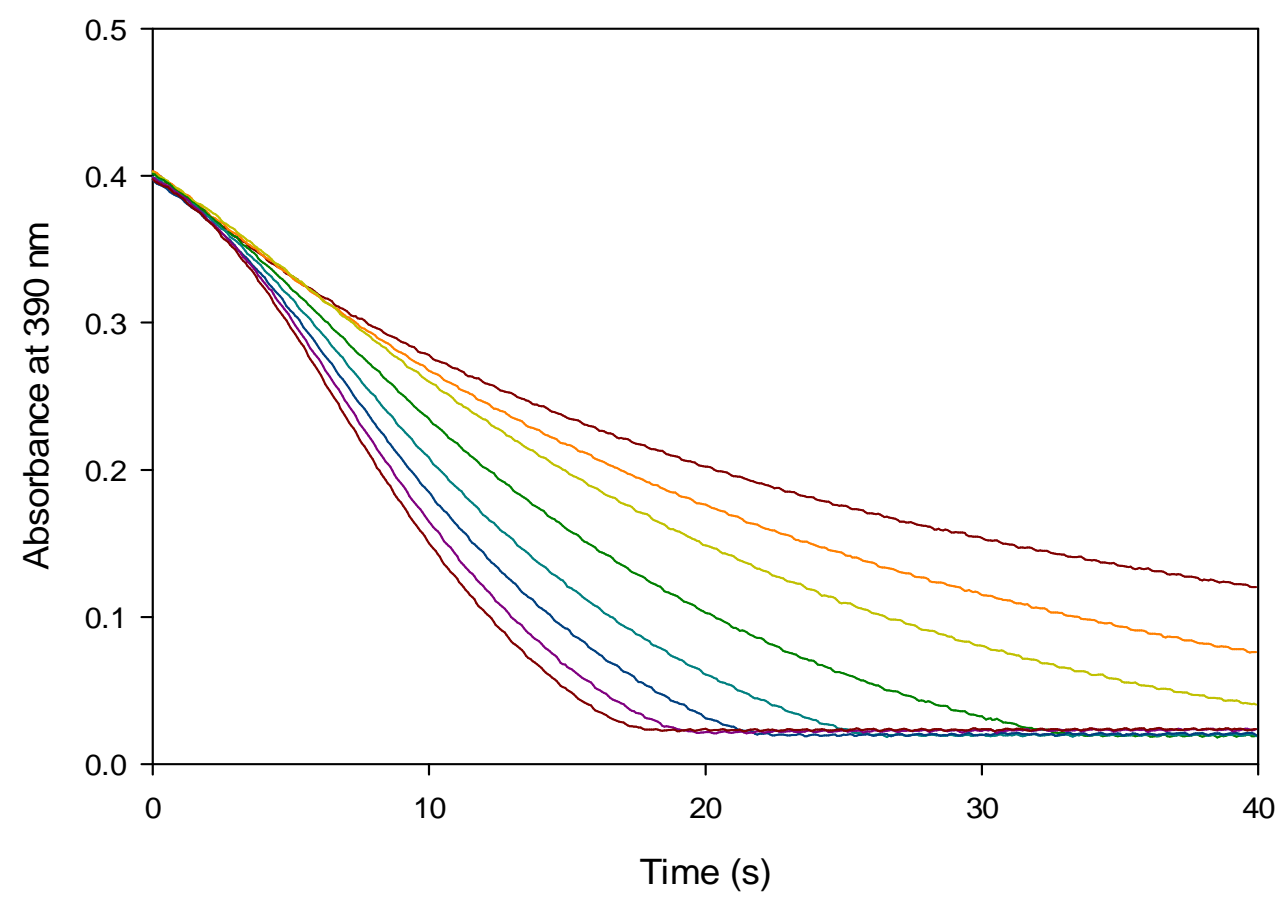

Figure 6-8b: Effect of changing initial concentrations of cysteine on NAMI-A-cysteine reaction under same reaction conditions with Figure 6-8a except for the absence of buffer.

6.2.2.3 Effect of ionic strength: Reaction rate is often affected by ions of reactants. This is corrected for by maintaining constant ionic strength, however, the effect of ionic strength can be isolated by varying amounts of an added inert salt. With reactant concentrations and other reaction conditions maintained constant, response of cysteineNAMI-A reaction was evaluated. A positive salt effect was observed, see Figure 6-9. This is suggestive of involvement of similarly charged ions in the rate limiting step. 


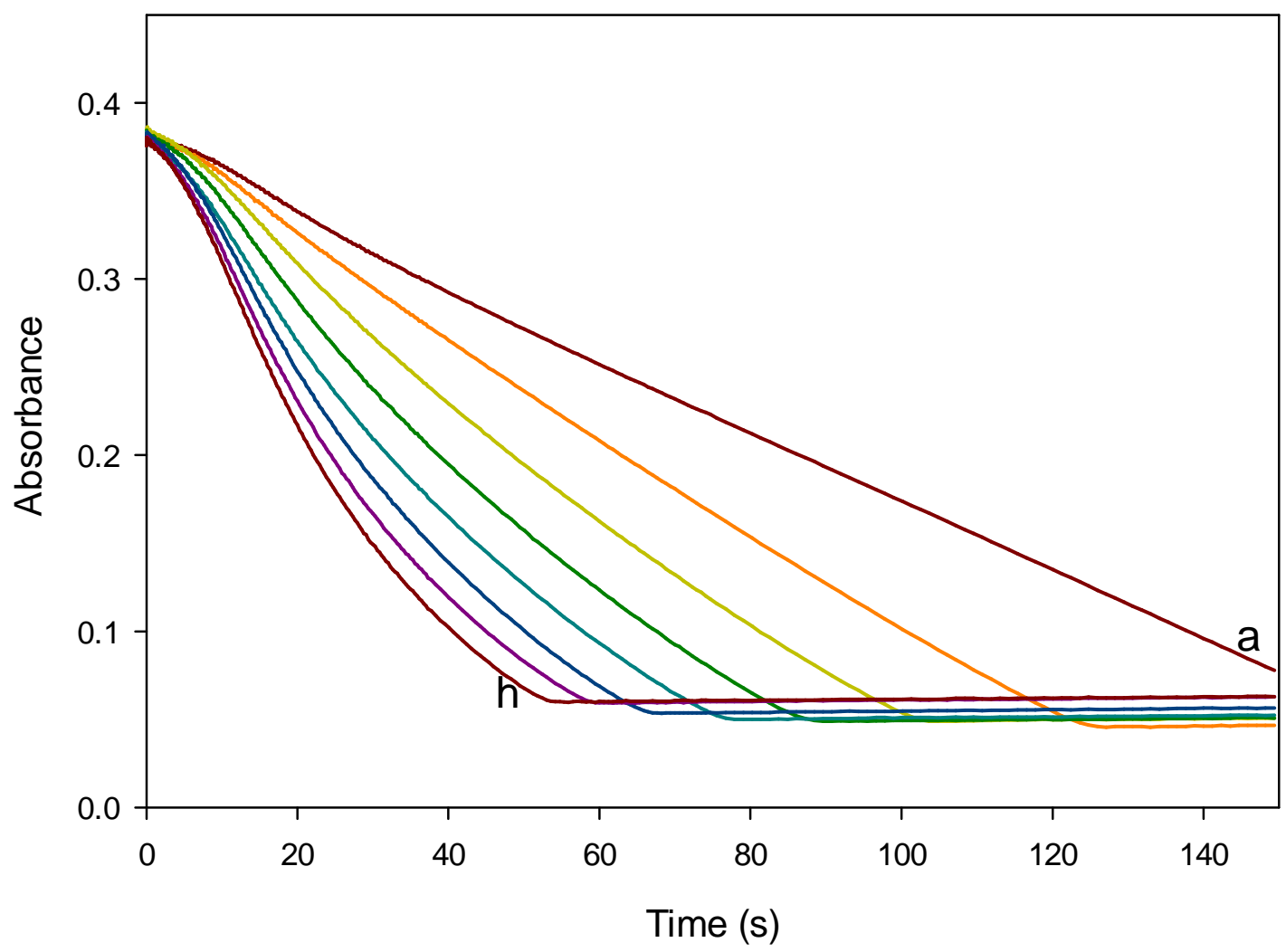

Figure 6-9: Effect of changing ionic strength on NAMI-A-cysteine reaction. [NAMI-A] $=1.0 \times 10^{-4} \mathrm{M} ;[\text { Cysteine }]_{o}=4.0 \times 10^{-3} \mathrm{M} ;$ Ionic strength maintained by addition of $\mathrm{NaClO}_{4}=\left(\right.$ a) no added $\mathrm{NaClO}_{4}($ b) $0.1 \mathrm{M}(\mathrm{c}) 0.2 \mathrm{M}(\mathrm{d}) 0.3 \mathrm{M}(\mathrm{e}) 0.4 \mathrm{M}(f) 0.5 \mathrm{M}(\mathrm{g}) 0.6$ M(h) 0.7 M. Reaction rate increased with increasing ionic strength.

6.2.2.4 Thermodynamic and activation parameters: Effect of varying temperature was evaluated under conditions of constant ionic strength, substrate and oxidant concentrations and $\mathrm{pH}$ of 7.4 (phosphate). Reaction rate increased with increasing temperatures as expected (see Figure 6-10a). The data obtained were used to construct an Arrhenius plot (see Figure 6-10b). Activation parameters calculated from this Arrhenius plot at $25{ }^{\circ} \mathrm{C}$ are: entropy of activation, $\Delta \mathrm{S}^{\neq}=-200.6 \mathrm{~J} \mathrm{~K}^{-1} \mathrm{~mol}^{-1}$, enthalpy of 
activation, $\Delta \mathrm{H}^{\neq}=19.0 \mathrm{~kJ} \mathrm{~mol}^{-1}$ and free energy of activation as $\Delta \mathrm{G}^{\neq}=78.8 \mathrm{~kJ} \mathrm{~mol}^{-1}$. These parameters are indicative of an associative mechanism.

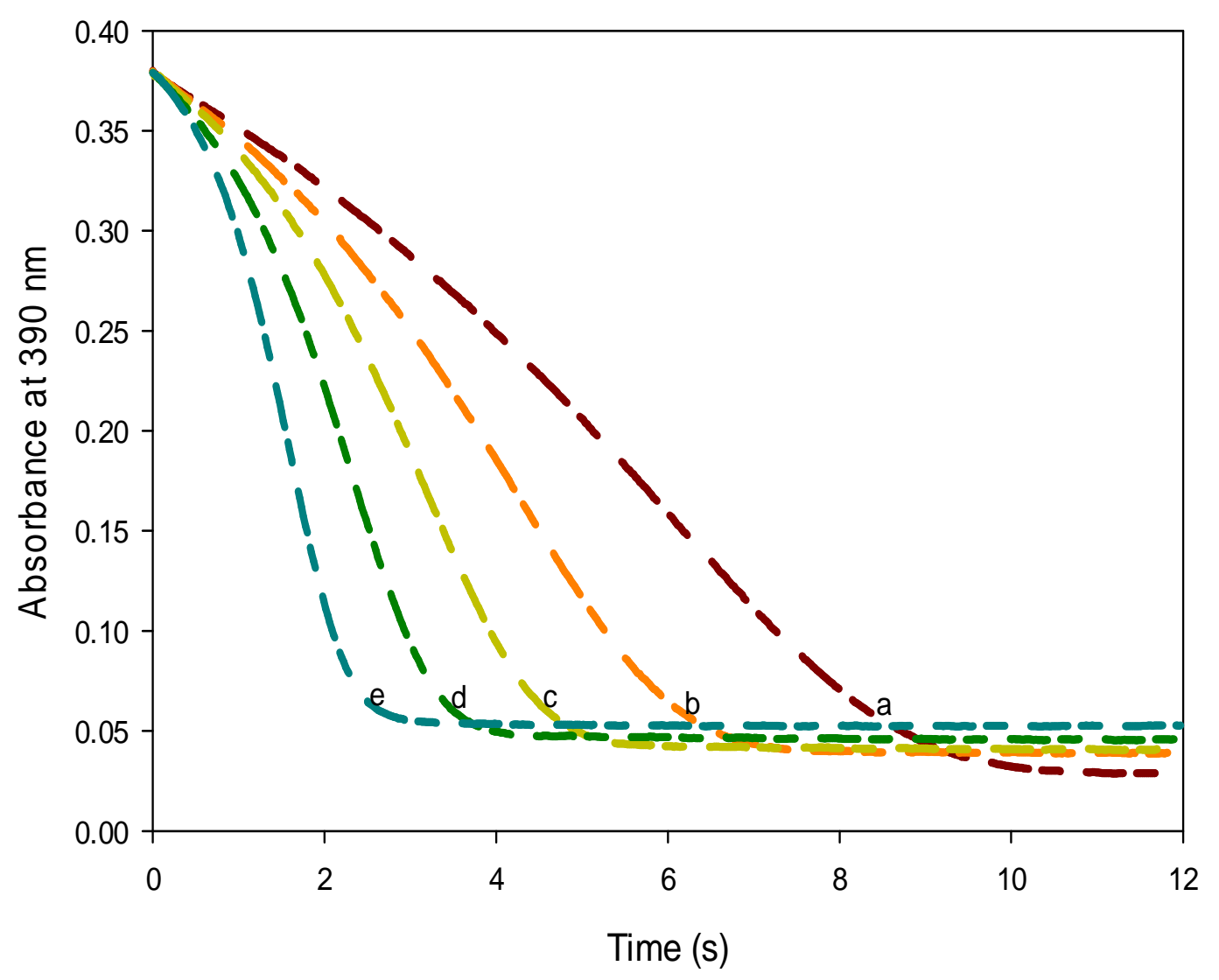

Figure 6-10a: Temperature dependence of cysteine-NAMI-A reaction. Increase in rate observed with temperature increase. $[\text { Cysteine }]_{o}=5.0 \times 10^{-2} \mathrm{M} ;[\mathrm{NAMI-A}]_{o}=1.0 \times 10^{-}$ ${ }^{4} \mathrm{M} ; \mathrm{Temp}=(a) 10^{\circ} \mathrm{C}\left(\right.$ b) $15^{\circ} \mathrm{C}(\mathrm{c}) 20^{\circ} \mathrm{C}(\mathrm{d}) 25^{\circ} \mathrm{C}(e) 37^{\circ} \mathrm{C}$ 


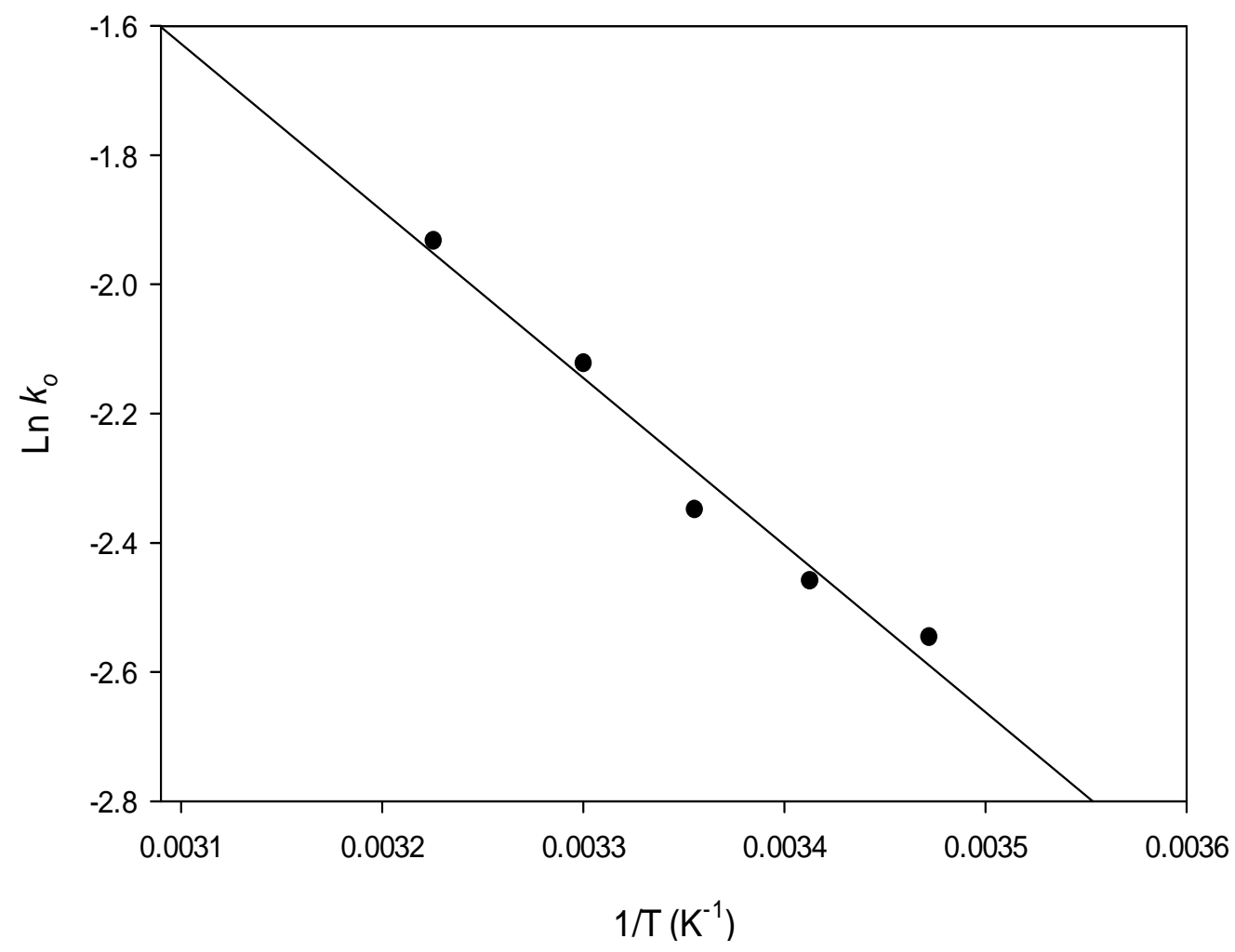

Figure 6-10b: Arrhenius plot extracted from study of effect of temperature (Figure 58a) for determination of activation parameters.

\subsection{Mechanism}

6.3.1 Electron Transfer: Considering the pKas for cysteine ionization, ${ }^{221}$ a solution buffered at $\mathrm{pH} 7.4$ will have cysteine ionized as represented in R2 and R3 where $\mathrm{H}_{2} \mathrm{OC}\left(\mathrm{NH}_{2}\right) \mathrm{CHCH}_{2} \mathrm{SH}$ is cysteine. Some thiolate form will also exist in solution although in low concentration compared to the zwitter ionic form as represented by R4.

$$
\begin{array}{lllll}
\mathrm{HO}_{2} \mathrm{C}\left(\mathrm{NH}_{2}\right) \mathrm{CHCH}_{2} \mathrm{SH} \rightleftharpoons{ }^{-} \mathrm{O}_{2} \mathrm{C}\left(\mathrm{NH}_{2}\right) \mathrm{CHCH}_{2} \mathrm{SH} & +\mathrm{H}^{+} & \mathrm{K}_{\mathrm{a} 1} & \mathrm{R} 2 \\
{ }^{-} \mathrm{O}_{2} \mathrm{C}\left(\mathrm{NH}_{2}\right) \mathrm{CHCH}_{2} \mathrm{SH}+\mathrm{H}^{+} \rightleftharpoons-{ }^{-} \mathrm{O}_{2} \mathrm{C}\left({ }^{+} \mathrm{NH}_{3}\right) \mathrm{CHCH}_{2} \mathrm{SH} & \mathrm{K}_{\mathrm{b}} & \mathrm{R} 3
\end{array}
$$




$$
{ }^{-} \mathrm{O}_{2} \mathrm{C}\left({ }^{+} \mathrm{NH}_{3}\right) \mathrm{CHCH}_{2} \mathrm{SH} \rightleftharpoons{ }^{-} \mathrm{O}_{2} \mathrm{C}\left({ }^{+} \mathrm{NH}_{3}\right) \mathrm{CHCH}_{2} \mathrm{~S}^{-}+\mathrm{H}^{+} \quad \mathrm{K}_{\mathrm{a} 2} \quad \mathrm{R} 4
$$

Zwitter ionic cysteine is expected to be the predominant species in solution. All of the different cysteine forms will react with NAMI-A to form products through a more ordered transition state, see R5 - R10.

$$
\begin{aligned}
& { }^{-} \mathrm{O}_{2} \mathrm{C}\left(\mathrm{NH}_{2}\right) \mathrm{CHCH}_{2} \mathrm{SH}+\left[\mathrm{ImRuCl}_{4} \mathrm{DMSO}^{-} \rightarrow\right. \\
& {\left[{ }^{-} \mathrm{O}_{2} \mathrm{C}\left(\mathrm{NH}_{2}\right) \mathrm{CHCH}_{2} \mathrm{SH} \ldots\left[\operatorname{ImRuCl}_{4} \mathrm{DMSO}\right]^{-}\right]^{\neq} \quad \mathrm{k}_{1} \quad \mathrm{R} 5} \\
& { }^{-} \mathrm{O}_{2} \mathrm{C}\left({ }^{+} \mathrm{NH}_{3}\right) \mathrm{CHCH}_{2} \mathrm{SH}+\left[\mathrm{ImRuCl}_{4} \mathrm{DMSO}^{-} \rightarrow\right. \\
& {\left[{ } ^ { - } \mathrm { O } _ { 2 } \mathrm { C } ( { } ^ { + } \mathrm { NH } _ { 3 } ) \mathrm { CHCH } _ { 2 } \mathrm { SH } \ldots \left[\left[\operatorname{ImRuCl}_{4} \mathrm{DMSO}^{-}\right]^{\ddagger} \quad \mathrm{k}_{2} \quad \mathrm{R} 6\right.\right.} \\
& { }^{-} \mathrm{O}_{2} \mathrm{C}\left({ }^{+} \mathrm{NH}_{3}\right) \mathrm{CHCH}_{2} \mathrm{~S}^{-}+\left[\mathrm{ImRuCl}_{4} \mathrm{DMSO}\right]^{-} \rightarrow \\
& {\left[{ }^{-} \mathrm{O}_{2} \mathrm{C}\left({ }^{+} \mathrm{NH}_{3}\right) \mathrm{CHCH}_{2} \mathrm{~S}^{-} \ldots\left[\mathrm{ImRuCl}_{4} \mathrm{DMSO}\right]^{-}\right]^{\neq} \quad \mathrm{k}_{3} \quad \mathrm{R} 7} \\
& 2\left[{ }^{-} \mathrm{O}_{2} \mathrm{C}\left(\mathrm{NH}_{2}\right) \mathrm{CHCH}_{2} \mathrm{SH} \ldots\left[\mathrm{ImRuCl}_{4} \mathrm{DMSO}\right]^{-}\right]^{\neq} \rightarrow \\
& \begin{array}{llll}
\mathrm{HO}_{2} \mathrm{C}\left(\mathrm{NH}_{2}\right) \mathrm{CHCH}_{2} \mathrm{SSCH}_{2} \mathrm{CH}\left(\mathrm{NH}_{2}\right) \mathrm{CO}_{2} \mathrm{H}+2\left[\mathrm{ImRuCl}_{4} \mathrm{DMSO}\right]^{2-} & \mathrm{k}_{4} & \mathrm{R} 8
\end{array} \\
& 2\left[{ }^{-} \mathrm{O}_{2} \mathrm{C}\left({ }^{+} \mathrm{NH}_{3}\right) \mathrm{CHCH}_{2} \mathrm{SH} \ldots\left[\mathrm{ImRuCl}_{4} \mathrm{DMSO}^{-}\right]^{\neq} \rightarrow\right. \\
& \mathrm{HO}_{2} \mathrm{C}\left(\mathrm{NH}_{2}\right) \mathrm{CHCH}_{2} \mathrm{SSCH}_{2} \mathrm{CH}\left(\mathrm{NH}_{2}\right) \mathrm{CO}_{2} \mathrm{H}+2\left[\mathrm{ImRuCl}_{4} \mathrm{DMSO}\right]^{2-}+2 \mathrm{H}^{+} \mathrm{k}_{5} \mathrm{R} 9
\end{aligned}
$$


$2\left[{ }^{-} \mathrm{O}_{2} \mathrm{C}\left({ }^{+} \mathrm{NH}_{3}\right) \mathrm{CHCH}_{2} \mathrm{~S}^{-} \ldots\left[\mathrm{ImRuCl}_{4} \mathrm{DMSO}\right]^{-}\right]^{\neq} \rightarrow$

$\mathrm{HO}_{2} \mathrm{C}\left(\mathrm{NH}_{2}\right) \mathrm{CHCH}_{2} \mathrm{SSCH}_{2} \mathrm{CH}\left(\mathrm{NH}_{2}\right) \mathrm{CO}_{2} \mathrm{H}+2\left[\mathrm{ImRuCl}_{4} \mathrm{DMSO}\right]^{2-} \quad \mathrm{k}_{6} \mathrm{R} 10$

Describing the reaction rate, $v$, in terms of disappearance of NAMI-A;

$$
\begin{gathered}
\mathrm{v}=\left[\mathrm { ImRuCl } \mathrm { DMSO } ^ { - } \left(\mathrm{k}_{1}\left[{ }^{-} \mathrm{O}_{2} \mathrm{C}\left(\mathrm{NH}_{2}\right) \mathrm{CHCH}_{2} \mathrm{SH}\right]+\mathrm{k}_{2}\left[{ }^{-} \mathrm{O}_{2} \mathrm{C}\left({ }^{+} \mathrm{NH}_{3}\right) \mathrm{CHCH}_{2} \mathrm{SH}\right]+\right.\right. \\
\mathrm{k} 3-\mathrm{O} 2 \mathrm{C}+\mathrm{NH} 3 \mathrm{CHCH} 2 \mathrm{~S}-
\end{gathered}
$$

Results obtained from ionic strength effects demonstrate that species of similar charges are involved in the rate limiting step, thus indicating that $k_{2}$, involving the zwitter ionic cysteine does not contribute significantly to the rate $\left(k_{2} \gg k_{1}, k_{3}\right)$. Including $k_{2}$ anyway, results in a rate that is linearly dependent on $\left[\mathrm{H}^{+}\right]$which contradicts observation of reduced rate at lower $\mathrm{pH}$. E1, therefore, reduces to

$v=\left[\mathrm{ImRuCl}_{4} \mathrm{DMSO}\right]^{-}\left(k_{1}\left[^{-} \mathrm{O}_{2} \mathrm{C}\left(\mathrm{NH}_{2}\right) \mathrm{CHCH}_{2} \mathrm{SH}\right]+k_{3}\left[{ }^{-} \mathrm{O}_{2} \mathrm{C}\left({ }^{+} \mathrm{NH}_{3}\right) \mathrm{CHCH}_{2} \mathrm{~S}^{-}\right] \quad \mathrm{E} 2\right.$

E2 can be expressed in terms of initial cysteine concentration, $\left[\mathrm{H}_{2} \mathrm{OC}\left(\mathrm{NH}_{2}\right) \mathrm{CHCH}_{2} \mathrm{SH}\right]_{\mathrm{o}}$ which is distributed between [ $\left.\left.\mathrm{O}_{2} \mathrm{C}\left(\mathrm{NH}_{2}\right) \mathrm{CHCH}_{2} \mathrm{SH}\right],\left[{ }^{-} \mathrm{O}_{2} \mathrm{C}^{+}{ }^{+} \mathrm{NH}_{3}\right) \mathrm{CHCH}_{2} \mathrm{SH}\right]$ and [$\left.\mathrm{O}_{2} \mathrm{C}\left({ }^{+} \mathrm{NH}_{3}\right) \mathrm{CHCH}_{2} \mathrm{~S}^{-}\right]$;

$\mathrm{v}=\left[\mathrm{H}_{2} \mathrm{OC}\left(\mathrm{NH}_{2}\right) \mathrm{CHCH}_{2} \mathrm{SH}\right]_{\mathrm{o}}\left[\mathrm{ImRuCl}_{4} \mathrm{DMSO}\right]^{-}\left(\frac{K a k_{1}}{\left[\mathrm{H}^{+}\right]}+K a_{2} K_{b} k_{3}\right)$ 
which in conditions of overwhelming excess of MESNA can be written as

$$
\text { Rate }=k_{o}\left[\mathrm{ImRuCl}_{4} \mathrm{DMSO}^{-}\right.
$$

where

$$
k_{o}=\left[\mathrm{HO}_{2} \mathrm{C}\left(\mathrm{NH}_{2}\right) \mathrm{CHCH}_{2} \mathrm{SH}\right]_{\mathrm{o}}\left(\frac{K a k_{1}}{\left[\mathrm{H}^{+}\right]}+K a_{2} K_{b} k_{3}\right)
$$

6.3.2 Ligand Exchange: Series of ligand substitution reactions are expected to occur especially following formation of the labile NAMI-A dianion, $\left[\mathrm{ImRuCl}_{4} \mathrm{dmso}\right]^{2-}$. Reactions R11 and R12 describe ligand exchange for supported by ESI-MS results (Figures 6-4a and b) for the loss of imidazole and dimethyl sulfoxide ligands with exchange of two chloride ligands.

$$
\begin{array}{ll}
{\left[\operatorname{ImRuCl}_{4} \mathrm{DMSO}^{2-}+2 \mathrm{H}_{2} \mathrm{O}\right.} & \rightarrow\left[\operatorname{ImRuCl}_{2}\left(\mathrm{I}_{2} \mathrm{O}\right)_{2} \mathrm{DMSO}\right]+2 \mathrm{Cl}^{-} \\
{\left[\mathrm{ImRuCl}_{2}\left(\mathrm{H}_{2} \mathrm{O}\right)_{2} \mathrm{DMSO}\right]} & \rightarrow\left[\mathrm{RuCl}_{2}\left(\mathrm{H}_{2} \mathrm{O}\right)_{2}\right]+\mathrm{Im}+\mathrm{DMSO}
\end{array}
$$

Greater reactivity of $\left[\mathrm{ImRuCl}_{4} \mathrm{dmso}\right]^{2-}$ is an indication that $\mathrm{R} 11$ and $\mathrm{R} 12$ are fast and would not influence the rate determining step. The overall reaction is summarized in Figure 6-11. $\mathrm{H},\left[\mathrm{RuCl}_{2}\left(\mathrm{H}_{2} \mathrm{O}\right)_{2}\right]$, attempts structural arrangement of the aquated product. Substitution could be on any two of the $\mathrm{Cl}^{-}$ligands, depending on activation enthalpy and free energy of the different configurations. Higher calculated energy values have 
been reported for second aquation step of NAMI-A leading to a trans configuration. $279 ; 280$
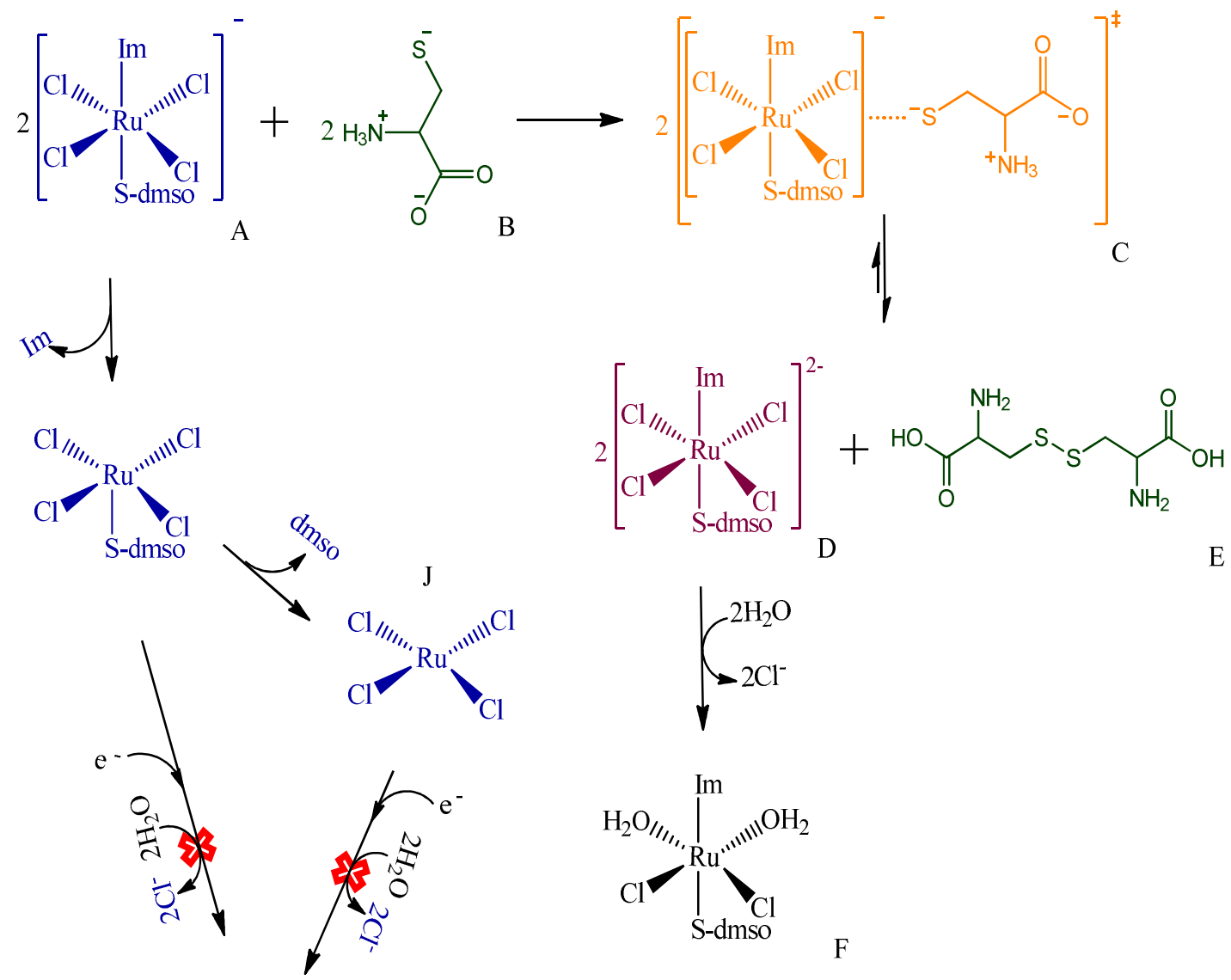

$\mathrm{H}$<smiles>O[Ge](Cl)(Cl)Cl</smiles>
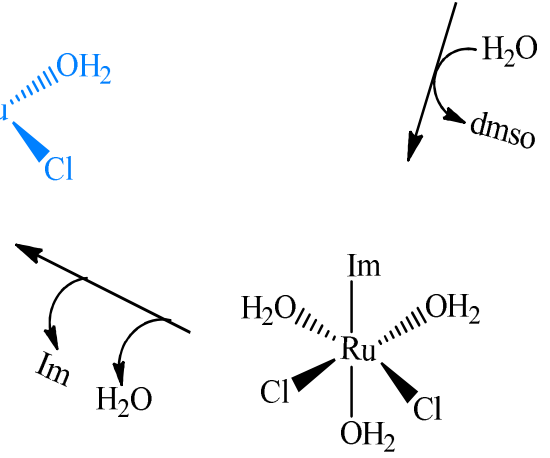

G

Scheme 6-1: Proposed mechanism for the reduction of NAMI-A by cysteine and subsequent hydrolysis. 
Orders of magnitude lower rate constants than obtained in this study have been reported for experimental and theoretical hydrolysis of NAMI-A. ${ }^{245} 281 ; 282$ This is in support of our proposed formation of aquated product through reduced NAMI-A. 


\section{CHAPTER SEVEN}

\subsection{Summary and Conclusions}

Decline in cancer mortality rates acknowledges improvements and advances in cancer treatment. For instance, surgical removal of primary tumors is becoming highly successful, however, afore-mentioned characteristics of metastasis warrant chemotherapy. Lack of effective therapeutics towards metastasis adequately maintain interest in drug candidates with antimetastatic potential such as NAMI-A. Studies of interactions of NAMI-A with bio-relevant molecules are of considerable interest due to the promising pharmacological benefits of this experimental drug in cancer therapy.

Solution chemistry of NAMI-A is quite interesting and this study has demonstrated that its interaction with biologically-relevant thiols can be as interesting and complex especially past the electron transfer process. Stoichiometry for the overall electron transfer reactions obtained in this study demonstrates a 1:1 ratio of oxidant to reductant which culminates in ligand exchange with water as described in chapters 3,4 and 6. Initial reactions were centered on sulfur atoms of thiols investigated, there was no evidence for interactions on the nitrogen or oxygen atoms. In all cases, reactions were dependent on NAMI-A to the first order. There was no clear evidence for binding of thiol to NAMI-A or any of the aquated species observed, though, our results demonstrate complex interactions with respect to cysteamine and GSH. Formation and identification of such species could be determined using time dependent NMR and LCMS. Further clarification of origin of $\left[\mathrm{RuCl}_{2}\left(\mathrm{H}_{2} \mathrm{O}\right)_{2}\right]$ species could be done using a Qband EPR which will show some signal for $\mathrm{Ru}^{3+}$ but would be EPR silent for $\mathrm{Ru}^{2+}$. 
Results of kinetics analysis of reactions of NAMI-A with select thiols yields effective rate constant, $k_{o}$, which are reported in Table 7-1 for the purpose of comparison.

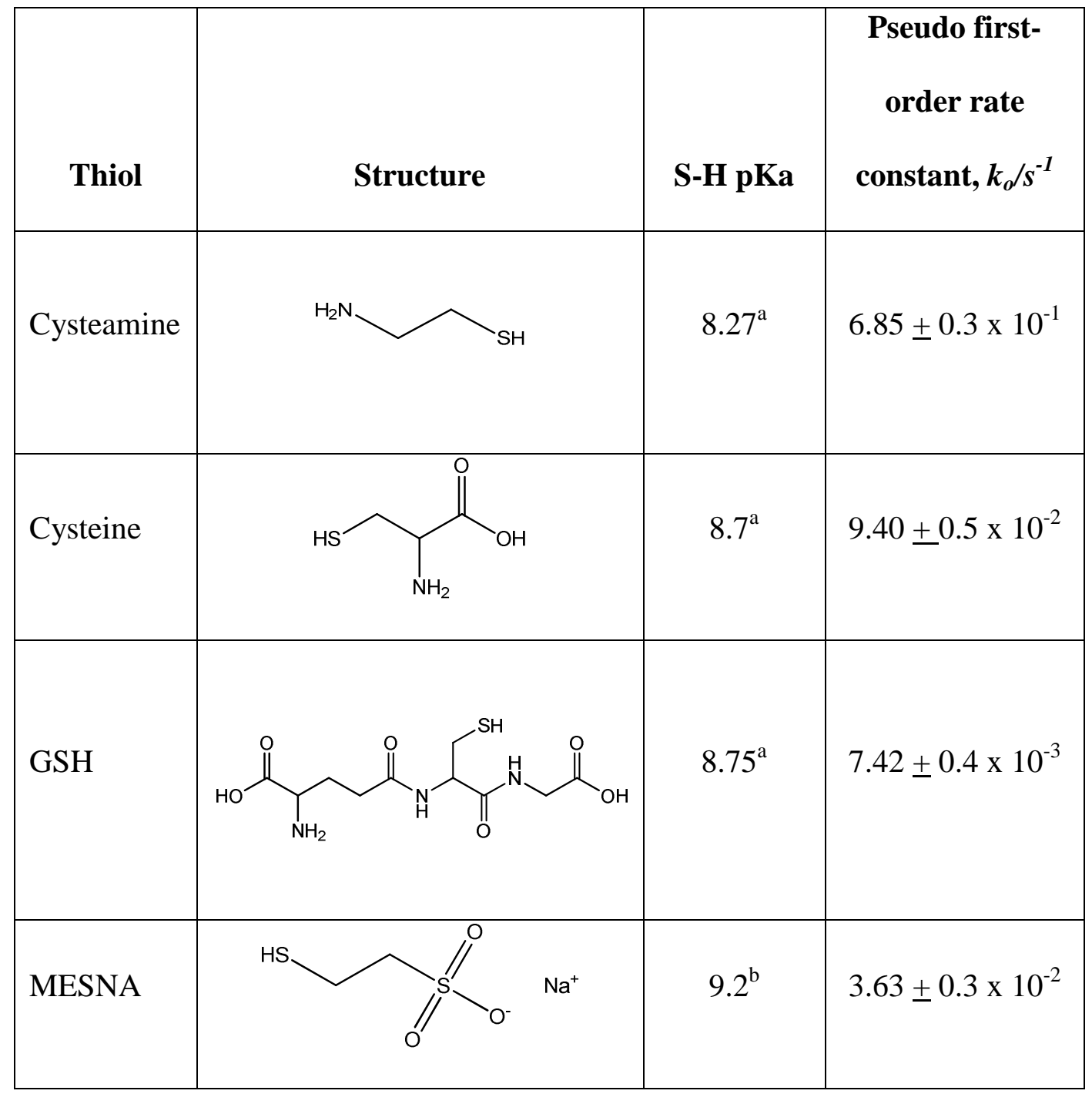

Table 7-1: Comparison of observed rate constants in relation to thiol $p K a{ }^{a} \mathrm{~S}-\mathrm{H} p \mathrm{Ka}$ adapted from Handbook of Chemistry and Physics. ${ }^{221} \quad$ b 283;284 GSH exhibits the lowest rate determined, an explanation might be drawn from its molecular structure where the thiol might not be necessarily accessible due to steric 
hindrance compared to other thiols studied. Also, the simple molecular structure of cysteamine might account for the observed high reactivity. This is not surprising since similar trends have been observed for kinetics analysis of reactions of GSH, MESNA and WR-1065 with metabolites of cyclophosphamide (4-hydroperoxycyclophosphamide and acrolein). ${ }^{285}$ 4-hydroperoxycyclophosphamide and acrolein have high reactivity towards MESNA and GSH than NAMI-A on the basis of reported rate constants ${ }^{285}$ which are orders of magnitude higher than those obtained in this study. A clinical indication of comparing our results with those obtained for 4hydroperoxycyclophosphamide and acrolein is that NAMI-A could not compete with these metabolites for the studied thiols provided rate constants are similar within and outside the cell.

A negative correlation of $k_{o}$ with thiol $\mathrm{p} K a$ was observed. Higher $\mathrm{p} K a$ corresponds to lower reaction rate with NAMI-A except for MESNA. Thiol with the lowest $\mathrm{pKa}$ should have higher amount of deprotonated sulfhydryl group (thiolate anion) and thus reacts faster at physiological $\mathrm{pH}$ 7.4. A Brønsted plot derived from data presented in Table 7-1 shows linearity as seen in Figure 7-1. Brønsted equation is $\log k_{o}$ $=-1.4 \mathrm{pKa}+11$. The plot demonstrates a positive slope when molecular weights of the thiols were factored in i.e. plot of $\log \left(\mathrm{MW} / k_{o}\right)$ vs $\mathrm{p} K a$ linear with positive slope. This correlation is indicative of significant contribution of thiolate anions of the different thiols in their reactivity with NAMI-A. Similar observations have been made in the reactions of thiols with Cytochrome c, a heme protein. ${ }^{286}$ WR-1065 has a lower pKa for thiol ionization of 7.7 and should have thiolate species up to $22 \%$ at $\mathrm{pH} 7.4$, one could 
predict that WR-1065 will have a higher rate compared to cysteine, MESNA and GSH. In all, our results suggest that NAMI-A interactions with any of the thiols investigated should not interfere with the protective effect of amifostine or MESNA when used in a therapy regimen combining NAMI-A with any anticancer drug for which chemoprotection is necessary.

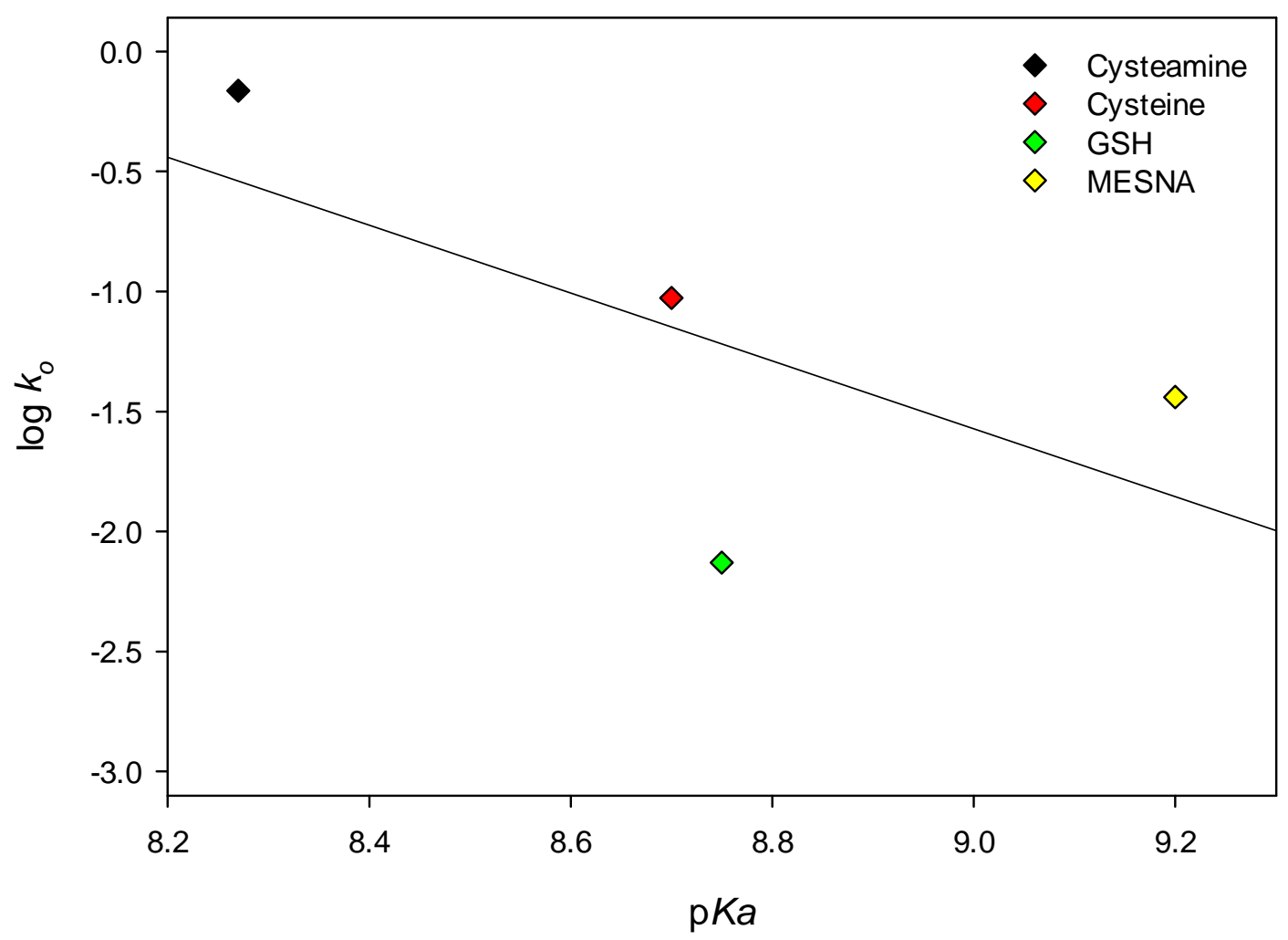

Figure 7-1: Brønsted relationship for the reactivities of thiols towards NAMI-A. Linearity of this plot demonstrates significance of thiolate species in the reactions.

All the reactions studied show positive temperature dependence. Positive low enthalpy of activation and distinctly negative entropy of activation (see Table 7-2) 
determined in all of the reactions are indicative of organized transition state prior to product formation.

\begin{tabular}{|c|c|c|c|}
\hline Thiol & $\Delta \mathbf{S}^{\neq} / \mathbf{J K}^{-1} \mathbf{m o l}^{-1}$ & $\Delta \mathbf{H}^{\neq} / \mathbf{k J m o l}^{-1}$ & $\Delta \mathbf{G}^{\neq} / \mathbf{k J m o l}^{-1}$ \\
\hline Cysteamine & -117 & +41 & +76 \\
\hline Cysteine & -200 & +19 & +79 \\
\hline MESNA & -175 & +21 & +73 \\
\hline GSH & -100 & +55 & +85 \\
\hline
\end{tabular}

Table 7-2: Activation parameters $\left(\right.$ at $25^{\circ} \mathrm{C}$ ) deduced from Arrhenius plot of Ln $k_{o}$ against $1 /$ T for thiols studied.

Order of increasing free energy of activation of NAMI-A reaction with thiols in this study is MESNA < cysteamine < cysteine < GSH. This might explain the low rate constant obtained for GSH reaction. Higher than expected $k_{o}$, of $3.63 \pm 0.3 \times 10^{-2} \mathrm{~s}^{-1}$ obtained for the MESNA reaction (refer to Table 7-1) in comparison to others might be due to occupation of a lower energy space by its transition state complex.

Our results could help to understand the mechanism of interaction of NAMI-A with cellular thiols, proteins and enzymes containing cysteine residues in their active sites and thiol containing chemoprotectants. Antimetastatic effects of NAMI-A appear independent of route of administration but dependent on amount administered. ${ }^{287}$ Mode of drug administration determines possible first contact. Intravenous NAMI-A 
administration suggests interactions with biomolecules (especially in the plasma) might occur before interaction with DNA or other cellular targets yet to be identified and may proceed through similar mechanisms as those derived in this study. The use of MESNA should be particularly advantageous as interactions which precede ligand substitution should produce a more effective chemoprotectant, dimeric MESNA. The GSH-NAMIA reaction is relatively slow compared to other thiols studied which might suggest minimal impact on cellular GSH especially in the presence of other cancer drugs which deplete GSH.

Reports attest to preferential binding of HSA to reduced NAMI-A, ${ }^{288}$ and reduced antimetastatic activity of NAMI-A upon binding to albumin and transferrin. ${ }^{93}$ Table 7-2 features results in literature of experimental and theoretical calculations for physiologically relevant interactions of NAMI-A.

\begin{tabular}{|c|c|c|c|c|}
\hline & $k_{o} / \mathbf{s}^{-1}$ & $\Delta \mathbf{H}^{\neq} / \mathbf{k J m o l}^{-1}$ & $\Delta \mathbf{G}^{\neq} / \mathbf{k J m o l}^{-1}$ & Ref. \\
\hline \multirow[t]{2}{*}{ Aquation } & $2.56 \times 10^{-4 * a}$ & - & - & 281 \\
\hline & $5.17 \times 10^{-4 * b}$ & - & - & 289 \\
\hline $1 \mathrm{st}$ & $3.96 \times 10^{-6 \#}$ & $+101.5^{\#}$ & $+103.7^{\#}$ & 279 \\
\hline 2nd & - & $+118.7^{\#}$ & $+125.0^{\#}$ & 279 \\
\hline Transferrin & $1.07 \times 10^{-3 * b}$ & - & - & 289 \\
\hline Albumin & $2.77 \times 10^{-3 * b}$ & - & - & 289 \\
\hline
\end{tabular}

Table 7-3: Observed rate constants and activation parameters reported by others for first/second aquation processes, transferrin and albumin binding constants. ${ }^{*}$ Phosphate buffer $p H 7.4,{ }^{\text {a }}$ at $25^{\circ} \mathrm{C},{ }^{\mathrm{b}}$ at $37^{\circ} \mathrm{C}, \quad{ }^{\#}$ from density functional theory calculations. 
Results reported in this dissertation demonstrate that interactions of NAMI-A with biologically-active thiols are kinetically and thermodynamically favored and therefore might play significant roles in in vivo metabolism of NAMI-A. 


\section{CHAPTER EIGHT: SUPPLEMENTARY RESULTS}

\subsection{Kinetics and Mechanism of One-electron Oxidation of L-Cysteine by Tris(1,10-phenanthroline)iron(III) complex}

8.1 Introduction: L-cysteine is the only sulfur contributor and the rate-limiting substrate in the biosynthesis of GSH. ${ }^{290} 1,10$-Phenanthroline ligand disturbs the proper functioning of a wide range of biological systems. In its metal-free state, it has been shown to have high inhibitory activity against candida albicaans and induced apoptosis in a yeast and mammalian cell line obtained from poorly differentiated carcinoma when complexed with metals. ${ }^{291 ; 292}$ Metal complexes are used to model biomolecules ${ }^{293 ; 294}$ and iron complexes in particular, have been used to model iron-porphyrin proteins ${ }^{295 ; 296}$ and active site of ribonucleotide reductase. ${ }^{297}$ Some metal complexes of substituted 1,10 phenathroline have also shown antineoplastic activity with up to $50 \%$ growth inhibition of human cancer cells at concentrations of 10 to 100 times lower than cisplatin. ${ }^{298}$ Structure-activity relationships have been established for metal complexes with anticancer activities. $^{289}$ In this study, tris(1,10-phenanthroline)iron(III) (see structure shown in Figure 8-1) is used as a model that offers a familiar metal to the physiological system and the octahedral structure of the antimetastatic prodrug of interest in an effort to establish mechanisms of interactions of the prodrug with biologically-active thiols. 


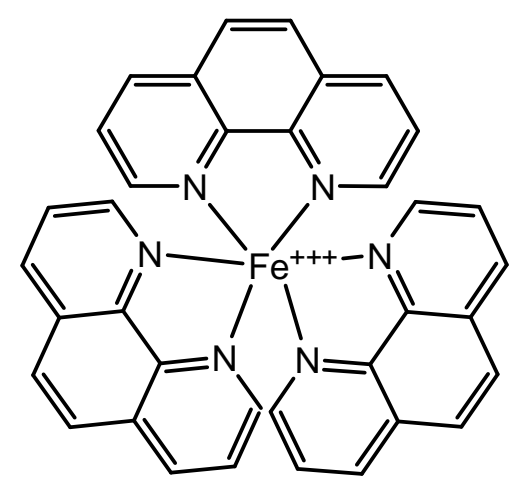

Figure 8-1 : $\quad$ Tris(1,10-phenanthroline)iron(III)

\subsection{Materials}

L-cysteine, sodium perchlorate $\left(\mathrm{NaClO}_{4}\right)$ and 1,10-phenanthroline monohydrate all with $99+\%$ assays were purchased from Acros. Chlorine gas (Aldrich), sulfuric acid, perchloric acid (Fisher) and ferrous ammonium sulfate $\left(\mathrm{Fe}\left(\mathrm{NH}_{4}\right)_{2}\left(\mathrm{SO}_{4}\right)_{2}\right.$ (GFS) were all used without further purification. Solutions were prepared in distilled deionized water obtained from a Barnstead Corporation Nanopure water system.

Tris(1,10-phenanthroline)iron(III) perchlorate was prepared according to a published method. ${ }^{299}$ A solution containing $0.3 \mathrm{~g}$ of $\mathrm{Fe}\left(\mathrm{NH}_{4}\right)_{2}\left(\mathrm{SO}_{4}\right)_{2} .6 \mathrm{H}_{2} \mathrm{O} \quad(0.76$ mmol), $0.6 \mathrm{~g}$ of 1,10-phenanthroline monohydrate and $0.2 \mathrm{~mL}$ of concentrated $\mathrm{H}_{2} \mathrm{SO}_{4}$ in $100 \mathrm{~mL}$ of water affords tris(1,10-phenathroline)iron(II) perchlorate. The iron(III) complex was prepared by oxidation of the iron(II) complex with chlorine gas. Chlorine gas was bubbled into this solution until the color changed from deep red to blue. $30 \%$ $\mathrm{NaClO}_{4}$ was added to the mixture and then cooled in ice bath. Blue crystalline $\mathrm{Fe}(\text { phen })_{3}\left(\mathrm{ClO}_{4}\right)_{3}$ was isolated by filtration and washed $3 \mathrm{x}$ with cold water. It was then dried in a desiccator. The blue iron(III) complex was recrystallized from aqueous 
perchlorate solution and characterized spectrophotometrically. Stock solutions of the iron(III) complexes were freshly made in $2.0 \mathrm{M} \mathrm{H}_{2} \mathrm{SO}_{4}$.

\subsection{Results and discussion}

\subsubsection{Stoichiometry and product identification}

The stoichiometry of the reaction was found to be 1:1 with one mole of cysteine reacting with one mole of tris(1,10-phenanthroline)iron(III), $\mathrm{Fe}(\mathrm{phen}) 3^{3+}$, to form cystine (disulfide of cysteine) and tris(1,10-phenanthroline)iron(II), Fe(phen) ${ }_{3}{ }^{2+}$, as shown in stoichiometric reaction $\mathrm{R} 1$ :

$2 \mathrm{RSH}+2 \mathrm{Fe}(\text { phen })_{3}{ }^{3+} \longrightarrow \mathrm{RSSR}+2 \mathrm{Fe}(\text { phen })_{3}{ }^{2+}+2 \mathrm{H}^{+} \mathrm{R} 1$

Figure 3.3 shows the spectral changes observed from a solution of cysteine and $\mathrm{Fe}(\text { phen })_{3}{ }^{3+}$ scanned at 30 second intervals. The absorbance at $350 \mathrm{~nm}\left(\lambda_{\max }\right.$ for

$\mathrm{Fe}(\mathrm{phen}){ }_{3}{ }^{3+}$ ) decreased as the reaction progressed showing conversion of $\mathrm{Fe}(\mathrm{phen}){ }_{3}{ }^{3+}$ to $\mathrm{Fe}(\text { phen })_{3}{ }^{2+}$. The absorption at $510 \mathrm{~nm}$ increases as the reaction progressed to a final absorbance at completion of reaction. The absorbance at $510 \mathrm{~nm}$ corresponds to $\mathrm{Fe}(\text { phen })_{3}{ }^{2+}$ produced. The characteristic absorption at $510 \mathrm{~nm}$ of $\mathrm{Fe}(\mathrm{phen})_{3}{ }^{2+}$ as shown in Figure 8-2 gives spectrophotometric evidence for our product. The observation of an isobestic point suggests there are no intermediates of kinetic significance during this oxidation and the only absorbing species in this region are $\mathrm{Fe}(\text { phen })_{3}{ }^{2+}$ and $\mathrm{Fe}(\mathrm{phen})_{3}{ }^{2+}$. 


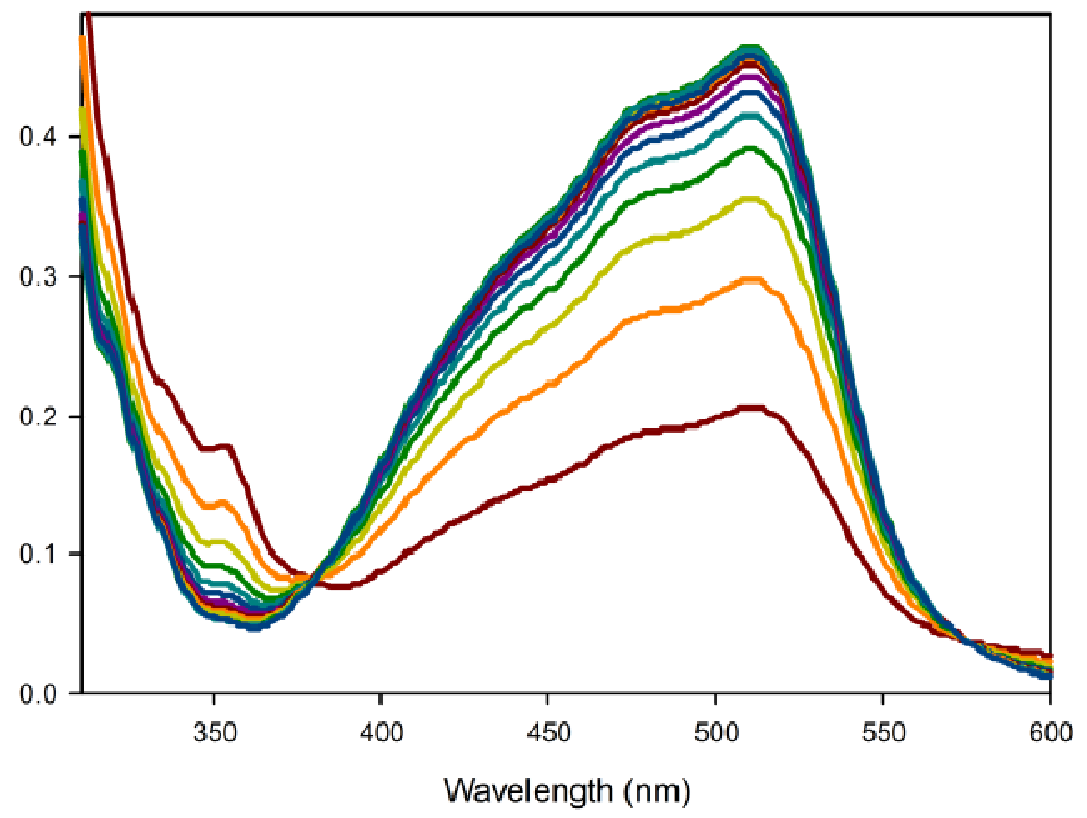

Figure 8-2: $\quad$ Rapid spectral scan of solution of cysteine and $\mathrm{Fe}(\text { phen })_{3}{ }^{3+}$ taken at $30 \mathrm{~s}$ interval. $[\text { Cysteine }]_{o}=2.0 \times 10^{-5} \mathrm{M} ;\left[\mathrm{Fe}(\text { phen })_{3}{ }^{3+}\right]_{o}=5.0 \times 10^{-5} \mathrm{M} ;\left[\mathrm{H}^{+}\right]_{o}=0.5 \mathrm{M}$

A full electro-spray ionization mass spectrum of stoichiometric solution was taken in the positive mode (Figure 8-3), showing m/z 241 and 298 for cysteine and $\mathrm{Fe}(\text { phen })_{3}{ }^{2+}$ respectively. The observed peak for $\mathrm{Fe}(\text { phen })_{3}{ }^{2+}$ is $[\mathrm{M}+\mathrm{H}]^{+}$, taking into account the molecular weight of $596.27 \mathrm{~g} / \mathrm{mol}$ and the +2 charge. 


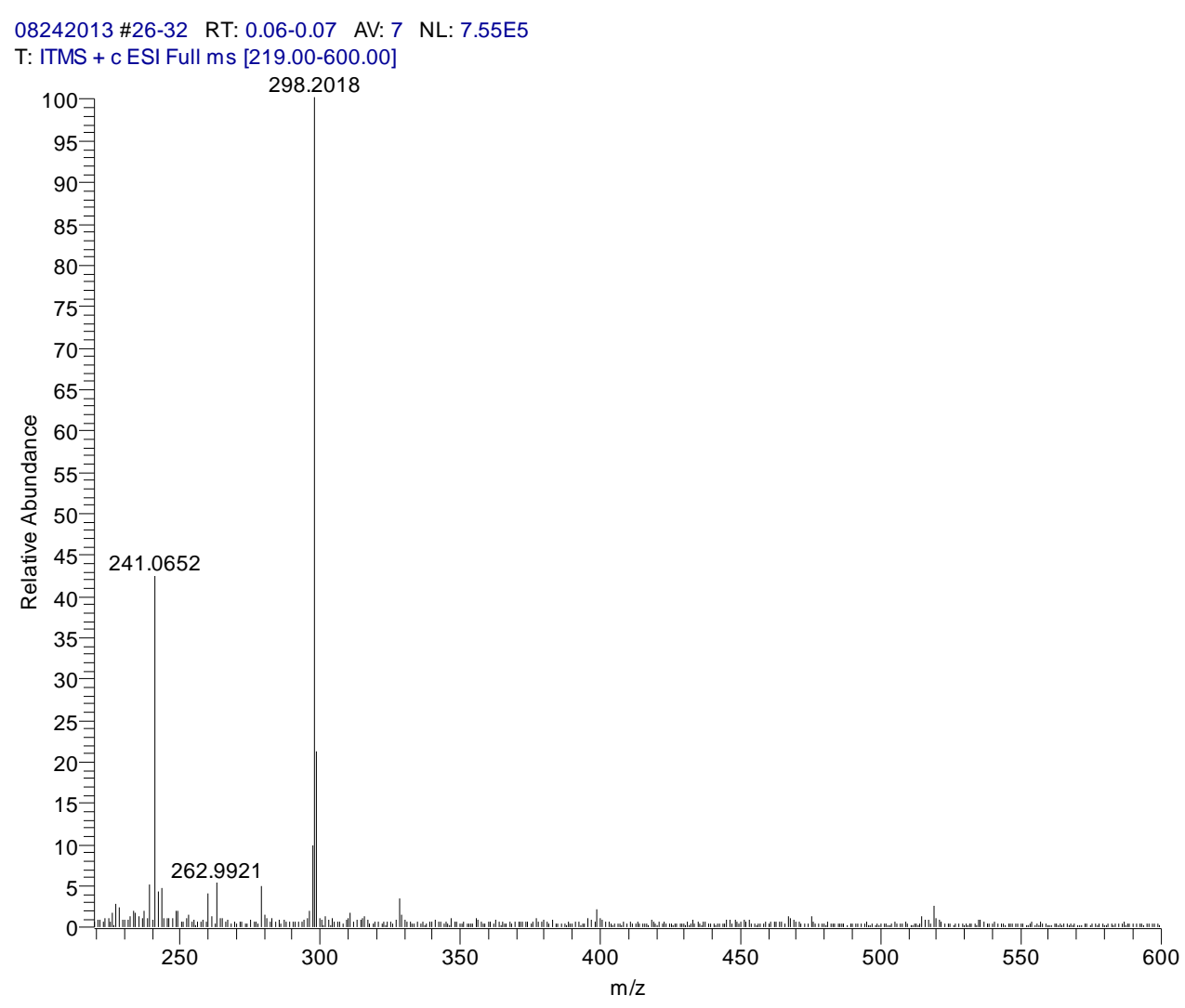

Figure 8-3: $\quad$ Positive ESI-MS spectrum of the reaction products of a stoichiometric solution of cysteine and Fe(phen $)_{3}^{3+}$ in 50/50 methanol-water.

\subsubsection{Effect of $\left[\mathrm{Fe}(\right.$ phen $\left.) 3^{3+}\right]$ on rate of reaction}

Kinetics of reaction were carried out under pseudo-first order conditions of excess cysteine. At constant temperature, ionic strength and concentration of cysteine as well as initial acid concentrations, effect of $\mathrm{Fe}($ phen $) 3^{3+}$ on rate of reaction was isolated at its wavelength of maximum absorption, $350 \mathrm{~nm}$ (see Figure 8-4a.). The rate of consumption of $\mathrm{Fe}(\text { phen })_{3}{ }^{3+}$ increases with increasing initial $\mathrm{Fe}(\text { phen })_{3}{ }^{3+}$ concentrations. The plot of initial rate against initial $\mathrm{Fe}(\text { phen })_{3}{ }^{3+}$ concentrations is linear, Figure $8-4 \mathrm{~b}$; clearly suggesting a first-order dependence in $\mathrm{Fe}(\text { phen })_{3}{ }^{3+}$. 


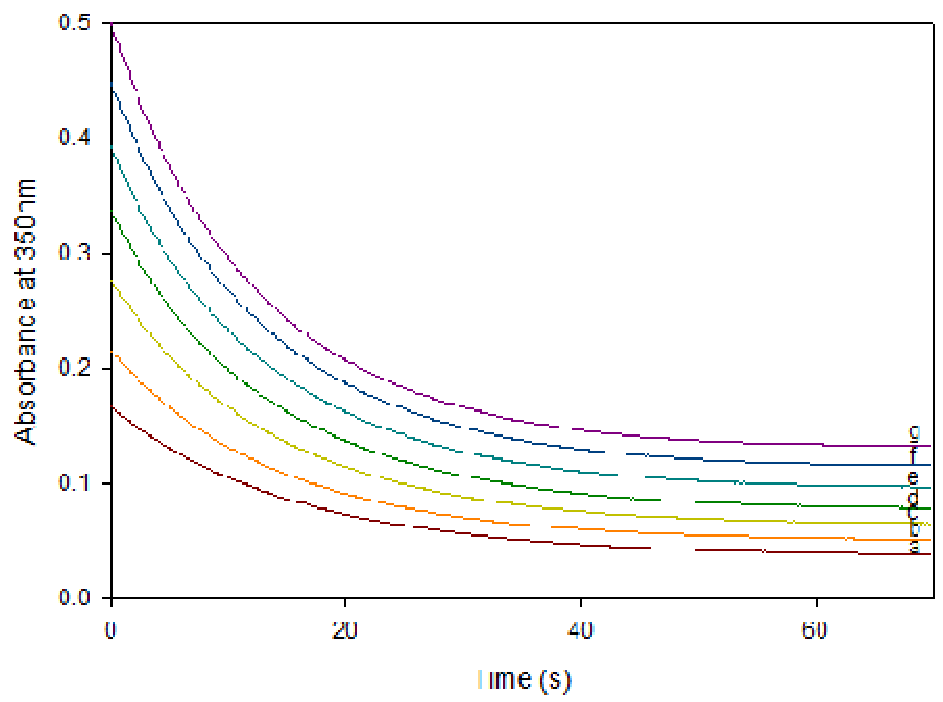

Figure 8-4a: Kinetic traces showing the on $\mathrm{Fe}(\text { phen })_{3}{ }^{3+}$ at its $\lambda_{\max }$ [Cysteine $]_{o}=2.0 x$ $10^{-3} \mathrm{M} ;\left[\mathrm{H}^{+}\right]_{o}=0.5 \mathrm{M} ;\left[\mathrm{Fe}(\text { phen })_{3}{ }^{3+}\right]_{o}=($ a $) 3.0 \times 10^{-5} \mathrm{M}(\mathrm{b}) 4.0 \times 10^{-5} \mathrm{M}(\mathrm{c}) 5.0 \times 10^{-5}$ $M(d) 6.0 \times 10^{-5} \mathrm{M}(\mathrm{e}) 7.0 \times 10^{-5} \mathrm{M}(\mathrm{f}) 8.0 \times 10^{-5} \mathrm{M}(\mathrm{g}) 9.0 \times 10^{-5} \mathrm{M}$

$\mathrm{Fe}(\text { phen })_{3}{ }^{2+}$ has maximum absorption at $510 \mathrm{~nm}$, and the effect of varying initial concentrations of $\mathrm{Fe}(\text { phen })_{3}{ }^{2+}$ on the reaction was also examined at this wavelength (Figure $8-4 \mathrm{c}$ ). The rate of formation of $\mathrm{Fe}(\text { phen })_{3}{ }^{2+}$ increased with increasing initial $\mathrm{Fe}(\text { phen })_{3}{ }^{3+}$ concentrations. The plot of initial rates against initial $\mathrm{Fe}(\text { phen })_{3}{ }^{3+}$ concentration gave a straight line with intercept kinetically indistinguishable from zero. This affirms the results obtained at $350 \mathrm{~nm}$ observation wavelength. A pseudo-firstorder rate constant of $1.43 \times 10^{-2} \mathrm{~s}^{-1}$ was deduced. 


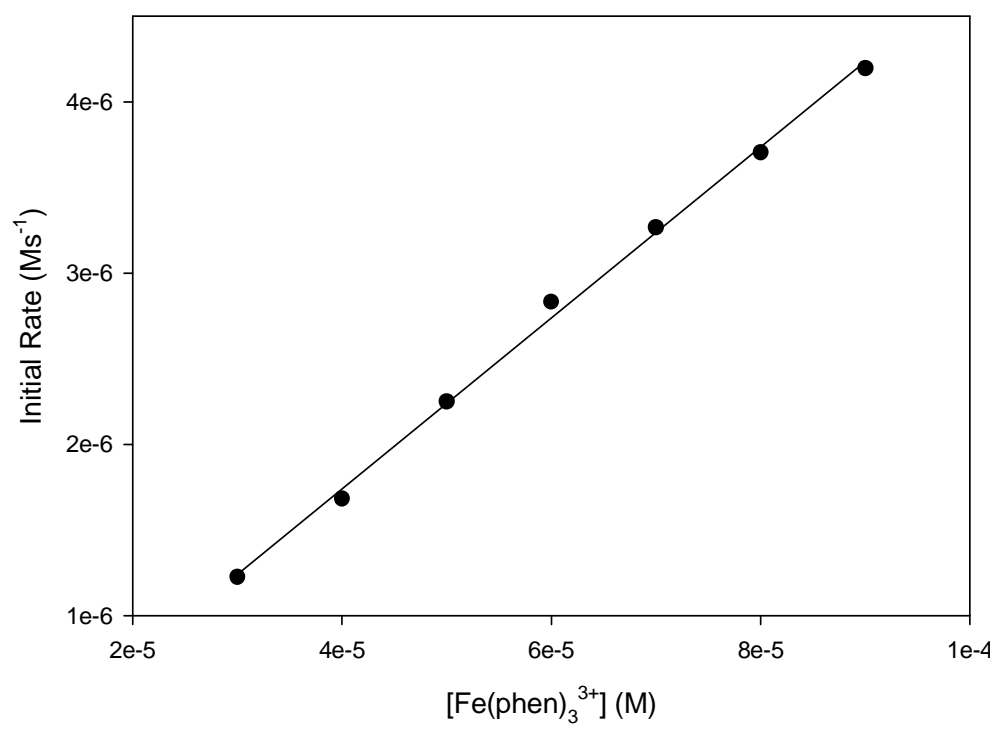

Figure 8-4b: Initial rate plot derived from Figure 8-4a, showing linear dependence on $\mathrm{Fe}(\text { phen })_{3}{ }^{3+}$.

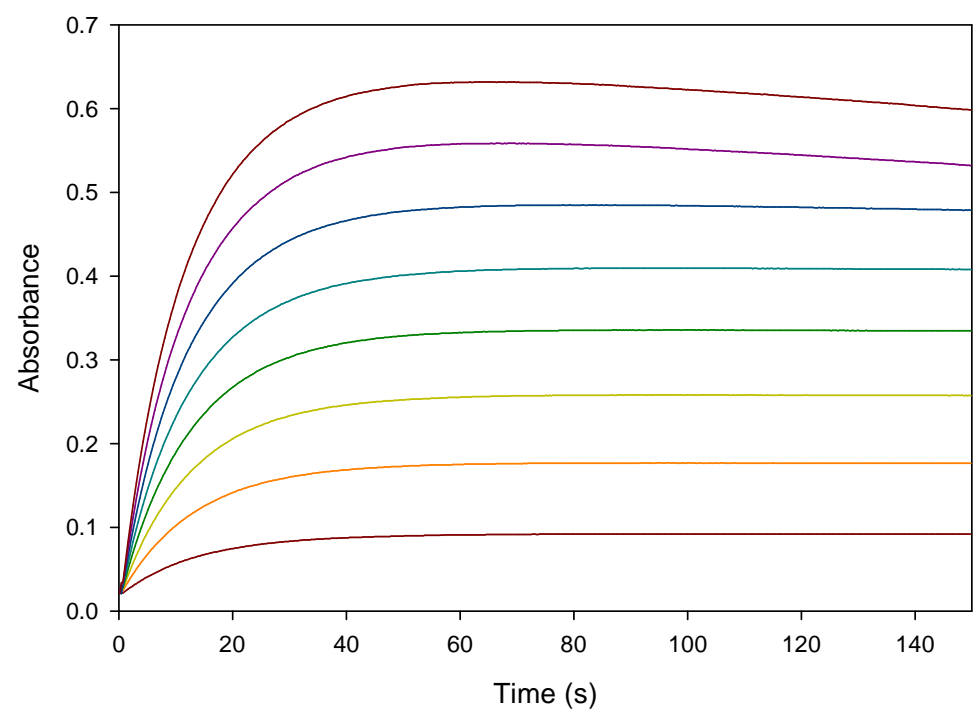

Figure 8-4c: Effect of $\left[\mathrm{Fe}(\text { phen })_{3}{ }^{3+}\right]$ variation on the formation of $\mathrm{Fe}(\text { phen })_{3}{ }^{2+}$ at 510 nm. $[\text { Cysteine }]_{o}=2.0 \times 10^{-3} \mathrm{M} ;\left[\mathrm{H}^{+}\right]_{o}=0.5 \mathrm{M} ;\left[\mathrm{Fe}(\text { phen })_{3}{ }^{3+}\right]_{o}=\left(\right.$ a) $1.0 \times 10^{-5} \mathrm{M}$ through (h) $8.0 \times 10^{-5} \mathrm{M}$ 
8.3.3 Effect of cysteine on reaction rate: The effect of cysteine on its oxidation by $\mathrm{Fe}(\text { phen })_{3}{ }^{3+}$ was monitored at $350 \mathrm{~nm}$ and $510 \mathrm{~nm}$ Figure 8-5, summarizes this effect. The rate of consumption of $\mathrm{Fe}(\mathrm{phen})_{3}{ }^{3+}$ (dashed lines) increased with increased concentrations of cysteine. The same trend was observed when monitoring the rate of formation of $\mathrm{Fe}(\mathrm{phen})_{3}{ }^{2+}$ at $510 \mathrm{~nm}$ (solid lines). Initial rate plots deduced from Figure S-5 show linear-order dependence but with saturation.

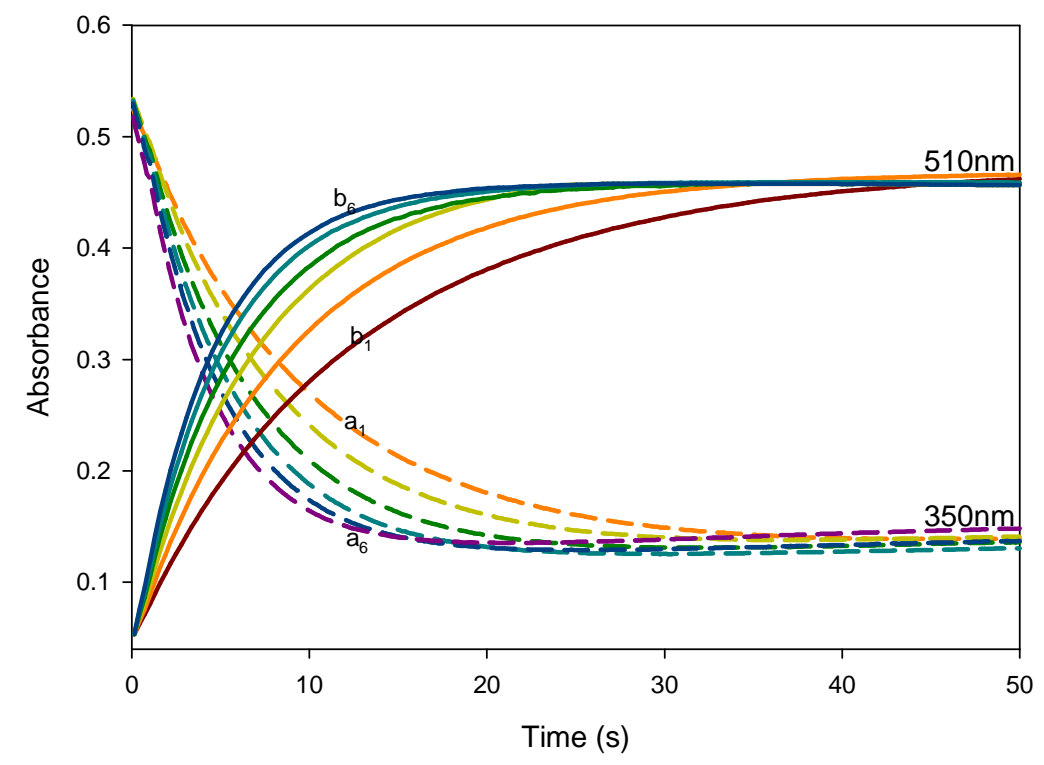

Figure 8-5: $\quad$ The dashed lines show consumption of the oxidant, $\mathrm{Fe}(\text { phen })_{3}{ }^{3+}$ at 350 $\mathrm{nm}$ and the solid lines show formation of $\mathrm{Fe}(\mathrm{phen})_{3}{ }^{2+}$ at $510 \mathrm{~nm}$. In both cases rate was increased with cysteine.

8.3.4 Effect of acid on reaction rate: While other reaction conditions were kept constant, the dependence of reaction on initial acid concentrations was evaluated. Figure 8-6 summarizes the effect of acid variation on both the rate of consumption of 
oxidant at $350 \mathrm{~nm}$ and the rate of formation of the reduced complex at $510 \mathrm{~nm}$. The range of possible variations with respect to initial acid concentrations is limited since the stock $\mathrm{Fe}(\text { phen })_{3}{ }^{3+}$ solution was made in $2.0 \mathrm{M}$ acid. This was to prevent the aquation of $\mathrm{Fe}$ (phen $)_{3}{ }^{3+}$ into the undetermined khaki colored polymeric hydroxo complexes. ${ }^{300}$ The observation is that acid has an inhibitory effect on the reaction as the rate of product formation decreases with increase in acid concentrations. Both initial rates show inverse acid dependence.

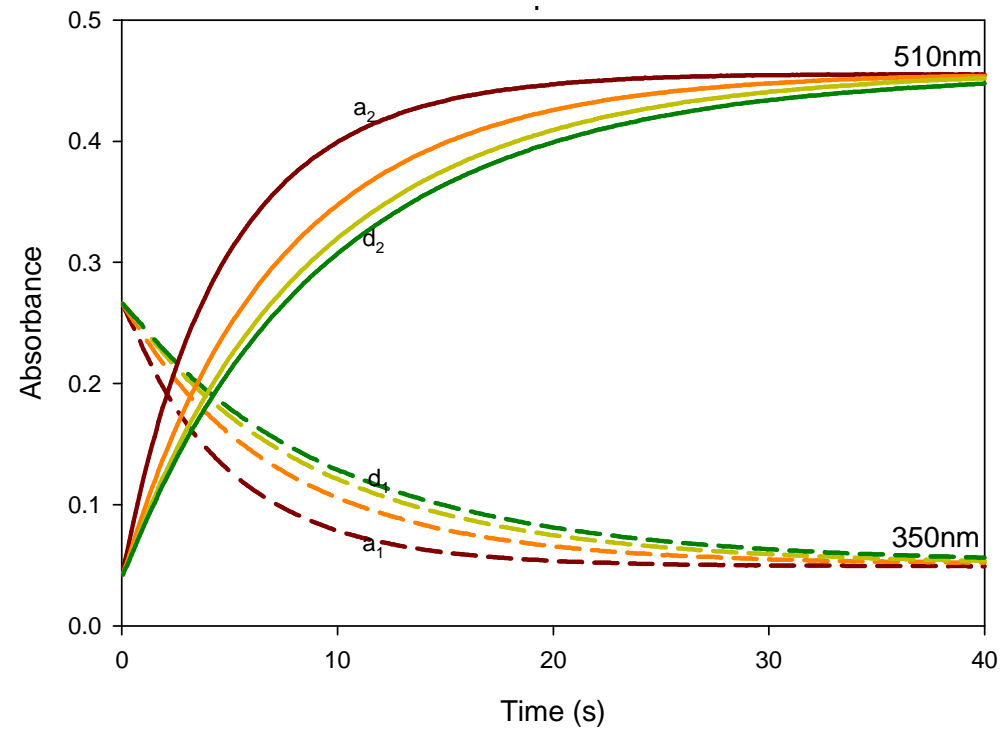

Figure 8-6: Evaluation of effect of initial acid concentrations. An inverse acid dependence observed on the rate of formation $\mathrm{Fe}(\text { phen })_{3}{ }^{2+}(510 \mathrm{~nm})$ and consumption

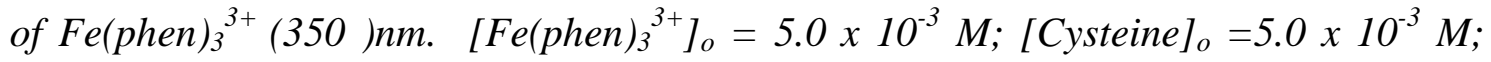
$\left[\mathrm{H}^{+}\right]_{o}=($ a) $0.30 \mathrm{M} ;($ b) $0.40 \mathrm{M} ;($ c) $0.50 \mathrm{M} ;(d) 0.60 \mathrm{M}$. 
8.3.5 Effect of ionic strength: The response of the present reaction to changes in concentration of an inert salt, at constant temperature and reactants concentrations, was examined (Figure 8-7). Increasing ionic strength decreased the rate of reaction. This might suggest that the rate determining step(s) contain species of different charges.

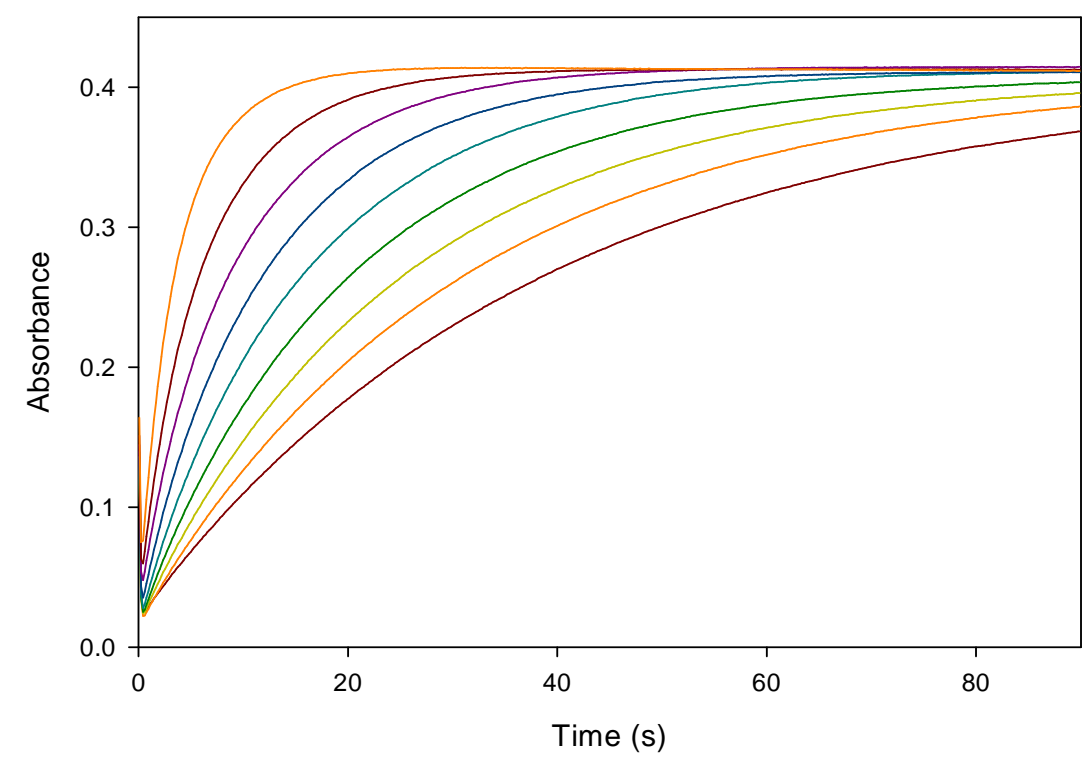

Figure 8-7: Evaluation of effect of ionic strength. $[\text { Cysteine }]_{o}=2.0 \times 10^{-3} \mathrm{M}$; $\left[\mathrm{Fe}(\text { phen })_{3}{ }^{3+}\right]_{o}=5.0 \times 10^{-5} \mathrm{M} ;\left[\mathrm{H}^{+}\right]_{o}=0.5 \mathrm{M} ;[\mu]_{\mathrm{NaClO} 4}=(a) 0.4 \mathrm{M}(\mathrm{b}) 0.6 \mathrm{M}(\mathrm{c}) 0.8 \mathrm{M}$ (d) $1.0 M(e) 1.2 M(f) 1.4 M(g) 1.6 M(h) 1.8 M(i) 2.0 M$.

8.3.6 Thermodynamic and activation parameters: At constant ionic strength, acid and concentrations of oxidant and substrate, the effect of temperature on the reaction was evaluated. Reaction rate increased proportionally with increasing temperatures as expected (see Figure 8-8a). The obtained kinetics data were used to construct an Arrhenius plot (see Figure 8-8b). 


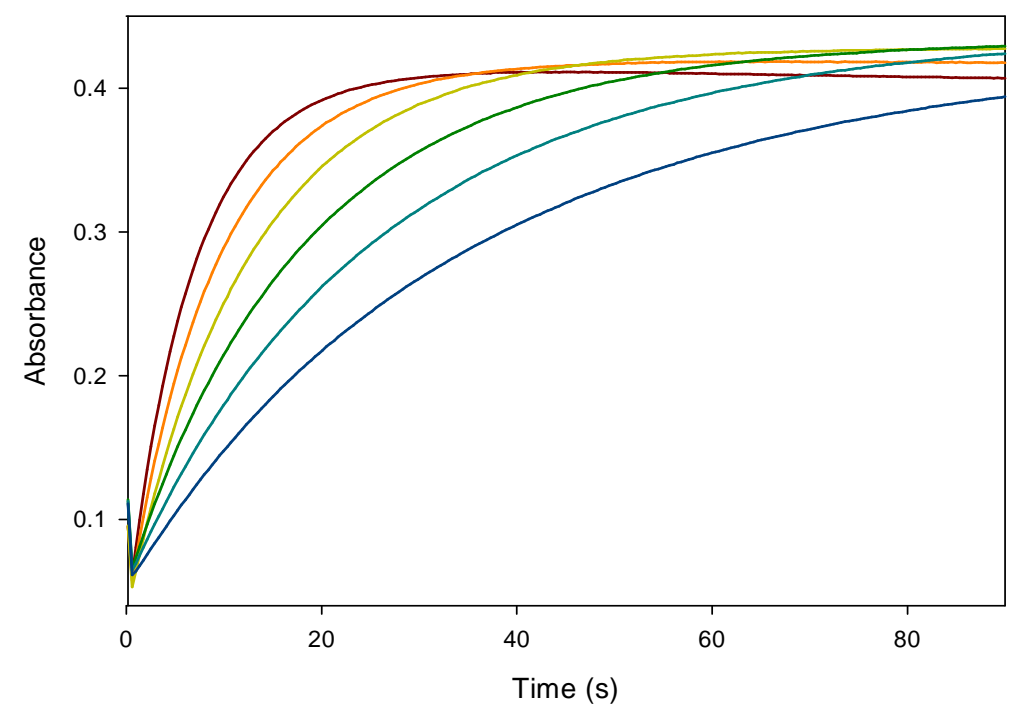

Figure 8-8a: Temperature dependence of cysteine-ferriin reaction. Increase in rate observed with temperature increase. $[\text { Cysteine }]_{o}=2.0 \times 10^{-3} \mathrm{M} ;\left[\mathrm{Fe}(\text { phen })_{3}{ }^{3+}\right]_{o}=5.0 x$ $10^{-5} \mathrm{M} ;\left[\mathrm{H}^{+}\right]_{o}=0.5 \mathrm{M}$; Temperature in increament of $5{ }^{\circ} \mathrm{C}$ from 10 through $30^{\circ} \mathrm{C}$.

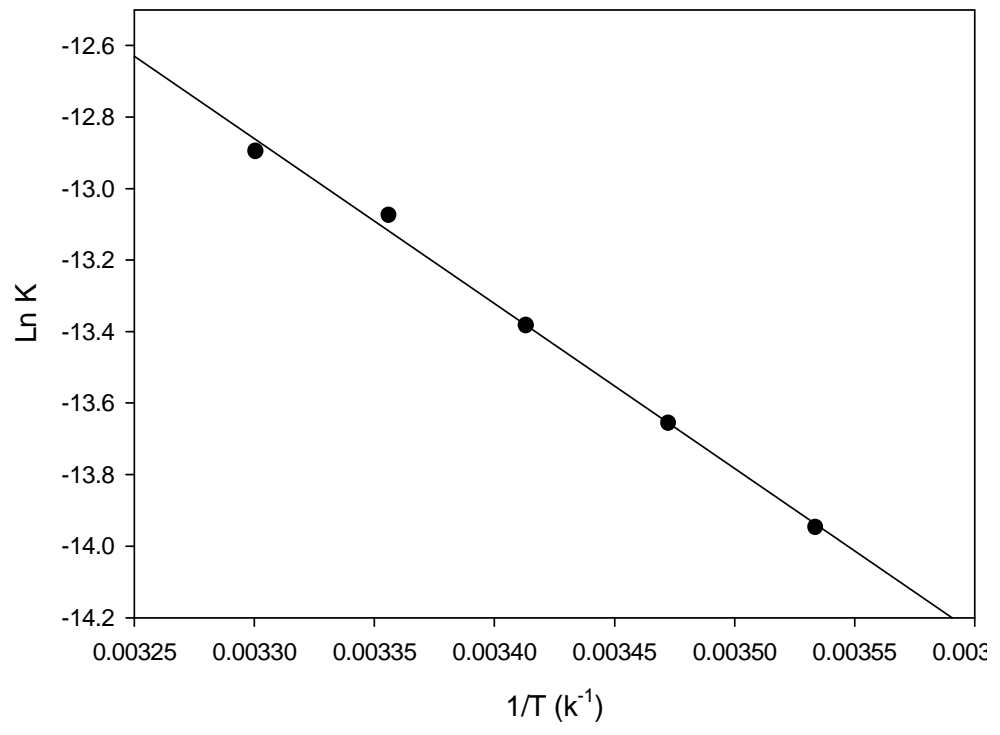

Figure 8-8b: Arrhenius plot extracted from study of effect of temperature variation on the reaction for determination of activation parameters. 
The Arrhenius plot afforded these activation parameters: entropy of activation, $\Delta \mathrm{S}^{\ddagger}=-217.02 \pm 0.03 \mathrm{~J} \mathrm{~K}^{-1} \mathrm{~mol}^{-1}$, enthalpy of activation, $\Delta \mathrm{H}^{\ddagger}=35.85 \pm 0.38 \mathrm{~kJ} \mathrm{~mol}^{-1}$ and free energy of activation as $\Delta \mathrm{G}^{\neq}=100.52 \mathrm{~kJ} \mathrm{~mol}^{-1}$. The distinctly negative entropy of activation suggests some degree of molecular ordering in the rate determining step. This is indicative of an associative mechanism.

\subsubsection{Mechanism}

The results obtained have allowed us to propose stepwise reactions involved in the oxidation of L-cysteine by $\mathrm{Fe}$ (phen) $3^{3+}$. Reactions were carried out in acidic medium, therefore, cysteine (RSH) exists mostly in the protonated form as shown in R2.
$\mathrm{RSH}+\mathrm{H}^{+}$

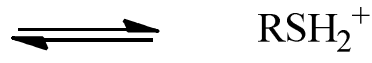
$\mathrm{K}_{\mathrm{b}}$
R2

Unprotonated cysteine also exists but to a lesser extent in the reaction. Both protonated and unprotonated cysteine can react with $\mathrm{Fe}(\mathrm{phen}){ }_{3}{ }^{3+}$ to associative complex (R3 and R4). This is supported by the thermodynamic parameters obtained from Figures 8-8a and $\mathrm{b}$. The activated complexes formed in R3 and R4 then proceed to form products as shown in R5. Contribution from intermediate complex formed by R4 would be minimal since unprotonated cysteine concentrations are negligible 


$$
\begin{aligned}
& \mathrm{RSH}+\mathrm{Fe}(\text { phen })_{3}{ }^{3+} \rightleftharpoons \quad\left(\mathrm{Fe}(\text { phen })_{3}{ }^{3+} \cdot \mathrm{RSH}\right) \quad \mathrm{k}_{1}, \mathrm{k}_{-1} \quad \mathrm{R} 3 \\
& \mathrm{RSH}_{2}{ }^{+}+\mathrm{Fe}(\text { phen })_{3}{ }^{3+} \rightleftharpoons \quad\left(\mathrm{Fe}(\text { phen })_{3}{ }^{3+} \cdot \mathrm{RSH}_{2}{ }^{+}\right) \quad \mathrm{k}_{1}, \mathrm{k}_{-1} \quad \mathrm{R} 4
\end{aligned}
$$

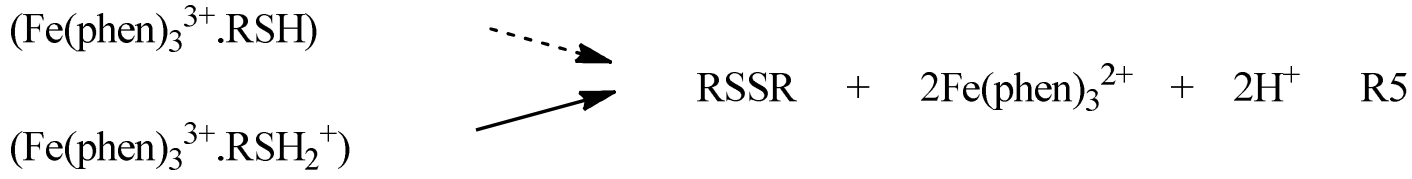

Following the disappearance of $\mathrm{Fe}(\mathrm{phen}){ }_{3}{ }^{3+}$ the rate of reaction can be written as:

$$
\frac{-\mathrm{d}\left[\mathrm{Fe}(\text { phen })_{3}{ }^{3+}\right]}{\mathrm{dt}}=\mathrm{k}_{1}\left[\mathrm{Fe}(\text { phen })_{3}{ }^{3+}\right][\mathrm{RSH}]+\mathrm{k}_{2}\left[\mathrm{Fe}(\text { phen })_{3}{ }^{3+}\right]\left[\mathrm{RSH}_{2}{ }^{+}\right]
$$

From R2, the concentration of protonated cysteine can be written as

$$
\left[\mathrm{RSH}_{2}^{+}\right]=\mathrm{K}_{\mathrm{b}}[\mathrm{RSH}]\left[\mathrm{H}^{+}\right]
$$

The concentrations of all cysteine species are derived from initial cysteine concentration, therefore,

$[\mathrm{RSH}]_{\mathrm{o}}=[\mathrm{RSH}]+\left[\mathrm{RSH}_{2}^{+}\right]$

Substituting for $\left[\mathrm{RSH}_{2}^{+}\right]$in equation

$$
[\mathrm{RSH}]=\frac{[\mathrm{RSH}]_{\mathrm{O}}}{1+\mathrm{K}_{\mathrm{b}}\left[\mathrm{H}^{+}\right]}
$$


The rate then becomes:

$$
\text { Rate }=\frac{\mathrm{k}_{1}+\mathrm{K}_{\mathrm{b}} \mathrm{k}_{2}\left[\mathrm{H}^{+}\right]}{1+\mathrm{K}_{\mathrm{b}}\left[\mathrm{H}^{+}\right]}\left\{[\mathrm{RSH}]_{\mathrm{o}}\left[\mathrm{Fe}(\text { phen })_{3}{ }^{3+}\right]\right\}
$$

There is a first-order dependence on $\mathrm{Fe}(\text { phen })_{3}{ }^{3+}$ and cysteine as demonstrated by Figures $8-4 \mathrm{a}-\mathrm{c}$ and Figure 8-5 respectively. This rate shows a complex dependence on acid concentration. Figure 8-6 demonstrates inhibitory effect of acid on the reaction. At low acid concentrations, rate would be first-order in acid but in high acid concentrations, however, the reaction saturates as observed in Figure 8-6. An explanation for retardation by acid is that high acid concentration increasingly stabilizes $\mathrm{Fe}(\text { phen })_{3}{ }^{3+}$, making it react more slowly. The rate law can then be simplified to

$$
\text { Rate }=\mathrm{k}_{\mathrm{o}}[\mathrm{RSH}]_{\mathrm{o}}\left[\mathrm{Fe}(\text { phen })_{3}{ }^{3+}\right]
$$

where

$$
\mathrm{k}_{\mathrm{o}}=\frac{\mathrm{k}_{1}+\mathrm{K}_{\mathrm{b}} \mathrm{k}_{2}\left[\mathrm{H}^{+}\right]}{1+\mathrm{K}_{\mathrm{b}}\left[\mathrm{H}^{+}\right]}
$$

The bimolecular rate constant for the reaction was $7.15 \mathrm{M}^{-1} \mathrm{~s}^{-1}$. The thermodynamic parameters obtained indicate formation of associative intermediate prior to product formation. Saturation in cysteine dependence can may be due to sequestering 
of cysteine by $\mathrm{Fe}(\text { phen })_{3}{ }^{3+}$ to form an initial complex which does not contribute significantly to the product. 


\section{REFERENCES}

1. Lehninger, A. L. Physiological Reviews 1950, 30, 393.

2. Lao, T. T.; Ho, L. F. Diabetes Care 2004, 27, 650-656.

3. Mackenzie, G. G.; Zago, M. P.; Aimo, L.; Oteiza, P. I. Iubmb Life 2007, 59, 299-307.

4. Olin, K.; Oteiza, P. I.; Keen, C. L. Faseb Journal 1994, 8, A716.

5. Oteiza, P. I. Free Radical Research 2006, 40, S41.

6. Pietrangelo, A. American Journal of Physiology-Gastrointestinal and Liver Physiology 2002, 282, 403-414.

7. Manunza, B.; Deiana, S.; Pintore, M.; Solinas, V.; Gessa, C. Journal of Molecular Structure: THEOCHEM 1997, 419, 33-36.

8. Lee, W. T.; Leung, S. S.; Leung, D. M.; Cheng, J. C. American Journal of Clinical Nutrition 1996, 64, 71-77.

9. Lloyd, R. V.; Hanna, P. M.; Mason, R. P. Free Radical Biology and Medicine 1997, 22, 885-888.

10. Crichton, R. R.; Ward, R. J. Biochemistry 1992, 31, 11255-11264. 
11. Smith, M. A.; Harris, P. L. R.; Sayre, L. M.; Perry, G. Proceedings of the National Academy of Sciences of the United States of America 1997, 94, 98669868.

12. Weinberg, E. D. Oxidative Medicine and Cellular Longevity 2009, 2, 107-109.

13. Ryan, T. P.; Aust, S. D. Critical Reviews in Toxicology 1992, 22, 119-141.

14. Fraga, C. G.; Oteiza, P. I. Toxicology 2002, 180, 23-32.

15. Berg, D.; Gerlach, M.; Youdim, M. B. H.; Double, K. L.; Zecca, L.; Riederer, P.; Becker, G. Journal of Neurochemistry 2001, 79, 225-236.

16. Ho, E. The Journal of nutritional biochemistry 2004, 15, 572-578.

17. Pearson, M. A.; Michel, L. O.; Hausinger, R. P.; Karplus, P. A. Biochemistry 1997, 36, 8164-8172.

18. Koehntop, K. D.; Emerson, J. P.; Que, L. Journal of Biological Inorganic Chemistry 2005, 10, 87-93.

19. David, S. S.; Meggers, E. Current Opinion in Chemical Biology 2008, 12, 194.

20. Moore, S. A.; Anderson, B. F.; Groom, C. R.; Haridas, M.; Baker, E. N. Journal of Molecular Biology 1997, 274, 222-236.

21. Rozenfeld, R.; Iturrioz, X.; Okada, M.; Maigret, B.; Llorens-Cortes, C. Biochemistry 2003, 42, 14785-14793. 
22. Jackson, M. S.; Lee, J. C. Inorganic Chemistry 2009, 48, 9303-9307.

23. Yaman, M.; Atici, D.; Bakirdere, S.; Akdeniz, I. Journal of Medicinal Chemistry 2005, 48, 630-634.

24. Hannon, M. J. Pure and Applied Chemistry 2007, 79, 2243-2262.

25. American Cancer Society. Cancer Basics. American Cancer Society . 7-182011. 1-22-2009.

Ref Type: Online Source

26. Heron, M.; Hoyert, D. L.; Murphy, S. L.; Xu, J.; Kochanek, K. D.; Tejada-Vera, B. National vital statistics reports: from the Centers for Disease Control and Prevention, National Center for Health Statistics 2009, 57, 1.

27. Heron, M.; Sutton, P. D.; Xu, J. Q.; Ventura, S. J.; Strobino, D. M.; Guyer, B. Pediatrics 2010, 125, 4-15.

28. Jemal, A.; Siegel, R.; Ward, E.; Hao, Y. P.; Xu, J. Q.; Thun, M. J. Ca-A Cancer Journal for Clinicians 2009, 59, 225-249.

29. Siegel, R.; Naishadham, D.; Jemal, A. CA: A Cancer Journal for Clinicians 2012.

30. Rosenberg, B. In Cisplatin: Chemistry and Biochemistry of a Leading Anticancer Drug, 1999; 3-27. 
31. BernersPrice, S. J.; Sadler, P. J. Coordination Chemistry Reviews 1996, 151, 140.

32. Jones, R. H.; Vasey, P. A. Lancet Oncology 2003, 4, 730-737.

33. Reisner, E.; Arion, V. B.; Keppler, B. K.; Pombeiro, A. J. L. Inorganica Chimica Acta 2008, 361, 1569-1583.

34. Jones, R. H.; Vasey, P. A. Lancet Oncology 2003, 4, 738-747.

35. Einhorn, L. H.; Donohue, J. Annals of internal medicine 1977, 87, 293.

36. Dobyan, D. C.; Levi, J.; Jacobs, C.; Kosek, J.; Weiner, M. W. Journal of Pharmacology and Experimental Therapeutics 1980, 213, 551-556.

37. Kelland, L. Nature Reviews Cancer 2007, 7, 573-584.

38. Desoize, B. Anticancer Research 2004, 24, 1529-1544.

39. Desoize, B.; Madoulet, C. Critical Reviews in Oncology Hematology 2002, 42, 317-325.

40. Yabroff, K. R.; Bradley, C. J.; Mariotto, A. B.; Brown, M. L.; Feuer, E. J. JNCI Journal of the National Cancer Institute 2008, 100, 1755.

41. Lezoche, E.; Baldarelli, M.; De Sanctis, A.; Lezoche, G.; Guerrieri, M. Digestive Diseases 2007, 25, 76-79. 
42. Perez, R. P. European Journal of Cancer 1998, 34, 1535-1542.

43. Jemal, A.; Siegel, R.; Ward, E.; Hao, Y.; Xu, J.; Murray, T.; Thun, M. J. CA: $a$ cancer journal for clinicians $\mathbf{2 0 0 8 , 5 8 , 7 1 .}$

44. Knight, K. R. G.; Kraemer, D. F.; Neuwelt, E. A. Journal of Clinical Oncology 2005, 23, 8588-8596.

45. Rybak, L. P.; Mukherjea, D.; Jajoo, S.; Ramkumar, V. Tohoku Journal of Experimental Medicine 2009, 219, 177-186.

46. Weiss, L. Cancer metastasis reviews 2000, 19, 193-383.

47. Jemal, A.; Clegg, L. X.; Ward, E.; Ries, L. A. G.; Wu, X. C.; Jamison, P. M.; Wingo, P. A.; Howe, H. L.; Anderson, R. N.; Edwards, B. K. Cancer 2004, 101, $3-27$.

48. Arlt, F.; Stein, U. The International Journal of Biochemistry \& Cell Biology 2009, 41, 2356-2359.

49. O'Connell, J. B.; Maggard, M. A.; Ko, C. Y. Journal of the National Cancer Institute 2004, 96, 1420-1425.

50. Gupta, G. P.; Massagu日, J. Cell 2006, 127, 679-695.

51. Weiss, L.; Ward, P. M. Cancer and Metastasis Reviews 1983, 2, 111-127.

52. Mehlen, P.; Puisieux, A. Nature Reviews Cancer 2006, 6, 449-458. 
53. Gupta, G. P.; Massague, J. Cell 2006, 127, 679-695.

54. Aslakson, C. J.; Miller, F. R. Cancer Research 1992, 52, 1399-1405.

55. Leibovici, J.; Klorin, G.; Huszar, M.; Hoenig, S.; Michowitz, M. International Journal of Experimental Pathology 1991, 72, 139-150.

56. Kuramochi, H.; Hayashi, K.; Uchida, K.; Miyakura, S.; Shimizu, D.; Vallbohmer, D.; Park, S.; Danenberg, K. D.; Takasaki, K.; Danenberg, P. V. International Journal of Cancer 2006, 119, 522-526.

57. Schmalfeldt, B.; Kuhn, W.; Reuning, U.; Pache, L.; Dettmar, P.; Schmitt, M.; Janicke, F.; Hofler, H.; Graeff, H. Cancer Research 1995, 55, 3958-3963.

58. Sava, G.; Bergamo, A. Anticancer Research 1999, 19, 1117-1124.

59. Testa, B. Current Opinion in Chemical Biology 2009, 13, 338-344.

60. Mura, P.; Casini, A.; Marcon, G.; Messori, L. Inorganica Chimica Acta 2001, $312,74-80$.

61. Mestroni, G.; Alessio, E.; Santi, A. S.; Geremia, S.; Bergamo, A.; Sava, G.; Boccarelli, A.; Schettino, A.; Coluccia, M. Inorganica Chimica Acta 1998, 273, $62-71$.

62. Sava, G.; Capozzi, I.; Clerici, K.; Gagliardi, G.; Alessio, E.; Mestroni, G. Clinical \& Experimental Metastasis 1998, 16, 371-379. 
63. Iengo, E.; Mestroni, G.; Geremia, S.; Calligaris, M.; Alessio, E. Journal of the Chemical Society-Dalton Transactions 1999, 3361-3371.

64. Heffeter, P.; Jakupec, M. A.; Korner, W.; Chiba, P.; Pirker, C.; Dornetshuber, R.; Elbling, L.; Sutterluty, H.; Micksche, M.; Keppler, B. K.; Berger, W. Biochemical Pharmacology 2007, 73, 1873-1886.

65. Sava, G.; Pacor, S.; Mestroni, G.; Alessio, E. Clinical \& Experimental Metastasis 1992, 10, 273-280.

66. Galanski, M.; Arion, V. B.; Jakupec, M. A.; Keppler, B. K. Current Pharmaceutical Design 2003, 9, 2078-2089.

67. Bergamo, A.; Masi, A.; Jakupec, M. A.; Keppler, B. K.; Sava, G. Metal-Based Drugs 2009, 2009, 1-9.

68. Hartinger, C. G.; Zorbas-Seifried, S.; Jakupec, M. A.; Kynast, B.; Zorbas, H.; Keppler, B. K. Journal of Inorganic Biochemistry 2006, 100, 891-904.

69. Bergamo, A.; Cocchietto, M.; Capozzi, I.; Mestroni, G.; Alessio, E.; Sava, G. Anti-Cancer Drugs 1996, 7, 697-702.

70. Mestroni, G., Alessio, E., and Sava, G. Salts of anionic complexes of RU (III), as antimetastatic and antineoplastic agents. Sigea S.r.l, Trieste IT. 09/214,254[US 6,221,905 B1]. 1998.

Ref Type: Patent 
71. Sava, G.; Gagliardi, R.; Bergamo, A.; Alessio, E.; Mestroni, G. Anticancer Research 1999, 19, 969-972.

72. Bergamo, A.; Gagliardi, R.; Scarcia, V.; Furlani, A.; Alessio, E.; Mestroni, G.; Sava, G. Journal of Pharmacology and Experimental Therapeutics 1999, 289, $559-564$.

73. Rademaker-Lakhai, J. M.; van den Bongard, D.; Pluim, D.; Beijnen, J. H.; Schellens, J. H. M. Clinical Cancer Research 2004, 10, 3717-3727.

74. Sava, G.; Zorzet, S.; Turrin, C.; Vita, F.; Soranzo, M.; Zabucchi, G.; Cocchietto, M.; Bergamo, A.; DiGiovine, S.; Pezzoni, G.; Sartor, L.; Garbisa, S. Clinical Cancer Research 2003, 9, 1898-1905.

75. Gava, B.; Zorzet, S.; Spessotto, P.; Cocchietto, M.; Sava, G. Journal of Pharmacology and Experimental Therapeutics 2006, 317, 284-291.

76. Bergamo, A.; Gaiddon, C.; Schellens, J. H. M.; Beijnen, J. H.; Sava, G. Journal of Inorganic Biochemistry 2012, 106, 90-99.

77. Frausin, F.; Scarcia, V.; Cocchietto, M.; Furlani, A.; Serli, B.; Alessio, E.; Sava, G. Journal of Pharmacology and Experimental Therapeutics 2005, 313, 227233.

78. Sava, G.; Frausin, F.; Cocchietto, M.; Vita, F.; Podda, E.; Spessotto, P.; Furlani, A.; Scarcia, V.; Zabucchi, G. European Journal of Cancer 2004, 40, 1383-1396. 
79. Bergamo, A.; Sava, G. Dalton Transactions 2007, 1267-1272.

80. Collins, V. P.; Loeffler, R. K.; Tivey, H. American Journal of Roentgenology Radium Therapy and Nuclear Medicine 1956, 76, 988-1000.

81. Sundararajan, S.; Tohno, E.; Kamma, H.; Ueno, E.; Minami, M. Clinical Radiology 2007, 62, 252-261.

82. Ravera, M.; Baracco, S.; Cassino, C.; Zanello, P.; Osella, D. Dalton Trans. 2004, 2347-2351.

83. Bouma, M.; Nuijen, B.; Jansen, M. T.; Sava, G.; Bult, A.; Beijnen, J. H. Journal of Pharmaceutical and Biomedical Analysis 2002, 30, 1287-1296.

84. Sava, G.; Bergamo, A.; Zorzet, S.; Gava, B.; Casarsa, C.; Cocchietto, M.; Furlani, A.; Scarcia, V.; Serli, B.; Iengo, E.; Alessio, E.; Mestroni, G. European Journal of Cancer 2002, 38, 427-435.

85. Groessl, M.; Hartinger, C. G.; Polec-Pawlak, K.; Jarosz, M.; Dyson, P. J.; Keppler, B. K. Chemistry \& Biodiversity 2008, 5, 1609-1614.

86. Cocchietto, M.; Zorzet, S.; Sorc, A.; Sava, G. Investigational new drugs 2003, $21,55-62$.

87. Clarke, M. J.; Bitler, S.; Rennert, D.; Buchbinder, M.; Kelman, A. D. Journal of Inorganic Biochemistry 1980, 12, 79-87. 
88. Laliberte, F.; Sun, I. L.; Crane, F. L.; Clarke, M. J. Journal of Bioenergetics and Biomembranes 1987, 19, 69-81.

89. Mestroni, G.; Alessio, E.; Sava, G.; Pacor, S.; Coluccia, M.; Boccarelli, A. Metal-Based Drugs 1994, 1, 41-63.

90. Tannock, I. F.; Rotin, D. Cancer Research 1989, 49, 4373-4384.

91. Sava, G.; Pacor, S.; Bregant, F.; Ceschia, V.; Mestroni, G. Anti-Cancer Drugs 1990, $1,99-108$.

92. Allardyce, C. S.; Dyson, P. J. Platinum Metals Review 2001, 45, 62-69.

93. Bergamo, A.; Messori, L.; Piccioli, F.; Cocchietto, M.; Sava, G. Investigational new drugs 2003, 21, 401-411.

94. Brindell, M.; Stawoska, I.; Supel, J.; Skoczowski, A.; Stochel, G.; van Eldik, R. Journal of Biological Inorganic Chemistry 2008, 13, 909-918.

95. Griffith, O. W. Free Radical Biology and Medicine 1999, 27, 922-935.

96. Jones, D. P.; Carlson, J. L.; Mody, V. C.; Cai, J. Y.; Lynn, M. J.; Sternberg, P. Free Radical Biology and Medicine 2000, 28, 625-635.

97. Jonas, C. R.; Ziegler, T. R.; Gu, L. H.; Jones, D. P. Free Radical Biology and Medicine 2002, 33, 1499-1506. 
98. Nkabyo, Y. S.; Ziegler, T. R.; Gu, L. H.; Watson, W. H.; Jones, D. P. American Journal of Physiology-Gastrointestinal and Liver Physiology 2002, 283, G1352G1359.

99. Nkabyo, Y. S.; Gu, L. H.; Jones, D. P.; Ziegler, T. R. Journal of Nutrition 2006, $136,1242-1248$.

100. Jones, D. P. Protein Sensors and Reactive Oxygen Species, Pt B, Thiol Enzymes and Proteins 2002, 348, 93-112.

101. Schafer, F. Q.; Buettner, G. R. Free Radical Biology and Medicine 2001, 30, 1191-1212.

102. Maher, P. Antioxidants \& Redox Signaling 2006, 8, 1941-1970.

103. Jonas, C. R.; Puckett, A. B.; Jones, D. P.; Griffith, D. P.; Szeszycki, E. E.; Bergman, G. F.; Furr, C. E.; Tyre, C.; Carlson, J. L.; Galloway, J. R.; Blumberg, J. B.; Ziegler, T. R. American Journal of Clinical Nutrition 2000, 72, 181-189.

104. De Flora, S.; Agostini, F. D.; Masiello, L.; Giunciuglio, D.; Albini, A. International Journal of Cancer 1998, 67, 842-848.

105. Shaw, I. C.; Graham, M. I. Cancer Treatment Reviews 1987, 14, 67-86.

106. Kabasakal, L.; Sehirli, A. O.; Cetinel, S.; Cikler, E.; Gedik, N.; Sener, G. Life Sciences 2004, 75, 2329-2340. 
107. Yurkow, E. J. and Mermelstein, F. H. Method for treating cancer. 10/522092[PCT/US03/23867]. 7-30-2003. Google Patents. 7-30-2003.

Ref Type: Patent

108. Ypsilantis, P.; Tentes, I.; Lambropoulou, M.; Anagnostopoulos, K.;

Papadopoulos, N.; Kortsaris, A.; Simopoulos, C. Journal of Gastroenterology and Hepatology 2008, 23, 328-335.

109. Weissman, I., Kristal, B., Sela, S., and Shahsa, S. Therapeutic uses for sodium 2-mercaptoethanesulphonate (mesna). 1997.

Ref Type: Patent

110. Yue, J.; Dong, G.; He, C.; Chen, J.; Liu, Y.; Peng, R. Toxicology 2009, 264, $185-191$.

111. Zhang, J. G.; Lindup, W. E. Toxicology and Applied Pharmacology 1996, 141, 425-433.

112. Koide, T.; Yamagushi, S.; Utsonomiya, M.; Yoshioka, T. "A new therapeutic agent for cystinuria".

Ref Type: Conference Proceeding

113. Hercelin, B.; Leroy, P.; Nicolas, A.; Gavriloff, C.; Chassard, D.; Thebault, J. J.; Reveillaud, M. T.; Salles, M. F.; Netter, P. European Journal of Clinical Pharmacology 1992, 43, 93-95. 
114. Kroning, R.; Lichtenstein, A. K.; Nagami, G. T. Cancer Chemotherapy and Pharmacology 2000, 45, 43-49.

115. Davis, D. A.; Dorsey, K.; Wingfield, P. T.; Stahl, S. J.; Kaufman, J.; Fales, H. M.; Levine, R. L. Biochemistry 1996, 35, 2482-2488.

116. Ambroz, H. B.; Kornacka, E. M.; Przybytniak, G. K. Radiation Physics and Chemistry 2004, 70, 677-686.

117. Moran, L. K.; Quinlan, G. J. Current medicinal chemistry 2001, 8, 763-772.

118. Stocker, R.; Huang, A.; Jeranian, E.; Hou, J. Y.; Wu, T. T.; Thomas, S. R.; Keaney, J. F. Arteriosclerosis Thrombosis and Vascular Biology 2004, 24, 2028-2033.

119. Fu, X. Y.; Mueller, D. M.; Heinecke, J. W. Biochemistry 2002, 41, 1293-1301.

120. Raftery, M. J.; Yang, Z.; Valenzuela, S. M.; Geczy, C. L. Journal of Biological Chemistry 2001, 276, 33393-33401.

121. Luo, D. Y.; Anderson, B. D. Pharmaceutical Research 2006, 23, 2239-2253.

122. Read, J. F.; Bewick, S. A.; Graves, C. R.; MacPherson, J. M.; Salah, J. C.; Theriault, A.; Wyand, A. E. H. Inorganica Chimica Acta 2000, 303, 244-255.

123. Read, J. F.; Graves, C. R.; Jackson, E. Inorganica Chimica Acta 2003, 348, 4149. 
124. El-Ayaan, U.; Linert, W. Journal of Coordination Chemistry 2002, 55, 13091314.

125. Nagy, P.; Jameson, G. N. L.; Winterbourn, C. C. Chemical research in toxicology 2009, 113-139.

126. Darkwa, J.; Mundoma, C.; Simoyi, R. H. Journal of the Chemical SocietyFaraday Transactions 1998, 94, 1971-1978.

127. Darkwa, J.; Olojo, R.; Chikwana, E.; Simoyi, R. H. Journal of Physical Chemistry A 2004, 108, 5576-5587.

128. Chigwada, T. R.; Simoyi, R. H. Journal of Physical Chemistry A 2005, 109, 1094-1104.

129. Chigwada, T. R.; Chikwana, E.; Simoyi, R. H. Journal of Physical Chemistry A 2005, 109, 1081-1093.

130. Martincigh, B. S.; Mundoma, C.; Simoji, R. H. Journal of Physical Chemistry A 1998, 102, 9838-9846.

131. Harman, L. S.; Mottley, C.; Mason, R. P. Journal of Biological Chemistry 1984, 259, 5606-5611.

132. Svensson, E.; Gräslund, A.; Moldeus, P. Free Radical Biology and Medicine 1993, $14,167-175$. 
133. DeGray J. A.; Mason, R. P. Biothiols in Health and Disease; Marcel Dekker, Inc.: New York, 1995; Chapter 4, pp. 65-81.

134. Wang, X.; Stanbury, D. M. Inorg.Chem 2008, 47, 1224-1236.

135. Oae S.; Doi, J. T. Organic sulfur chemistry: structure and mechanism; CRC Press Inc.: Boca Raton, Florida, 1991; Chapter 6, pp. 203-291.

136. Harman, L. S.; Mottley, C.; Mason, R. P. Journal of Biological Chemistry 1984, $259,5606-5611$.

137. Filho, J. R.; Silva, W. C.; Pereira, J. C.; Franco, D. W. Inorganica Chimica Acta 2006, 359, 2888-2895.

138. Wang, F.; Chen, H.; Parkinson, J. A.; Murdoch, P. S.; Sadler, P. J. Inorganic Chemistry 2002, 41, 4509.

139. Lee, Y.; Choi, S.; Cho, M.; im, Y. Bull.Korean Chem.Soc 1990, 11, 281-286.

140. Crichton, R. R.; Dexter, D. T.; Ward, R. J. Monatshefte fur Chemie 2011, 142, 341-355.

141. Durand, F.; Bernuau, J.; Giostra, E.; Mentha, G.; Shouval, D.; Degott, C.; Benhamou, J. P.; Valla, D. Gut 2001, 48, 849-852.

142. Brewer, G. J. Current Treatment Options in Neurology 2000, 2, 193-203. 
143. Tummino, P. J.; Scholten, J. D.; Harvey, P. J.; Holler, T. P.; Maloney, L.; Gogliotti, R.; Domagala, J.; Hupe, D. Proceedings of the National Academy of Sciences of the United States of America 1996, 93, 969-973.

144. Loo, J. A.; Holler, T. P.; Sanchez, J.; Gogliotti, R.; Maloney, L.; Reily, M. D. J.Med.Chem 1996, 39, 4313-4320.

145. Tummino, P. J.; Harvey, P. J.; McQuade, T.; Domagala, J.; Gogliotti, R.; Sanchez, J.; Song, Y.; Hupe, D. Antimicrobial agents and chemotherapy 1997, $41,394$.

146. Aposhian, H. V.; Aposhian, M. M. Annual Review of Pharmacology and Toxicology 1990, 30, 279-306.

147. Aposhian, H. V.; Maiorino, R. M.; Gonzalez-Ramirez, D.; Zuniga-Charles, M.; Xu, Z.; Hurlbut, K. M.; Junco-Munoz, P.; Dart, R. C.; Aposhian, M. Toxicology 1995, 97, 23-38.

148. Domingo, J. L. Reproductive Toxicology 2003, 9, 105-113.

149. Andersen, O. Chem.Rev 1999, 99, 2683-2710.

150. Graziano, J. H.; Lolacono, N. J.; Moulton, T.; Mitchell, M. E.; Slavkovich, V.; Zarate, C. Journal of Pediatrics 1992, 120, 133-139.

151. Giles, N. M.; Watts, A. B.; Giles, G. I.; Fry, F. H.; Littlechild, J. A.; Jacob, C. Chemistry \& Biology 2003, 10, 677-693. 
152. Tognella, S. Cancer Treatment Reviews 1990, 17, 139-142.

153. Wang, X.; Guo, Z. Anti-Cancer Agents in Medicinal Chemistry (Formerly Current Medicinal Chemistry 2007, 7, 19-34.

154. Johnson, S. W.; Ferry, K. V.; Hamilton, T. C. Drug Resistance Updates 1998, 1, 243-254.

155. Kartalou, M.; Essigmann, J. M. Mutation Research-Fundamental and Molecular Mechanisms of Mutagenesis 2001, 478, 23-43.

156. Oprea, A.; Bazzazi, H.; Kangarloo, B.; Wolff, J. E. A. Anticancer Research 2001, 21, 1225-1229.

157. Stewart, D. J. Critical Reviews in Oncology/Hematology 2007, 63, 12-31.

158. Bose, R. N.; Ghosh, S. K.; Moghaddas, S. Journal of Inorganic Biochemistry 1997, 65, 199-205.

159. Brindell, M.; Piotrowska, D.; Shoukry, A. A.; Stochel, G.; van Eldik, R. Journal of Biological Inorganic Chemistry 2007, 12, 809-818.

160. Bacac, M.; Hotze, A. C. G.; van der Schilden, K.; Haasnoot, J. G.; Pacor, S.; Alessio, E.; Sava, G.; Reedijk, J. Journal of Inorganic Biochemistry 2004, 98, $402-412$. 
161. Chatlas, J.; Vaneldik, R.; Keppler, B. K. Inorganica Chimica Acta 1995, 233, 59-63.

162. Pluim, D.; van Waardenburg, R. C. A. M.; Beijnen, J. H.; Schellens, J. H. M. Cancer Chemotherapy and Pharmacology 2004, 54, 71-78.

163. Ravera, M.; Baracco, S.; Cassino, C.; Colangelo, D.; Bagni, G.; Sava, G.; Osella, D. Journal of Inorganic Biochemistry 2004, 98, 984-990.

164. Gallori, E.; Vettori, C.; Alessio, E.; Vilchez, F. G.; Vilaplana, R.; Orioli, P.; Casini, A.; Messori, L. Archives of Biochemistry and Biophysics 2000, 376, 156162.

165. Malina, J.; Novakova, O.; Keppler, B. K.; Alessio, E.; Brabec, V. Journal of Biological Inorganic Chemistry 2001, 6, 435-445.

166. Gibson, D. Dalton Trans. 2009, 10681-10689.

167. Perkin Elmer UV WinLab Software User's Guide, Perkin Elmer Inc: United Kingdom, 2000.

168. Smith, R. D.; Loo, J. A.; Edmonds, C. G.; Barinaga, C. J.; Udseth, H. R. Analytical Chemistry 1990, 62, 882-899.

169. Fenn, J. B.; Mann, M.; Meng, C. K.; Wong, S. F.; Whitehouse, C. M. Science 1989, 246, 64-71. 
170. Gates, P. Mass Spectrometry Resource: Electrospray Ionization. The University of Bristol, School of Chemistry . 2004. 2-4-2012.

Ref Type: Online Source

171. Makarov, A.; Denisov, E.; Lange, O.; Horning, S. Journal of the American Society for Mass Spectrometry 2006, 17, 977-982.

172. Makarov, A.; Denisov, E.; Kholomeev, A.; Baischun, W.; Lange, O.; Strupat, K.; Horning, S. Analytical Chemistry 2006, 78, 2113-2120.

173. Ewing, G. W. Analytical Instrumentation Handbook, 2nd ed.; Dekker, Inc.: New York Marcel, 1997.

174. Marder, K.; Stosser, R.; Borchert, H. H. Free Radical Biology and Medicine 1993, $14,339-342$.

175. Velasco, J.; Andersen, M. L.; Skibsted, L. H. Food Chemistry 2004, 85, 623632.

176. Sibrian-Vazquez, M.; Escobedo, J. O.; Lim, S.; Samoei, G. K.; Strongin, R. M. Proceedings of the National Academy of Sciences of the United States of America 2010, 107, 551-554.

177. Mestroni, G., Alessio, E., and Sava, G. Salts of Anionic Complexes of Ru(III), as Antimetastatic and Antineoplastic Agents. Sigea S.r.l., Trieste IT. WO/1998/000431[US]. 1998. 6-30-1997. 
Ref Type: Patent

178. Messori, L.; Orioli, P.; Vullo, D.; Alessio, E.; Iengo, E. European Journal of Biochemistry 2000, 267, 1206-1213.

179. Bouma, M.; Nuijen, B.; Jansen, M. T.; Sava, G.; Bult, A.; Beijnen, J. H. Journal of Pharmaceutical and Biomedical Analysis 2002, 30, 1287-1296.

180. Schluga, P.; Hartinger, C. G.; Egger, A.; Reisner, E.; Galanski, M.; Jakupec, M. A.; Keppler, B. K. Dalton Trans. 2006, 1796-1802.

181. Rademaker-Lakhai, J. M.; van den Bongard, D.; Pluim, D.; Beijnen, J. H.; Schellens, J. H. M. Clinical Cancer Research 2004, 10, 3717-3727.

182. National cancer Institute. Types of Treatment. National Institute of Health . 2012. 5-10-2009.

Ref Type: Online Source

183. al-Mefty, O.; Kersh, J. E.; Routh, A.; Smith, R. R. J Neurosurg 1990, 73, 502512.

184. Choi, Y. W.; Munden, R. F.; Erasmus, J. J.; Joo Park, K.; Chung, W. K.; Jeon, S. C.; Park, C. K. Radiographics 2004, 24, 985-997.

185. de Jonge, M. J. A.; Verweij, J. Seminars in Oncology 2006, 33, 68-73.

186. Kintzel, P. E. Drug Safety 2001, 24, 19-38. 
187. Ahles, T.; Saykin, A. Cancer Investigation 2001, 19, 812.

188. Sahni, V.; Choudhury, D.; Ahmed, Z. Nature Reviews Nephrology 2009, 5, 450462.

189. Jennifer, J. Leukemia Research 1998, 22, Supplement 1, S27-S33.

190. Antonadou, D.; Throuvalas, N.; Petridis, A.; Bolanos, N.; Sagriotis, A.; Synodinou, M. International Journal of Radiation Oncology*Biology*Physics 2003, 57, 402-408.

191. Tannehill, S. P.; Mehta, M. P.; Larson, M.; Storer, B.; Pellet, J.; Kinsella, T. J.; Schiller, J. H. Journal of Clinical Oncology 1997, 15, 2850-2857.

192. William, P. Seminars in Oncology Nursing 2007, 23, 213-224.

193. Hosseinimehr, S. J.; Karami, M. Archives of Toxicology 2005, 79, 482-486.

194. Culy, C. R.; Spencer, C. M. Drugs 2001, 61.

195. Santini, V. Expert Opin.Pharmacother. 2001, 2, 479-489.

196. Sweeney, T. R. "A survey of compounds from the antiradiation drug development program of the US Army Medical Research and Development Command," 1979.

197. Vujaskovic, Z.; Feng, Q. F.; Rabbani, Z. N.; Samulski, T. V.; Anscher, M. S.; Brizel, D. M. Experimental Lung Research 2002, 28, 577-590. 
198. Hospers, G. A. P.; Eisenhauer, E. A.; Vries, E. G. E. British Journal of Cancer 1999, 80, 629.

199. Majsterek, I.; Gloc, E.; Blasiak, J.; Reiter, R. J. Journal of Pineal Research 2005, 38, 254-263.

200. Aydemir, N.; Sevim, N.; Celikler, S.; Vatan, O.; Bilaloglu, R. Mutation Research/Genetic Toxicology and Environmental Mutagenesis 2009, 679, 1-5.

201. Brizel, D. M.; Wasserman, T. H.; Henke, M.; Strnad, V.; Rudat, V.; Monnier, A.; Eschwege, F.; Zhang, J.; Russell, L.; Oster, W.; Sauer, R. Journal of Clinical Oncology 2000, 18, 3339-3345.

202. Calabro-Jones, P. M.; Aguilera, J. A.; Ward, J. F.; Smoluk, G. D.; Fahey, R. C. Cancer Research 1988, 48, 3634-3640.

203. Shaw, L. M.; Glover, D.; Turrisi, A.; Brown, D. Q.; Bonner, H. S.; Norfleet, A. L.; Weiler, C.; Glick, J. H.; Kligerman, M. M. Pharmacology \& Therapeutics 1988, 39, 195-201.

204. Block, K. I.; Block, P. B.; Gyllenhaal, C.; Nathan, D.; de la Torre, M. Journal of Clinical Oncology 2005, 23, 798S.

205. Djurhuus, R.; Svardal, A. M.; Ueland, P. M. Molecular Pharmacology 1990, 38, 327-332. 
206. Vitvitsky, V.; Garg, S. K.; Banerjee, R. Journal of Biological Chemistry 2011, $286,32002-32010$.

207. Dominy, J. E., Jr.; Simmons, C. R.; Hirschberger, L. L.; Hwang, J.; Coloso, R. M.; Stipanuk, M. H. J.Biol.Chem. 2007, 282, 25189-25198.

208. Cavallini, D.; Scandurra, R.; De Marco, C. Journal of Biological Chemistry 1963, 238, 2999-3005.

209. Stipanuk, M.; Simmons, C.; Andrew Karplus, P.; Dominy, J. Amino Acids 2011, $41,91-102$.

210. Gahl, W. A.; Tietze, F.; Butler, J. D.; Schulman, J. D. Biochemical Journal 1985, 228,545 .

211. Gahl, W. A.; Balog, J. Z.; Kleta, R. Ann.Intern.Med. 2007, 147, 242-250.

212. Kleta, R.; Gahl, W. A. Expert Opin.Pharmacother. 2004, 5, 2255.

213. Min-Oo, G.; Ayi, K.; Bongfen, S. E.; Tam, M.; Radovanovic, I.; Gauthier, S.; Santiago, H.; Rothfuchs, A. G.; Roff+ᄀ, E.; Sher, A.; Mullick, A.; Fortin, A.; Stevenson, M. M.; Kain, K. C.; Gros, P. Experimental Parasitology 2010, 125, 315-324.

214. Min-Oo, G.; Fortin, A.; Poulin, J. F.; Gros, P. Antimicrob.Agents Chemother. 2010, 54, 3262-3270. 
215. Min-Oo, G.; Gros, P. Mamm.Genome 2011, 22, 486-494.

216. Ozcan, A. G. Cancer Chemother.Pharmacol. 2005, 56, 221-229.

217. Santos-Mello, R.; Deimling, L. I.; Lauer J+'nior, C.; Carvalho, T. R. Genetics and Molecular Biology 2005, 28, 156-160.

218. Hoffmann, G. R.; Shorter, R. A.; Quaranta, J. L.; McMaster, P. D. Toxicol.In Vitro 1999, 13, 1-9.

219. Purdie, J. W. Radiation research 1979, 77, 303.

220. Shrieve, D. C.; Harris, J. W. International Journal of Radiation Oncology*Biology*Physics 2003, 8, 585-588.

221. Lide, D. R. CRC handbook of chemistry and physics: a ready-reference book of chemical and physical data, CRC Pr I Llc: 2004.

222. Webb, M. I.; Walsby, C. J. Dalton Trans. 2011, 40, 1322-1331.

223. Tredan, O.; Galmarini, C. M.; Patel, K.; Tannock, I. F. Journal of the National Cancer Institute 2007, 99, 1441-1454.

224. Tannock, I. F. Cancer and Metastasis Reviews 2001, 20, 123-132.

225. Braun, S.; Hepp, F.; Sommer, H. L.; Pantel, K. Int.J.Cancer 1999, 84, 1-5. 
226. Chu, E.; Devita, V. T. Physicians' Cancer Chemotherapy Drug Manual, 10th ed.; Jones and Bartlett Publishers: Sudbury, MA, 2010.

227. Sava, G.; Capozzi, I.; Clerici, K.; Gagliardi, G.; Alessio, E.; Mestroni, G. Clinical \& Experimental Metastasis 1998, 16, 371-379.

228. Bergamo, A.; Sava, G. Dalton Trans. 2007, 1267-1272.

229. Bergamo, A.; agliardi, R.; carcia, V.; urlani, A.; Alessio, E.; estroni, G.; ava, G. Journal of Pharmacology and Experimental Therapeutics 1999, 289, 559-564.

230. Dyson, P. J.; Sava, G. Dalton Trans. 2006, 1929-1933.

231. Kaye, S. B. British Journal of Cancer 1998, 78, 1.

232. Grady, W. M.; Ulrich, C. M. Gut 2007, 56, 318.

233. Hausheer, F. H.; Kochat, H.; Parker, A. R.; Ding, D.; Yao, S.; Hamilton, S. E.; Petluru, P. N.; Leverett, B. D.; Bain, S. H.; Saxe, J. D. Cancer Chemotherapy and Pharmacology 2003, 52, 3-15.

234. Schuchter, L. M.; Hensley, M. L.; Meropol, N. J.; Winer, E. P. Journal of Clinical Oncology 2002, 20, 2895-2903.

235. Links, M.; Lewis, C. Drugs 1999, 57, 293-308.

236. Hensley, M. L.; Hagerty, K. L.; Kewalramani, T.; Green, D. M.; Meropol, N. J.; Wasserman, T. H.; Cohen, G. I.; Emami, B.; Gradishar, W. J.; Mitchell, R. B.; 
Thigpen, J. T.; Trotti, A.; von Hoff, D.; Schuchter, L. M. Journal of Clinical Oncology 2009, 27, 127-145.

237. Brock, N.; Hilgard, P.; Pohl, J.; Ormstad, K.; Orrenius, S. Journal of Cancer Research and Clinical Oncology 1984, 108, 87-97.

238. Brock, N.; Pohl, J.; Stekar, J.; Scheef, W. European Journal of Cancer \& Clinical Oncology 1982, 18, 1377-1387.

239. Hausheer, F. H.; Shanmugarajah, D.; Leverett, B. D.; Chen, X. H.; Huang, Q. L.; Kochat, H.; Petluru, P. N.; Parker, A. R. Cancer Chemotherapy and Pharmacology 2010, 65, 941-951.

240. Verschraagen, M.; Boven, E.; Torun, E.; Erkelens, C. A. M.; Hausheer, F. H.; van der Vijgh, W. J. F. British Journal of Cancer 2004, 90, 1654-1659.

241. Parker, A. R.; Petluru, P. N.; Wu, M.; Zhao, M.; Kochat, H.; Hausheer, F. H. Molecular Cancer Therapeutics 2010, 9, 2558-2567.

242. Khalaila, I.; Bergamo, A.; Bussy, F.; Sava, G.; Dyson, P. J. International Journal of Oncology 2006, 29, 261-268.

243. Masuda, N.; Negoro, S.; Hausheer, F.; Nakagawa, K.; Matsui, K.; Kudoh, S.; Takeda, K.; Yamamoto, N.; Yoshimura, N.; Ohashi, Y.; Fukuoka, M. Cancer Chemotherapy and Pharmacology 2011, 67, 533-542. 
244. Verschraagen, M.; Boven, E.; Ruijter, R.; van der Born, K.; Berkhof, J.; Hausheer, F. H.; van der Vijgh, W. J. F. Clinical Pharmacology \& Therapeutics 2003, 74, 157-169.

245. Bouma, M.; Nuijen, B.; Jansen, M. T.; Sava, G.; Flaibani, A.; Bult, A.; Beijnen, J. H. International Journal of Pharmaceutics 2002, 248, 239-246.

246. Valko, M.; Leibfritz, D.; Moncol, J.; Cronin, M. T. D.; Mazur, M.; Telser, J. International Journal of Biochemistry \& Cell Biology 2007, 39, 44-84.

247. Jones, D. P. Protein Sensors and Reactive Oxygen Species, Pt B, Thiol Enzymes and Proteins 2002, 348, 93-112.

248. Wu, G.; Fang, Y. Z.; Yang, S.; Lupton, J. R.; Turner, N. D. The Journal of nutrition 2004, 134, 489-492.

249. Fang, Y. Z.; Yang, S.; Wu, G. Nutrition 2002, 18, 872-879.

250. Dalton, T. P.; Chen, Y.; Schneider, S. N.; Nebert, D. W.; Shertzer, H. G. Free Radical Biology and Medicine 2004, 37, 1511-1526.

251. Townsend, D. M.; Tew, K. D.; Tapiero, H. Biomedicine \& Pharmacotherapy 2003, 57, 145-155.

252. Helmut, S. Free Radical Biology and Medicine 1999, 27, 916-921. 
253. Filomeni, G.; Rotilio, G.; Ciriolo, M. R. Biochemical Pharmacology 2002, 64, 1057-1064.

254. Circu, M. L.; Yee Aw, T. Free Radic Res 2008, 42, 689-706.

255. Mitchell, J. B.; Russo, A. The British journal of cancer.Supplement 1987, 8, 96.

256. Ortega, A. L.; Mena, S.; Estrela, J. M. Cancers 2011, 3, 1285-1310.

257. Perez, R. P. European Journal of Cancer 1998, 34, 1535-1542.

258. Komiya, S.; Gebhardt, M. C.; Mangham, D. C.; Inoue, A. Journal of Orthopaedic Research 1998, 16, 15-22.

259. Burg, D.; Mulder, G. J. Drug Metabolism Reviews 2002, 34, 821-863.

260. Russo, A.; Carmichael, J.; Friedman, N.; Degraff, W.; Tochner, Z.; Glatstein, E.; Mitchell, J. B. International Journal of Radiation Oncology Biology Physics 1986, $12,1347-1354$.

261. Joncourt, F.; Buser, K.; Altermatt, H.; Bacchi, M.; Oberli, A.; Cerny, T. Gynecologic Oncology 1998, 70, 176-182.

262. Balendiran, G. K.; Dabur, R.; Fraser, D. Cell Biochemistry and Function 2004, $22,343-352$.

263. Chaudhary, S.; Van Horn, J. D. Mutation Research-Genetic Toxicology and Environmental Mutagenesis 2006, 610, 56-65. 
264. Deleve, L. D.; Kaplowitz, N. Pharmacology \& Therapeutics 1991, 52, 287-305.

265. Duh, P. D.; Wu, S. C.; Chang, L. W.; Chu, H. L.; Yen, W. J.; Wang, B. S. Food Chemistry 2009, 114, 87-92.

266. Giles, N. M.; Giles, G. I.; Jacob, C. Biochemical and Biophysical Research Communications 2003, 300, 1-4.

267. Aldini, G.; Vistoli, G.; Regazzoni, L.; Gamberoni, L.; Facino, R. M.; Yamaguchi, S.; Uchida, K.; Carini, M. Chemical Research in Toxicology 2008, $21,824-835$.

268. Roche, M.; Rondeau, P.; Singh, N. R.; Tarnus, E.; Bourdon, E. FEBS Letters 2008, 582, 1783-1787.

269. Quinlan, G. J.; Martin, G. S.; Evans, T. W. Hepatology 2005, 41, 1211-1219.

270. Sarasin, A.; Giglia-Mari, G. Experimental Dermatology 2002, 11, 44-47.

271. Osborne, R. J.; Merlo, G. R.; Mitsudomi, T.; Venesio, T.; Liscia, D. S.; Cappa, A. P. M.; Chiba, I.; Takahashi, T.; Nau, M. M.; Callahan, R.; Minna, J. D. Cancer Research 1991, 51, 6194-6198.

272. Hollstein, M.; Sidransky, D.; Vogelstein, B.; Harris, C. C. Science 1991, 253, 49-53.

273. Harris, C. C. Journal of the National Cancer Institute 1996, 88, 1442-1455. 
274. Kim, D. H.; Kundu, J. K.; Surh, Y. J. Mol.Carcinog. 2011, 50, 222-234.

275. Buzek, J.; Latonen, L.; Kurki, S.; Peltonen, K.; Laiho, M. Nucleic Acids Research 2002, 30, 2340-2348.

276. Scotcher, J.; Clarke, D.; Weidt, S.; Mackay, C.; Hupp, T.; Sadler, P.; LangridgeSmith, P. Journal of the American Society for Mass Spectrometry 2011, 22, 888897.

277. Rainwater, R.; Parks, D.; Anderson, M. E.; Tegtmeyer, P.; Mann, K. Molecular and Cellular Biology 1995, 15, 3892-3903.

278. Jung, H.; Seong, H. A.; Ha, H. Journal of Biological Chemistry 2008, 283, 20383-20396.

279. Besker, N.; Coletti, C.; Marrone, A.; Re, N. Journal of Physical Chemistry B 2008, 112, 3871-3875.

280. Vargiu, A. V.; Robertazzi, A.; Magistrato, A.; Ruggerone, P.; Carloni, P. Journal of Physical Chemistry B 2008, 112, 4401-4409.

281. Bouma, M.; Nuijen, B.; Jansen, M. T.; Sava, G.; Bult, A.; Beijnen, J. H. Journal of Pharmaceutical and Biomedical Analysis 2002, 30, 1287-1296.

282. Chen, J.; Chen, L.; Liao, S.; Zheng, K.; Ji, L. J Phys Chem B 2007, 111, 78627869. 
283. Souid, A. K.; Fahey, R. C.; Aktas, M. K.; Sayin, O. A.; Karjoo, S.; Newton, G. L.; Sadowitz, P. D.; Dubowy, R. L.; Bernstein, M. L. Drug Metabolism and Disposition 2001, 29, 1460-1466.

284. Whitesides, G. M.; Lilburn, J. E.; Szajewski, R. P. Journal of Organic Chemistry 1977, 42, 332-338.

285. Tacka, K. A.; Dabrowiak, J. C.; Goodisman, J.; Souid, A. K. Drug Metabolism and Disposition 2002, 30, 875-882.

286. Hu, T. M.; Ho, S. C. J Med Sci 2011, 31, 109-115.

287. Cocchietto, M.; Zorzet, S.; Sorc, A.; Sava, G. Investigational new drugs 2003, $21,55-62$.

288. Brindell, M.; Stawoska, I.; Supel, J.; Skoczowski, A.; Stochel, G.; van Eldik, R. Journal of Biological Inorganic Chemistry 2008, 13, 909-918.

289. Groessl, M.; Reisner, E.; Hartinger, C. G.; Eichinger, R.; Semenova, O.; Timerbaev, A. R.; Jakupec, M. A.; Arion, V. B.; Keppler, B. K. Journal of Medicinal Chemistry 2007, 50, 2185-2193.

290. Owen, W. Free Radical Biology and Medicine 1999, 27, 922-935.

291. Coyle, B.; Kavanagh, K.; McCann, M.; Devereux, M.; Geraghty, M. Biometals 2003, 16, 321-329. 
292. Coyle, B.; Kinsella, P.; McCann, M.; Devereux, M.; O'Connor, R.; Clynes, M.; Kavanagh, K. Toxicology in Vitro 2004, 18, 63-70.

293. Doonan, C. J.; Nielsen, D. J.; Smith, P. D.; White, J. M.; George, G. N.; Young, C. G. Journal of the American Chemical Society 2006, 128, 305-316.

294. Hoffmeyer, R. E.; Singh, S. P.; Doonan, C. J.; Ross, A. R. S.; Hughes, R. J.; Pickering, I. J.; George, G. N. Chemical Research in Toxicology 2006, 19, 753759.

295. Munro, O. Q.; Marques, H. M. Inorganic Chemistry 1996, 35, 3768-3779.

296. James, B. R.; Lyons, J. R.; Williams, R. J. P. Biochemistry 1962, 1, 379-+.

297. Goldberg, D. P.; Caneschi, A.; Delfs, C. D.; Sessoli, R.; Lippard, S. J. Journal of the American Chemical Society 1995, 117, 5789-5800.

298. Gracia-Mora, I.; Ruiz-Ramírez, L.; Gómez-Ruiz, C.; Tinoco-Méndez, M.; Márquez-Quiñones, A.; Romero-De Lira, L.; Marín-Hernández, A.; MacíasRosales, L.; Bravo-Gómez, M. Metal-Based Drugs 2001, 8, 19-28.

299. Schilt, A. A.; Taylor, R. C. Journal of Inorganic \& Nuclear Chemistry 1959, 9, 211-221.

300. SAUD, M.; FARRUKH, M. A.; NAQVI, I. I. Nucleus 2003, 40, 107-114. 